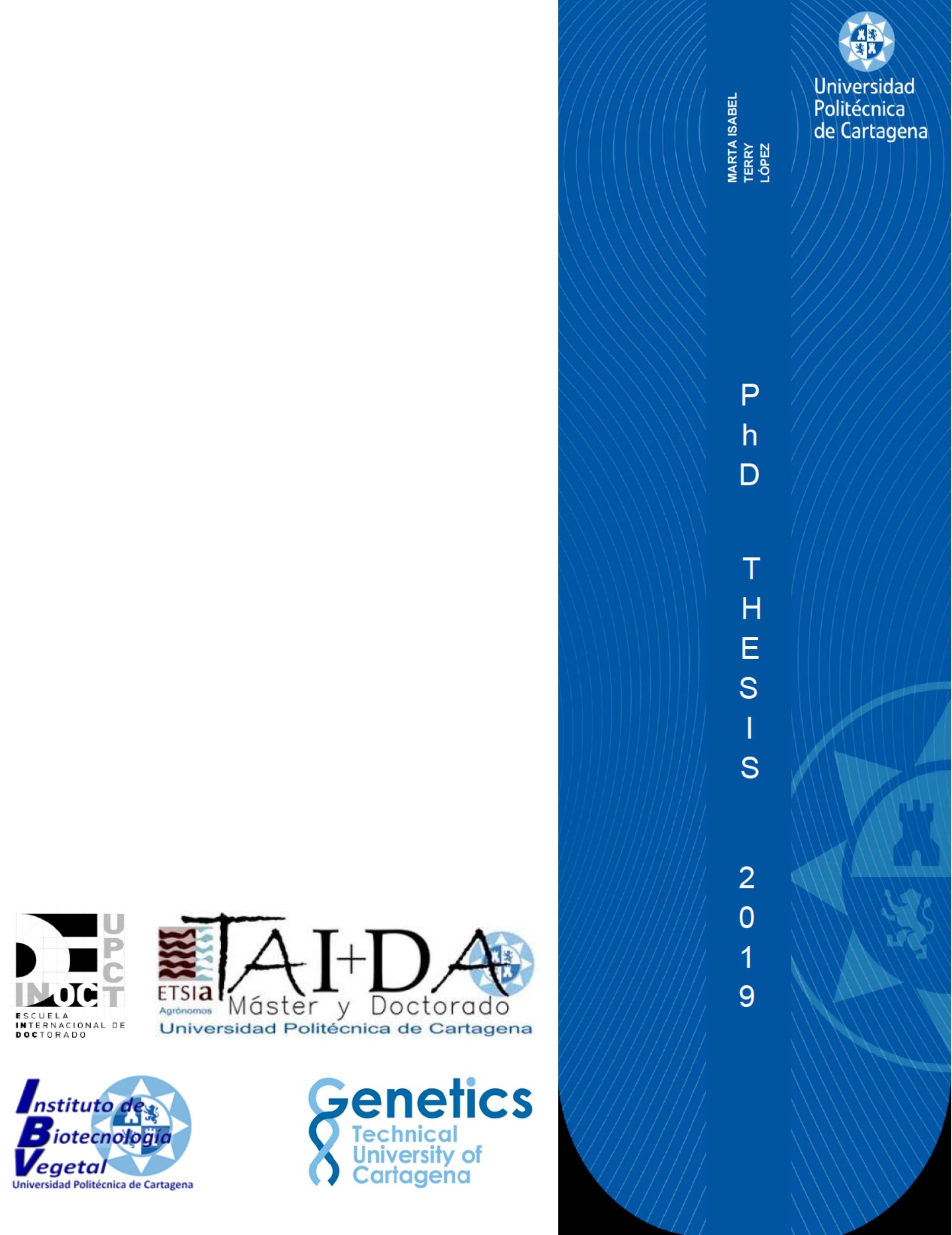

Analysis of the Circadian Clock and its Role in Scent Emission in Antirrhinum majus and Petunia hybrida

Técnicas Avanzadas en Investigación y Desarrollo Agrario y Alimentario

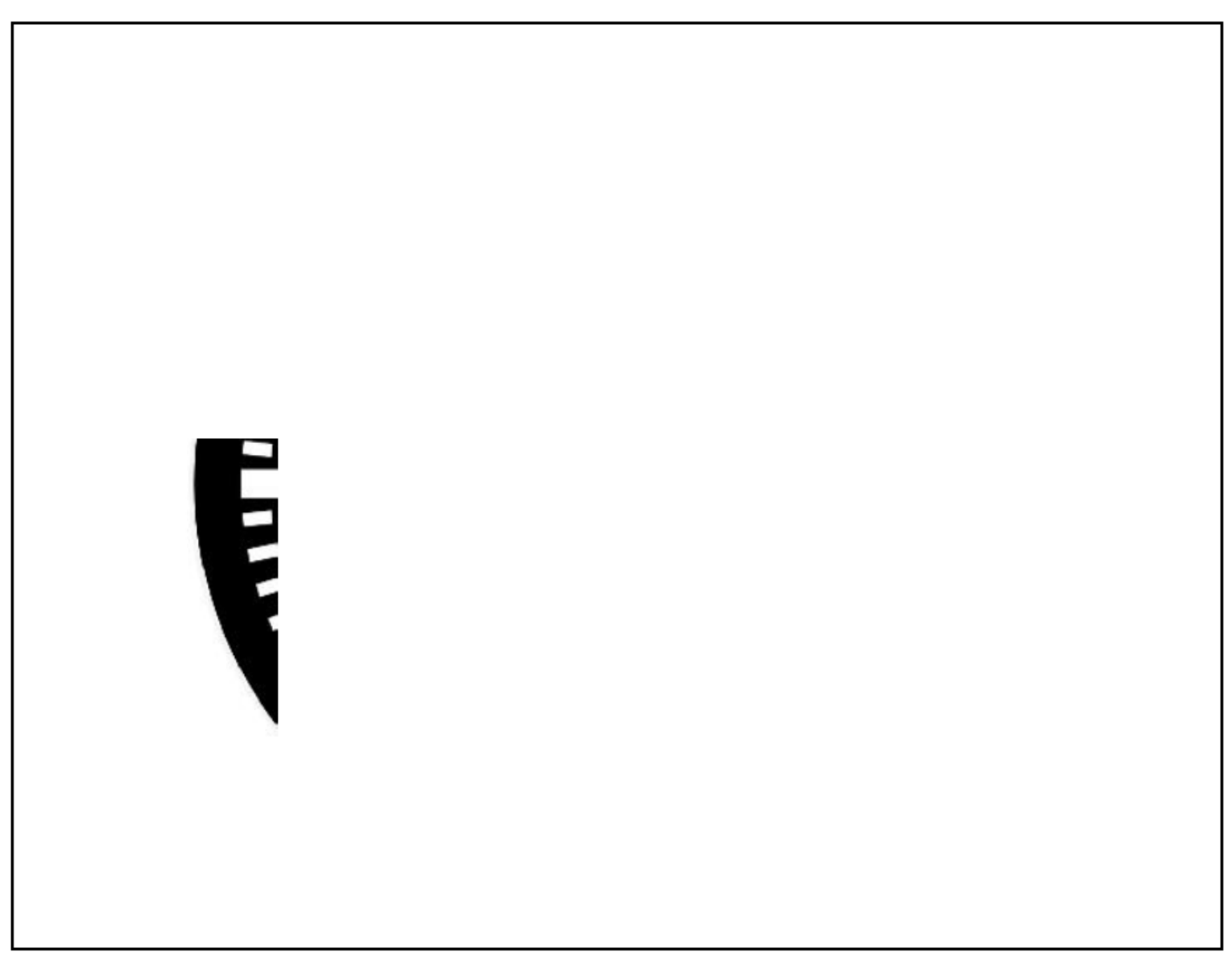

Author: Marta Isabel Terry López Directors: Julia Weiss Marcos Egea Gutiérrez-Cortines 


\section{CONFORMIDAD DE SOLICITUD DEAUTORIZACIÓN DE DEPÓSITO DE}

TESIS DOCTORAL POR EL/LA DIRECTOR/A DE LA TESIS

$\mathrm{D}^{\mathrm{a}}$. Julia Weiss Directora y D. Marcos Egea Gutiérrez-Cortines Codirector de la Tesis doctoral "Analysis of the circadian clock and its role in scent emission in Antirrhinum majus and Petunia hybrida".

\section{INFORMA:}

Que la referida Tesis Doctoral, ha sido realizada por $\mathrm{D}^{\mathrm{a}}$. Marta Isabel Terry López dentro del Programa de Doctorado Técnicas Avanzadas en Investigación y Desarrollo Agrario y Alimentario dando mi conformidad para que sea presentada ante el Comité de Dirección de la Escuela Internacional de Doctorado para ser autorizado su depósito.

Informe positivo sobre el plan de investigación y documento de actividades de la doctoranda emitido por los Directores (RAPI).

La rama de conocimiento en la que esta tesis ha sido desarrollada es:

x Ciencias

Ciencias Sociales y Jurídicas

Ingeniería y Arquitectura

En Cartagena, a 7 de noviembre de 2019

\section{LA DIRECTORA DE LA TESIS}

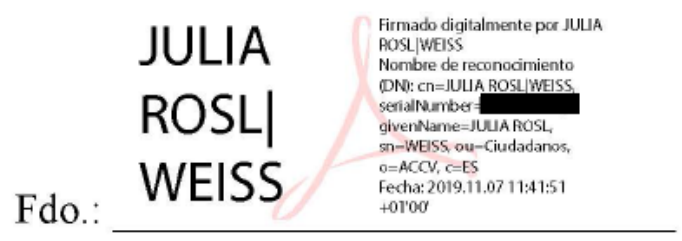

EL CODIRECTOR DE LA TESIS

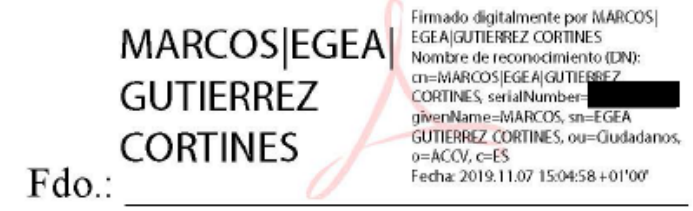





\section{Universidad \\ Politécnica \\ de Cartagena}

DT-17

\section{CONFORMIDAD DE DEPÓSITO DE TESIS DOCTORAL POR LA COMISIÓN ACADÉMICA DEL PROGRAMA}

D. Francisco Artés Hernández, Presidente de la Comisión Académica del Programa Técnicas Avanzadas en Investigación y Desarrollo Agrario y Alimentario.

\section{INFORMA:}

Que la Tesis Doctoral titulada, "Analysis of the circadian clock and its role in scent emission in Antirrhimum majus and Petunia hybrida", ha sido realizada, dentro del mencionado Programa de Doctorado, por $\mathrm{D}^{\mathrm{a}}$. Marta Isabel Terry López, bajo la dirección y supervisión de la Dra. Julia Weiss y el Dr. Marcos Egea Gutiérrez-Cortines.

En reunión de la Comisión Académica, visto que en la misma se acreditan los indicios de calidad correspondientes y la autorización del Director/a de la misma, se acordó dar la conformidad, con la finalidad de que sea autorizado su depósito por el Comité de Dirección de la Escuela Internacional de Doctorado.

$\square \chi$ Evaluación positiva del plan de investigación y documento de actividades por el Presidente de la Comisión Académica del programa (RAPI).

La Rama de conocimiento por la que esta tesis ha sido desarrollada es:

$\mathrm{x}$ Ciencias

Ciencias Sociales y Jurídicas

Ingeniería y Arquitectura

En Cartagena, a 7 de noviembre de 2019

EL PRESIDENTE DE LA COMISIÓN ACADÉMICA

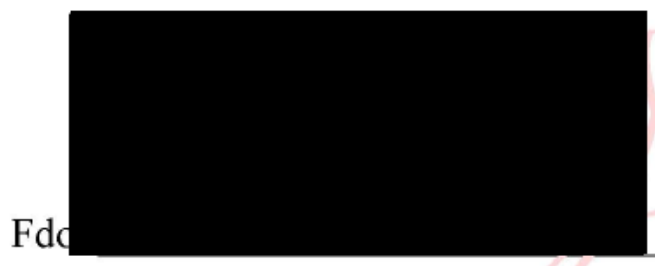

Firmado digitalmente por FRANCISCO DE ASIS|ARTES| HERNANDEZ 



\section{General index}

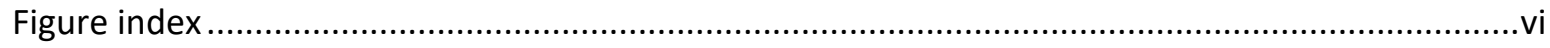

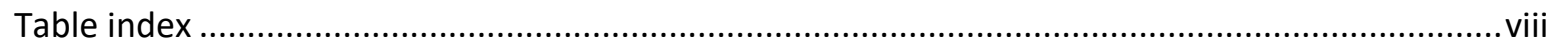

Preface

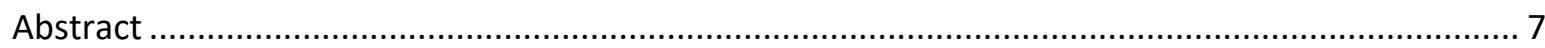

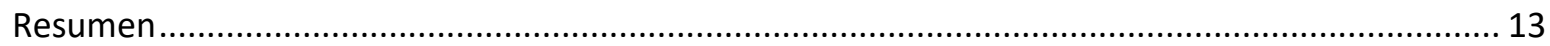

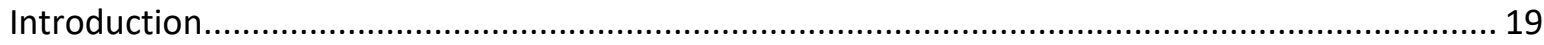

Adaptation and anticipation to periodic oscillations: Biological clocks .................................... 19

A simplified model of the circadian clock in plants: The picoalga Ostreococcus tauri.................. 20

Biological clocks in plants: The model derived from thale cress (Arabidopsis thaliana) .............. 22

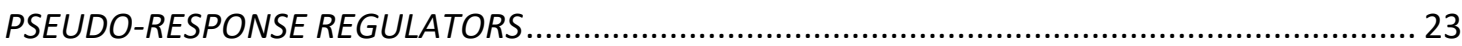

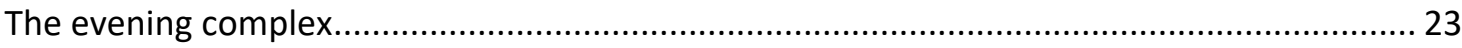

GIGANTEA and ZEITLUPE/FLAVIN-BINDING KELCH REPEAT F-BOX 1/LOV-KELCH PROTEIN 2

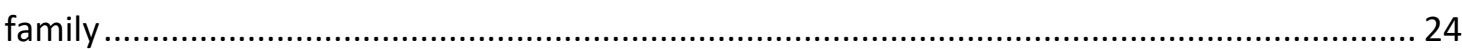

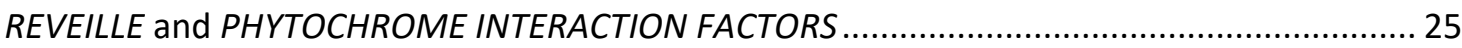

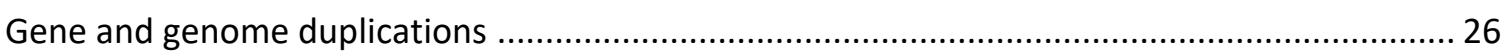

Going further in plant models: Snapdragon (Antirrhinum majus) and petunia (Petunia hybrida) 27

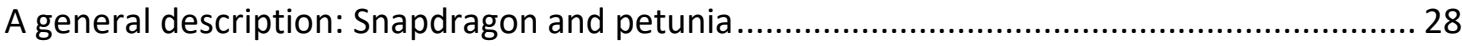

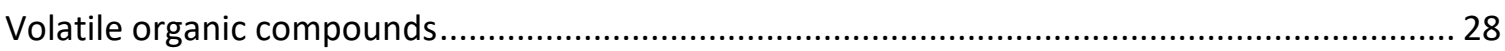

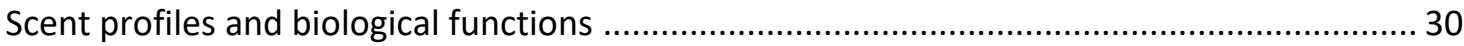

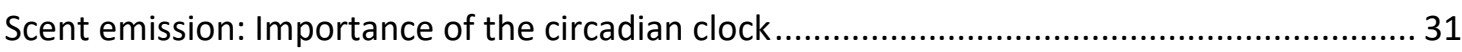

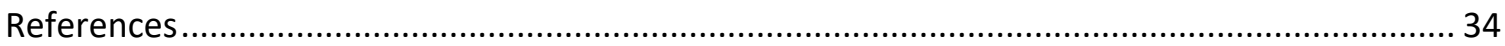

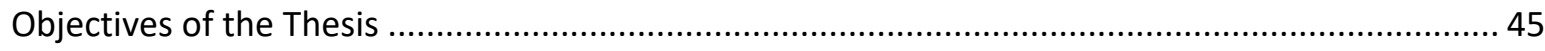

Chapter I: Transcriptional structure of petunia clock in leaves and petals................................... 47

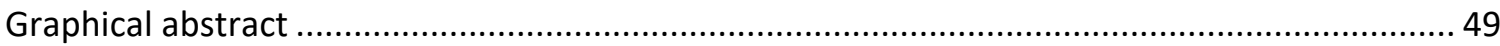

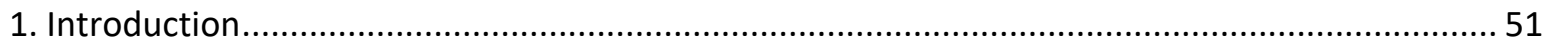

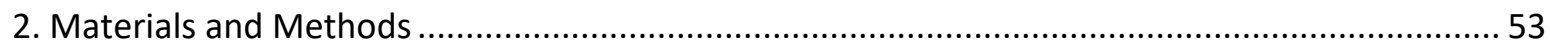

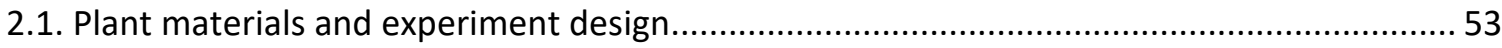

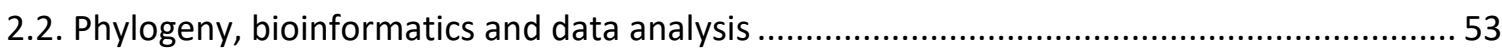


3. Results

3.1. The duplicated PRR7, PRR5 and GI diverge in intron number and coding sequence

3.2. The leaf clock has its maximum during the day while the petal clock shifts towards the night

3.3. Continous darkness shifted the expression patterns of clock genes 61

3.4. Rhythmicity and photoperiod sensitivity are tissue specific 63

3.5. Transcriptional noise is gene and tissue specific 65

4. Discussion. 68

4.1. The petunia clock genes show structural evolutionary changes ...................................6. 68

4.2. Daily expression of petunia clock genes is tissue specific 69

4.3. Leaves and petals have different clock coordination ............................................. 70

4.4. Photoperiod sensitivity is organ-specific........................................................... 70

4.5 Transcriptional noise is tissue-specific and depends on photoperiod ............................ 70

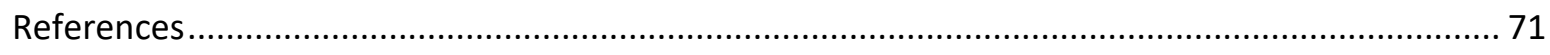

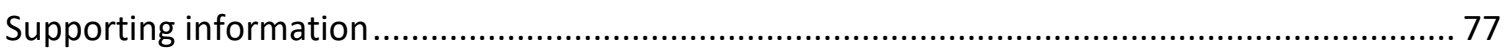

Chapter II: The Petunia CHANEL Gene is a ZEITLUPE Ortholog Coordinating Growth and Scent

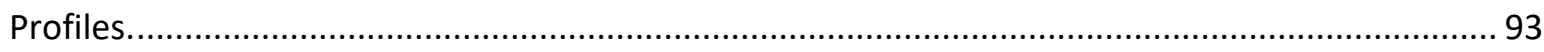

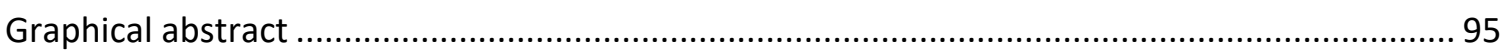

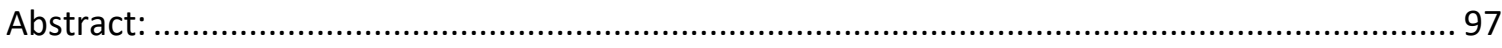

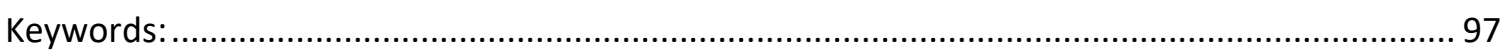

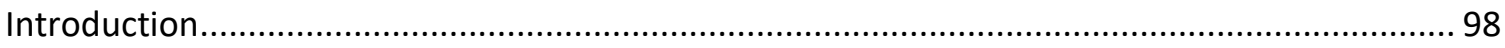

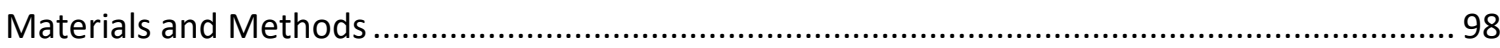

Gene Identification and Phylogenetic Analysis ......................................................... 98

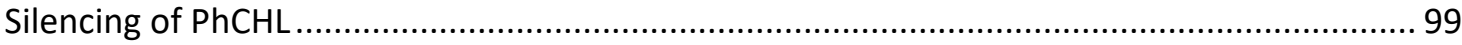

Plant Growth Conditions and Sampling ................................................................. 99

Housekeeping Genes and Gene Expression Analysis by qPCR ....................................... 99

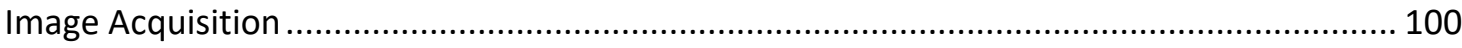

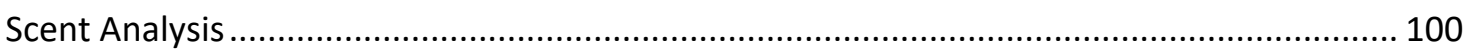

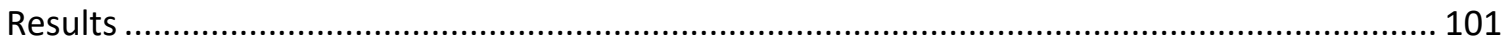




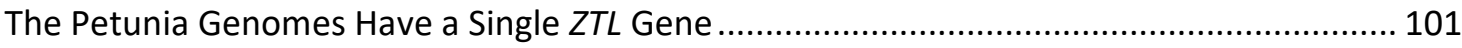

The Expression of PhCHL is Organ Specific and Affected by Day Length ................................ 101

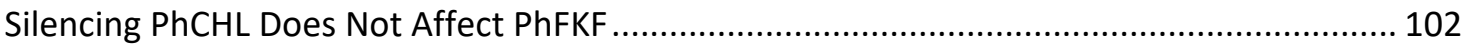

PhCHL Is a Positive Regulator of Lateral Organ Growth...................................................... 103

PhCHL Is Involved in Flower Angle Changes but Not Leaf Movement ................................... 103

Differential Effect of PhCHL on Stem and Flower Growth Rate ........................................... 105

PhCHL Coordinates Daily Changes in Scent Profiles............................................................. 107

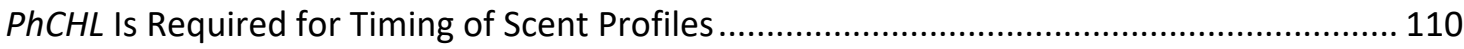

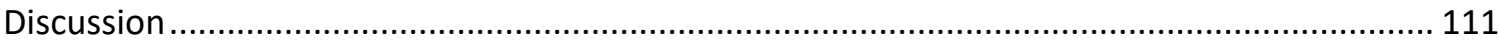

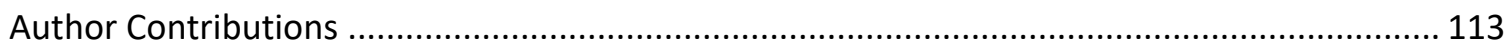

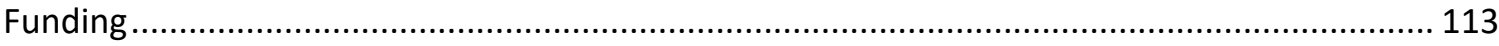

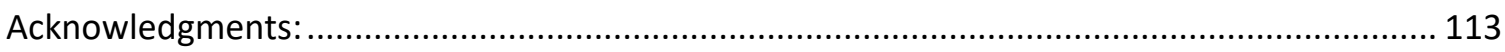

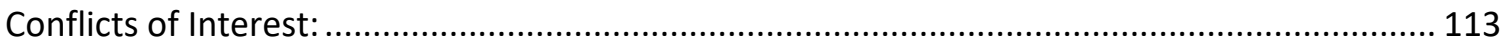

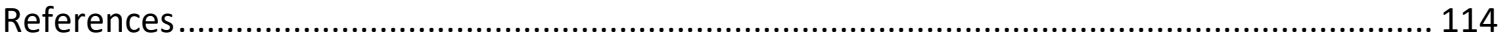

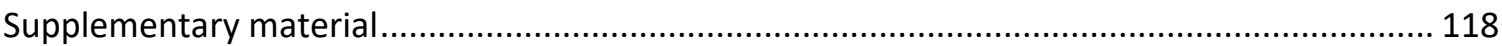

Chapter III: The snapdragon LATE ELONGATED HYPOCOTYL plays a dual role in activating floral

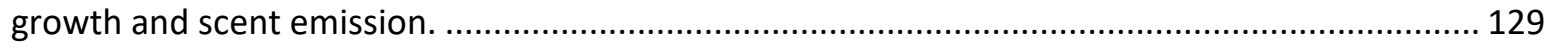

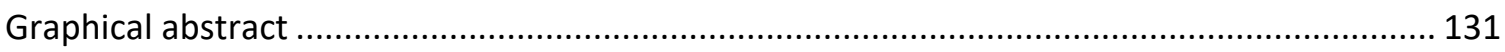

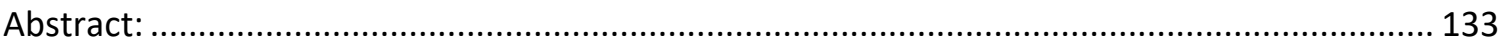

Keywords:

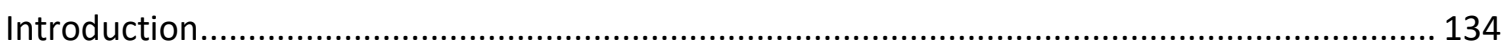

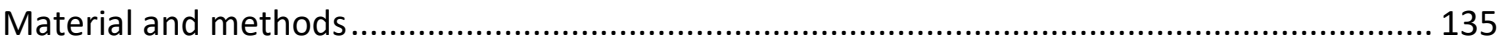

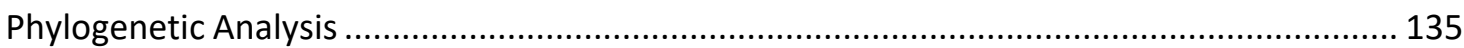

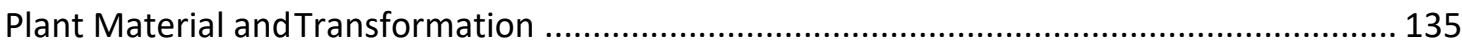

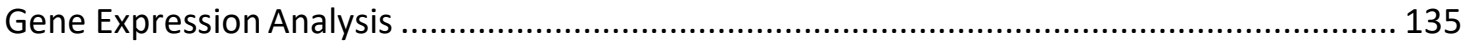

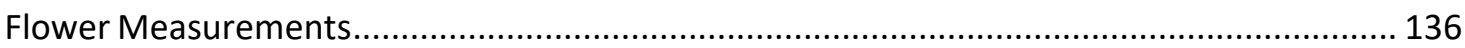

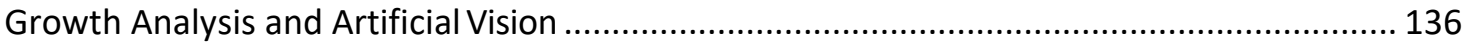

Volatiles Collection, Gas Chromatography Mass Spectrometry, and Scent Analysis............... 137

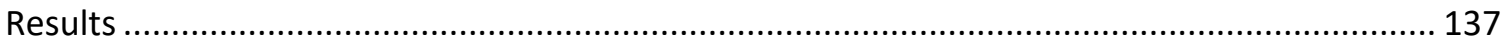

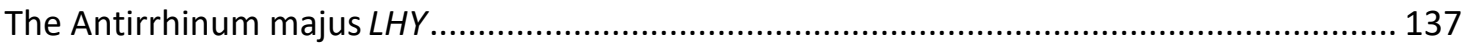


The AmLHY Shows A Diurnal Expression Pattern ................................................ 137

AmLHY Does Not Affect Flower Morphology andSize ............................................... 138

AmLHY Enhances Growth Speed ........................................................................ 139

$A m L H Y$ is Required for Major Volatile Production .................................................... 139

AmLHY Controls the Timing of ScentEmission ......................................................... 141

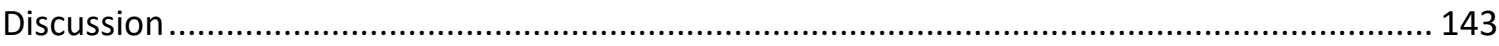

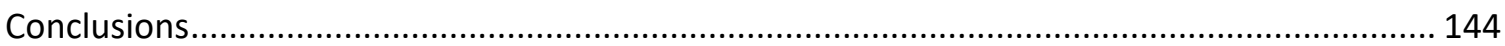

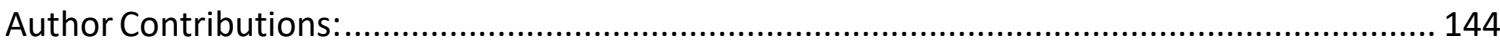

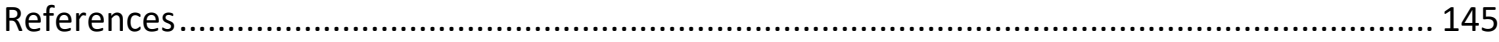

Supplementary files................................................................................................ 150

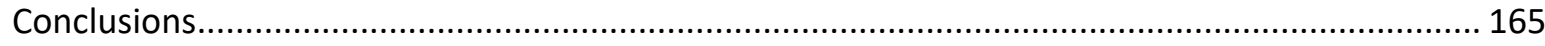

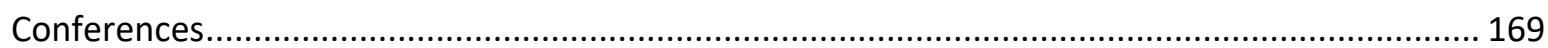

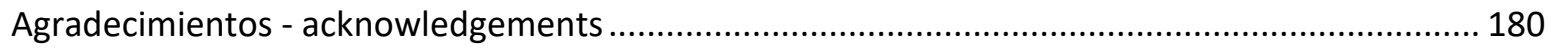




\section{Figure index}

\section{Introduction}

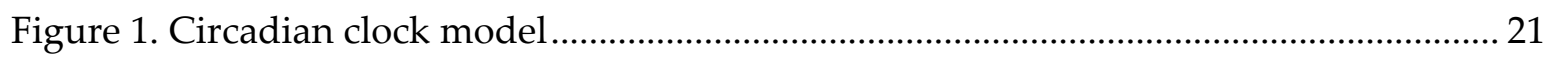

Figure 2. Volatile organic compounds: Metabolic pathways................................................ 29

\section{Chapter I}

Figure 1. PSEUDO-RESPONSE REGULATORS (PRRs) phylogenetic tree. 56

Figure 2. Repression motifs of PSEUDO-RESPONSE REGULATORS (PRRs) local

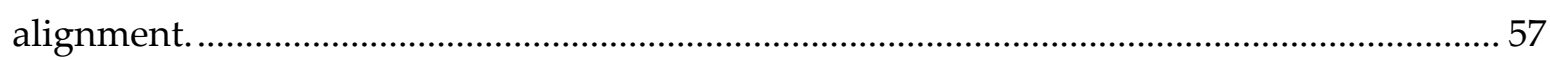

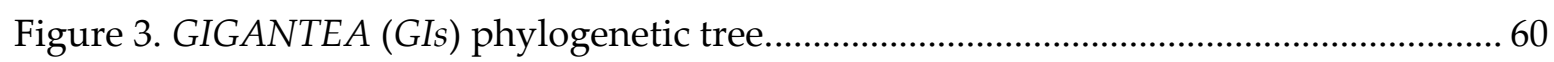

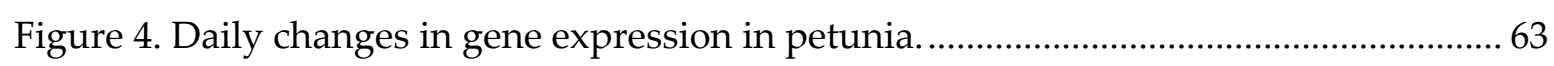

Figure 5. Variability in clock gene expression in petunia leaves and petals..........................6 68

Figure S1: Melt or dissociation curve analysis of petunia genes. .......................................... 78

Figure S2:Exon-intron structure of Petunia axillaris (PaxiN) PRR5 and PRR7 genes ........... 79

Figure S3: Domain structure of PRRs proteins................................................................... 80

Figure S4. Local alignment of repression motifs of PRR5 proteins ...................................... 81

Figure S5: Local alignment of GIGANTEA proteins. ............................................................ 84

Figure S6. Normalized expression (NE) for biological replicates........................................ 86

\section{Chapter II}

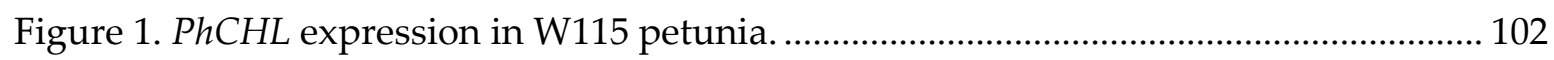

Figure 2. PhCHL (A) and PhFKF (B) expression in wild-type and RNAi:PhCHL plants ... 102

Figure 3. Down regulation of $\mathrm{PhCHL}$ does not affect leaf movement. ................................ 104

Figure 4. Down regulation of $\mathrm{PhCHL}$ affects growth length in stems and growth rate in

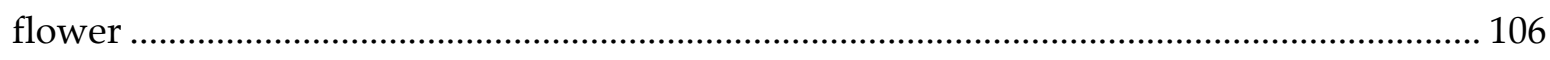

Figure 5. Petunia scent profiles expressed as percentage .................................................. 108

Figure S1: Expression levels of candidate housekeeping genes ........................................... 118

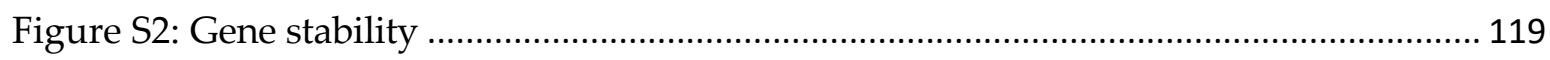

Figure S3: Melt or dissociation curve analysis of petunia genes ...................................... 120

Figure S4: Phylogenetic tree of CHL, FKF, LKP2 and ZTL genes.................................... 121

Figure S5: Petunia scent profiles expressed as percentage, including methyl benzoate.... 123 


\section{Chapter III}

Figure 1: AmLHY expression.

Figure 2: Growth curve expressed in $\mathrm{mm}$, of flowers of non-transgenic and

RNAi:AmLHY27

Figure 3: Daily scent emission of major compounds in wild type and transgenic lines..... 140

Figure 4: Daily scent emission of minor compounds in wild type and transgenic lines..... 141

Figure 5: Schematic view of some phenylpropanoids/benzenoids, monoterpenes and

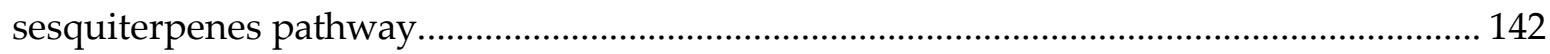

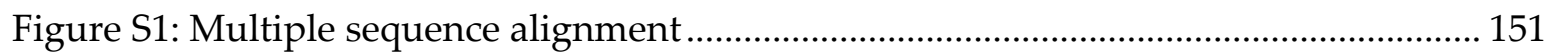

Figure S2: AtLHY and AmLHY protein alignment........................................................... 152

Figure S3: Floral parameters in non-transgenic (WT) and transgenic lines (RNAi:AmLHY).

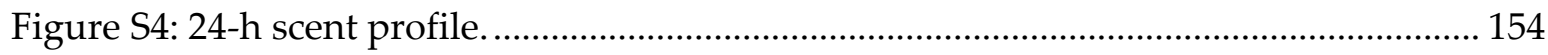

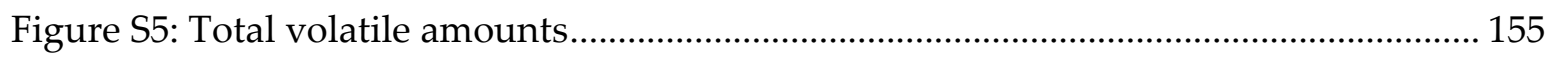




\section{Table index}

\section{Chapter I}

Table 1. Rhythmic analysis of transcriptional data

Table 2. Analysis of differential gene expression in petunia leaves and petals under two light conditions

Table 3. Detection of changes in noise in petunia clock genes in two tissues, leaves and petals, comparing light:dark (LD) and constant darkness (DD) cycles ................................. 70

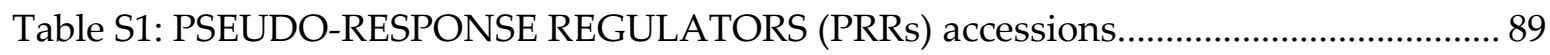

Table S2: GIGANTEA (GI) protein accessions used in the phylogenetic reconstruction. ... 91

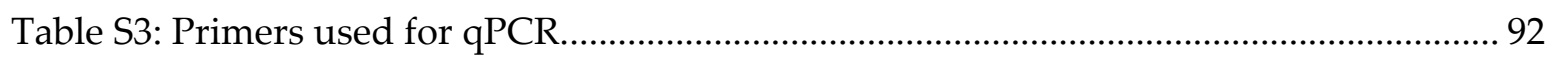

\section{Chapter II}

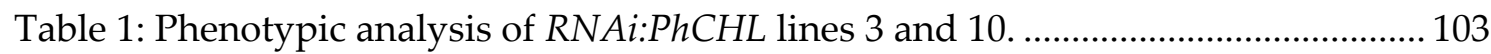

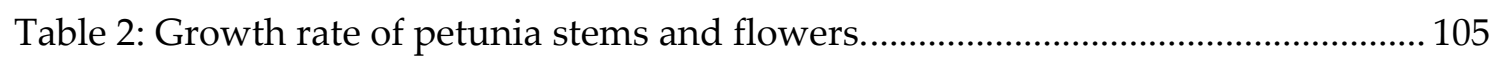

Table 3: Retention time, name and CAS number of selected volatiles. ........................... 107

Table 4: Analysis of emitted volatiles with MetaCycle................................................... 110

Table S1: GenBank, Snapdragon Genome Sol Genomics Network Database accession

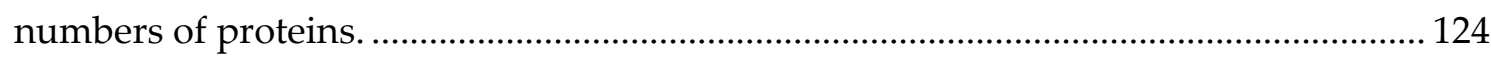

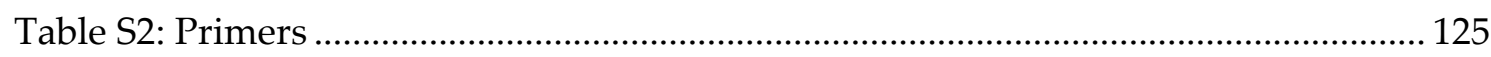

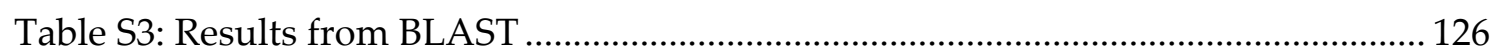

Table S4: Analysis of leaf movement in RNAi:PhCHL and non-transgenic siblings..... 127

\section{Chapter III}

Table 1: AmLHY expression in wild-type and RNAi lines at ZT 1.5............................. 138

Table 2: Parameters obtained from the phenomic analysis............................................ 139

Table S1: Accession numbers of proteins used in phylogenetic reconstruction............. 156

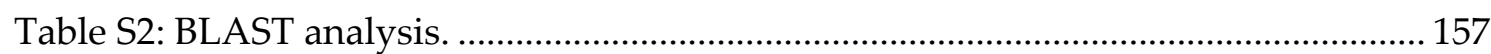

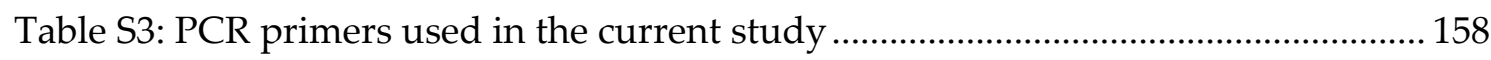

Table S4: Analysis of floral parameters in non-transgenic and transgenic lines........... 159

Table S5: Retention time and CAS number of selected volatiles. .................................... 160

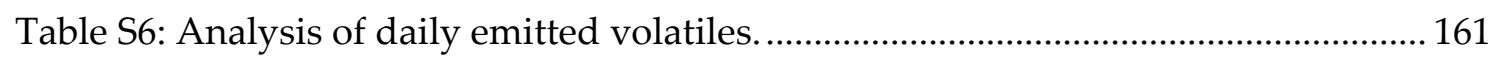



Preface 



\section{Preface}

This document has been written according to the regulations of the Universidad Politécnica de Cartagena. This thesis has the following sections: a general introduction, three chapters which correspond to accepted publications and the conclusions obtained from the present work. Every chapter includes its "material and methods" section.

During my PhD I performed a research stay at the University of Amsterdam in the research group of Dr. Robert Schuurink. This stay was financed by the Programa de Movilidad de doctorandos en Técnicas Avanzadas en Investigación y Desarrollo Agrario y Alimentario (TAIDA) de la Universidad Politécnica de Cartagena.

\section{Publications derived from the PhD thesis}

Terry, M.I., Pérez-Sanz, F., Díaz-Galián, M., Pérez de los Cobos, F., Navarro, P. J., EgeaCortines, M., \& Weiss, J. (2019). The Petunia CHANEL Gene is a ZEITLUPE Ortholog Coordinating Growth and Scent Profiles. Cells, 8(4), 343.

Terry, M.I., Pérez-Sanz, F., Navarro, P.J., Weiss, J. \& Egea-Cortines, M. (2019). The Snapdragon LATE ELONGATED HYPOCOTYL Plays A Dual Role in Activating Floral Growth and Scent Emission. Cells, 8, 920.

Terry, M.I., Carrera-Alesina, M., Weiss, J., \& Egea-Cortines, M. (2019). Transcriptional Structure of Petunia Clock in Leaves and Petals. Genes, 10(11), 860. 


\section{Publications unrelated to the PhD thesis}

Terry, M.I., \& Mallona, I. (2015). First record of albinism in salema, Sarpa salpa (Perciformes: Sparidae), in the Mediterranean Sea. Marine Biodiversity Records, 8.

Weiss, J., Terry, M.I., Martos-Fuentes, M., Letourneux, L., Ruiz-Hernández, V., Fernández, J. A., \& Egea-Cortines, M. (2018). Diel pattern of circadian clock and storage protein gene expression in leaves and during seed filling in cowpea (Vigna unguiculata). BMC Plant Biology, 18(1),33. 
Abstract 



\begin{abstract}
Organisms are adapted to cyclic environmental changes, such as tidals, day-night alternance or seasonality. An innate timing device that registers these changes is called biological clock. Circadian clocks are comprised of interlocked regulatory loops of genes and proteins. Anticipation to periodic changes allows organisms to adapt their secondary metabolism, growth or reproduction. In plants, the simplest model found to date is the picoalga Ostreococcus tauri, which has only two clock genes: CIRCANDIAN CLOCK ASSOCIATED 1 and TIMING OF CAB EXPRESSION 1. The analysis of species as Arabidopsis thaliana revealed the existence of a more complex net of clock elements, including the PSEUDO-RESPONSE REGULATORS family, the evening complex and the blue light receptors ZEITLUPE and FLAVIN KELCH F-BOX PROTEIN 1, among others.
\end{abstract}

An example of a character controlled by the circadian clock in flowering plants is scent emission, which shows a daily pattern even under constant light or dark conditions, a characteristic feature of processes controlled by the circadian clock. Although the volatile biosynthesis has been widely characterized, the regulation by the integration of external cues, such as light or temperature, is still poorly understood.

In the present work we followed two approaches in order to get a better understanding about circadian clock structure and processes controlled by the circadian clock. First, we characterized and compared the structure of circadian clock genes in leaves and petals of petunia (Petunia hybrida) under two different light conditions. We show that the clock genes PSEUDO RESPONSE REGULATOR 7, 5 and GIGANTEA are duplicated in petunia and that the gene expression patterns differ in leaves and petals with most genes peaking during the light phase in leaves and during the dark phase in petals. One of the petunia duplicated paralogs PaxiNPRR5a from P.axillaris and PinfSPRR5a from P.inflata have lost the canonical repression domain indicating a departure of their function from a standard transcriptional repression. When plants where transfered to constant darkness, clock genes tended to delay their maximum expression in both tissues. However, LATE ELONGATED HYPOCOTYL, which is a highly conserved gene across the green lineage, did not vary its expression pattern, regardless of the tissue or light conditions. We found that gene expression variability in leaves and petals depended on the time of the day. We studied the variability of expression and under light:dark condition, most analyzed genes showed their highest stability during the light 
period in leaves, whereas in petals, stability was higher during the dark period. In general, when petunia was kept under constant darkness, the variability increased in both tissues.

In a second approach, we performed a detailed analysis of the effect of silencing two clock genes on growth, flower phenotype and scent emission. We silenced $C H A N E L$ (PhCHL), a ZEITLUPE ortholog, in petunia and LATE ELONGATED HYPOCOTYL (AmLHY) in snapdragon (Antirrhinum majus). The expression of $P h C H L$ in leaves and petals differed when plants were acclimated to short days, characterized by an earlier expression peak in petals. RNAi:PhCHL silenced lines were shorter than wildtype plants and growth analysis revealed that stem and flower growth rate was slower. We also observed differences in the daily scent emission between nontransgenic and RNAi:PhCHL lines, both concerning the amount of scent emission, the scent profile and the timing of emission. While the emission of most volatiles, including ethyl benzoate and acetophenone, decreased in the silenced lines, others increased including benzaldehyde and phenylcetaldehyde. This differing effect was also found for timing as ethyl benzoate, displayed an early scent-emission phenotype while benzyl benzoate, displayed a delayed emission.

In case of RNAi:AmLHY snapdragon lines, down-regulation of AmLHY led to a decrease in the flower growth speed, even so final flower size was not affected. The floral scent profile in silenced lines was characterized-by a higher percentage of linalool and ocimene, whereas other volatiles such as 3,5-dimethoxytoluene, nonanal and decanal decreased. Interestingly, compounds such as the benzenoids methyl benzoate and methyl salicylate and the monoterpenes myrcene and ocimene showed a delayed emission, whereas maximum emission of phenylpropanoid methyl cinnamate was advanced compared to wild-type.

The present work leads to several general conclusion: first, the circadian clock transcriptional structure is tissue specific, and this specificity may be related to specialized functions perfomed in the different tissues, such as stomata opening in leaves or volatile emission in petals. Second, the variation in gene expression as well as the transcriptional noise depended on the tissue, day time and light:dark conditions. Finally, the floral aroma, in terms of contribution and amount of every single compound as well as number and class of volatiles, is controlled by the circadian clock. Circadian clock genes are involved in the maintainance of composition and timing of emission. Another interesting aspect is that the clock gene $A m L H Y$ regulated volatile biosynthesis at the biosynthetic pathway level: the 
compounds that derive from benzoic acid, such as methyl benzoate and methyl salicylate, displayed a delayed emission whereas the monoterpenes myrcene and ocimene advanced their emission. 

Resumen 



\section{Resumen}

Los organismos están adaptados a cambios cíclicos y ambientales, tales como las mareas, la alternacia día-noche o el paso de las estaciones. Este sistema innato que registra dichos cambios se denominada reloj biológico, consiste en una red de genes y proteínas. Los genes reloj conforman bucles interconectados y mutuamente regulados. La anticipación a los cambios periódicos permite a los organismos ajustar su metabolismo secundario, crecimiento o reproducción. In plantas, el modelo más simple descrito hasta la fecha se encuentra en la picoalga Ostreococcus tauri, que solo posee dos genes reloj: CIRCANDIAN CLOCK ASSOCIATED 1 y TIMING OF CAB EXPRESSION 1. El análisis de especies como Arabidopsis thaliana reveló la existencia de una red más compleja, incluyendo a la familia de los PSEUDO-RESPONSE REGULATORS, el complejo de la tarde y los receptores de luz azul ZEITLUPE y FLAVIN KELCH F-BOX PROTEIN 1 entre otros.

Un ejemplo de un carácter controlado por el reloj circadiano en plantas con flor es la emisión de aromas, la cual muestra un patrón diario, incluso bajo condiciones de luz u oscuridad constante, una característica de los procesos controlado por el reloj circadiano. Aunque la biosíntesis de volátiles ha sido ampliamente estudiada, la regulación por parte del reloj circadiano continúa siendo poco conocida.

En el presente trabajo hemos seguido dos aproximaciones con el objetivo de entender mejor el reloj circadiano y los procesos controlados por el reloj circadiano. Primero, analizamos y caracterizamos la estructura de los genes reloj en hojas y pétalos de petunia (Petunia hybrida) bajo dos condiciones de luz diferentes. Mostramos que los genes PSEUDO RESPONSE REGULATOR 7, 5 y GIGANTEA están duplicados en petunia y los patrones de expresión génica variaron entre hojas y pétalos, la mayoría de genes mostraban su máximo durante la fase de luz y durante la fase de oscuridad en pétalos. Cuando las plantas se transfirieron a oscuridad continua, los genes reloj tendieron a retrasar su máximo de expresión en ambos tejidos. Sin embargo, LATE ELONGATED HYPOCTYL, un gen altamente conservado en el linaje verde, no varió su patrón de expresión, independientemente del tejido o de las condiciones de luz. Además, encontramos que la variabilidad en la expresión génica en hoja y pétalo dependió de la hora del día. Con referencia a la variabilidad de expresión, en condiciones de luz-oscuridad la mayoría de genes analizados en hoja mostró su mayor estabilidad durante el periodo luminoso mientras que el pétalo mostró su estabilidad en la oscuridad. En general, cuando bajo condiciones de oscuridad constante, la variabilidad aumentó en ambos tejidos. 
Hemos realizado un detallado análisis del efecto del silenciamiento de dos genes reloj en el crecimiento, fenotipo de la flor y la emisión de aromas. Silenciamos CHANEL (PhCHL), un ortólogo de ZEITLUPE, en petunia y LATE ELONGATED HYPOCOTYL (AmLHY) en boca de dragón (Antirrhinum majus). La expresión de PhCHL en hojas y pétalos difirió cuando las plantas se aclimataron a días cortos, caracterizado por una expresión PhCHL avanzada en pétalos. Las líneas silenciadas RNAi:PhCHL eran más pequeñas que las silvestres y el análisis del crecimiento reveló que la tasa de crecimiento de tallo y flor era más lenta en plantas RNAi:PhCHL. Observamos también diferencias en la emisión de aromas diaria entre líneas no transgénicas y $R N A i: P h C H L$, en el perfil de aromas y en el tiempo de emisión. Mientras que la emisión de la mayoría de los volátiles, incluyendo el benzoato de etilo o acetofenona, disminuyó en las líneas transgénicas, otros aumentaron incluyendo benzaldehído y fenilacetaldehído aumentó en las plantas RNAi:PhCHL. Además en las líneas RNAi, algunos compuestos como el benzoato de etilo mostraron un fenotipo de emisión adelantada y el benzoato de bencilo, una emisión tardía.

En el caso de las líneas RNAi:AmLHY de boca de dragón, el silenciamiento de $A m L H Y$ disminuyó la velocidad de crecimiento de la flor, pero no afectó al tamaño final de la flor. El perfil aromático en las líneas silenciadas estuvo caracterizado por un porcentaje mayor de linalool y ocimeno, mientras que otros volátiles como el 3,5dimetoxitolueno, nonanal y decanal disminuyeron. Curiosamente, encontramos compuestos tales como los bencenoides benzoato de metilo y salicilato de metilo y los monoterpenos mirceno y ocimeno que mostraron una emisión tardía, mientras que la emisión máxima del fenilpropanoide cinnamato de metilo fue avanzada en comparación con el silvestre.

De la presente tesis, podemos esbozar unas conclusiones generales. Primero, la transcripción del reloj circadiano es tejido específico, lo cual podría estar relacionado con funciones especializadas como la apertura de estomas en hojas o la emisión de volátiles en pétalos. Segundo, la variación en expresión génica o ruido transcripcional dependió del tejido, hora del día y condiciones de luz-oscuridad. Finalmente, el aroma floral depende de la contribución o cantidad de cada volátil y del número y clase de volátiles. Este perfil aromático varió a lo largo del día y está controlado por el reloj circadiano. Los genes reloj son necesarios para mantener la composición y tiempo de emisión. Otro aspecto interesante es que el gene AmLHY reguló la biosíntesis de volátiles en diferentes puntos: compuestos que derivan del ácido benzóico como benzoato de metilo y el salicilato de metilo mostraron una 
emisión tardía mientras que los monoterpenos mirceno y ocimeno adelantaron su emisión. 



\section{Introduction}





\section{Introduction}

\section{Adaptation and anticipation to periodic oscillations: Biological clocks}

Organisms are exposed to a changing environment: tides, day and night or season alternances are some examples. These changes are periodic, allowing organisms to anticipate and coordinate several internal processes such as metabolism, growth or reproduction, which tipically show a rhythmic pattern. For example, the seasonal migrations in birds and mammals, sleep patterns or daily patterns of plasma hormones are well known rhythmic events. This innate timing control is known as biological clock has been widely studied in several models, including bacteria, plants and animals [1].

Most Biological clocks consist in a set of genes that establish interlocked feedback loops. At the same time, the integration of external and regulatory factors form key elements that maintain and set this clock. External cues can be classified in abiotic, such as temperature and light, and biotic, as interactions with relatives or other species, as pests [2], [3]. Internal cues include redox state, sugar availiability and nutrients [4]. Circadian clocks share three characteristics: endogenous rhythmicity (persists in absence of external cues), entrainment (biological clocks are set by external signals, such as light or temperature) and temperature compensation (rhythm periodicity is maintained close to 24-h in a range of temperatures).[5]-[7]

In absence of these stimuli during a certain time (e.g. days), the periodicity may change, either becoming shorter or longer. A classical experiment consists in acclimating an organism to constant darkness or light and constant temperature. In this situation, called free-running conditions, cyclic processes or behavior of organisms, such as locomotor activity, hormone metabolism or clock gene 
expression, can be irregular or damped. The study of organisms under natural and/or free-running conditions is usefull in order to identify clock genes, analyze their functions and possible regulation, using mutants or genetically modified organism (GMOs) in comparison to wild-type. Interestingly, when an organism presents, for example, a disrupted locomotor activity as a result of exposure to constant light or darkness, this disruption can be "fixed". If the organism is acclimated or reentrained to a light:dark cycle, it will recover its rhythmic behavior [8] . As most analyzed cycles have a periodicity (or duration) of approximately 24h, biological clocks are also called circadian clocks.

\section{A simplified model of the circadian clock in plants: The picoalga Ostreococcus tauri}

Picophytoplankton, which covers organisms with a maximum size of $2 \mu \mathrm{m}$, include several cyanobacteria and algae species such as Synechococcus spp., Prochlorococcus spp. and Ostreococcus spp. In the last years, phytoplankton, especially O. tauri, has become important in studies related to ecology and genomics [9], [10].

Ostreococcus has been proposed as a model to study the biological clock in the green lineage. Recent works have identified and described the simplest clock model in this species comprised of the genes TIMING OF CAB EXPRESSION 1 (TOC1), also called PSEUDO-RESPONSE REGULATOR 1 (PRR1), and CIRCADIAN CLOCKASSOCIATED1 (CCA1). They constitute a simple but effective loop [11]. The expression of TOC1 increases during the day, peaking before dusk, while CCA1 increases its expression levels towards the end of the light phase, reaching its maximum at night. Interestingly, these oscillations are maintained under continuous light (LL). TOC1 encodes a protein that contains two domains: CONSTANS, CONSTANS-like and TIMING OF CAB EXPRESSION1 (CCT) and RESPONSE REGULATORY (REG) whereas CCA1 protein has a MYB-domain. CCA1 represses 
TOC1 via direct binding to the promoter. TOC1 activates the expression of CCA1, conforming a simple but effective biological clock [11] (Figure 1A). Other clock related genes such as EARLY FLOWERING (ELF) or GIGANTEA (GI) are absent in O. tauri [11].

A

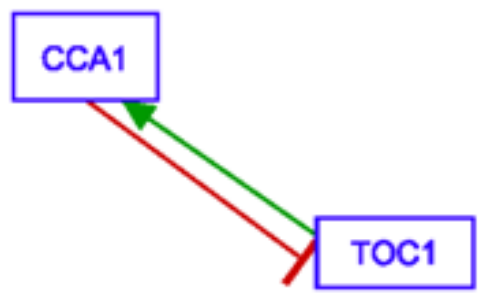

C

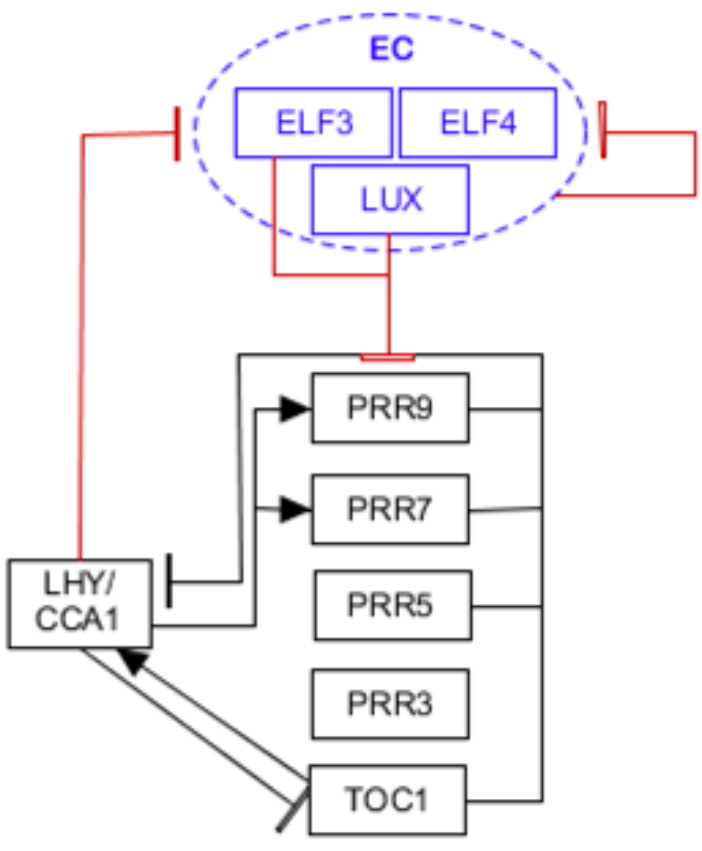

B

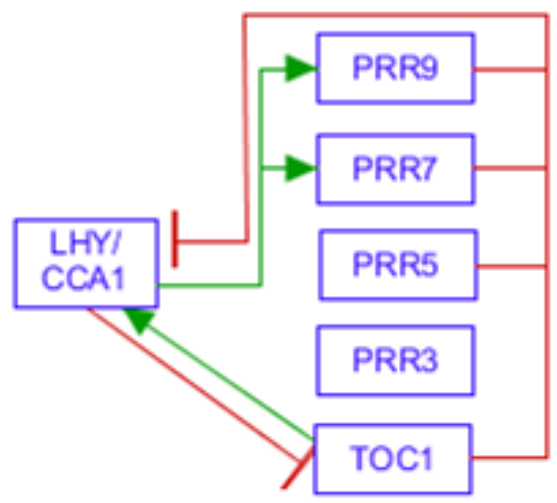

D

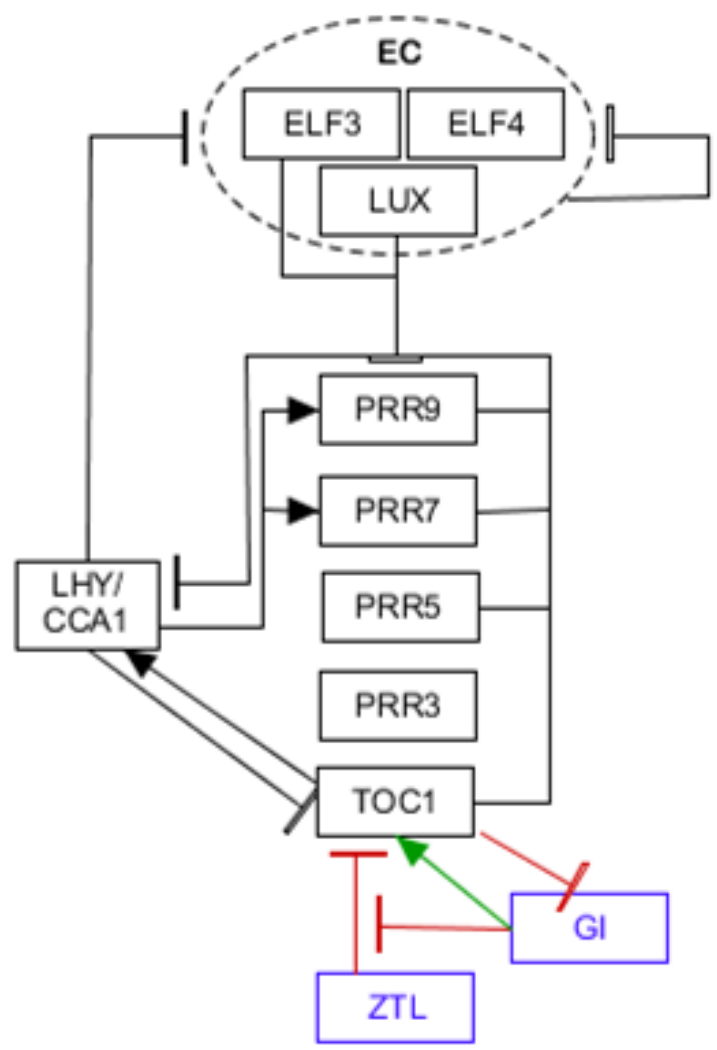

Figure 1: Circadian clock model

Ostreococcus tauri model (A), PRRs loop in Arabidopsis thaliana (B), the role of the evening complex (EC) (C) and the role of $G I$ and $Z T L$ (D). Every panel updates the previous scheme. Green arrow indicates activation, red line indicates inhibition. The transcriptional regulation of flowering is not shown here. Schematic representation based on Corellou et al 2009 (A), 
Ito et al., 2008 and Nakamichi et al., 2010 (B), Kolmos et al., 2011; Onai and Ishiura, 2005 and Helfer et al., 2011 (C), Más et al., 2003 and Kim et al., 2007 (D).

\section{Biological clocks in plants: The model derived from thale cress (Arabidopsis thaliana)}

As mentioned above, the core loop of the circadian clock in plants consists of two genes, TIMING OF CAB EXPRESSION1 (TOC1) and CIRCADIAN CLOCKASSOCIATED1 (CCA1) (Figure 1) [11]. TOC1 and CCA1 or the related gene LATE ELONGATED HYPOCOTYL (LHY), which also encodes a MYB protein, are highly conserved along the green lineage including the earthmoss (Physcomitrella patens), umbrella liverwort (Marchantia polymorpha), gymnosperms as the Japanese cedar (Cryptomeria japonica), grass species as rice (Oryza sativa) and flowering plants such as thale cress (Arabidopsis thaliana), garden petunia (Petunia $x$ hybrida), wild tobacco (Nicotiana attenuata) and snapdragon (Antirrhinum majus) [12]-[17].

In Arabidopsis, lines overexpressing LHY and CCA1 display a similar phenotype, which consists in altered flowering time and elongated hypocotyls, suggesting that their functions may be similar [15], [18]. The possible effect of CCA1 or LHY on growth rate has not been reported, but they coordinate hypocotyl elongation with other genes such as ELF3, MLK1 and MLK2. CCA1 and LHY are partially redundant and necessary to maintain the circadian rhythmicity [19], [20]. In addition, LHY/CCA1 repress the expression of TIMING OF CAB EXPRESSION 1 (TOC1) whereas TOC1 activates LHY/CCA1 [21].

Other clock genes described include members of the PSEUDO-RESPONSE REGULATOR (PRR) family, the evening complex (EC), which includes the genes EARLY FLOWERING3, EARLY FLOWERING4 (ELF3 and ELF4) and LUX ARRHYTHMO (LUX), and the related genes ZEITLUPE (ZTL), FLAVING-BINDING KELCH REPEAT F-BOX1 (FKF1) and LOV KELH PROTEIN2 (LKP2); which are also involved in flowering signaling. The addition of these genes to the circadian clock 
model resulted in a complex network established for the well know model plant Arabidopsis thaliana.

\section{PSEUDO-RESPONSE REGULATORS}

In Arabidopsis, five PSEUDO-RESPONSE REGULATORS (PRRs) members have been identified and widely studied -based on their role in the circadian clock: PRR9, PRR7, PRR5, PRR3 and TOC1/PRR1 [22], [23]. The mentioned order denotes the sequential expression maxima during the day. $P R R s$ genes encode a protein that contain two principal domains: pseudo-receiver (PR) and CONSTANS, CONSTANS-LIKE and TOC1 (CCT) [24], [25]. Loss of function phenotypes for different PRR diverge slightly: prr9 and prr7 mutants display a longer period [26] whereas prr5 and toc1 shown a shorter period [27]. LHY/CCA1 proteins activate the expression of $P R R 7$ and $P R R 9$ but repress TOC1. At the same time, TOC1 acts as a positive regulator of $L H Y / C C A 1$. Moreover, the $P R R s P R R 5, P R R 7$ and $P R R 9$ repress the expression of $L H Y / C C A 1$ during the day until midnight (from ZT2 to ZT16). PRR5, PRR7 and PRR9 have a repression motif which consists in two regions, $\mathrm{L}(\mathrm{E} / \mathrm{D})(\mathrm{L} / \mathrm{I}) \mathrm{S}(\mathrm{L} / \mathrm{I})(\mathrm{R} / \mathrm{K}) \mathrm{R}$ and $\mathrm{SXXSAF}(\mathrm{S} / \mathrm{T})(\mathrm{R} / \mathrm{Q})(\mathrm{Y} / \mathrm{F})$, located between the PR and CCT domains [28] (Figure 1B).

\section{The evening complex}

The evening complex (EC) comprises the clock genes EARLY FLOWERING 3 (ELF3), EARLY FLOWERING 4 (ELF4) and LUX ARRHYTHMO (LUX, also known as PHYTOCLOCK 1, PCL1). ELF3 and ELF4 were identified in Arabidopsis as genes involved in flowering time [29], [30]. The elf3 and elf4 mutants display an early flowering phenotype compared to wild-type plants, as well as longer hypocotyls, 
indicating that these genes play a role in photoreception. The EC is repressed by the core clock genes CCA1/LHY (Figure 1C) and by itself. In addition, ELF3 has been proposed as a repressor of $P R R 7$ and $P R R 9$ [31]. On the other hand, LUX is a MYB transcription factor necessary to maintain a robust oscillation in higher plants [32]. LUX binds to PSEUDO-RESPONSE REGULATOR 9 (PRR9) promoter, acting as a repressor [33] (Figure 1C).

GIGANTEA and ZEITLUPE/FLAVIN-BINDING KELCH REPEAT F-BOX 1/LOV-KELCH PROTEIN 2 family

GIGANTEA (GI) plays a critical role in flowering time but is also needed to maintain the amplitude and period length of clock genes [34], [35]. On the other hand, ZEITLUPE (ZTL or ADAGIO1, ADO1), FLAVIN-BINDING KELCH REPEAT F-BOX1 (FKF1, also known as ADAGIO3, ADO3) and LOV-KELCH PROTEIN2 (LKP2 or ADAGIO2, ADO2) are paralogs. This family shares a PAS domain, kelch motifs and a LOV (Light-Oxygen-Voltage) domain, acting as a blue-light receptor. GI, ZTL, FKF1 and LKP2 are regulated by the circadian clock and are involved in flowering [36]-[38].

FKF1 encodes a protein that is $62 \%$ identical to its paralog ZEITLUPE [36]. In Arabidopsis, flowering is acelerated under long days. Under this condition, GI and FKF1 proteins reach their maximum at the same time, before dusk, allowing the formation of the FKF1-GI complex [39]. The FKF-GI protein complex plays a role in the transition from the vegetative to reproductive phase-by degrading CYCLING DOF FACTOR 1 (CDF1), a flowering repressor.

ZTL is a gene related to the circadian clock but it is also involved in flowering and growth: $z t l$ mutants display shorter hypocotyls and delayed flowering [40], while its 
effect on growth speed has not been reported. This gene is not rhythmically expressed but its protein production shows a daily pattern. mRNA accumulation of ZTL is light independent, indicating that this gene does not participate in a feedback loop although it is necessary to maintain the circadian clock [37]. ZTL mediates the degradation of TOC1 via its F-box domain [41] whereas GI, which is evening expressed, stabilizes ZTL, preventing TOC1 from degradation [42] (Figure 1D). ZTL and LKP2 delay flowering as these proteins avoid the interaction FKF1-CDF1 [43], [44].

\section{REVEILLE and PHYTOCHROME INTERACTION FACTORS}

REVEILLES and PHYTOCHROME-INTERACTION FACTORS are involved in several processes such as growth and light transduction. These genes also play a role on the regulation of the circadian clock.

REVEILLES (RVEs) are MYB-like transcription factors, homologs to CCA1/LHY. In Arabidopsis, there are at least eight $R V E s$. RVE8 displays a robust oscillation, reaching its maximum at dusk. This gene binds directly to the evening element EE, a regulatory element present in some clock genes such as TOC1 or PRR5, activating the expression of PRR5 [45]. RVE4 and RVE6 seem to act similar to their close homolog RVE8, binding to EE sites. RVE4, RVE6 and RVE8 may be partially redundant [46]. In constrast, RVE1 connects the circadian clock and growth by promoting the activation of auxin synthesis during the light period [47].

The PHYTOCHROMES (PHYS) and PHYTOCHROME-INTERACTION FACTORS (PIFs) are bHLH transcription factors and regulate the light/dark and temperature transduction to the circadian clock and growth [48]. PHYs and the evening complex repress PIF4 and PIF5, which causes the inhibition of growth at night [49], [50]. 


\section{Gene and genome duplications}

Gene and genome duplication events have been documented in animals and plants. Gene duplication may be followed by a mutation that causes a loss of function or an inactivation of one copy. Alternatively, both copies (paralogs) may retain part of the original function (subfunctionalization) or one of the duplicate genes may acquire a new function as a result of one or more new mutations (neofunctionalization) (see [51]-[53]).

Interestingly, duplicated genes seem to be retained in plants. Whole genome duplications (WGD, also refered as polyploidy) have occurred during plant evolution, contributing to speciation and diversification [54], [55]. The first recorded plant genome duplication occurred 319 million years ago (Mya) followed by another duplication event 192 Mya. These two events affected common ancestors of extant seed plants and extant angiosperms, respectively [56]. Then, genome triplication occurred associated with early diversification of Eudicots (gamma or $\gamma$-event) [57], which has been found in several genus including Solanum, Glycine or Brassica [16], [58], [59]. These species differ in the copy number of clock genes. As mentioned above, Arabidopsis presents one GIGANTEA copy gene whereas soybean (Glycine max) has three copies and show differences in daily expression (temporal) and among tissues (spatial) [60]. Brassica rapa shows a genome triplication event that occurred after the Arabidopsis-Brassica speciation and while Arabidopsis has five PSEUDO-RESPONSE REGULATOR members (PRRs), B. rapa has eleven copies which differ in structure, including partial deletions and partial fusions [61]. Structural changes, temporal and spatial expression patterns are congruent with subfunctionalization and neofunctionalization after duplication events, and can elucidate the evolution and specialization of the circadian clock across the green lineage. 


\section{Going further in plant models: Snapdragon (Antirrhinum majus) and petunia (Petunia hybrida)}

The well-known plant model Arabidopsis thaliana, also known as thale cress, was the first plant to be completely sequenced [62]. This species has been widely used for studying plant development, genetics and evolution. There are other species useful to investigate other aspects related to plant biology, including dormancy in cherry trees (Prunus avium) and poplars (Populus spp.) [63], anthocyanin accumulation and synthesis in petunia (Petunia spp.) [64] or volatile organic compound (VOCs) biosynthesis [65].

Volatile organic compounds comprise a complex group of metabolites which plays a critical role in plant defense, acting as pest repellents or as bactericides and fungicides, in plant-plant interaction and in attracting pollinators. Two flowering plants, garden petunia (Petunia spp.) and snapdragon (Antirrhinum majus), have been used to study the synthesis and emission of floral volatiles, which are mainly emitted by petals [66]-[69]. In addition, the petunia and snapdragon genomes have been recently sequenced [16], [70], which allows us, combined with other techniques including gene silencing and CRISPR editing, to understand the molecular basis of biological processes. 


\section{A general description: Snapdragon and petunia}

The snapdragon (Antirrhinum majus) is an herbaceous and annual plant, characterized by a flower of bilateral simmetry with five petals, partially fused resulting in a tube that ends in two lobes. Antirrhinum was included in the Scrophulariaceae family until 2005, when it was reassigned to the Plantaginaceae family [71]. The number of valid species seems uncertain. The European Environment Agency (EEA) lists 35 species (without including subspecies) but only 21 are valid names, i.e. Antirrhinum orontium is a synonym of Misopates orontium (consulted online September 2019). In constrast, other studies considered at least 25 species, which are widely distributed in the Mediterranean basin [72].

Petunia is a genus in the Solanaceae family, which includes the crops aubergine, tomato, pepper and potato, widely distributed in South America. Typically, Petunia spp. are herbaceous and annual plants, with flowers composed of five petals with actinomorphic or zygomorphic symmetry. Petunia species are pollinated by diurnal or nocturnal insects [73], except $P$. exserta, that is pollinated by hummingbirds. Thus, flower shape and size, color and floral frangance vary widely among the genus Petunia. Several studies focused on these differences among species, such as Petunia axillaris, P. exserta and P. integrifolia. Furthermore, their hybrids, such as Petunia $x$ hybrida, a cross between $P$. axillaris and P. integrafolia, are commonly used lines. Interestingly, most of the garden petunias correspond to P. hybrida.

\section{Volatile organic compounds}

Volatile organic compounds (VOCs) are involved in several processes including stress responses, plant defense, plant-plant interaction and pollinator attraction. Plant volatiles are classified in four principal groups based on their metabolic 
pathway: lipoxygenase (LOX), mevalonic acid (MVA), methylerythritol (MEP) and shikimate/phenylalanine (Figure 2) [74].

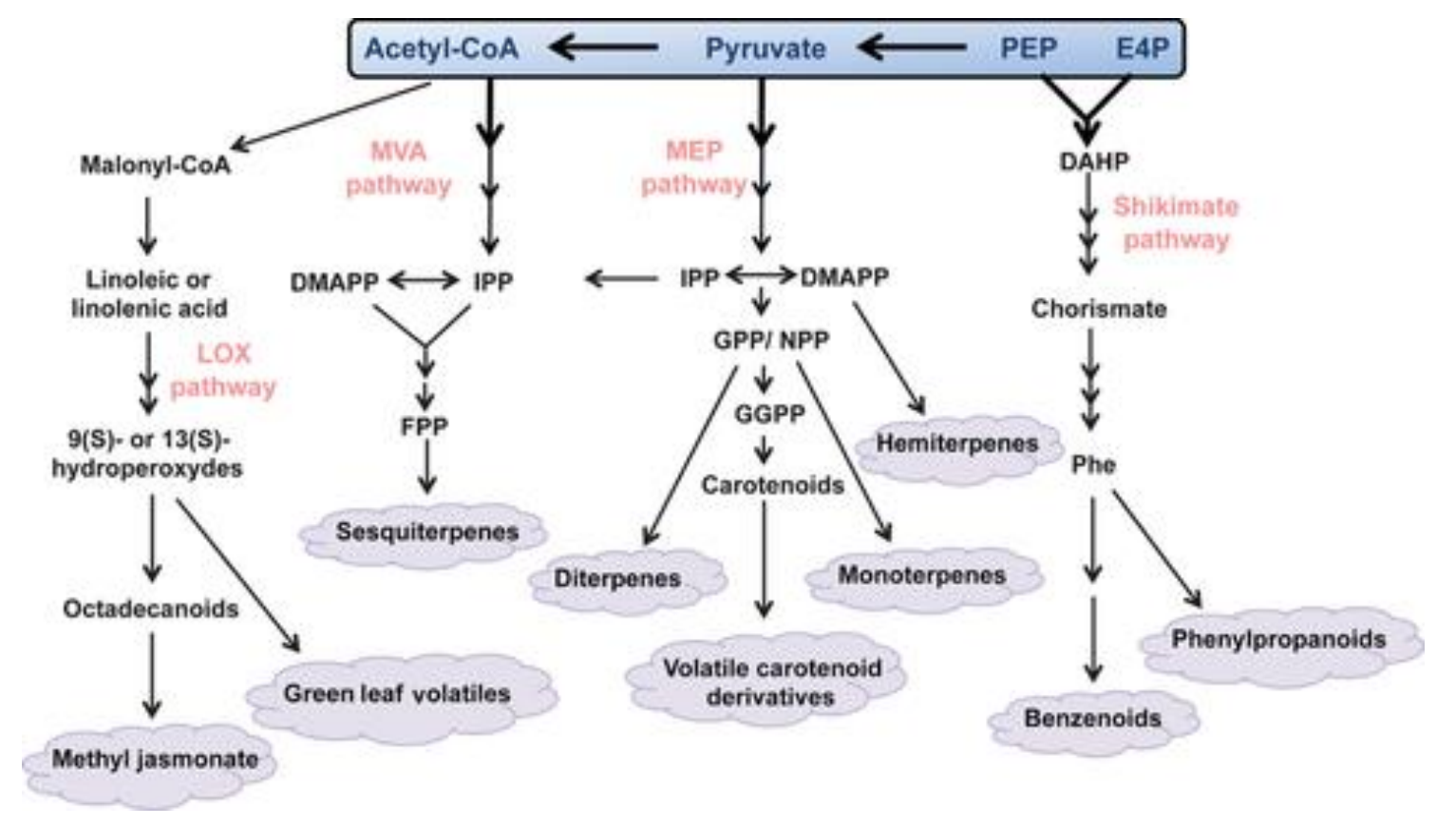

Figure 2: Volatile organic compounds: Metabolic pathways.

Pathways: LOX: lipoxygenase, MVA: mevalonic acid, MEP: methylerythritol and shikimate/phenylalanine. (From Dudareva et al., 2013).

There is another classification of plant volatiles, based on the type of molecule:

- Phenylpropanoid/benzenoids are compounds derived from the aromatic aminoacid phenylalanine (Phe) through the shikimic acid pathway. These volatiles are characterized by an aromatic ring. Phenylpropanoids and benzenoids are commonly found in the floral fragrance of petunia, wild tobacco or snapdragon [75], [76], [77], [78].

- Terpenes. This group of compounds is derived from the five carbons $\left(\mathrm{C}_{5}\right)$ unit isopentenyl diphosphate (IPP). The addition of $\mathrm{C}_{5}$ units results in monoterpenes $\left(\mathrm{C}_{10}\right)$ that included the volatiles linalool, myrcene and ocimene, sesquiterpenes $\left(\mathrm{C}_{15}\right)$ such as the VOCs farnesene or caryophyllene and diterpenes $\left(\mathrm{C}_{20}\right)$ as gibberellins, among other terpenoids [74], [79], [80]. 
- Fatty acid derivatives. Several volatiles, including the aldehydes $n$-hexenal and n-nonenal and methyl jasmonate (MeJA) derive from the fatty acid linolenic acid [74]. These volatile organic compounds are commonly found in leaves and are known as green leaf volatiles (GLVs). GLVs are involved in plant defense acting as repellents [81], conferring fungy resistance or acting as fungicides [82], bactericides [83] or in the attraction of predators and parasites of pests (parasitoids) [84], [85]. In addition, MeJA also is involved in the stress signaling network [86], can induce a defensive response in unharmed plants and is related with germination and flowering among other pathways.

- Nitrogen containing compounds (NCC), which include benzoxazinoids and oximes, are involved in plant defense due to their toxicity and antifeedant activity among other functions [87], [88]. The NCC group includes volatiles organic compounds such as indole and methyl nicotinate. When a plant is damaged by an herbivore, the plant activates a defense mechanism consisting on volatile release, which is enhanced by the NCC indole [89].

\section{Scent profiles and biological functions}

The complexity of the floral fragrance depends on the contribution (or amount) of every single VOC, but also on the class (e.g. monoterpene, pheylpropanoid) and number of emitted compounds [90]. The combination of these factors results in a specific aroma blend. The aroma of Petunia is mainly composed of benzenoids [91], while in the carrion flower (Caralluma europaea), monoterpenes are the most abundant compounds [92]. Interestingly, this particular aroma varies among species and accessions [77], [93], [94]. Pollinators are capable to discriminate and identify the floral fragrance of different plant species [95], [96] or even cultivars, differing in their scent profile [97]. In addition, the emission of certain species is positively 
correlated with pollinator activity, such as bumblebees and snapdragon or moths and petunia [66], [98]. The daily scent emission is maintained under constant light or dark conditions, indicating that this trait is controlled by the circadian clock. Besides, the flower scent, in qualitative and quantitative terms, can vary depending on the flower age or developmental stage, environmental conditions and after pollination [77], [78], [99], [100]. For example, the number of detected VOCs in Lilium flowers increases during flower development while the amount decreases towards the last stage [99]. The synthesis of volatile compounds and their emission is therefore a complex process influenced by the development stage as well as abiotic and biotic factors.

Several studies have questioned whether a floral fragrance, or a single volatile, is attractant or repellent. There are different approaches such as counting and/or capturing insect visitors per plant or flower for a period of time [101], [102] or analyzing electroantennogram responses [103]. However, it can be difficult to determine if a single volatile acts as attractant or deterrant: an insect can be exposed to a pure compound but the response may vary depending on the volatile concentration [104]. The relationship between insects and other animals, both pollinators and harmful species, and flowers suggest an interesting viewpoint: the scent profile may attract non-desired herbivores or repell potential pollinators. This possibility leads to the conclusion that flower fragrance may be under selective pressure. Kessler et al. [105] demonstrate by using transgenic petunias that a lower VOC emission or the lack of emission of certain VOCs, leads to a reduction in damage by herbivores.

\section{Scent emission: Importance of the circadian clock}

Several studies describing the daily fragrance emission in flowering plants including Antirrhinum [66], Silene [106], Petunia [98], Nicotiana [107] or Rosa [108], show sthat VOC emission follows a rhythmic pattern. Although the biosynthesis of volatile 
compounds has been described in detail, the regulation of scent emission by the circadian clock genes is still poorly known. The analysis of natural variation, mutant lines or genetically modified organism (GMOs) are the key to understand the relationship between scent synthesis, its release and the integration of environmental cues. Recently, the knock-down regulation of the clock genes LATE ELONGATED HYPOCOTYL (LHY) in garden petunia [109], and LHY, ZEITLUPE (ZTL) and TIMING OF CAB EXPRESSION1 (TOC1) in wild tobacco [110], [111] has revealed that these genes are involved in the regulation of scent emission. In petunia, LHY represses the expression of ODORANT1 (ODO1) [109], which regulates the phenylpropanoid/benzenoid pathway [112]. As result, the emitted levels of the benzenoids methyl benzoate, benzyl benzoate and benzaldehyde and the phenylpropanoid isoeugenol are in general lower and shifted, showing an advanced phenotype. These results are similar to observations in wild tobacco, where the down regulation of $L H Y$ decreases the emission of the benzenoid benzyl acetone and also advances its maximum emission. Similarly, silencing of ZTL decreases drastically the emission of this volatile [110]. In contrast, the silenced TOC1 tobacco lines show a slight delay in the emission time of benzyl acetone and an increase in the emitted amount [111].

Petunia and wild tobacco belong to the Solanaceae family and are considered nocturnally emitting plants [98], [113]. So, the regulation of floral fragrance emission by the circadian clock may vary in daytime emitting species, such as snapdragon or orchids [66], [114]. Furthermore, the regulation of compounds other than phenylpropanoid/ benzenoids, such as terpenes and fatty acid derivatives, may also differ. Another important aspect is the biological effect of the altered floral aroma on pests or pollinators. Yon et al. [111] found that flowers with early emission and flower angle movement (irLHY lines) were preferred by moths and as a result, these plants presented more mature capsules than control plants. The advanced phenotype does not explain this preference, as moth activity occurs later, but authors 
suggest an alternative hypothesis based on changes in minor volatiles with special attraction to moths [111]. In conclusion, the analysis of clock gene effects on volatile organic compounds should include major and minor compounds in order to describe changes in the scent profile. 


\section{References}

[1] C. R. McClung, «The Plant Circadian Oscillator», Biology, vol. 8, n. ${ }^{\circ}$ 1, p. 14, mar. 2019.

[2] J. Lei, G. K. Jayaprakasha, J. Singh, R. Uckoo, E. J. Borrego, S. Finlayson, S, ... , K. Zhu-Salzman, "CIRCADIAN CLOCK-ASSOCIATED1 controls resistance to aphids by altering indole glucosinolate production», Plant Physiology, p. pp.00676.2019, ene. 2019.

[3] M. J. Haydon, O. Mielczarek, F. C. Robertson, K. E. Hubbard, A. A. R. Webb, «Photosynthetic entrainment of the Arabidopsis circadian clock», Nature, vol. 502, n. ${ }^{\circ} 7473$, oct. 2013.

[4] N. Dalchau, S. J. Baek, H. M. Briggs, F. C. Robertson, A. N. Dodd, M. J. Gardner, M. J, ... , A. A. Webb, «The circadian oscillator gene GIGANTEA mediates a long-term response of the Arabidopsis thaliana circadian clock to sucrose», PNAS, vol. 108, n. ${ }^{\circ} 12$, pp. 5104-5109, mar. 2011.

[5] W. F. Zimmerman, C. S. Pittendrigh, T. Pavlidis, «Temperature compensation of the circadian oscillation in Drosophila pseudoobscura and its entrainment by temperature cycles», Journal of Insect Physiology, vol. 14, n. ${ }^{\circ}$ 5, pp. 669-684, may 1968.

[6] Jean-Jacques de Mairan., "Observation botanique», Histoire de l'Académie Royale des Sciences Paris, p. 35, 1729.

[7] D. E. Somers, P. F. Devlin, S. A. Kay, «Phytochromes and Cryptochromes in the Entrainment of the Arabidopsis Circadian Clock», Science, vol. 282, n. ${ }^{\circ}$ 5393, pp. 1488-1490, nov. 1998.

[8] J. Aschoff, «Freerunning and Entrained Circadian Rhythms», en Biological Rhythms, J. Aschoff, Ed. Boston, MA: Springer US, 1981, pp. 81-93.

[9] A. Z. Worden, J. K. Nolan, B. Palenik, «Assessing the dynamics and ecology of marine picophytoplankton: The importance of the eukaryotic component», Limnology and Oceanography, vol. 49, n. ${ }^{\circ}$ 1, pp. 168-179, 2004.

[10] E. Derelle, C. Ferraz, S. Rombauts, P. Rouzé, A. Z. Worden, S. Robbens, ... , Y. Saeys, «Genome analysis of the smallest free-living eukaryote Ostreococcus tauri unveils many unique features», Proceedings of the National Academy of Sciences, vol. 103, n. ${ }^{\circ} 31$, pp. 11647-11652, ago. 2006.

[11] F. Corellou, C. Schwartz, J. P. Motta, E. Djouani-Tahri, F. Sanchez, F. Y. Bouget, «Clocks in the Green Lineage: Comparative Functional Analysis of the Circadian Architecture of the Picoeukaryote Ostreococcus», Plant Cell, vol. 21, n. ${ }^{\circ}$ 11, pp. 3436-3449, 2009.

[12] R. Okada, S. Kondo, S. B. Satbhai, N. Yamaguchi, M. Tsukuda, S. Aoki, «Functional characterization of CCA1/LHY homolog genes, PpCCA1a and PpCCA1b, in the moss Physcomitrella patens», Plant Journal, vol. 60, n. ${ }^{\circ}$ 3, pp. 551-563, 2009.

[13] M. Nose, A. Watanabe, "Clock genes and diurnal transcriptome dynamics in summer and winter in the gymnosperm Japanese cedar (Cryptomeria japonica (L.f.) D.Don).», BMC plant biology, vol. 14, n. ${ }^{\circ}$, p. 308, ene. 2014.

[14] M. Murakami, Y. Tago, T. Yamashino, T. Mizuno, "Comparative Overviews of Clock-Associated Genes of Arabidopsis thaliana and Oryza sativa», Plant and Cell Physiology, vol. 48, n. ${ }^{\circ} 1$, pp. 110-121, 2007.

[15] R. Schaffer, N. Ramsay, A. Samach, S. Corden, J. Putterill, I. A. Carré, I. A., G. Coupland, «The late elongated hypocotyl Mutation of Arabidopsis Disrupts Circadian Rhythms and the Photoperiodic Control of Flowering», Cell, vol. 93, n. ${ }^{\circ}$ 7, pp. 1219-1229, 1998. 
[16] A. Bombarely, M. Moser, A. Amrad, M. Bao, L. Bapaume, C. S. Barry, ... , M. Bucher, «Insight into the evolution of the Solanaceae from the parental genomes of Petunia hybrida», Nature Plants, vol. 2, n. ${ }^{\circ}$ May, pp. 1-9, 2016.

[17] F. Yon, P.-J. Seo, J. Y. Ryu, C.-M. Park, I. T. Baldwin, S.-G. Kim, «Identification and characterization of circadian clock genes in a native tobacco, Nicotiana attenuata», BMC plant biology, vol. 12, n. ${ }^{\circ}$ 1, p. 172, ene. 2012.

[18]Z.-Y. Wang, E. M. Tobin, «Constitutive Expression of the CIRCADIAN CLOCK ASSOCIATED 1 (CCA1) Gene Disrupts Circadian Rhythms and Suppresses Its Own Expression», Cell, vol. 93, n. ${ }^{\circ}$ 7, pp. 1207-1217, jun. 1998.

[19] D. Alabadí, M. J. Yanovsky, P. Más, S. L. Harmer, S. A. Kay, «Critical Role for CCA1 and LHY in Maintaining Circadian Rhythmicity in Arabidopsis», Current Biology, vol. 12, n. ${ }^{\circ}$ 9, pp. 757-761, abr. 2002.

[20] R. M. Green, E. M. Tobin, «Loss of the circadian clock-associated protein 1 in Arabidopsis results in altered clock-regulated gene expression», PNAS, vol. 96, n. ${ }^{\circ}$, pp. 4176-4179, mar. 1999.

[21] D. Alabadi, T. Oyama, M. J. Yanovsky, F. G. Harmon, P. Mas, S. A. Kay, «Reciprocal regulation between TOC1 and LHY/CCA1 within the Arabidopsis circadian clock», Science, vol. 293, n. ${ }^{\circ}$ 5531, pp. 880-883, 2001.

[22] A. Matsushika, S. Makino, M. Kojima, T. Mizuno, "Circadian Waves of Expression of the APRR1/TOC1 Family of Pseudo-Response Regulators in Arabidopsis thaliana: Insight into the Plant Circadian Clock», Plant and Cell Physiology, vol. 41, n. ${ }^{\circ}$ 9, pp. 1002-1012, 2000.

[23] N. Nakamichi, M. Kita, S. Ito, T. Yamashino, T. Mizuno, «PSEUDO-RESPONSE REGULATORS, PRR9, PRR7 and PRR5, Together play essential roles close to the circadian clock of Arabidopsis thaliana», Plant and Cell Physiology, vol. 46, n. ${ }^{\circ}$ 5, pp. 686-698, 2005.

[24] J. Cockram, T. Thiel, B. Steuernagel, N. Stein, S. Taudien, P. C. Bailey, D. M. O'Sullivan, "Genome Dynamics Explain the Evolution of Flowering Time CCT Domain Gene Families in the Poaceae», PLOS ONE, vol. 7, n. ${ }^{\circ}$ 9, p. e45307, sep. 2012.

[25] E. M. Farré y T. Liu, «The PRR family of transcriptional regulators reflects the complexity and evolution of plant circadian clocks», Current Opinion in Plant Biology, vol. 16, n. ${ }^{\circ}$ 5, pp. 621629, 2013.

[26] E. M. Farré, S. L. Harmer, F. G. Harmon, M. J. Yanovsky, S. A. Kay, «Overlapping and Distinct Roles of PRR7 and PRR9 in the Arabidopsis Circadian Clock», Current Biology, vol. 15, n. ${ }^{\circ} 1, \mathrm{pp}$. 47-54, ene. 2005.

[27] S. Ito, Y. Niwa, N. Nakamichi, H. Kawamura, T. Yamashino, T. Mizuno, «Insight into Missing Genetic Links Between Two Evening-Expressed Pseudo-Response Regulator Genes TOC1 and PRR5 in the Circadian Clock-Controlled Circuitry in Arabidopsis thaliana», Plant Cell Physiol, vol. 49, n. ${ }^{\circ}$ 2, pp. 201-213, feb. 2008.

[28] N. Nakamichi, T. Kiba, R. Henriques, T. Mizuno, N.-H. Chua, H. Sakakibara, «PSEUDORESPONSE REGULATORS 9,7 , and 5 are transcriptional repressors in the Arabidopsis circadian clock», The Plant cell, vol. 22, n. ${ }^{\circ}$ 3, pp. 594-605, 2010.

[29] K. A. Hicks, A. J. Millar, I. A. Carre, D. E. Somers, M. Straume, D. R. Meeks-Wagner, S. A. Kay, S., "Conditional Circadian Dysfunction of the Arabidopsis early-flowering 3 Mutant», Science, vol. 274, n. ${ }^{\circ}$ 5288, pp. 790-792, nov. 1996. 
[30] M. R. Doyle, S. J. Davis, R. M. Bastow, H. G. McWatters, L. Kozma-Bognár, F. Nagy, ... , R. M. Amasino, "The ELF4 gene controls circadian rhythms and flowering time in Arabidopsis thaliana», Nature, vol. 419, n. ${ }^{\circ} 6902$, pp. 74-77, 2002.

[31] E. Kolmos, E. Herrero, N. Bujdoso, A. J. Millar, R. Tóth, P. Gyula, ... , S. J. Davis, «A ReducedFunction Allele Reveals That EARLY FLOWERING3 Repressive Action on the Circadian Clock Is Modulated by Phytochrome Signals in Arabidopsis», The Plant Cell, vol. 23, n. ${ }^{\circ}$ 9, pp. 32303246, sep. 2011.

[32] K. Onai, M. Ishiura, «PHYTOCLOCK 1 encoding a novel GARP protein essential for the Arabidopsis circadian clock», Genes to Cells, vol. 10, n. ${ }^{\circ}$ 10, pp. 963-972, 2005.

[33] A. Helfer, D. A. Nusinow, B. Y. Chow, A. R. Gehrke, M. L. Bulyk, S. A. Kay, «LUX ARRHYTHMO Encodes a Nighttime Repressor of Circadian Gene Expression in the Arabidopsis Core Clock», Current Biology, vol. 21, n. ${ }^{\circ}$ 2, pp. 126-133, ene. 2011.

[34] S. Fowler, K. Lee, H. Onouchi, A. Samach, K. Richardson, B. Morris, ... , J. Putterill, «GIGANTEA: a circadian clock-controlled gene that regulates photoperiodic flowering in Arabidopsis and encodes a protein with several possible membrane-spanning domains», The EMBO Journal, vol. 18, n. ${ }^{\circ}$ 17, pp. 4679-4688, 1999.

[35] D. H. Park, D. E. Somers, Y. S. Kim, Y. H. Choy, H. K. Lim, M. S. Soh, ... , H. G. Nam, «Control of Circadian Rhythms and Photoperiodic Flowering by the Arabidopsis GIGANTEA Gene», Science, vol. 285, n. ${ }^{\circ}$ 5433, pp. 1579-1582, sep. 1999.

[36] D. C. Nelson, J. Lasswell, L. E. Rogg, M. a Cohen, B. Bartel, «FKF1, a clock-controlled gene that regulates the transition to flowering in Arabidopsis.», Cell, vol. 101, n. ${ }^{\circ}$ 3, pp. 331-340, 2000.

[37] D. E. Somers, T. F. Schultz, M. Milnamow, S. A. Kay, «ZEITLUPE Encodes a Novel ClockAssociated PAS Protein from Arabidopsis», Cell, vol. 101, n. ${ }^{\circ}$ 3, pp. 319-329, abr. 2000.

[38] T. F. Schultz, T. Kiyosue, M. Yanovsky, M. Wada, S. A. Kay, «A role for LKP2 in the circadian clock of Arabidopsis», The Plant cell, vol. 13, n. ${ }^{\circ}$ 12, pp. 2659-2670, 2001.

[39] M. Sawa, D. A. Nusinow, S. A. Kay, T. Imaizumi, «FKF1 and GIGANTEA complex formation is required for day-length measurement in Arabidopsis», Science, vol. 318, n. ${ }^{\circ}$ 5848, pp. 261265, oct. 2007.

[40] É. Kevei, P. Gyula, A. Hall, L. Kozma-Bognár, W. Y. Kim, M. E. Eriksson, ... , R. M. Bastow, "Forward Genetic Analysis of the Circadian Clock Separates the Multiple Functions of ZEITLUPE», Plant Physiology, vol. 140, n. ${ }^{\circ}$ 3, pp. 933-945, mar. 2006.

[41] P. Más, W.-Y. Kim, D. E. Somers, S. A. Kay, «Targeted degradation of TOC1 by ZTL modulates circadian function in Arabidopsis thaliana», Nature, vol. 426, n. ${ }^{\circ}$ 6966, pp. 567-570, dic. 2003.

[42] W. Y. Kim, S. Fujiwara, S. S. Suh, J. Kim, Y. Kim, L. Han, ... , D. E. Somers, «ZEITLUPE is a circadian photoreceptor stabilized by GIGANTEA in blue light», Nature, vol. 449, n. ${ }^{\circ} 7160$, pp. 356-360, sep. 2007.

[43] T. Takase, Y. Nishiyama, H. Tanihigashi, Y. Ogura, Y. Miyazaki, Y. Yamada, T. Kiyosue, «LOV KELCH PROTEIN2 and ZEITLUPE repress Arabidopsis photoperiodic flowering under noninductive conditions, dependent on FLAVIN-BINDING KELCH REPEAT F-BOX1», The Plant Journal, vol. 67, n. ${ }^{\circ} 4$, pp. 608-621, 2011.

[44] T. Imaizumi, S. A. Kay, «Photoperiodic control of flowering: not only by coincidence», Trends in Plant Science, vol. 11, n. ${ }^{\circ} 11$, pp. 550-558, 2006. 
[45] R. Rawat, N. Takahashi, P. Y. Hsu, M. A. Jones, J. Schwartz, M. R. Salemi, ... , S. L. Harmer, "REVEILLE8 and PSEUDO-REPONSE REGULATOR5 Form a Negative Feedback Loop within the Arabidopsis Circadian Clock», PLOS Genetics, vol. 7, n. ${ }^{\circ}$ 3, p. e1001350, mar. 2011.

[46] P. Y. Hsu, U. K. Devisetty, S. L. Harmer, "Accurate timekeeping is controlled by a cycling activator in Arabidopsis», eLife, vol. 2, abr. 2013.

[47] R. Rawat, J. Schwartz, M. A. Jones, I. Sairanen, Y. Cheng, C. R. Andersson, ... , S. L. Harmer, «REVEILLE1, a Myb-like transcription factor, integrates the circadian clock and auxin pathways», PNAS, vol. 106, n. ${ }^{\circ}$ 39, pp. 16883-16888, sep. 2009.

[48] P. Leivar, E. Monte, «PIFs: Systems Integrators in Plant Development», The Plant Cell, vol. 26, n. ${ }^{\circ}$, pp. 56-78, ene. 2014.

[49] I. Paik, P. K. Kathare, J.-I. Kim, E. Huq, «Expanding Roles of PIFs in Signal Integration from Multiple Processes», Molecular Plant, vol. 10, n. ${ }^{\circ}$ 8, pp. 1035-1046, ago. 2017.

[50] J. Shin, M. U. Anwer, S. J. Davis, «Phytochrome-Interacting Factors (PIFs) as Bridges between Environmental Signals and the Circadian Clock: Diurnal Regulation of Growth and Development», Molecular Plant, vol. 6, n. ${ }^{\circ}$ 3, pp. 592-595, may 2013.

[51] S. Rastogi, D. A. Liberles, «Subfunctionalization of duplicated genes as a transition state to neofunctionalization», BMC Evolutionary Biology, vol. 5, n. ${ }^{\circ}$ 1, p. 28, abr. 2005.

[52]X. He, J. Zhang, «Rapid Subfunctionalization Accompanied by Prolonged and Substantial Neofunctionalization in Duplicate Gene Evolution», Genetics, vol. 169, n. ${ }^{\circ}$ 2, pp. 1157-1164, feb. 2005.

[53] M. Lynch, A. Force, «The Probability of Duplicate Gene Preservation by Subfunctionalization», Genetics, vol. 154, n. ${ }^{\circ} 1$, pp. 459-473, ene. 2000.

[54] L. Cui, P. K. Wall, J. H. Leebens-Mack, B. G. Lindsay, D. E. Soltis, J. J. Doyle, ... , V. A. Albert, «Widespread genome duplications throughout the history of flowering plants», Genome Res., vol. 16, n. ${ }^{\circ} 6$, pp. 738-749, ene. 2006.

[55] K. L. Adams, J. F. Wendel, «Polyploidy and genome evolution in plants», Current Opinion in Plant Biology, vol. 8, n. ${ }^{\circ}$ 2, pp. 135-141, 2005.

[56] Y. Jiao, N. J. Wickett, S. Ayyampalayam, A. S. Chanderbali, L. Landherr, P. E. Ralph, ... , D. E. Soltis, «Ancestral polyploidy in seed plants and angiosperms», Nature, vol. 473, n. ${ }^{\circ} 7345$, pp. 97-100, may 2011.

[57] Y. Jiao, J. Leebens-Mack, S. Ayyampalayam, J. E. Bowers, M. R. McKain, J. McNeal, ... , X. Wu, "A genome triplication associated with early diversification of the core eudicots», Genome Biology, vol. 13, n. ${ }^{\circ}$ 1, p. R3, ene. 2012.

[58] J. Schmutz, S. B. Cannon, J. Schlueter, J. Ma, T. Mitros, W. Nelson, ... . D. Xu, «Genome sequence of the palaeopolyploid soybean», Nature, vol. 463, n. ${ }^{\circ} 7278$, pp. 178-183, ene. 2010.

[59] J. H. Mun, S. J. Kwon, T. J. Yang, Y. J. Seol, M. Jin, J. A. Kim, ... , H. J. Yu, «Genome-wide comparative analysis of the Brassica rapa gene space reveals genome shrinkage and differential loss of duplicated genes after whole genome triplication», Genome Biology, vol. 10, n. ${ }^{\circ} 10$, p. R111, oct. 2009.

[60] F. Li, X. Zhang, R. Hu, F. Wu, J. Ma, Y. Meng, Y. Fu, «Identification and molecular characterization of FKF1 and GI homologous genes in soybean», PLOS ONE, vol. 8, n. ${ }^{\circ} 11$, pp. 26-28, 2013. 
[61] P. Lou, J. Wu, F. Cheng, L. G. Cressman, X. Wang, C. R. McClung, «Preferential retention of circadian clock genes during diploidization following whole genome triplication in Brassica rapa.», The Plant Cell, vol. 24, n. ${ }^{\circ}$ 6, pp. 2415-26, 2012.

[62] The Arabidopsis Genome Initiative, "Analysis of the genome sequence of the flowering plant Arabidopsis thaliana», Nature, vol. 408, n. ${ }^{\circ}$ 6814, pp. 796-815, dic. 2000.

[63] C. Cesaraccio, D. Spano, R. L. Snyder, P. Duce, «Chilling and forcing model to predict bud-burst of crop and forest species», Agricultural and Forest Meteorology, vol. 126, n. ${ }^{\circ} 1$, pp. 1-13, nov. 2004.

[64] D. Weiss, «Regulation of flower pigmentation and growth: Multiple signaling pathways control anthocyanin synthesis in expanding petals», Physiologia Plantarum, vol. 110, n. ${ }^{\circ} 2$, pp. 152$157,2000$.

[65] N. Dudareva, E. Pichersky, J. Gershenzon, «Biochemistry of Plant Volatiles 1», Plant physiology, vol. 135, n. ${ }^{\circ}$ August, pp. 1893-1902, ago. 2004.

[66] N. Kolosova, N. Gorenstein, C. M. Kish, N. Dudareva, «Regulation of Circadian Methyl Benzoate Emission in Diurnally and Nocturnally Emitting Plants», The Plant Cell, vol. 13, n. ${ }^{\circ} 10$, pp. $2333-$ 2347, oct. 2001.

[67] N. Oyama-Okubo, T. Ando, N. Watanabe, E. Marchesi, K. Uchida, M. Nakayama, «Emission mechanism of floral scent in Petunia axillaris.», Bioscience, biotechnology, and biochemistry, vol. 69, n. ${ }^{\circ} 4$, pp. 773-777, abr. 2005.

[68] F. Adebesin, J. R. Widhalm, B. Boachon, F. Lefèvre, B. Pierman, J. H. Lynch, ... , J. A. F. Porter, «Emission of volatile organic compounds from petunia flowers is facilitated by an $A B C$ transporter», Science, vol. 356, n. ${ }^{\circ}$ 6345, pp. 1386-1388, 2017.

[69] V. Ruiz-Hernández, B. Hermans, J. Weiss, M. Egea-Cortines, «Genetic Analysis of Natural Variation in Antirrhinum Scent Profiles Identifies BENZOIC ACID CARBOXYMETHYL TRANSFERASE As the Major Locus Controlling Methyl Benzoate Synthesis», Frontiers in Plant Science, vol. 8, n. ${ }^{\circ}$ January, pp. 1-13, 2017.

[70] M. Li, D. Zhang, Q. Gao, Y. Luo, H. Zhang, B. Ma, ... , Q. Li, «Genome structure and evolution of Antirrhinum majus L», Nature Plants, vol. 5, n. ${ }^{\circ}$ 2, p. 174, feb. 2019.

[71] D. C. Albach, H. M. Meudt, B. Oxelman, «Piecing together the "new" Plantaginaceae», American Journal of Botany, vol. 92, n. ${ }^{\circ}$ 2, pp. 297-315, 2005.

[72] P. Vargas, E. Carrió, B. Guzmán, E. Amat, J. Güemes, «A geographical pattern of Antirrhinum (Scrophulariaceae) speciation since the Pliocene based on plastid and nuclear DNA polymorphisms», Journal of Biogeography, vol. 36, n. ${ }^{\circ}$ 7, pp. 1297-1312, 2009.

[73] T. Ando, M. Nomura, J. Tsukahara, H. Watanabe, H. Kokubun, T. Tsukamoto, ... , I. J. Kitching, "Reproductive Isolation in a Native Population of Petunia sensu Jussieu (Solanaceae)", Annals of Botany, vol. 88, n. ${ }^{\circ}$ 3, pp. 403-413, sep. 2001.

[74] N. Dudareva, A. Klempien, J. K. Muhlemann, I. Kaplan, «Biosynthesis, function and metabolic engineering of plant volatile organic compounds», New Phytologist, vol. 198, n. ${ }^{\circ} 1$, pp. 16-32, 2013.

[75] H. Peled-Zehavi, M. Oliva, Q. Xie, V. Tzin, M. Oren-Shamir, A. Aharoni, G. Galili, «Metabolic Engineering of the Phenylpropanoid and Its Primary, Precursor Pathway to Enhance the Flavor of Fruits and the Aroma of Flowers», Bioengineering, vol. 2, n. ${ }^{\circ}$ 4, pp. 204-212, 2015. 
[76] M. Oliva, E. Bar, R. Ovadia, A. Perl, G. Galili, E. Lewinsohn, M. Oren-Shamir, «Phenylpyruvate Contributes to the Synthesis of Fragrant Benzenoid-Phenylpropanoids in Petunia $\times$ hybrida Flowers», Frontiers in Plant Science, vol. 8, n. ${ }^{\circ}$ May, p. 769, 2017.

[77] J. Weiss, J. K. Mühlemann, V. Ruiz-Hernández, N. Dudareva, M. Egea-Cortines, «Phenotypic Space and Variation of Floral Scent Profiles during Late Flower Development in Antirrhinum», Frontiers in Plant Science, vol. 7, n. ${ }^{\circ}$ December, pp. 1-12, 2016.

[78] R. A. Raguso, R. A. Levin, S. E. Foose, M. W. Holmberg, L. A. McDade, «Fragrance chemistry, nocturnal rhythms and pollination "syndromes" in Nicotiana», Phytochemistry, vol. 63, n. ${ }^{\circ} 3$, pp. 265-284, jun. 2003.

[79] D. Tholl, «Terpene synthases and the regulation, diversity and biological roles of terpene metabolism», Current Opinion in Plant Biology, vol. 9, n. ${ }^{\circ}$ 3, pp. 297-304, jun. 2006.

[80] E. Pichersky, R. A. Raguso, «Why do plants produce so many terpenoid compounds?», New Phytologist, vol. 220, n. ${ }^{\circ}$ 3, pp. 692-702, 2018.

[81] G. Vancanneyt, C. Sanz, T. Farmaki, M. Paneque, F. Ortego, P. Castañera, J. J. Sánchez-Serrano, "Hydroperoxide lyase depletion in transgenic potato plants leads to an increase in aphid performance», Proceedings of the National Academy of Sciences, vol. 98, n. ${ }^{\circ} 14$, pp. 8139 8144, jul. 2001.

[82] D. Ulrich, T. Bruchmüller, H. Krüger, F. Marthe, "Sensory Characteristics and Volatile Profiles of Parsley (Petroselinum crispum [Mill.] Nym.) in Correlation to Resistance Properties against Septoria Blight (Septoria petroselini)», Journal of Agricultural and Food Chemistry, vol. 59, n. ${ }^{\circ}$ 19, pp. 10651-10656, oct. 2011.

[83] M. J. Cho, R. W. Buescher, M. Johnson, M. Janes, «Inactivation of Pathogenic Bacteria by Cucumber Volatiles ( E,Z )-2,6-Nonadienal and ( E )-2-Nonenal», Journal of Food Protection, vol. 67, n. ${ }^{\circ}$ 5, pp. 1014-1016, may 2004.

[84] D. W. Whitman, F. J. Eller, "Parasitic wasps orient to green leaf volatiles», Chemoecology, vol. 1, n. ${ }^{\circ}$ 2, pp. 69-76, ago. 1990.

[85] A. Scala, S. Allmann, R. Mirabella, M. A. Haring, R. C. Schuurink, "Green Leaf Volatiles: A Plant's Multifunctional Weapon against Herbivores and Pathogens», International Journal of Molecular Sciences, vol. 14, n. ${ }^{\circ}$ 9, pp. 17781-17811, sep. 2013.

[86] A. Devoto, J. G. Turner, «Jasmonate-regulated Arabidopsis stress signalling network», Physiologia Plantarum, vol. 123, n. ${ }^{\circ}$ 2, pp. 161-172, 2005.

[87] F. C. Wouters, B. Blanchette, J. Gershenzon, D. G. Vassão, «Plant defense and herbivore counter-defense: benzoxazinoids and insect herbivores», Phytochem Rev, vol. 15, n. ${ }^{\circ}$ 6, pp. 1127-1151, dic. 2016.

[88] M. Sørensen, E. H. J. Neilson, B. L. Møller, «Oximes: Unrecognized Chameleons in General and Specialized Plant Metabolism», Molecular Plant, vol. 11, n. ${ }^{\circ}$ 1, pp. 95-117, ene. 2018.

[89] M. Erb et al., «Indole is an essential herbivore-induced volatile priming signal in maize», Nat Commun, vol. 6, n. ${ }^{\circ}$ 1, pp. 1-10, feb. 2015.

[90] J. T. Knudsen, R. Eriksson, J. Gershenzon, B. Stahl, «Diversity and distribution of floral scent», Botanical Review, vol. 72, n. ${ }^{\circ}$ 1, pp. 1-120, 2006.

[91] D. G. Clark, E. Pichersky, J. Verdonk, N. Dudareva, M. Haring, U. Klahre, R. Schuurink, «Benzenoids Dominate the Fragrance of Petunia Flowers», en Petunia: Evolutionary, 
Developmental and Physiological Genetics, T. Gerats y J. Strommer, Eds. New York, NY: Springer New York, 2009, pp. 51-69.

[92] C. Formisano, F. Senatore, G. Della Porta, M. Scognamiglio, M. Bruno, A. Maggio, ... , M. Sajeva, «Headspace Volatile Composition of the Flowers of Caralluma europaea N.E.Br. (Apocynaceae)", Molecules, vol. 14, n. ${ }^{\circ}$ 11, pp. 4597-4613, nov. 2009.

[93] A. Jürgens, T. Witt, G. Gottsberger, «Flower scent composition in night-flowering Silene species (caryophyllaceae)», Biochemical Systematics and Ecology, vol. 30, n. ${ }^{\circ}$ 5, pp. 383-397, 2002.

[94] E. Georgieva, N. Handjieva, S. Popov, L. Evstatieva, "Comparative analysis of the volatiles from flowers and leaves of three Gentiana species», Biochemical Systematics and Ecology, vol. 33, n. ${ }^{\circ}$ 9, pp. 938-947, sep. 2005.

[95] P. Vargas, C. Ornosa, F. J. Ortiz-Sánchez, J. Arroyo, «ls the occluded corolla of Antirrhinum beespecialized?», Journal of Natural History, vol. 44, n. ${ }^{\circ}$ 23-24, pp. 1427-1443, may 2010.

[96] C. Suchet, L. Dormont, B. Schatz, M. Giurfa, V. Simon, C. Raynaud, J. Chave, «Floral scent variation in two Antirrhinum majus subspecies influences the choice of naïve bumblebees», Behavioral Ecology and Sociobiology, vol. 65, n. ${ }^{\circ}$ 5, pp. 1015-1027, 2011.

[97] G. A. Wright, A. Lutmerding, N. Dudareva, B. H. Smith, «Intensity and the ratios of compounds in the scent of snapdragon flowers affect scent discrimination by honeybees (Apis mellifera)», J Comp Physiol A, vol. 191, n. ${ }^{\circ}$ 2, pp. 105-114, feb. 2005.

[98] M. E. Hoballah et al., «The composition and timing of flower odour emission by wild Petunia axillaris coincide with the antennal perception and nocturnal activity of the pollinator Manduca sexta.», Planta, vol. 222, n. ${ }^{\circ} 1$, pp. 141-50, sep. 2005.

[99]Z. Hu, H. Zhang, P. Leng, J. Zhao, W. Wang, S. Wang, «The emission of floral scent from Lilium 'siberia' in response to light intensity and temperature», Acta Physiologiae Plantarum, vol. 35, n. ${ }^{\circ}$ 5, pp. 1691-1700, may 2013.

[100] J. S. Yuan, S. J. Himanen, J. K. Holopainen, F. Chen, C. N. Stewart, «Smelling global climate change: mitigation of function for plant volatile organic compounds», Trends in Ecology \& Evolution, vol. 24, n. ${ }^{\circ}$ 6, pp. 323-331, jun. 2009.

[101] J. Fründ, K. E. Linsenmair, N. Blüthgen, «Pollinator diversity and specialization in relation to flower diversity», Oikos, vol. 119, n. ${ }^{\circ}$ 10, pp. 1581-1590, 2010.

[102] B. Geslin, B. Gauzens, E. Thébault, I. Dajoz, «Plant Pollinator Networks along a Gradient of Urbanisation», PLOS ONE, vol. 8, n. ${ }^{\circ}$ 5, p. e63421, may 2013.

[103] J. H. Visser, «Electroantennogram Responses of the Colorado Beetle, Leptinotarsa Decemlineata, to Plant Volatiles», Entomologia Experimentalis et Applicata, vol. 25, n. ${ }^{\circ} 1$, pp. 86-97, 1979.

[104] A. A. Cossé, T. C. Baker, «Electrophysiologically and Behaviorally Active Volatiles of Buffalo Gourd Root Powder for Corn Rootworm Beetles», J Chem Ecol, vol. 25, n. ${ }^{\circ} 1$, pp. 51-66, ene. 1999.

[105] D. Kessler, C. Diezel, D. G. Clark, T. A. Colquhoun, I. T. Baldwin, «Petunia flowers solve the defence/apparency dilemma of pollinator attraction by deploying complex floral blends», Ecology Letters, vol. 16, n. ${ }^{\circ}$ 3, pp. 299-306, 2013.

[106] S. Dötterl, L. M. Wolfe, A. Jürgens, "Qualitative and quantitative analyses of flower scent in Silene latifolia», Phytochemistry, vol. 66, n. ${ }^{\circ}$ 2, pp. 203-213, ene. 2005. 
[107] J. H. Loughrin, T. R. Hamilton-Kemp, R. A. Andersen, D. F. Hildebrand, «Circadian rhythm of volatile emission from flowers of Nicotiana sylvestris and N. suaveolens», Physiologia Plantarum, vol. 83, n. ${ }^{\circ} 3$, pp. 492-496, 1991.

[108] J. P. F. G. Helsper, J. A. Davies, H. J. Bouwmeester, A. F. Krol, M. H. van Kampen, «Circadian rhythmicity in emission of volatile compounds by flowers of Rosa hybrida L. cv. Honesty», Planta, vol. 207, n. ${ }^{\circ} 1$, pp. 88-95, 1998.

[109] M. P. Fenske, K. D. H. Hazelton, A. K. Hempton, J. S. Shim, B. M. Yamamoto, J. A. Riffell, T. Imaizumi, "Circadian clock gene LATE ELONGATED HYPOCOTYL directly regulates the timing of floral scent emission in Petunia», Proceedings of the National Academy of Sciences of the United States of America, vol. 112, n. ${ }^{\circ}$ 31, pp. 9775-80, ago. 2015.

[110] F. Yon, Y. Joo, L. Cortés Llorca, E. Rothe, I. T. Baldwin, S. G. Kim, «Silencing Nicotiana attenuata LHY and ZTL alters circadian rhythms in flowers», New Phytologist, vol. 209, n. ${ }^{\circ} 3$, pp. 1058-1066, 2015.

[111] F. Yon, D. Kessler, Y. Joo, L. Cortés Llorca, S. G. Kim, I. T. Baldwin, «Fitness consequences of altering floral circadian oscillations for Nicotiana attenuata», Journal of Integrative Plant Biology, vol. 59, n. ${ }^{\circ}$ 3, pp. 180-189, 2017.

[112] J. C. Verdonk, M. A. Haring, A. J. van Tunen, R. C. Schuurink, "ODORANT1 Regulates Fragrance Biosynthesis in Petunia Flowers», Plant Cell, vol. 17, n. ${ }^{\circ}$ 5, pp. 1612-1624, may 2005.

[113] M. Euler, I. T. Baldwin, "The chemistry of defense and apparency in the corollas of Nicotiana attenuata», Oecologia, vol. 107, n. ${ }^{\circ}$ March, pp. 102-112, 1996.

[114] Y. C. Chuang, M. C. Lee, Y. L. Chang, W. H. Chen, H. H. Chen, «Diurnal regulation of the floral scent emission by light and circadian rhythm in the Phalaenopsis orchids», Botanical Studies, vol. 58, n. ${ }^{\circ} 1,2017$. 

Objectives of the Thesis 



\section{Objectives of the Thesis}

The general aim of this Thesis was to characterize the transcriptional structure of the circadian clock in Petunia hybrida leaves and petals and uncover the role of clock genes in the regulation of scent emission in the diurnally emitting plant Antirrhinum majus and the nocturnally emitting P. hybrida. The present work contributes to understand the integration of external cues and volatile organic compound emission.

\section{Chapter I}

- Identification and characterization of the transcriptional structure of circadian clock genes in leaves and petals of petunia (Petunia hybrida) under light:dark and constant darkness.

- Characterization of gene expression variability (transcriptional noise) across tissues and light conditions.

\section{Chapter II}

- Characterization of daily expression by qPCR of CHANEL (PhCHL), a ZEITLUPE ortholog, in petunia (Petunia hybrida) leaves and petals. We also validated the reference genes in leaves and petals.

- Analysis of the effect of knocking down PhCHL on scent profile and daily scent emission.

\section{Chapter III}

- Characterization of daily expression by qPCR of LATE ELONGATED HYPOCOTYL (AmLHY), in snapdragon (Antirrhinum majus) leaves.

- Analysis of the effect of knocking down PhCHL on flower phenotype, scent profile and daily flower fragrance emission. 



\section{Chapter I: Transcriptional structure of petunia clock in leaves and petals.}





\section{Graphical abstract}

- Genes and proteins identification (Arabidopsis as query sequence)

- Primer design

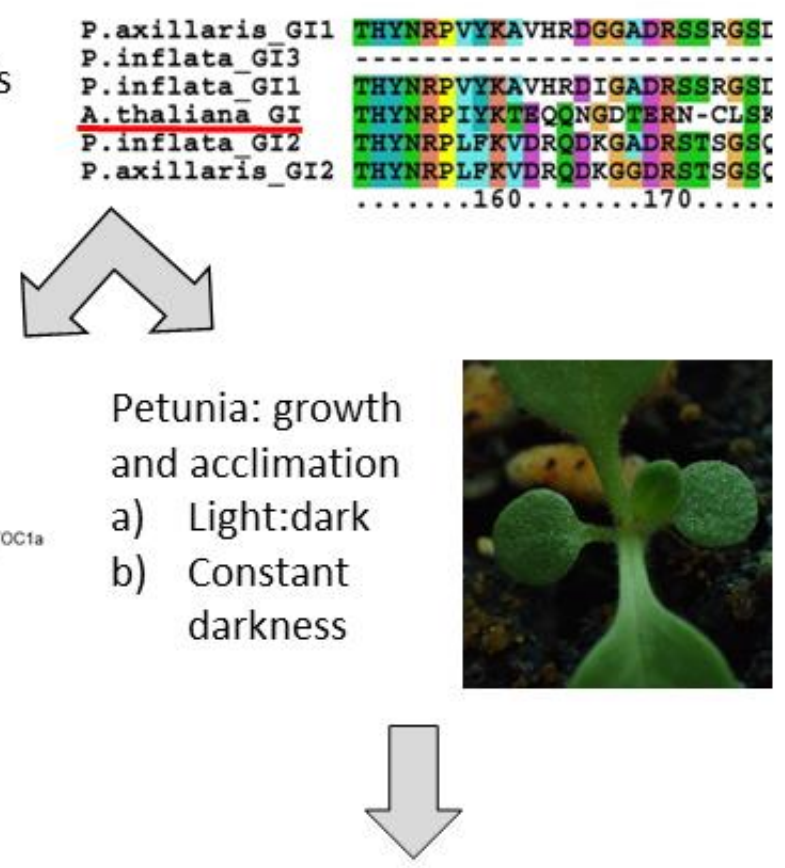

- Phylogeny

- Domain identification

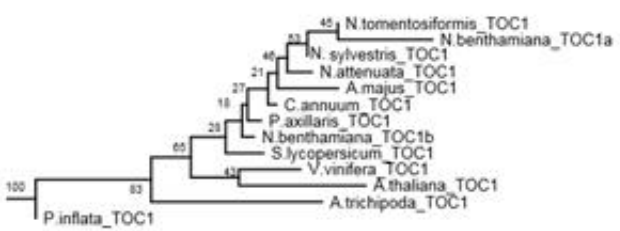

a) Light:dark

b) Constant darkness

- Sampling: leaves and petals (time course)

- RNA extraction for qPCR

- Data analysis 
Article

\title{
Transcriptional structure of petunia clock in leaves and petals.
}

\author{
Marta I. Terry ${ }^{1}$, Marta Carrera-Alesina ${ }^{1}$ and Julia Weiss ${ }^{1}$ and Marcos Egea-Cortines ${ }^{1, *}$ \\ 1 Genética Molecular, Instituto de Biotecnología Vegetal, Edificio I+D+I, Plaza del Hospital s/n, Universidad \\ Politécnica de Cartagena, 30202, Cartagena, Spain; marta.terry@edu.upct.es (MIT); \\ martacalesina@gmail.com (MCA); julia.weiss@upct.es (JW) \\ * Correspondence: marcos.egea@upct.es; Tel.: +34-968-325-777 (MEC)
}

Genes 2019, 10(11), 860; https://doi.org/10.3390/genes10110860

Received: 23 September 2019 / Revised: 25 October 2019 / Accepted: 28 October 2019 / Published: 30 October 2019

(This article belongs to the Special Issue Genetic Mechanisms Underpinning Floral Architecture)

\begin{abstract}
The plant circadian clock coordinates environmental signals with internal processes including secondary metabolism, growth, flowering and volatile emission. Plant tissues are specialized in different functions, and petals conceal the sexual organs while attracting pollinators. Here we have analyzed the transcriptional structure of the petunia (Petunia $x$ hybrida) circadian clock in leaves and petals. We recorded the expression of 13 clock genes in petunia under light:dark (LD) and constant darkness (DD). Under light:dark conditions, clock genes reached maximum expression during the light phase in leaves and the dark period in petals. Under free running conditions of constant darkness, maximum expression was delayed, especially in petals. Interestingly, the rhythmic expression pattern of $P h L H Y$ persisted in leaves and petals in LD and DD. Gene expression variability differed among leaves and petals, day time and photoperiod. The transcriptional noise was higher especially in leaves under constant darkness. We found that PhPRR7, PhPRR5 and PhGI paralogs showed changes in gene structure including exon number and deletions of CCT domain of the PRR family. Our results revealed that petunia petals presented a specialized clock.
\end{abstract}

Keywords: Flower development; circadian clock; entrainment of circadian rhythm; petal; Solanaceae; tissue specific; transcriptional noise

\section{Introduction}

Organisms, from bacteria to human beings, are subjected to periodic oscillations in the environment due the planet rotation around its axis. Circadian clocks are a complex set of genes allowing organisms to anticipate and adapt to daily environmental variations. In plants, the circadian clock is a network of interlocked loops comprising transcriptional, translational, and posttranslational coordination [1]. Circadian processes have been studied in plants for a long period of time (see McClung for a historical overview [2]). Most molecular studies have been done in Arabidopsis thaliana. The Arabidopsis core clock is formed by several genes. Two MYB transcription factors CIRCADIAN CLOCK ASSOCIATED 1 (CCA1), LATE ELONGATED HYPOCOTYL (LHY), and the pseudo response regulator TIMING OF CAB EXPRESSION (TOC1) form the so-called core clock. Later studies found other clock components including the PSEUDO-RESPONSE REGULATOR gene family $(P R R)$, out of which PRR3, PRR5, PRR7, and PRR9 are clock genes, and the Evening 
Complex (EC), which is formed by the EARLY FLOWERING 3 (ELF3), EARLY FLOWERING 4 (ELF4), and LUX ARRHYTMO (LUX) proteins. In addition, other genes playing a key role and considered part of the clock include the protein with blue light reception capacity ZEITLUPE (ZTL) and the single copy gene GIGANTEA (GI). The various models developed are based on mutually repressing genes and a set of activating genes coded by the REVEILLE MYB transcription factors [3]. Every new discovery has added a level of complexity and new interpretation of the circadian clock model [4].

Two aspects emerge from comparative genomics with lower organisms and within higher plants. First the core clock components identified in the picoeukaryote Ostreococcus comprise a MYB gene homolog to $L H Y$ and a PRR gene similar to TOC1 [5]. There is an additional blue-light receptor component with histidine kinase activity and circadian clock effects [6]. Therefore, basic clocks may be found with two or maybe three components that function via transcriptional control. A second aspect is that the fine tuning of the different clock modules is based to a large extent on proteinprotein interactions. As protein complexes require certain stoichiometries to maintain their function they are target of genetic constraints in terms of gene dosages and are especially sensitive to gene duplications. Duplicated genes follow four paths including gene loss, maintenance of redundancy, subfunctionalization, or neofunctionalization [7]. Plant genomes have been subject to genome duplications and in some cases, followed by non-random elimination of duplicated genes [8,9]. In Brassica, polyploidization events have involved subsequent gene loss but with a preferential retention of circadian clock genes as compared to house-keeping genes, supporting a gene dosage sensitivity model [10].

The genomes of the garden petunia and its ancestors Petunia axillaris and P. integrifolia have been recently sequenced [11]. Petunia forms an early branching in the Solanaceae clade departing from Solanum lycopersicon, S. tuberosum, Nicotiana spp. and Capsicum spp. that have a chromosome number of $n=12$. Petunia has $n=7$ and this, together with a high activity of transposition, may have shaped a somewhat different genome evolution. Petunia shares a paleohexaplodization specific to the Solanaceae. A comprehensive analysis of the circadian clock genes found in the Petunia genomes shows that there is a set of genes that has remained as single copy. These include the petunia orthologs for PRR9, PRR3, TOC1, and LHY. In contrast, other genes are present in two to four copies, PRR7, PRR5, GI, ELF3, or ELF4 [11]. Altogether these data indicate a possible departure of the circadian clock network from the one known in Arabidopsis, and suggests the evolution of the clock at different levels including gene structure, expression pattern, and genetic functions.

The bulk of work on plant circadian rhythms has been done in Arabidopsis using leaf tissue and seedlings. Like in animals, there is important evidence that the circadian clock expression network differs between different organs. The current view is that the shoot apical meristem may work as a center of coordination [12], and leaves and roots differ in the regulatory network, as a result of differences in light inputs [13,14].

Petal development starts with the activation of the so-called B function genes in both gymnosperms and angiosperms [15]. The initial transcriptional activation is followed at early stages by an autoregulatory positive regulation of the MADS-box genes controlling petal morphogenesis in Antirrhinum, Arabidopsis, and petunia [16-21]. Once organ identity is established and right after anthesis, there is a transcriptional reprogramming [22]. Furthermore, in sympetalous flowers with petals forming a tube and a limb, both parts of the flower appear to have different functions and transcriptional control $[23,24]$. The petal function after anthesis includes concealing the sexual organs and attracting pollinators. The lifespan of a flower is relatively short with most flowers surviving two to five days after anthesis. After anthesis, metabolism and scent emission changes rapidly $[25,26]$. Flowers enter rapid senescence upon pollination as a result of ethylene release [27-29].

Floral scent release depends on petal development in a quantitative way [22], and is circadian regulated in monocots and dicots such as Antirrhinum, Narcissus, rose, or garden petunia [30-34]. Most flowers analyzed emit scent preferentially during the day or during the night. The LHY and ZTL orthologs control scent emission in Petunia, Nicotiana attenuata, and Antirrhinum majus [35-38]. 
The Solanaceae Petunia and Nicotiana emit higher quantities during the night, indicating an identity and circadian component controlling this trait $[34,39]$.

In the current work, we have addressed the structure of the petunia circadian clock from three different perspectives: gene structure, transcript abundance, and gene expression variability. The gene structure diverges as $P R R$ paralogs have different intron numbers and PhGI1 and PhGI2 vary in the coding region. The transcriptional structure showed maximum expression during the day in leaves and during the dark in petals. This maximum tended to delay in both tissues under constant darkness conditions. We further identified opposite levels of transcriptional noise at dawn in leaves and dusk in petals. Our results reflect the evolution of the plant circadian clock at the structural and expression level and suggests an organ specific transcriptional structure of the plant circadian clock.

\section{Materials and Methods}

\subsection{Plant materials and experiment design}

We used the Petunia hybrida W115 or Mitchell for all the analyses. Plants were grown under greenhouse conditions until further use. Experiments under controlled conditions in growth chambers were performed as described [40], with the following modifications. For the control experiments, plants were adapted to light:dark growth chamber conditions for at least 1 week. Day:night (LD) conditions were matched with thermoperiods of $23{ }^{\circ} \mathrm{C}: 18^{\circ} \mathrm{C}$ during the light and dark periods. Zeitgeber time (ZT) was defined as ZT0 for light on and ZT12 for light off. Plants were transferred from LD cycle to a continuous dark cycle (DD) with the same temperature regimes.

Flowers were marked before opening, and samples were taken at day 2-3 after anthesis. We used the petal limbs for all experimental procedures. We used young leaves with a length of 1.5-2.5 $\mathrm{cm}$ for all the experiments. Sampling of petal limbs and leaves was made every $3 \mathrm{~h}$, starting at ZT0 and tissues were immediately frozen in liquid nitrogen. In the case of DD experiment, sampling also started at ZT0, during the first $24 \mathrm{~h}$ under continuous dark.

\subsection{Phylogeny, bioinformatics and data analysis}

Previous studies showed that most genes of Petunia W115 can be assigned to Petunia axillaris [11]. We used clock genes sequences from Arabidopsis thaliana (https://www.arabidopsis.org/) to identify P. axillaris orthologs by blast in Sol Genomics Network (https://solgenomics.net/). Protein sequences from Petunia and other species were obtained from several databases including Sol Genomics Network (https://solgenomics.net/, Solanaceae), Snapdragon Genome Database (http://bioinfo.sibs.ac.cn/Am/, Antirrhinum majus) [41], Phytozome (https://phytozome.jgi.doe.gov/pz/portal.html) and GenBank (https://www.ncbi.nlm.nih.gov/genbank/) (Tables S1 and S2 for protein accessions and details). We used the corresponding predicted proteins to identify the intron-exon boundaries using Genewise [42]. The corresponding exon-intron boundaries were plotted using the exon-intron graphic maker (http://wormweb.org/exonintron). Protein alignment was performed with CLUSTALX [43]. Phylogenetic analysis was performed with MEGA X [44] using neighbor-joining method (NJ), JTT (Jones, Taylor and Thornton, [45]) as model of amino acid substitution and 500 bootstrap replicates. Phylogenetic tree of PSEUDO-RESPONSE REGULATORS (PRR) proteins was conducted by using the highly conserved domain pseudo-receiver (PR) [46] whereas phylogenetic tree of GIGANTEA (GI) proteins was performed by using full length proteins. Trees were visualized and annotated with "ggtree" [47] using R (R version 3.5.1), as well as the multiple sequence alignment. Protein domains were predicted using the web-based tool PROSITE [48], schematic proteins were plotted with the $\mathrm{R}$ package "drawProteins" [49].

Detection of rhythmic gene expression was performed using the non-parametric statistical algorithm "RAIN" [50]. We analyzed leaves and petals, under two light conditions, $12 \mathrm{~h}$ light/12 h dark (LD) and constant darkness (DD). To determine if the gene expression pattern of certain gene differed between tissues (leaves and petals) or light conditions (light:dark and constant darkness), 
we used an harmonic ANOVA (HANOVA) and to detect noise changes we used a scale test (HarmScaleTest) implemented in the R package "DODR" [51]. The HANOVA detects changes in amplitude and phases and HarmScaleTest uses a F-Test for variances to determine if the biological noise levels differed or not in two time series. We plotted the graphics with "ggplot2" [52].

\subsection{Gene expression analysis by $q P C R$}

RNA was extracted from three biological replicates per time point of leaves and petals (flower tubes were excluded) using acid phenol [53]. Concentrations were measured using NanoDrop (Thermo-Fisher). Equal amounts of total RNA were used to obtain cDNA using Maxima kits (Thermo-Fisher).

PCR analysis was performed as described before [54], the following protocol was used for 40 cycles: $95^{\circ} \mathrm{C}$ for $5 \mathrm{~s}, 60^{\circ} \mathrm{C}$ for $20 \mathrm{~s}$ and $72{ }^{\circ} \mathrm{C}$ for $15 \mathrm{~s}$ (Clontech SYBR Green Master Mix and Mx3000P qPCR Systems, Agilent Technologies). Primers for circadian clock genes were designed using pcrEfficiency [55] (Table S3) and the following protocol was used for 40 cycles: $95^{\circ} \mathrm{C}$ for $5 \mathrm{~s}, 60^{\circ} \mathrm{C}$ for $20 \mathrm{~s}\left(55^{\circ} \mathrm{C}\right.$ for PhGI1 and PhGI2) and $72{ }^{\circ} \mathrm{C}$ for $15 \mathrm{~s}$. Samples were run in duplicate. Primer combinations were tested with genomic DNA from Mitchell and we found that all of them gave a single copy DNA on agarose gels. The endpoint PCR was further verified by melting point analysis where all primer combinations gave a single peak of melting (Figure S1). Normalized expression was calculated as described [56] and ACTIN (PhACT) was the internal control gene, a stable gene in circadian studies in petunia leaves and petals [37].

We determined the mean normalized expression. For each gene, tissue, and light condition, normalized expression was calculated as described previously [56], then the expression level for each time point was divided by the average expression across the time-course [57]. In addition, to analyze the gene expression variability, we calculated the coefficient of variation $(\mathrm{CV})$ of every gene per time point, tissue and light:dark conditions. We also plotted the normalized expression of every biological replicate.

\section{Results}

\subsection{The duplicated PRR7, PRR5 and GI diverge in intron number and coding sequence}

We used the laboratory line Petunia hybrida W115, also known as Mitchell, which contains the circadian clock genes corresponding to $P$. axillaris [11] for a detailed analysis of the structure of the $P R R$ and GI paralogs. Several genes forming the morning and evening loops of the circadian clock in petunia have undergone gene duplication. The genome of petunia has seven $P R R$ genes as $P R R 7$ and PRR5 are duplicated both in P. axillaris and P. integrifolia while Arabidopsis has the canonical set of five genes, $P R R 1$ or TOC1, PRR3, PRR5, PRR7, and PRR9 involved in circadian regulation [11]. We reconstructed a phylogenetic tree of $P R R$ genes, by using the conserved domain pseudo-receiver (PR), of Solanaceae and Arabidopsis (Table S1) in order to deduce the evolutionary relationships of the duplicated genes. As found previously for other Angiosperms, the $P R R$ genes of Solanaceae form three major clades: the TOC1/PRR1 clade, the $P R R 7 / 3$ clade, and the $P R R 9 / 5$ clade (Figure 1) [58]. The PRR5a genes of P. axillaris, P. integrifolia are closer to the Arabidopsis AtPRR5 while the rest of the $P R R$ genes of Solanaceae, including the $P R R 5 b$, form an additional subclade. This topology indicates that the $P R R a$ paralogs may be an ancestral form and the $P R R b$ may have been formed later and retained, in some cases as single copy genes. The $P R R 7$ genes also showed a similar topology where PaxiNPRR7a and PinfS6PRR7a are closer to the Arabidopsis gene than the single copy genes of the rest of the Solanaceae, and the $P R R 7 b$ paralogs. This topology is also seen in petunia PRR9, PRR3, and TOC1 that are somewhat between the Arabidopsis gene and the rest of the Solanaceae, according to the early departure of Petunia from the rest of the family [11]. 


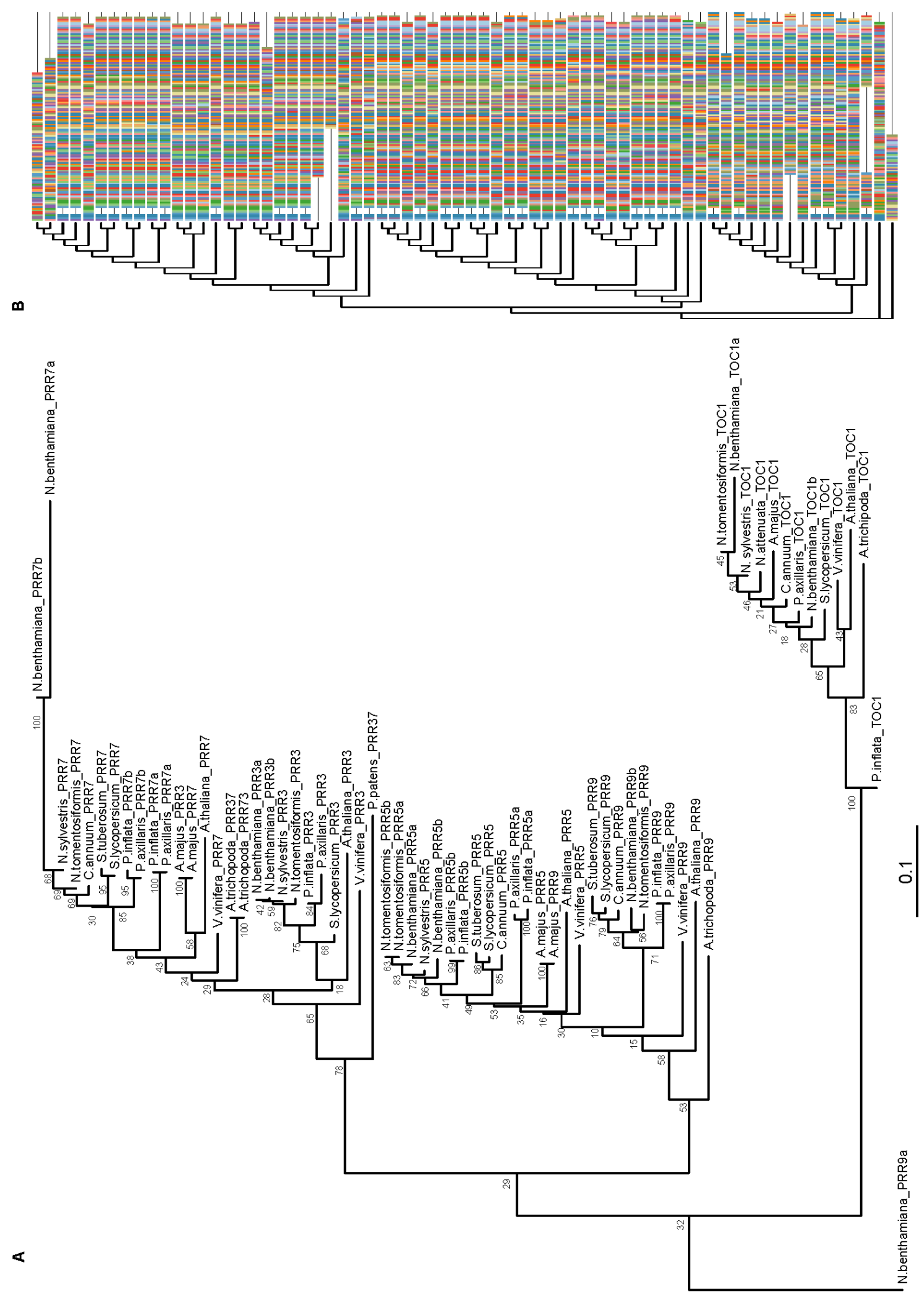




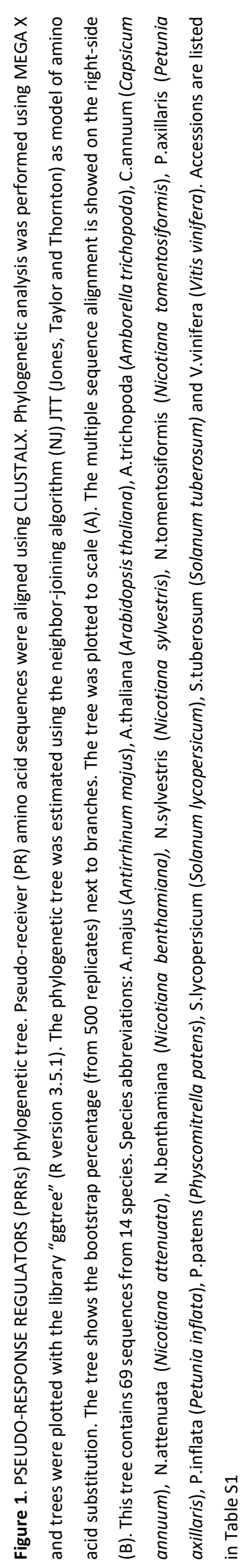

Chapter I- 56

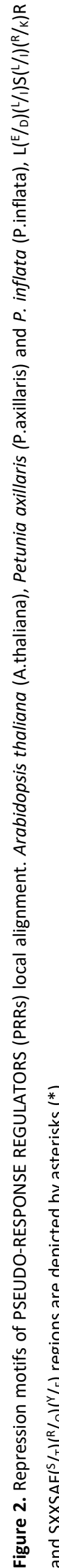


We found that the gene models for PhPRR $5 a$ and PhPRR5b differ in the number of exons comprising the coding region as PhPRR5a has seven and PhPRR5b eight exons (Figure S2). The gene model in Arabidopsis comprises six exons in AT5G24470 (AtPRR5), indicating that changes in intronexon structure has occurred in the evolution of the $P R R$ family. The number of exons also differed between $P h P R R 7 a$ with eight exons while PhPRR7b had seven exons. The Arabidopsis AT5G02810 AtPRR7 has nine exons out of which eight correspond to coding region, thus coinciding with the phylogenetically closer $P h P R R 7 a$.

The PRR family of Arabidopsis has two conserved domains: PR (Pseudo-receiver Domain) and a CCT (CONSTANS, CONSTANS-like, and TIMING OF CAB EXPRESSION 1 (TOC1/PRR1)) [59] (Figure S3A). PRR5, PRR7, and PRR9 have a repression motif which consists of two regions, $\mathrm{L}(\mathrm{E} / \mathrm{D})(\mathrm{L} / \mathrm{I}) \mathrm{S}(\mathrm{L} / \mathrm{I})(\mathrm{R} / \mathrm{K}) \mathrm{R}$ and $\operatorname{SXXSAF}(\mathrm{S} / \mathrm{T})(\mathrm{R} / \mathrm{Q})(\mathrm{Y} / \mathrm{F})$, located between the PR and CCT domains. They interact with TOPLESS (TPL) and TOPLESS-RELATED PROTEINS (TPRs) [59,60], creating a transcriptional repression complex. This complex represses the transcription of the core genes CIRCADIAN CLOCK ASSOCIATED 1 (CCA1) and LATE ELONGATED HYPOCOTYL (LHY) [59,61]. We used Arabidopsis as the model, and we compared it with petunia sequences. We found that all the PRR members of $P$. axillaris and P. inflata shared the PR domain (Figure S3A). The CCT domain was found in all the coding genes except for PaxiNPRR7b, PinfPRR7a, and PinfPRR7b. The presence of the CCT domain in PaxiNPRR7a and absence from the rest of the gene group in petunia was surprising, thus we analyzed other Solanaceae, member of the Convolvulaceae (Cuscuta australis and Ipomea nil) and Plantaginaceae (Antirrhinum majus). We found that the CCT domain was absent from the PRR7 protein in the Solanaceae analyzed (Capsicum annuum, C. baccatum, Nicotiana benthamiana, N. sylvestris, N. tabacum, N. tomentosiformis, Petunia axillaris, P. inflata, Solanum lycopersicum, S. melongena, S. pennellii, S. pimpinellifolium, and S. tuberosum) (Figure S3B). However, the CCT domain was found in the rest of the species analyzed. This indicates an early change in the PRR7 family in Solanaceae with possible implications in clock functioning.

We also identified the repression motif in Petunia axillaris and $P$. inflata, which shared a high homology with Arabidopsis (Figure 2). These motifs are present in PRR5, PRR7, and PRR9 but absent in PRR3 and TOC1 (Figure 2). We found that the paralog PRR5a of P. axillaris and P.inflata had two major differences. The $\mathrm{L}(\mathrm{E} / \mathrm{D})(\mathrm{L} / \mathrm{I}) \mathrm{S}(\mathrm{L} / \mathrm{I})(\mathrm{R} / \mathrm{K}) \mathrm{R}$ motif present in the PRR9, 7 , and 5 was not canonical as the glutamic/aspartic amino acid of the second position had been replaced by an alanine. Furthermore, both PRR5a had lost the $\operatorname{SXXSAF}(\mathrm{S} / \mathrm{T})(\mathrm{R} / \mathrm{Q})(\mathrm{Y} / \mathrm{F})$ motif. We compared the PRR5 proteins of several Solanaceae and Arabidopsis and found that all share the aspartic acid in the second position of the first motif and the complete repression motif absent in PaxiNPRR5a and PinfSPRR5a (Figure S4). This indicates that the D->A amino acid substitution and motif deletion are specific to the Petunia linage.

The SXXSAF $(\mathrm{S} / \mathrm{T})(\mathrm{R} / \mathrm{Q})(\mathrm{Y} / \mathrm{F})$ of PaxiNPRR7b was interrupted by a sequence insertion of 26 amino acids. The sequence of both regions varied among paralogs, as SELSAFSRY was found in the PRR7a lineage and SHLSAFSRY in the PRR7b lineage (Figure 2). Altogether, these changes indicate that PRR duplication occurred before Petunia speciation. The absence of the transcriptional repression motif in PRR5a and the interruption of PRR7b in Petunia inflata suggest that these paralogs have lost their repression activity.

GIGANTEA (GI) plays a role in flowering time but is needed to maintain the period and amplitude of clock genes [62,63]. GI is a single copy gene in the Arabidopsis genome [62] and it is found in one to three copies in the Solanaceae genomes. Petunia axillaris has two copies PaxiNGI1, PaxiNGI2, whereas P. inflata has three copies PinfS6GI1, PinfS6GI2, and PinfS6GI3 [11]. Interestingly, the genes PaxiNGI1 and PaxiNGI2 are present in the genome of $P$. hybrida Mitchell. We will refer to GIGANTEA genes in P. hybrida as PhGI1 and PhGI2. The proteins PinfS6GI1 and PaxiNGI1 share an N-terminus conserved with AtGI that was absent in PaxiNGI2 (Figure 3, Figure S5). Furthermore, PaxiNGI2 showed a 41 amino acid insertion that was not conserved in PinfS6GI2 or other GI genes. The PinfS6GI3 was much shorter than the other paralogs, a feature conserved in Nicotiana benthamiana 
NbGI3 (Figure 3). The PinfSGI1 had an additional C-terminal fragment of 105 amino acids absent from the rest of the GI genes analyzed (Figure 3, Figure S5).

We can conclude that the structural evolution of core circadian clock genes and associated genes has occurred at via changes in the number of retained paralogs, gene structure, and coding region. 
A

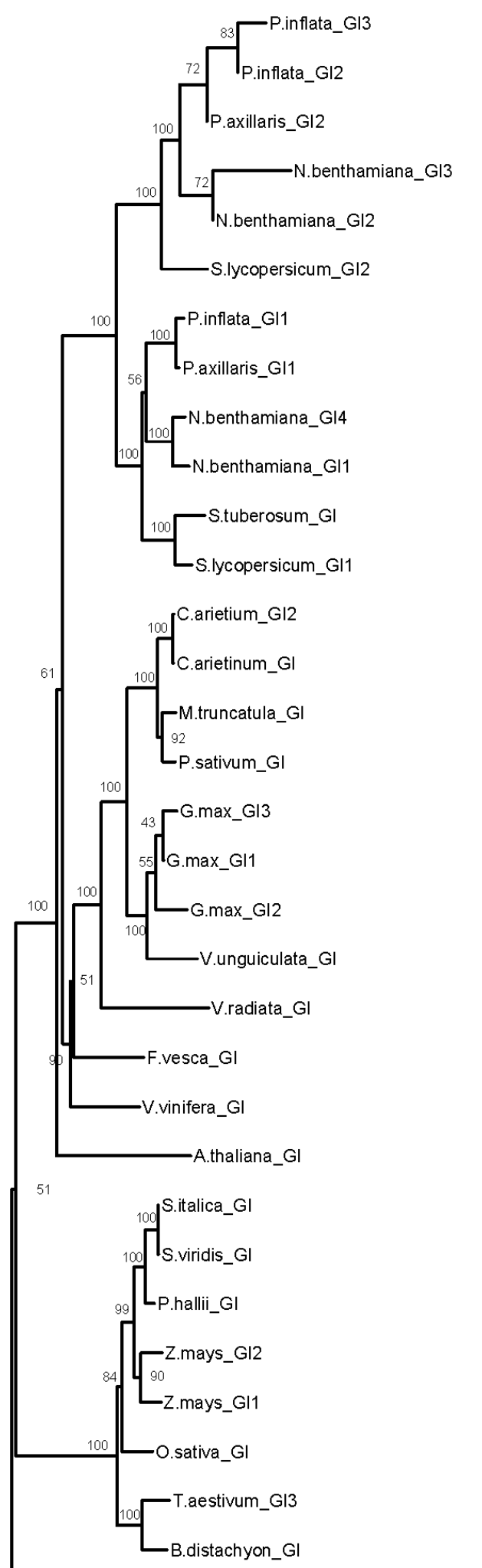

M.polymorpha_GI

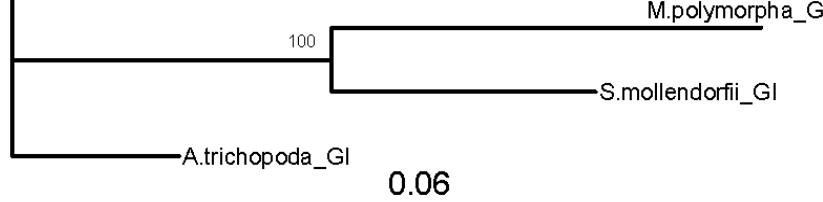

B

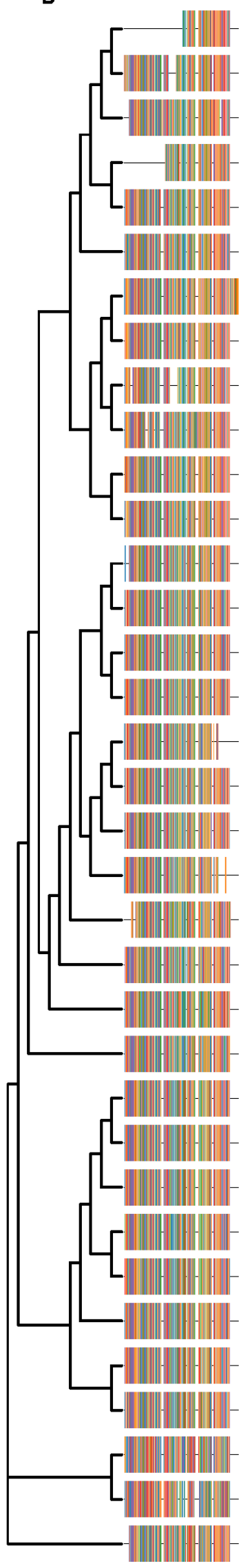


Figure 3. GIGANTEA (GIs) phylogenetic tree. Amino acid sequences were aligned using CLUSTALX. Phylogenetic analysis was performed using MEGA $X$ and trees were plotted with the library "ggtree" (R version 3.5.1). The phylogenetic trees were built with the neighbor-joining method (NJ) and JTT (Jones, Taylor and Thornton) as model of amino acid substitution. The tree displays the bootstrap percentage (from 500 replicates) next to branches (A). The multiple sequence alignment is displayed on the right-side (B). This tree contains 35 sequences from 25 species. Species abbreviations: A.majus (Antirrhinum majus), A.thaliana (Arabidopsis thaliana), A.trichopoda (Amborella trichopoda), B.distachyon (Brachypodium distachyon), C.arietinum (Cicer arietinum), F.vesca (Fragaria vesca), G.max (Glycine max), M.polymorpha (Marchantia polymorpha), M.truncatula (Medicago truncatula), N.benthamiana (Nicotiana benthamiana), O.sativa (Oryza sativa), P.axillaris (Petunia axillaris), P.hallii (Panicum hallii), P.inflata (Petunia inflata), P.sativum (Pisum sativum), S.italica (Setaria italica), S.lycopersicum (Solanum lycopersicum), S.moellendorffii (Selaginella moellendorffii), S.tuberosum (Solanum tuberosum), S.viridis (Setaria viridis), T.aestivum (Triticum aestivum), S.italica (Setaria italica), V.radiata (Vigna radiata), V.unguiculata (Vigna unguiculata), V.vinifera (Vitis vinifera) and Z.mays (Zea mays). Accessions are listed in Table S2.

\subsection{The leaf clock has its maximum during the day while the petal clock shifts towards the night}

Several clock models have been described in the last years; one of the most popular plant clocks defines three loops called morning, central, and evening loops. These describe the time of the day when certain genes are preferentially expressed [64]. In Arabidopsis, during the morning CIRCADIAN CLOCK-ASSOCIATED 1 and LATE ELONGATED HYPOCOTYL (CCA1/LHY) repress PSEUDO-RESPONSE REGULATOR members (PRRs), which are sequentially expressed (PRR9, PRR7, PRR5 and finally TIMING OF CAB EXPRESSION 1, TOC1 or PRR1, at dusk) [59]. The PRR family represses CCA1/LHY. CCA1/LHY also inhibits GIGANTEA (GI) and the evening complex (EC) expression during the morning [65]. The EC is comprised by LUX ARRHYTHMO (LUX), EARLY FLOWERING 4 and 3, (ELF4 and ELF3). At dusk, TOC1 represses the evening genes GI, ELF4, and LUX. TOC1 interacts with CCA1 HIKING EXPEDITION (CHE) and mediates the repression of CCA1 [66]. Several activators have been described, including REVEILLE 8 (RVE8) and LIGHT-INDUCIBLE AND CLOCK-REGULATED (LNKs) that positively regulate the transcription of PRR5 and TOC1 or the complex LIGHT-REGULATED WD-TEOSINTE BRANCHED 1-CYCLOIDEA-PCF (LWD-TCP), which activates the transcription of CCA1 [67-69]. We established the expression patterns of the different clock genes in leaves and petals. As the genes contained in P. hybrida cv Mitchell correspond to $P$. axillaris [11], we further describe them as $P h$ genes. These included the morning loop genes PhPRR9, PhPRR7a, PhPRR7b, PhPRR5a, PhPRR5b, and PhPRR3. The core loop was represented by PhTOC1 and PhLHY. Finally, the evening and clock-associated genes analyzed included PhGI1, PhGI2, PhELF4, PhCHL (the ZEITLUPE ortholog), and PhFKF (FLAVIN-BINDING KELCH REPEAT FBOX1). This analysis was performed in petunia that was acclimated to light:dark conditions of $12 \mathrm{~h}$ light and $12 \mathrm{~h}$ dark (LD) or continuous dark (DD) conditions.

The non-parametric algorithm RAIN groups gene expression data by their sampling time point e.g., ZT0, ZT3. These groups are assigned to the falling and to the rising part of the oscillation or wave. Then each part, falling and rising, is analyzed by a test against umbrella alternatives [70]. The peak of the umbrella varied, allowing RAIN to test different wave forms. Regardless, if a gene is rhythmically expressed (significant $p$-value) or not, RAIN provides the time point of a peak, if found. We compared two parameters between leaves and petals under a LD cycle: rhythmicity of expression (oscillation) and time point with maximum expression (phase) (Table 1). Concerning rhythmicity, most genes showed a robust oscillation pattern except PhELF4 and PhCHL in leaves, and PhCHL in petals, that showed a peak but no significant rhythm (Table 1).

In leaves, most genes had their maximum expression during the light phase, except PhELF4 that reached its maximum level at ZT12. Petunia clock genes peaked at early morning (PhLHY, at ZT0), midday (PhPRR9 and PhGI2, at ZT6), and before dusk (PhPRR3, PhPRR5a, PhPRR5b, PhPRR7a, 
PhPRR7b, PhTOC1, PhCHL, PhGI1, and PhFKF, at ZT9) (Table 1). In contrast in petals, whereas the clock genes PhPRR5b, PhPRR7a, PhPRR7b, PhCHL, PhELF4, and PhLHY peaked at the same time as observed in leaves, the remaining genes delayed their expression. PhPRR9 peaked at ZT9 meanwhile PhPRR5a, PhPRR3, PhTOC1, PhGI1, PhGI2, and PhFKF shifted their expression maximum to the dark period. These genes peaked at ZT12 (PhPRR5a, PhGI1, PhGI2 and PhELF4) and ZT15 (PhPRR3, PhTOC1, and PhFKF) (Table 1).

Table 1. Rhythmic analysis of transcriptional data. Detection of rhythmicity in petunia clock genes in leaves and petals under a light:dark cycle (LD) and constant darkness (DD). This analysis was performed with a non-parametric method implemented in the Bioconductor package "RAIN". Significant $p$-values $(p<0.05)$ indicate a robust oscillation. Phase denotes the time point with the maximum gene expression or peak.

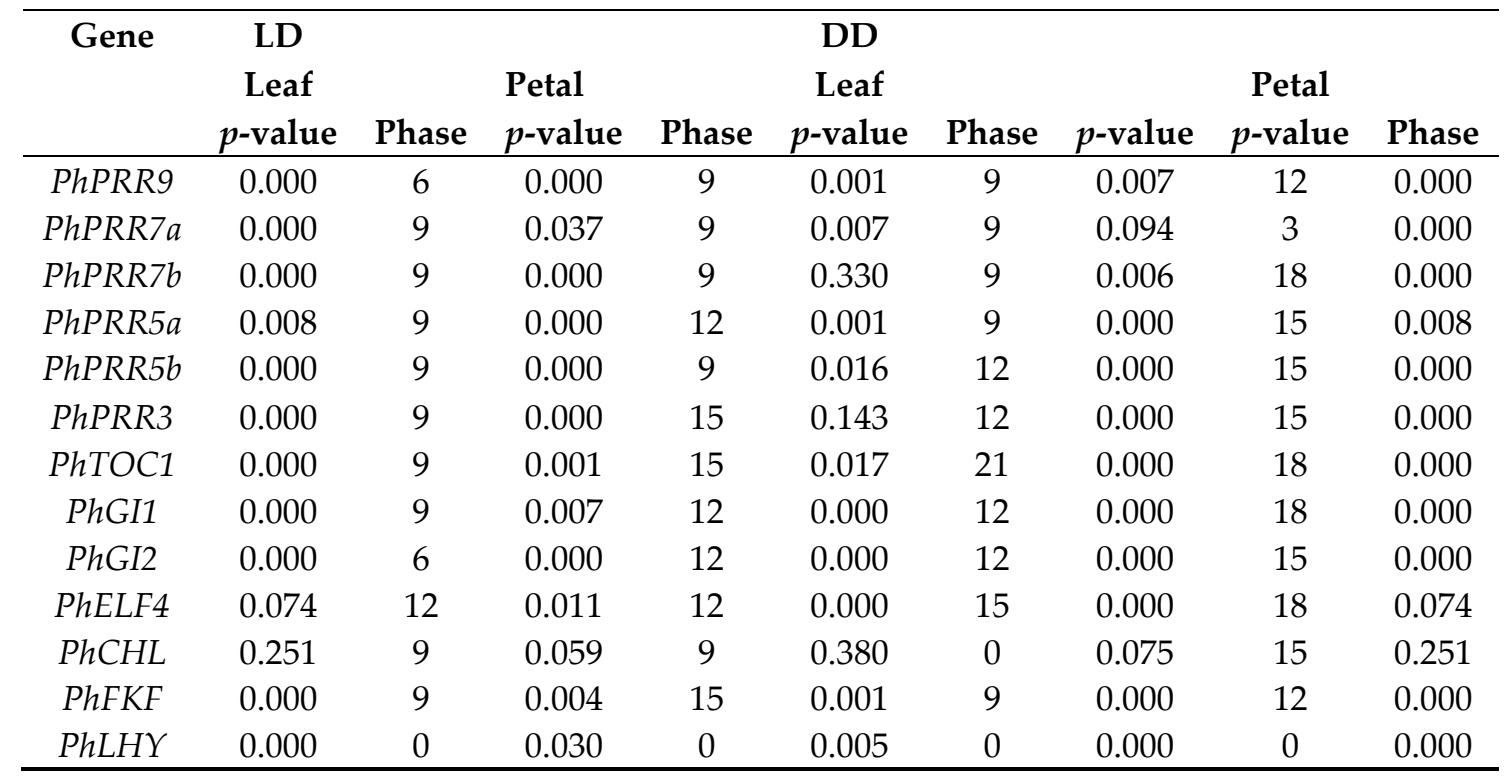

\subsection{Continous darkness shifted the expression patterns of clock genes}

In order to study the entrainment of the petunia circadian clock to the light:dark cycle, petunia plants were transferred from $12 \mathrm{~h}$ light:dark (LD) conditions to continuous darkness (DD). We found that PhPRR7b and PhPRR7a lost their robust oscillation $(p>0.05)$ in leaves and petals, respectively; and as described under a LD cycle, PhCHL did not oscillate significantly $(p>0.05)$. In addition, we observed that DD tended to shift the expression patterns of some genes (Table 1,).

In leaves, we divided the clock genes into three groups. The first group included PhPRR5a, PhPRR7a, PhPRR7b, PhFKF, and PhLHY, which maintained their time of maximum expression. The second group included $P h C H L$, advanced by $9 \mathrm{~h}$. Finally, the last group comprised $P h P R R 3, P h P R R 5 b$, PhPRR9, PhGI1, and PhELF4 delayed by $3 \mathrm{~h}$, PhGI2 by $6 \mathrm{~h}$, and PhTOC1 by $15 \mathrm{~h}$ (Figure 4, Table 1).

The effect of continuous darkness on petunia petals differed from leaves. Only two genes, PhPRR3 and PhLHY kept their peak or time with maximum expression. PhPRR7a and PhFKF showed an advanced pattern, peaking $3 \mathrm{~h}$ early. Finally, the maximum expression was delayed $3 \mathrm{~h}$ for PhPRR5a, PhTOC1, PhGI1, PhGI2, $6 \mathrm{~h}$ for PhPRR5b, PhPRR9, PhCHL, and PhELF4 and $9 \mathrm{~h}$ PhPRR7b (Figure 4, Table 1).

Altogether, PhLHY showed a rhythmic oscillation, peaking at early morning regardless of light conditions and tissue. On the other hand, PhCHL did not show a rhythmic expression in leaves or petals under light:dark or constant darkness. Besides, we observed that continuous darkness had a 
different effect on clock genes in leaves and petals, as PhPRR7b, PhPRR5a, or PhPRR3 that showed an organ specific change in phase in response to constant darkness (Table 1).
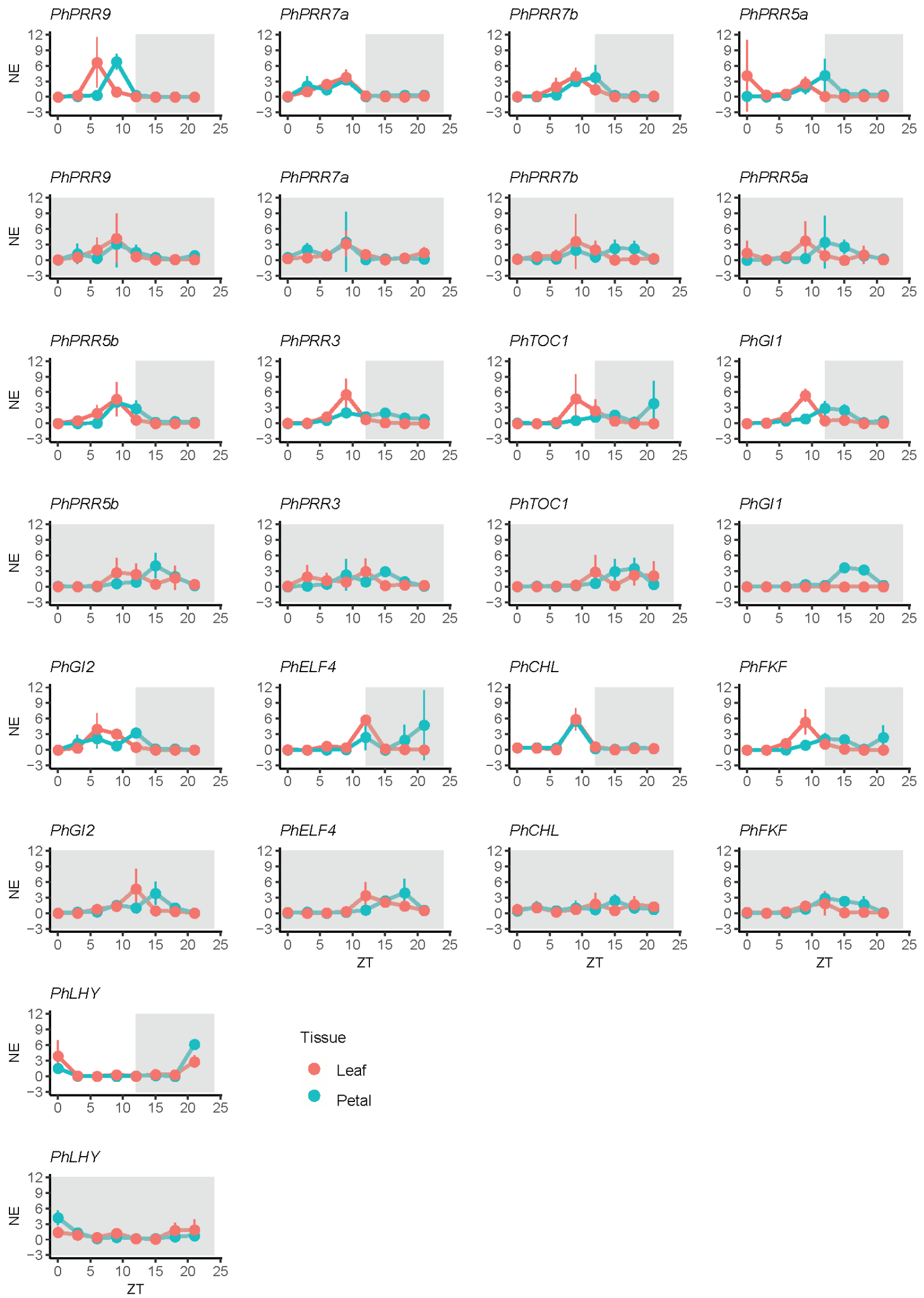
Figure 4. Daily changes in gene expression in petunia. Expression of clock genes in leaves (red) and petals (blue) under a 12 light:dark cycle (LD) and constant darkness (DD). LD cycle is represented by a white and grey area whereas DD cycle is represented by a dark area. Gene expression is represented as mean normalized expression (NE), first every clock gene was normalized to PhACT and then, for each time point the expression was divided by the mean expression level. ZT 0 (zeitgeber time) denoting light on, and ZT12, light off. Results represent mean \pm SD $(n=3)$.

\subsection{Rhythmicity and photoperiod sensitivity are tissue specific}

An important paradigm in the analysis of circadian clock gene expression is the effect of continuous darkness on the genes thought to have a circadian control [71]. We performed an analysis to detect changes in amplitude and phase, in two time series by using Harmonic ANOVA [51]. First, we analyzed differences between tissues by comparing daily gene expression in leaf and petals under light:dark (LD) and under constant darkness (DD). Second, in order to identify the effect on light conditions, we compared LD and DD cycles for leaves and for petals (Table 2). We found that PhPRR5a, PhPRR7a, PhPRR9, and PhLHY showed a robust expression pattern regardless of the tissue or photoperiod $(p<0.05)$. In contrast, under light:dark conditions, PhGI1, PhPRR3, and PhTOC1 had higher amplitude and were delayed in petals compared to leaves (Table 2). PhFKF showed higher amplitude in leaves and was delayed in petals (Table 2). When we compared leaves and petals at LD versus DD, PhTOC1, PhCHL, and PhGI2 in leaves, and PhPRR7b, PhPRR5b, PhCHL, PhGI1, and PhGI2 in petals, showed a different expression pattern. Interestingly, all these genes were delayed under constant darkness, but differed in their highest amplitude. In leaves, PhTOC1 displayed the highest amplitude in LD whereas PhGI2 and PhCHL, in DD. In petals, PhPRR7b and PhGI1 amplitude was higher under a light:dark cycle and PhPRR5b, PhGI2, and PhCHL showed their maximum amplitude in DD (Table 2).

These results indicate that there are two sets of genes with changes in rhythmicity, both in phase and amplitude, in leaves and petals and a group of stable genes comprising PhPRR5a, PhPRR7a, PhPRR9, and PhLHY. Furthermore, the effect of photoperiod appeared to be organ-specific for those genes that showed significant changes. From all the different genes analyzed, $P h P R R 7 b$ appeared to be specifically affected by DD in petals, indicating a modified control in this organ. 


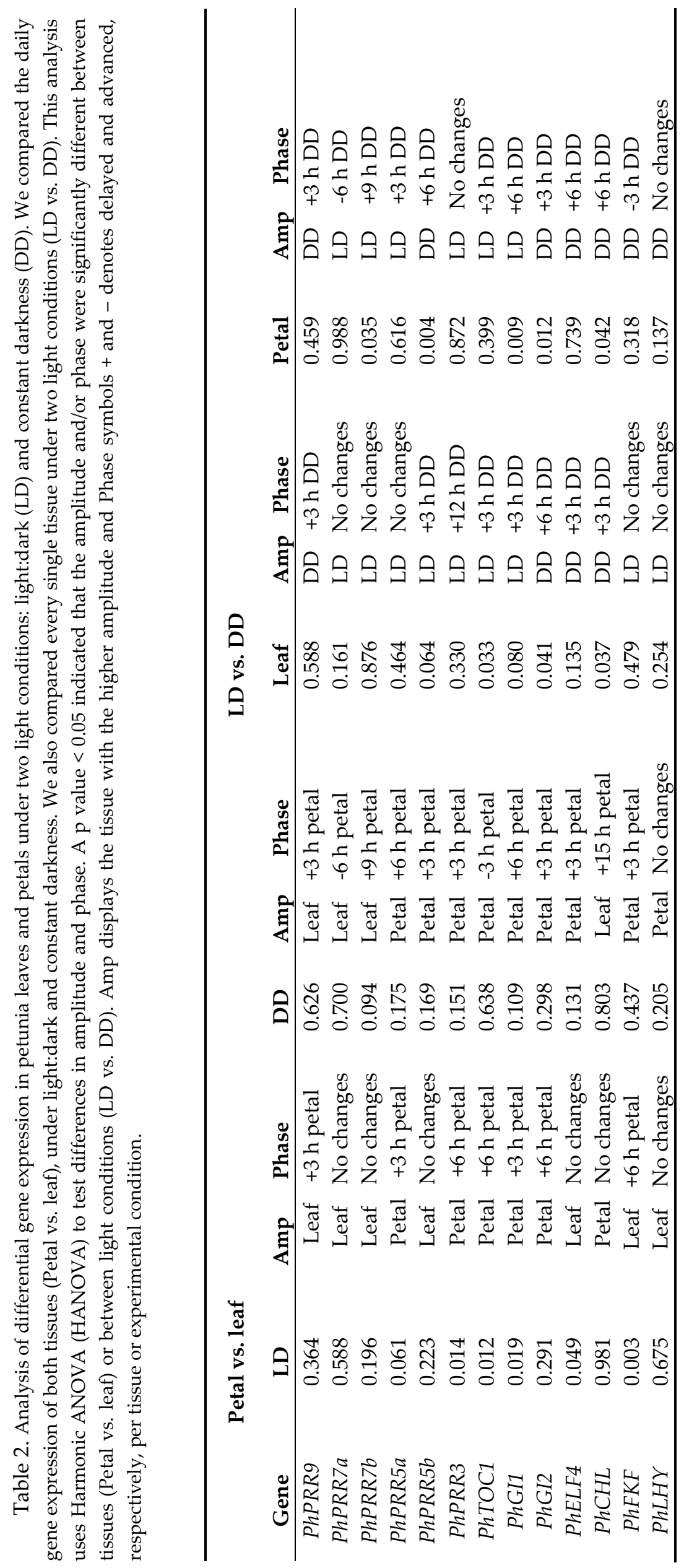




\subsection{Transcriptional noise is gene and tissue specific}

Although gene expression quantities were determined for the same set of mRNA extractions, the degree of significance in terms of gene expression levels was not always as expected based on average expressions. We asked if the variability of gene expression depended on tissue, time, and/or light conditions. When we analyzed the variability under a light:dark cycle (LD) we found that the clock genes PhPRR7b and PhPRR3 showed the lowest variation in leaves and petals whereas PhELF4 was a highly variable gene in both tissues. The stability of remaining genes varied among tissues, such as PhPRR9 or PhTOC1, showing lower transcriptional noise in leaves than petals. In addition, we observed that the lowest and the highest variability for all analyzed genes varied along the day, suggesting that transcriptional noise may be time-dependent (Figure 5, Figure S6).

When plants were transferred to constant darkness (DD), we found that the variability of clock genes tended to increase, except for PhLHY in leaves and PhGI2 in petals that were the most stable genes. Interestingly, the increase in CV was higher in leaves (Figure 5, Figure S6). The genes PhPRR7a, $P h P R R 7 b, P h P R R 3$, and PhFKF showed the highest variability under constant darkness. In petals, the transcriptional noise of PhPRR5a and PhTOC1 increased under a DD cycle (Figure 5). As previously mentioned, under a light:dark cycle, the coefficient of variation changed depending on the time point. The highest and lowest noise for leaves coincided with early and late day respectively, while in petals transcriptional noise was low in the subjective night and higher noise was found at subjective time ZT9.

We used a scale test (HarmScaleTest) implemented in the DODR package [51] in order to detect significant changes in noise when petunia was transferred to constant darkness (Table 3). The CV was in general higher under constant darkness, suggesting that the transcriptional noise tended to increase in DD. The exceptions were PhGI1 and PhELF4 in leaves and PhCHL, PhFKF, PhGI1, and PhGI2 in petals, displaying slightly higher CV under a LD cycle. We confirmed that the effect was tissue dependent, as changes in CV were significant $(p<0.05)$ in leaves for PhPRR7b, PhFKF, and PhGI1 and in petals, for PhPRR7a, PhPRR3, and PhELF4 (Table 3). The only gene affected in leaves and petals was $P h C H L$, but it also displayed opposite trends of increased CV (Table 3). This indicates that an endogenous component governs transcriptional noise of the clock genes, which also differs in leaves and petal 

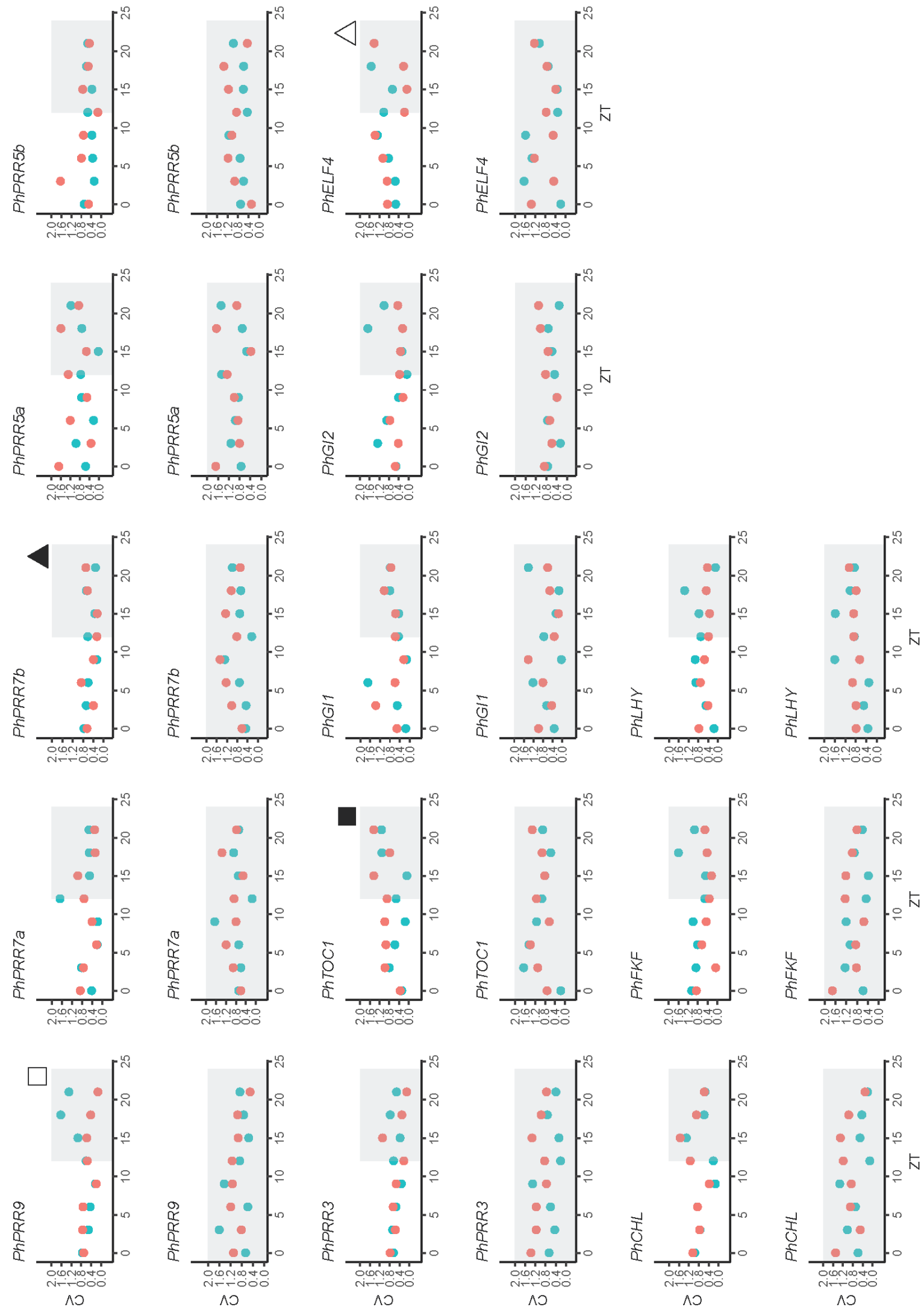


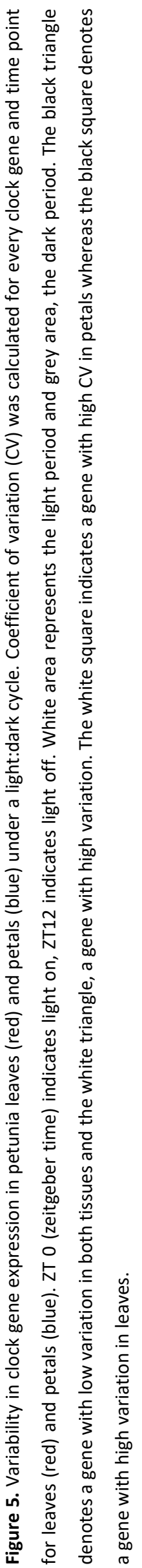

Chapter I- 67 
Table 3. Detection of changes in noise in petunia clock genes in two tissues, leaves and petals, comparing light:dark (LD) and constant darkness (DD) cycles. This analysis was performed by using the function HarmScaleTest provided by the R package DODR. A $p$ value $<0.05$ indicates significant changes between LD and $\mathrm{DD}$, the phase with higher variability is specified in Noise columns.

\begin{tabular}{ccccc}
\hline Gene & Leaf, LD vs. DD & Noise & Petal, LD vs. DD & Noise \\
\hline PhPRR9 & 0.341 & DD & 0.508 & DD \\
$P h P R R 7 a$ & 0.228 & DD & 0.002 & DD \\
$P h P R R 7 b$ & 0.014 & DD & 0.958 & DD \\
$P h P R R 5 a$ & 0.137 & DD & 0.312 & DD \\
$P h P R R 5 b$ & 0.839 & DD & 0.805 & DD \\
$P h P R R 3$ & 0.385 & DD & 0.004 & DD \\
$P h T O C 1$ & 0.575 & DD & 0.137 & DD \\
$P h G I 1$ & 0.000 & LD & 0.580 & LD \\
$P h G I 2$ & 0.301 & DD & 0.860 & LD \\
$P h E L F 4$ & 0.082 & LD & 0.005 & DD \\
$P h C H L$ & 0.016 & DD & 0.007 & LD \\
$P h F K F$ & 0.013 & DD & 0.124 & LD \\
$P h L H Y$ & 0.140 & DD & 0.084 & DD \\
\hline
\end{tabular}

\section{Discussion}

\subsection{The petunia clock genes show structural evolutionary changes}

The evolution of the plant circadian clock is considered an important driver of adaptation in a variety of plants including tomato, Opuntia ficus-indica, or barley [40,72-74]. The plant clock is an important coordinator of primary and secondary metabolism in plants. It defines the timing of floral scent emission and floral blend in a variety of plants including Antirrhinum majus, Nicotiana attenuatta, or Petunia [35-38]. The plant circadian clock appears to have a specific transcriptional structure in different tissues such as leaves, pods, seeds, or roots $[13,14,75,76]$. As the transcriptional structure of the clock in petals is currently unknown, we used Petunia hybrida to perform a detailed analysis. We characterized the structural changes in PhPRR5a, PhPRR5b, $P h P R R 7 a, P h P R R 7 b$, PhGI1, and PhGI2 and the transcriptional structure of the petunia circadian clock and associated genes in petals and leaves, using standard growth and continuous darkness.

The complete genome paleohexaploidization of petunia, found in the Solanaceae group [11] is reflected in the retaining of several clock genes as duplications that are found as single copy genes in Arabidopsis and other species. These include PhPRR5a, PhPRR5b, PhPRR7a, PhPRR7b, $P h G I 1$, and PhGI2. Other genes that are found as single copy include PhLHY, PhPRR9, PhPRR3, PhTOC1, PhFKF, and PhCHL the ortholog of ZTL. Interestingly, genes found as single copy in petunia such as PhTOC1, PhPRR9, and PhPRR3 are found as single copy in most Solanaceae except for Nicotiana benthamiana that appears to have two copies of each gene (Figure 1). Two of the petunia paralogs of AtPRR7, PhPRR7a, PinfS6PRR7a and the ones corresponding to AtPRR5 PhPRR5a, and PinfS6PRR5a cluster between Arabidopsis and the rest of the Solanaceae genes. In contrast the single copy genes TOC1, PRR3, and PRR9 are found as a subclade for all the Solanaceae together including Petunia. This indicates that there has been a loss of PRR5 and PRR7 paralogs in the Solanaceae that have a single copy gene, while Petunia has retained the older copy closer to the Arabidopsis, Vitis vinifera, and Amborella trichopoda genes. The additional changes observed in the number of exons indicate a specific evolution of one paralog. Indeed, AtPRR 5 has six exons whereas AtPRR7 presents nine exons (NP_568446.2 and AT5G02810, consulted in NCIB and TAIR database) while PhPRR5a and PhPRR7b present seven exons whereas PhPRR5b and $P h P R R 7 a$ have eight exons, indicating possible sub or neofunctionalization of these paralogs (see below). 
We found two domains, PR and CCT in all analyzed TOC1, PRR3, PRR5, and PRR9 sequences. In contrast, the CCT domain was absent in most PRR7 paralogs in Capsicum spp., Petunia spp., Solanum spp. and Nicotiana spp. Interestingly, we only found the CCT domain in PhPRR7a, which shared more similarities in the amino acids sequence with AtPRR7. The lack of CCT domains in Solanaceae but not in the related Convolvulaceae family suggests that this event occurred in the early history of Solanaceae. In addition, this alteration, which has been described in PRR orthologs in crops such as rice and soybean, can modify growth and flowering time $[77,78]$. This may result in a specific clock in the Solanaceae family.

The current hypothesis about the transcriptional structure of the plant circadian clock includes a three component repressilator structure [64]. The PRR9, 7, and 5 genes function as transcriptional repressors in Arabidopsis [59]. The interaction between PRR9, 7, and 5 with TOPLESS occurs via two motifs. We found that the repression motifs were lost in the PhPRR5a and PinfS6PRR5a but was present in the rest of the paralogs of the PRR9, 5, and 3 genes. In addition, in P. axillaris PRR7b repression motif was interrupted by a sequence of 26 amino acids. This may result in the loss of gene repression activity of PRR5a and PRR7b [79]. Our results thus indicate that one of the repressilator loops in Petunia is maintained by one of the paralogs, while the second one PRR5a and PRR7b missing the repression domain may have undergone neofunctionalization.

The gene GI appeared in land plants and is absent in mosses or picoalgae [80]. In the Solanaceae we found two to three copies, and in Petunia hybrida, there are significant differences in the coding region between PhGI1 and PhGI2 suggesting a diversification of functions. Furthermore, the amino acid differences between $P$. axillaris and $P$. inflata indicate species specific changes in this master regulator that may be related to the differing environmental niches where both species grow.

We used the predicted protein sequences to infer the domain structure of GIGANTEA. Although a previous study describes that GI encodes a protein with six transmembrane domains [63], the biochemical functions of GI are not understood. In yeast, two hybrid experiments performed with the Arabidopsis GI protein show that the N-terminal domain interacts with FKF1 [81], while the complete protein shows interactions with the CYCLING DOF FACTOR6 and DELLA protein $[82,83]$. As the differences in protein structure found between PhGI1 and PhGI2 do not match well known domains we cannot understand their functional differences. Nevertheless, the PinfS6GI3 does lack the N terminus required for interactions with FKF1 and ZTL in Arabidopsis.

\subsection{Daily expression of petunia clock genes is tissue specific}

The current transcriptional model of the plant circadian clock is largely based on the expression of genes in the Arabidopsis hypocotyls and leaves [84]. It includes the morning, midday or core, and the evening loops. During the morning, the genes CCA1 and LHY repress the evening genes GI and TOC1 and activate PRR9 and PRR7. At the same time, TOC1 acts repressing GI and PRR9 but activating CCA1/LHY. On the other hand, GI stabilizes ZTL that is a TOC1 repressor [85].

Previous studies have revealed that the circadian clock is tissue-specific $[14,75,76]$. Differential expression of clock genes has been reported in several tissues including seeds, roots, leaves, stems, and flowers at several developmental stages in different plant species such as bamboo [86], radish [87], or daisy [88].

Changes in gene expression of timing, quantity, and rhythm may hint at possible subfunctionalization or neofunctionalization of duplicated clock genes. We found that gene expression patterns of PhPRR5 and PhGI paralogs differed in petals and leaves respectively, under a light:dark cycle. PhPRR5b and PhGI2 displayed an advanced phase, peaking before $P h P R R 5 a$ and $P h G I 1$. Under DD, PhPRR5 $b$ was delayed $3 \mathrm{~h}$ in leaves. In petals, $P h P R R 7 a$ advanced $6 \mathrm{~h}$ while PhPRR7b delayed $9 \mathrm{~h}$. Given the differences in protein structure observed between 
PhPRR5a, PhPRR5b, PhPRR7a, and PhPRR7b, and the drastic changes in expression pattern we can conclude that these paralogs have undergone important changes in biological function. As changes are tissue specific, it appears that the coordination of the clock in petals differs from the canonical expression in leaves.

\subsection{Leaves and petals have different clock coordination}

The current hypothesis is that several independent inputs such as light, temperature, or sugar act as signals helping the plant clock to remain stable. One of the signals considered differing between tissues is light [89]. In the present work we explored oscillations in gene expression in leaves and petals that do not differ in their exposure to light or temperature. We used the RAIN algorithm, a non-parametric method which also provided measures of phase [50]. We also performed an HANOVA test comparing tissues and light conditions. The core clock genes $L H Y$ and TOC1 are found in basal picoeukaryotes, mosses, Marchantia polymorpha, and all higher plants $[5,80,90]$. We found that PhLHY and PhPRR9 did not show any statistical differences regardless the tissue or light cycle. In contrast, PhTOC1 expression pattern differed between leaves and petals in LD, i.e., standard growing conditions. This indicates a basal change in the clock coordination between both tissues. This scenario may be further supported by the significant changes found for PhFKF, PhPRR3, PhGI1, and PhGI2 between tissues. Finally, PhGI1, a gene found only in flowering plants showed significant changes between tissues and photoperiods indicating that it may play a role in the coordination between development and environmental signals. An initial hypothesis proposed different clock structures in leaves and roots of Arabidopsis based on the light reception by the organs [14]. However work performed in cowpea shows that aerial organs exposed to light such as leaves, pods, or developing seeds show different transcriptional clock structures [76]. Our results indeed indicate a differential coordination of the leaf and petal clock that may be the result of the establishment of the petal identity by the floral organ identity genes.

\subsection{Photoperiod sensitivity is organ-specific}

The effect of day length on biological clocks has been widely studied. For example, floral transition is controlled by CONSTANS (CO) and FLOWERING LOCUS T (FT) genes which are regulated by the circadian clock, including ELF3, ELF4, GI, LHY, PRRs, and ZTL genes [91-93]. These genes are capable to integrate environmental cues, mainly day length, but also temperature. Clock genes are therefore sensitive to ambient changes resulting in an adaptive advantage [85]. The present study revealed that a constant dark regime induced phase-shift even in the first $24 \mathrm{~h}$. Most analyzed genes tended to delay their maximum expression, especially in leaves. Only $P h L H Y$ did not change its expression and displayed a robust oscillation in leaves and petals. Other genes, PhPRR7a and PhELF4 (in leaves), did not retain their rhythmicity, suggesting that the integration of environmental cues and phototransduction varies depending on the tissue. This is consistent with previous studies, that have reported the effect of light on organ-specific circadian clocks and photoperiodic sensitivity [14,94].

Constant dark also had an effect on oscillations, which in general tended to decrease in most analyzed genes in leaves and petals. Similar results have been reported in other plant species: LHY/CCA1, ELF4, GI, and TOC1 gene expression dampens under constant light or constant dark conditions in Arabidopsis [35,63,95,96]. Loss of circadian rhythmicity could be key and be involved in responses to environmental changes, such as seasonal dormancy during winter in Japanese cedar or chestnut $[97,98]$.

\subsection{Trarnscriptional noise is tissue-specific and depends on photoperiod}

One of the main features of the transcriptional structure of circadian clocks is the capacity to integrate noisy environmental signals and internal transcriptional variation [99]. The robustness 
of circadian oscillation is related to the number of mRNA molecules, interactions, and complex formation, and it is stabilized by the entrainment to the light:dark cycle [100].

In the present work we used a set of biological samples to analyze 13 genes under two light conditions and two tissues. We found that for the same set of samples some genes showed very high noise at a given time of the day, while others were very stable (Figure 5). We also found that molecular noise differed in leaves and petals and it was influenced by the time of the day. While in leaves highest stability appeared at the beginning of the subjective day, petals displayed the lowest stability. This was also noticeable when plants were transferred to continuous darkness. Interestingly, the time point with the highest transcriptional noise shifted both in leaves and petals. The lowest stability advanced in petals, and delayed in leaves. Furthermore, the increased transcriptional robustness early in the day in leaves, and in the late day-early night in petals, coincide with the major functional changes in both tissues, initiation of photosynthesis, and scent emission. As noise increases thereafter in both tissues, it could be that funneling transcriptional noise into robustness at certain times of the day may have biological implications to achieve consistent outputs. However, the molecular function, if any, is not understood as this is the first report of this phenomenon.

Taken together the differential transcriptional structure and response to light, we conclude that the circadian clock in leaves and petals show substantial differences, that may reflect the underlying function in controlling photosynthesis and secondary metabolism in both tissues. The functional differences between leaves and petals may rely in part on a circadian clock reprogramming during flower development.

Supplementary Materials: The following are available online at https://www.mdpi.com/20734425/10/11/860/s1, Figure S1: Metl or dissociation curve analysis of petunia genes, Figure S2: Exon-intron structure of Petunia axillaris (PaxiN) PRR5 and PRR7 genes, Figure S3: Domain structure of PSEUDORESPONSE REGULATORS (PRRs), Figure S4: Local alignment of repression motifs of PRR5, Figure S5: Local alignment of GIGANTEA (GIs) proteins, Figure S6: Normalized expression (NE) for the biological replicates, Table S1: PSEUDO-RESPONSE REGULATORS (PRRs) protein accessions used in the phylogenetic reconstruction and for the annotation of protein sequences, Table S2: GIGANTEA (GI) protein accessions used in the phylogenetic reconstruction, Table S3: Primers used for qPCR,

Author Contributions: Conceptualization, M.I.T., J.W. and M.E.-C.; Data curation, M.I.T.; Formal analysis, M.I.T., M.C.-A. and M.E.-C.; Funding acquisition, J.W. and M.E.-C.; Investigation, M.I.T., M.C.-A. and M.E.C.; Methodology, M.I.T., J.W. and M.E.-C.; Project administration, J.W. and M.E.-C.; Supervision, M.E.-C.; Validation, M.I.T.; Visualization, M.I.T. and J.W.; Writing - original draft, M.I.T., J.W. and M.E.-C.; Writing - review \& editing, M.I.T., M.C.-A., J.W. and M.E.-C.

Funding: This work was developed under projects Fundación Séneca 19398/PI/14, MICINN-FEDER BFU2013-45148-R and BFU-2017-88300-C2-1-R.

Conflicts of Interest: The authors declare no conflict of interest.

\section{References}

1. Harmer, S.L. The Circadian System in Higher Plants. Ann. Rev. Plant Biol. 2009, 60, 357-377.

2. McClung, C.R. Plant circadian rhythms. Plant Cell 2006, 18, 792-803.

3. Hsu, P.Y.; Devisetty, U.K.; Harmer, S.L. Accurate timekeeping is controlled by a cycling activator in Arabidopsis. eLife 2013, 2, e00473.

4. Hernando, C.E.; Romanowski, A.; Yanovsky, M.J. Transcriptional and post-transcriptional control of the plant circadian gene regulatory network. Biochim. Biophys. Acta Gene Regul. Mech. 2017, 1860, 84-94.

5. Corellou, F.; Schwartz, C.; Motta, J.P.; Djouani-Tahri, E.; Sanchez, F.; Bouget, F.Y. Clocks in the Green Lineage: Comparative Functional Analysis of the Circadian Architecture of the Picoeukaryote Ostreococcus. Plant Cell 2009, 21, 3436-3449. 
6. Djouani-Tahri, E.B.; Christie, J.M.; Sanchez-Ferandin, S.; Sanchez, F.; Bouget, F.Y.; Corellou, F. A eukaryotic LOV-histidine kinase with circadian clock function in the picoalga Ostreococcus. Plant J. 2011, 65, 578-588.

7. Airoldi, C.A.; Davies, B. Gene Duplication and the Evolution of Plant MADS-box Transcription Factors. J. Genet. Gen. 2012, 39, 157-165.

8. Wendel, J.F.; Jackson, S.A.; Meyers, B.C.; Wing, R.A. Evolution of plant genome architecture. Genome Biol. 2016, 17, 37.

9. $\quad$ Adams, K.L.; Wendel, J.F. Polyploidy and genome evolution in plants. Curr. Opin. Plant Biol. 2005, 8, 135141.

10. Lou, P.; Wu, J.; Cheng, F.; Cressman, L.G.; Wang, X.; McClung, C.R. Preferential Retention of Circadian Clock Genes during Diploidization following Whole Genome Triplication in Brassica Rapa. Plant Cell 2012, 24, 2415-2426.

11. Bombarely, A.; Moser, M.; Amrad, A.; Bao, M.; Bapaume, L.; Barry, C.S.; Bliek, M.; Boersma, M.R.; Maaike, B.; Lorenzo, B.; et al. Insight into the evolution of the Solanaceae from the parental genomes of Petunia hybrida. Nat. Plants 2016, 2, 1-9.

12. Takahashi, N.; Hirata, Y.; Aihara, K.; Mas, P. A Hierarchical Multi-Oscillator Network Orchestrates the Arabidopsis Circadian System. Cell 2015, 163, 148-159.

13. James, A.B.; Monreal, J.A.; Nimmo, G.A.; Kelly, C.L.; Herzyk, P.; Jenkins, G.I.; Nimmo, H.G. The Circadian Clock in Arabidopsis Roots Is a Simplified Slave Version of the Clock in Shoots. Science 2008, 322, 1832-1835.

14. Bordage, S.; Sullivan, S.; Laird, J.; Millar, A.J.; Nimmo, H.G. Organ specificity in the plant circadian system is explained by different light inputs to the shoot and root clocks. New Phytol. 2016, 212, 136149.

15. Theissen, G.; Becker, A. Gymnosperm orthologues of class B floral homeotic genes and their impact on understanding flower origin. Crit. Rev. Plant Sci. 2004, 23, 129-148.

16. Schwarz-Sommer, Z.; Hue, I.; Huijser, P.; Flor, P.J.; Hansen, R.; Tetens, F.; Lönnig, W.E.; Saedler, H.; Sommer, H. Characterization of the Antirrhinum floral homeotic MADS-box gene deficiens: Evidence for DNA binding and autoregulation of its persistent expression throughout flower development. EMBO J. 1992, 11, 251-263.

17. Goto, K.; Meyerowitz, E.M. Function and Regulation of the Arabidopsis Floral Homeotic Gene Pistillata. Genes Dev. 1994, 8, 1548-1560.

18. Jack, T.; Fox, G.L.; Meyerowitz, E.M. Arabidopsis homeotic gene APETALA3 ectopic expression: Transcriptional and posttranscriptional regulation determine floral organ identity. Cell 1994, 76, 703716.

19. Vandenbussche, M.; Zethof, J.; Royaert, S.; Weterings, K.; Gerats, T. The duplicated B-class heterodimer model: Whorl-specific effects and complex genetic interactions in Petunia hybrida flower development. Plant Cell 2004, 16, 741-754.

20. Samach, A.; Kohalmi, S.E.; Motte, P.; Datla, R.; Haughn, G.W. Divergence of function and regulation of class B floral organ identity genes. Plant Cell 1997, 9, 559-570.

21. Zachgo, S.; Silva, E.D.; Motte, P.; Trobner, W.; Saedler, H.; Schwarz-Sommer, Z. Functional analysis of the Antirrhinum floral homeotic deficiens gene in vivo and in vitro by using a temperature-sensitive mutant. Development 1995, 121, 2861-2875.

22. Manchado-Rojo, M.; Delgado-Benarroch, L.; Roca, M.J.; Weiss, J.; Egea-Cortines, M. Quantitative levels of Deficiens and Globosa during late petal development show a complex transcriptional network topology of B function. Plant J. 2012, 72, 294-307.

23. Delgado-Benarroch, L.; Weiss, J.; Egea-Cortines, M. Floral organ size control. Plant Signal. Behav. 2009, 4, 814817.

24. Manchado-Rojo, M.; Weiss, J.; Egea-Cortines, M. Validation of Aintegumenta as a gene to modify floral size in ornamental plants. Plant Biotechnol. J. 2014, 12, 1053-1065.

25. Muhlemann, J.K.; Maeda, H.; Chang, C.Y.; Miguel, P.S.; Baxter, I.; Cooper, B.; Perera, M.A.; Nikolau, B.J.; Vitek, O.; Morgan, J.A.; et al. Developmental Changes in the Metabolic Network of Snapdragon Flowers. PLoS ONE 2012, 7, e40381. 
26. Weiss, J.; Mühlemann, J.K.; Ruiz-Hernández, V.; Dudareva, N.; Egea-Cortines, M. Phenotypic Space and Variation of Floral Scent Profiles during Late Flower Development in Antirrhinum. Front. Plant Sci. 2016, 7, 1-12.

27. Shaw, J.-F.; Chen, H.-H.; Tsai, M.-F.; Kuo, C.-I.; Huang, L.-C. Extended flower longevity of Petunia hybrida plants transformed with boers, a mutated ERS gene of Brassica oleracea. Mol. Breed. 2002, 9, 211216.

28. Van Doorn, W.G.; Woltering, E.J. Physiology and molecular biology of petal senescence. J. Exp. Bot. 2008, 59, 453-480.

29. Liu, J.; Li, J.; Wang, H.; Fu, Z.; Liu, J.; Yu, Y. Identification and expression analysis of ERF transcription factor genes in Petunia during flower senescence and in response to hormone treatments. J. Exp. Bot. 2011, 62, 825-840.

30. Verdonk, J.C.; Ric de Vos, C.H.; Verhoeven, H.A.; Haring, M.A.; van Tunen, A.J.; Schuurink, R.C. Regulation of floral scent production in Petunia revealed by targeted metabolomics. Phytochemistry 2003, 62, 997-1008.

31. Ruíz-Ramón, F.; Águila, D.J.; Egea-Cortines, M.; Weiss, J. Optimization of fragrance extraction: Daytime and flower age affect scent emission in simple and double narcissi. Ind. Crops Prod. 2014, 52, 671-678.

32. Helsper, J.P.F.G.; Davies, J.A.; Bouwmeester, H.J.; Krol, A.F.; Kampen, M.H.V.; van Kampen, M.H. Circadian rhythmicity in emission of volatile compounds by flowers of Rosa hybrida L. cv. Honesty. Planta 1998, 207, 88-95.

33. Kolosova, N.; Gorenstein, N.; Kish, C.M.; Dudareva, N. Regulation of Circadian Methyl Benzoate Emission in Diurnally and Nocturnally Emitting Plants. Plant Cell 2001, 13, 2333-2347.

34. Hoballah, M.E.; Stuurman, J.; Turlings, T.C.J.; Guerin, P.M.; Connétable, S.; Kuhlemeier, C.; Connetable, S.; Kuhlemeier, C. The composition and timing of flower odour emission by wild Petunia axillaris coincide with the antennal perception and nocturnal activity of the pollinator Manduca sexta. Planta 2005, 222, 141-50.

35. Fenske, M.P.; Hewett Hazelton, K.D.; Hempton, A.K.; Shim, J.S.; Yamamoto, B.M.; Riffell, J.A.; Imaizumi, T. Circadian clock gene LATE ELONGATED HYPOCOTYL directly regulates the timing of floral scent emission in Petunia. Proc. Natl. Acad. Sci. USA 2015, 112, 9775-9780.

36. Yon, F.; Joo, Y.; Cort, L.; Rothe, E.; Baldwin, I.T.; Kim, S.; Kim, S. Silencing Nicotiana attenuata LHY and ZTL alters circadian rhythms in flowers. New Phytol. 2015, 209, 1058-1066.

37. Terry, M.I.; Pérez-Sanz, F.; Díaz-Galián, M.V.; Pérez de los Cobos, F.; Navarro, P.J.; Egea-Cortines, M.; Weiss, J. The Petunia Chanel Gene is a Zeitlupe Ortholog Coordinating Growth and Scent Profiles. Cells 2019, 8, 343

38. Terry, M.I.; Pérez-Sanz, F.; Navarro, P.J.; Weiss, J.; Egea-Cortines, M. The Snapdragon Late Elongated Hypocotyl Plays A Dual Role in Activating Floral Growth and Scent Emission. Cells 2019, 8, 920.

39. Raguso, R.A.; Levin, R.A.; Foose, S.E.; Holmberg, M.W.; McDade, L.A. Fragrance chemistry, nocturnal rhythms and pollination "syndromes" in Nicotiana. Phytochemistry 2003, 63, 265-284.

40. Mallona, I.; Egea-Cortines, M.; Weiss, J. Conserved and divergent rhythms of CAM-related and core clock gene expression in the cactus Opuntia ficus-indica. Plant Physiol. 2011, 156, 1978-1989.

41. Li, M.; Zhang, D.; Gao, Q.; Luo, Y.; Zhang, H.; Ma, B.; Chen, C.; Whibley, A.; Zhang, Y.; Cao, Y.; et al. Genome structure and evolution of Antirrhinum majus L. Nat. Plants 2019, 5, 174.

42. Birney, E.; Clamp, M.; Durbin, R. GeneWise and Genomewise. Genome Res. 2004, 14, 988-95.

43. Larkin, M.A.; Blackshields, G.; Brown, N.P.; Chenna, R.; McGettigan, P.A.; McWilliam, H.; Valentin, F.; Wallace, I.M.; Wilm, A.; Lopez, R.; et al. Clustal W and clustal X v2.0. Bioinformatics 2007, 23, 29478.

44. Kumar, S.; Stecher, G.; Li, M.; Knyaz, C.; Tamura, K. Mega X: Molecular Evolutionary Genetics Analysis across Computing Platforms. Mol. Biol. Evol. 2018, 35, 1547-1549.

45. Jones, D.T.; Taylor, W.R.; Thornton, J.M. The rapid generation of mutation data matrices from protein sequences. Bioinformatics 1992, 8, 275-282.

46. Makino, S.; Kiba, T.; Imamura, A.; Hanaki, N.; Nakamura, A.; Suzuki, T.; Taniguchi, M.; Ueguchi, C.; Sugiyama, T.; Mizuno, T. Genes Encoding Pseudo-Response Regulators: Insight into His-to-Asp Phosphorelay and Circadian Rhythm in Arabidopsis thaliana. Plant Cell Physiol. 2000, 41, 791-803. 
47. Yu, G.; Smith, D.K.; Zhu, H.; Guan, Y.; Lam, T.T.-Y. ggtree: An r package for visualization and annotation of phylogenetic trees with their covariates and other associated data. Methods Ecol. Evol. 2017, 8, 28-36.

48. Hulo, N.; Bairoch, A.; Bulliard, V.; Cerutti, L.; De Castro, E.; Langendijk-Genevaux, P.S.; Pagni, M.; Sigrist, C.J.A. The Prosite Database. Nucl. Acids Res. 2006, 34, D227-D230.

49. Brennan, P. DrawProteins: A Bioconductor/R package for reproducible and programmatic generation of protein schematics. F1000Res 2018, 7, 1-15.

50. Thaben, P.F.; Westermark, P.O. Detecting rhythms in time series with RAIN. J. Biol. Rhythms 2014, 29, 391400.

51. Thaben, P.F.; Westermark, P.O. Differential rhythmicity: Detecting altered rhythmicity in biological data. Bioinformatics 2016, 32, 2800-2808.

52. Wickman, H. ggplot2-Elegant Graphics for Data Analysis (2nd Edition). J. Stat. Softw. 2017, 77, 3-5.

53. Box, M.S.; Coustham, V.; Dean, C.; Mylne, J.S. Protocol: A simple phenol-based method for 96-well extraction of high quality RNA from Arabidopsis. Plant Methods 2011, $7,7$.

54. Mallona, I.; Lischewsky, S.; Weiss, J.; Hause, B.; Egea-Cortines, M.; Mallona, I.; Lischewsky, S.; Weiss, J.; Hause, B.; Egea-Cortines, M.; et al. Validation of reference genes for quantitative real-time PCR during leaf and flower development in Petunia hybrida. BMC Plant Biol. 2010, 10, 4.

55. Mallona, I.; Weiss, J.; Egea-Cortines, M. pcrEfficiency: A Web tool for PCR amplification efficiency prediction. BMC Bioinf. 2011, 12, 404.

56. Simon, P. Q-Gene: Processing quantitative real-time RT-PCR data. Bioinformatics 2003, 19, 1439-1440.

57. Cortijo, S.; Aydin, Z.; Ahnert, S.; Locke, J.C. Widespread inter-individual gene expression variability in Arabidopsis thaliana. Mol. Syst. Biol. 2019, 15, e8591.

58. Uemura, M.; Takata, N.; Saito, S.; Saito, C.T.; Uemura, M. Phylogenetic footprint of the plant clock system in angiosperms: Evolutionary processes of Pseudo-Response Regulators. BMC Evolut. Biol. 2010, 10, 126.

59. Nakamichi, N.; Kiba, T.; Henriques, R.; Mizuno, T.; Chua, N.-H.; Sakakibara, H. Pseudo-response regulators 9, 7, and 5 are transcriptional repressors in the Arabidopsis circadian clock. Plant cell 2010, 22, 594-605.

60. Causier, B.; Ashworth, M.; Guo, W.; Davies, B. The Topless Interactome: A Framework for Gene Repression in Arabidopsis. Plant Physiol. 2012, 158, 423-438.

61. Wang, L.; Kim, J.; Somers, D.E. Transcriptional corepressor topless complexes with pseudoresponse regulator proteins and histone deacetylases to regulate circadian transcription. Proc. Natl. Acad. Sci. USA 2013, 110, 761-6.

62. Fowler, S.; Lee, K.; Onouchi, H.; Samach, A.; Richardson, K.; Morris, B.; Coupland, G.; Putterill, J. Gigantea: A circadian clock-controlled gene that regulates photoperiodic flowering in Arabidopsis and encodes a protein with several possible membrane-spanning domains. EMBO J. 1999, 18, 4679-4688.

63. Park, D.H.; Somers, D.E.; Kim, Y.S.; Choy, Y.H.; Lim, H.K.; Soh, M.S.; Kim, H.J.; Kay, S.A.; Nam, H.G. Control of Circadian Rhythms and Photoperiodic Flowering by the Arabidopsis Gigantea Gene. Science 1999, 285, 1579-1582.

64. Pokhilko, A.; Fernández, A.P.; Edwards, K.D.; Southern, M.M.; Halliday, K.J.; Millar, A.J. The clock gene circuit in Arabidopsis includes a repressilator with additional feedback loops. Mol. Syst. Biol. 2012, 8,574 .

65. Lu, S.X.; Webb, C.J.; Knowles, S.M.; Kim, S.H.J.; Wang, Z.; Tobin, E.M. CCA1 and ELF3 Interact in the Control of Hypocotyl Length and Flowering Time in Arabidopsis. Plant Physiol. 2012, 158, 1079-1088.

66. Pruneda-Paz, J.L.; Breton, G.; Para, A.; Kay, S.A. A Functional Genomics Approach Reveals CHE as a Component of the Arabidopsis Circadian Clock. Science 2009, 323, 1481-1485.

67. Wu, J.-F.; Tsai, H.-L.; Joanito, I.; Wu, Y.-C.; Chang, C.-W.; Li, Y.-H.; Wang, Y.; Hong, J.C.; Chu, J.-W.; Hsu, C.-P.; et al. LWD-TCP complex activates the morning gene CCA1 in Arabidopsis. Nat. Commun. 2016, 7, 110.

68. Xie, Q.; Wang, P.; Liu, X.; Yuan, L.; Wang, L.; Zhang, C.; Li, Y.; Xing, H.; Zhi, L.; Yue, Z.; et al. LNK1 and LNK2 Are Transcriptional Coactivators in the Arabidopsis Circadian Oscillator. Plant Cell 2014, 26, 28432857. 
69. Nohales, M.A.; Kay, S.A. Molecular mechanisms at the core of the plant circadian oscillator. Nat. Struct. Mol. Biol. 2016, 23, 1061-1069.

70. Mack, G.A.; Wolfe, D.A. K-Sample Rank Tests for Umbrella Alternatives. J. Am. Stat. Assoc. 1981, 76, 175181.

71. Somers, D.E.; Devlin, P.F.; Kay, S.A. Phytochromes and Cryptochromes in the Entrainment of the Arabidopsis Circadian Clock. Science 1998, 282, 1488-1490.

72. Zakhrabekova, S.; Gough, S.P.; Braumann, I.; Müller, A.H.; Lundqvist, J.; Ahmann, K.; Dockter, C.; Matyszczak, I.; Kurowska, M.; Druka, A.; et al. Induced mutations in circadian clock regulator Mat-a facilitated short-season adaptation and range extension in cultivated barley. PNAS 2012, 109, 43264331.

73. Müller, N.A.; Wijnen, C.L.; Srinivasan, A.; Ryngajllo, M.; Ofner, I.; Lin, T.; Ranjan, A.; West, D.; Maloof, J.N.; Sinha, N.R.; et al. Domestication selected for deceleration of the circadian clock in cultivated tomato. Nat. Genet. 2016, 48, 89-93.

74. Müller, N.A.; Zhang, L.; Koornneef, M.; Jiménez-Gómez, J.M. Mutations in EID1 and LNK2 caused light-conditional clock deceleration during tomato domestication Proc. Natl. Acad. Sci. 2018, 7135-7140.

75. Thain, S.C.; Murtas, G.; Lynn, J.R.; McGrath, R.B.; Millar, A.J. The circadian clock that controls gene expression in Arabidopsis is tissue specific. Plant Physiol. 2002, 130, 102-110.

76. Weiss, J.; Terry, M.; Martos-Fuentes, M.; Letourneux, L.; Ruiz-Hernández, V.; Fernández, J.A.; EgeaCortines, M. Diel pattern of circadian clock and storage protein gene expression in leaves and during seed filling in cowpea (Vigna unguiculata). BMC Plant Biol. 2018, 18, 33-53.

77. Lenser, T.; Theißen, G. Molecular mechanisms involved in convergent crop domestication. Trends Plant Sci. 2013, 18, 704-714.

78. Li, M.-W.; Liu, W.; Lam, H.-M.; Gendron, J.M. Characterization of Two Growth Period QTLs Reveals Modification of PRR3 Genes During Soybean Domestication. Plant Cell Physiol. 2019, 60, 407-420.

79. Toda, Y.; Kudo, T.; Kinoshita, T.; Nakamichi, N. Evolutionary Insight into the Clock-Associated PRR5 Transcriptional Network of Flowering Plants. Sci. Rep. 2019, 9, 1-14.

80. Linde, A.-M.; Eklund, D.M.; Kubota, A.; Pederson, E.R.A.; Holm, K.; Gyllenstrand, N.; Nishihama, R.; Cronberg, N.; Muranaka, T.; Oyama, T.; et al. Early evolution of the land plant circadian clock. New Phytol. 2017, 216, 576-590.

81. Sawa, M.; Nusinow, D.A.; Kay, S.A.; Imaizumi, T. FKF1 and gigantea complex formation is required for day-length measurement in Arabidopsis. Science 2007, 318, 261-265.

82. Krahmer, J.; Goralogia, G.S.; Kubota, A.; Zardilis, A.; Johnson, R.S.; Song, Y.H.; MacCoss, M.J.; Bihan, T.L.; Halliday, K.J.; Imaizumi, T.; et al. Time-resolved interaction proteomics of the gigantea protein under diurnal cycles in Arabidopsis. FEBS Lett. 2019, 593, 319-338.

83. Nohales, M.A.; Kay, S.A. GIGANTEA gates gibberellin signaling through stabilization of the DELLA proteins in Arabidopsis. PNAS 2019, 201913532.

84. Staiger, D.; Shin, J.; Johansson, M.; Davis, S.J. The circadian clock goes genomic. Genome Biol. 2013, 14, 208.

85. Pokhilko, A.; Hodge, S.K.; Stratford, K.; Knox, K.; Edwards, K.D.; Thomson, A.W.; Mizuno, T.; Millar, A.J. Data assimilation constrains new connections and components in a complex, eukaryotic circadian clock model. Mol. Syst. Biol. 2010, 6, 1-10.

86. Dutta, S.; Biswas, P.; Chakraborty, S.; Mitra, D.; Pal, A.; Das, M. Identification, characterization and gene expression analyses of important flowering genes related to photoperiodic pathway in bamboo. BMC Genom. 2018, 19, 1-19.

87. Wang, J.; Qiu, Y.; Cheng, F.; Chen, X.; Zhang, X.; Wang, H.; Song, J.; Duan, M.; Yang, H.; Li, X. Genomewide identification, characterization, and evolutionary analysis of flowering genes in radish (Raphanus sativus L.). BMC Genom. 2017, 18, 1-10.

88. Fu, J.; Yang, L.; Dai, S. Conservation of Arabidopsis thaliana circadian clock genes in Chrysanthemum lavandulifolium. Plant Physiol. Biochem. 2014, 80, 337-347.

89. Endo, M. Tissue-specific circadian clocks in plants. Curr. Opin. Plant Biol. 2016, 29, 44-49.

90. Holm, K.; Källman, T.; Gyllenstrand, N.; Hedman, H.; Lagercrantz, U. Does the core circadian clock in the moss Physcomitrella patens (Bryophyta) comprise a single loop? BMC Plant Biol. 2010, 10, 109. 
91. Samach, A.; Onouchi, H.; Gold, S.E.; Ditta, G.S.; Schwarz-Sommer, Z.; Yanofsky, M.F.; Coupland, G. Distinct Roles of Constans Target Genes in Reproductive Development of Arabidopsis. Science 2000, 288, 1613-1616.

92. Suárez-López, P.; Wheatley, K.; Robson, F.; Onouchi, H.; Valverde, F.; Coupland, G. Constans mediates between the circadian clock and the control of flowering in Arabidopsis. Nature 2001, 410, 1116-1120.

93. Valverde, F.; Mouradov, A.; Soppe, W.; Ravenscroft, D.; Samach, A.; Coupland, G. Photoreceptor Regulation of Constans Protein in Photoperiodic Flowering. Science 2004, 303, 1003-1006.

94. Shimizu, H.; Araki, T.; Endo, M. Photoperiod sensitivity of the Arabidopsis circadian clock is tissuespecific. Plant Signal. Behav. 2015, 10, 5-6.

95. Wang, Z.-Y.; Tobin, E.M. Constitutive Expression of the Circadian Clock Associated 1 (CCA1) Gene Disrupts Circadian Rhythms and Suppresses Its Own Expression. Cell 1998, 93, 1207-1217.

96. Liew, L.C.; Hecht, V.; Sussmilch, F.C.; Weller, J.L. The Pea Photoperiod Response Gene STERILE NODES Is an Ortholog of LUX ARRHYTHMO. Plant Physiol. 2014, 165, 648-657.

97. Nose, M.; Watanabe, A. Clock genes and diurnal transcriptome dynamics in summer and winter in the gymnosperm Japanese cedar (Cryptomeria japonica (L.f.) D.Don). BMC Plant Biol. 2014, 14, 308.

98. Ramos, A.; Pérez-Solís, E.; Ibáñez, C.; Casado, R.; Collada, C.; Gómez, L.; Aragoncillo, C.; Allona, I. Winter disruption of the circadian clock in chestnut. Proc. Natl. Acad. Sci. USA 2005, 102, 7037-42.

99. Hogenesch, J.B.; Ueda, H.R. Understanding systems-level properties: Timely stories from the study of clocks. Nat. Rev. Genet. 2011, 12, 407-416.

100. Gonze, D.; Halloy, J.; Goldbeter, A. Robustness of circadian rhythms with respect to molecular noise. PNAS 2002, 99, 673-678.

(C) 2019 by the authors. Submitted for possible open access publication under the terms and conditions of the Creative Commons Attribution (CC BY) license (http://creativecommons.org/licenses/by/4.0/). 


\section{Supporting information}
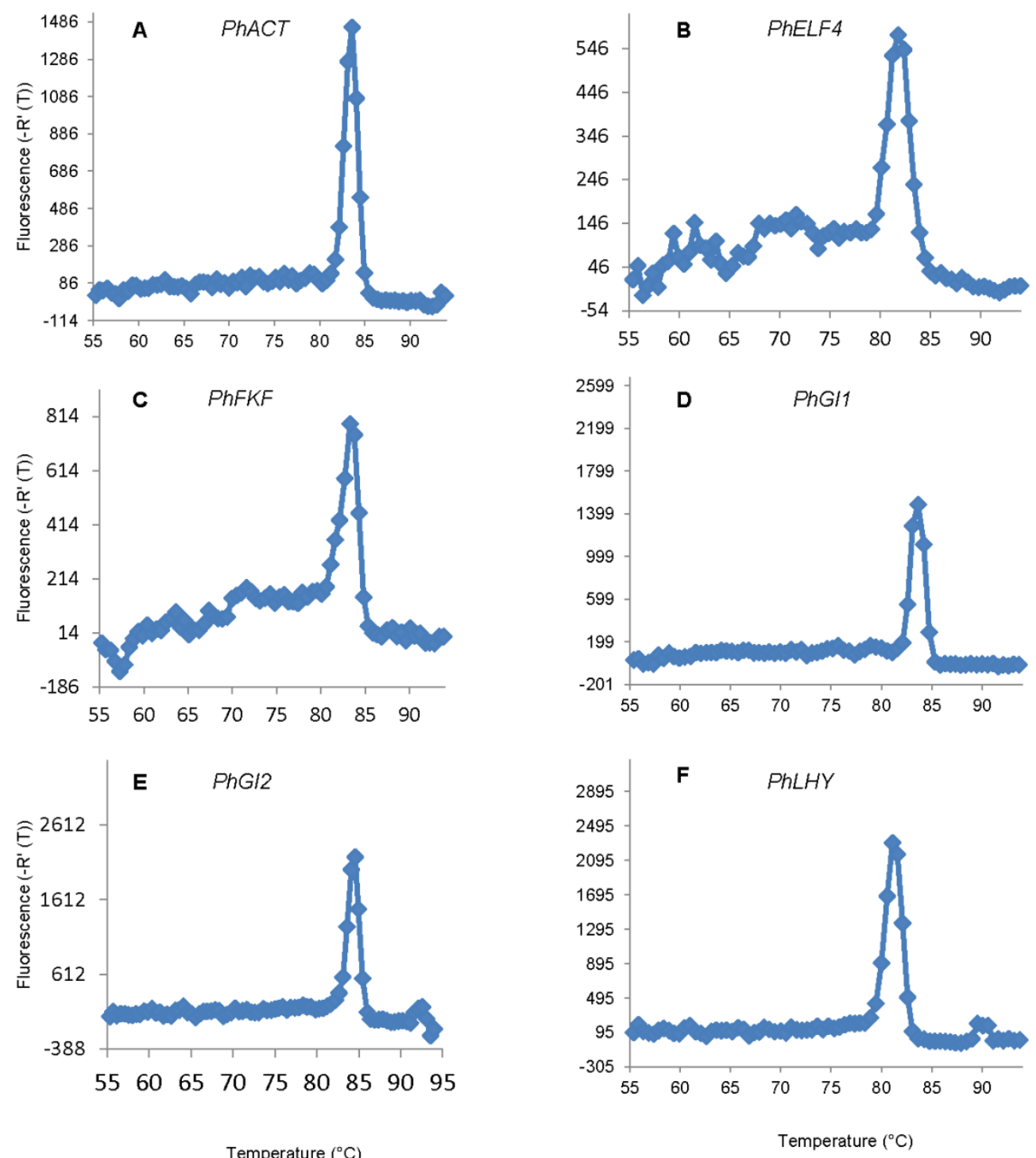

Temperature $\left({ }^{\circ} \mathrm{C}\right)$ 

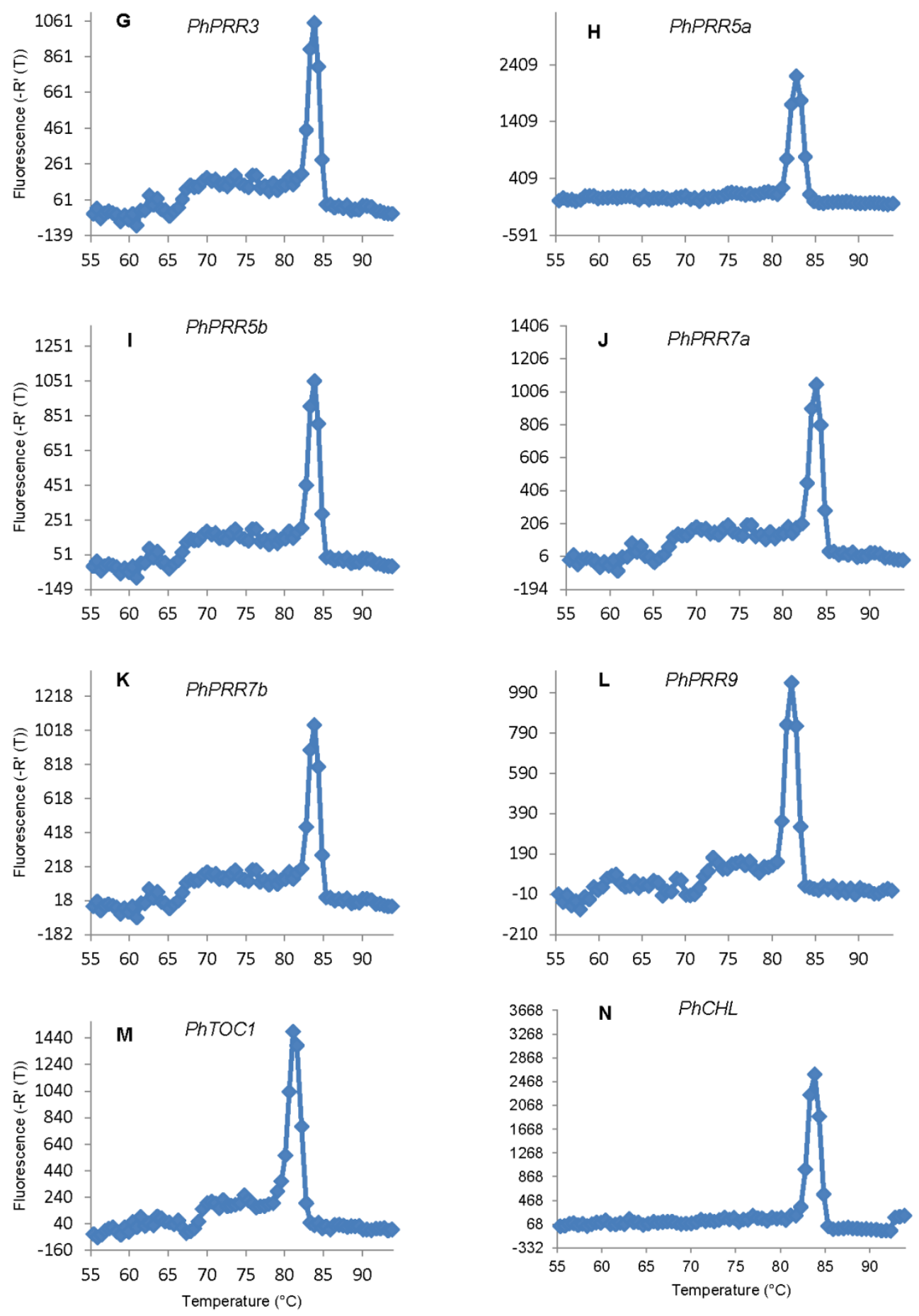

Figure S1: Melt or dissociation curve analysis of petunia genes. 


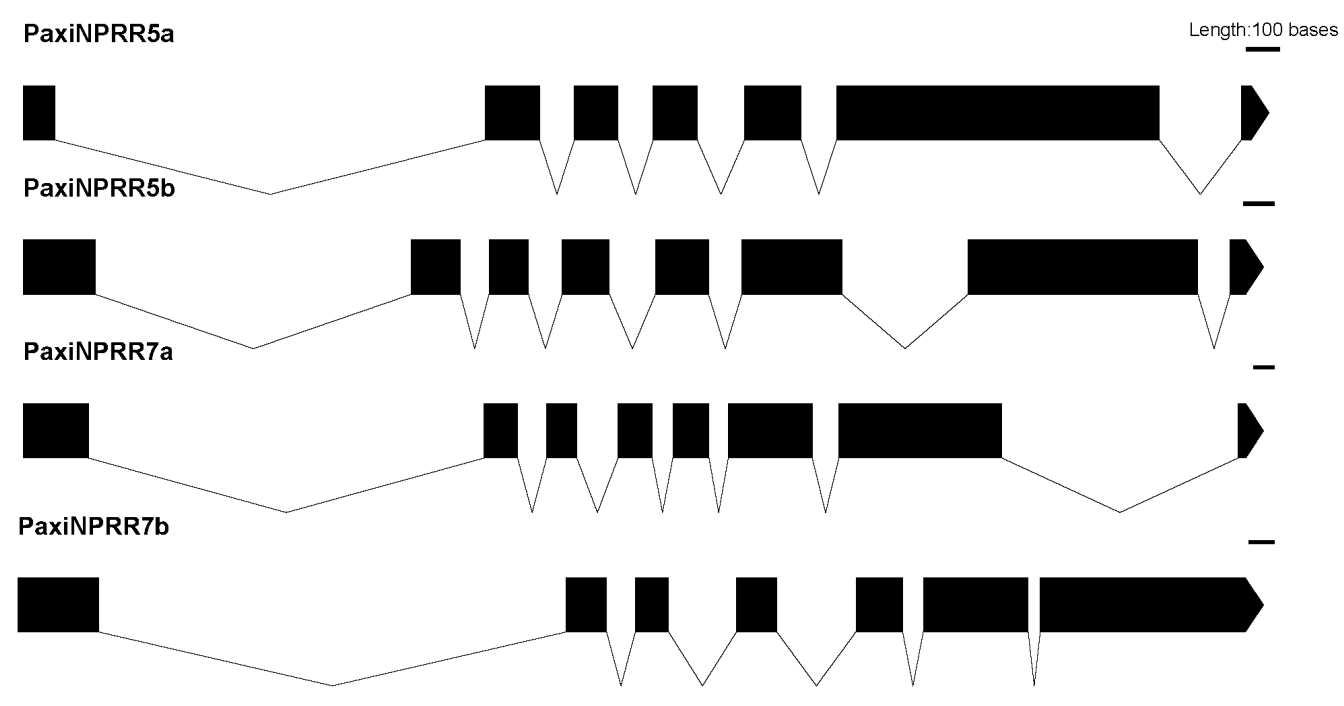

Figure S2:Exon-intron structure of Petunia axillaris (PaxiN) PRR5 and PRR7 genes. The exon-intron boundary was calculated using the predicted mRNA molecules from petunia and aligning them to the corresponding genomic sequences. 


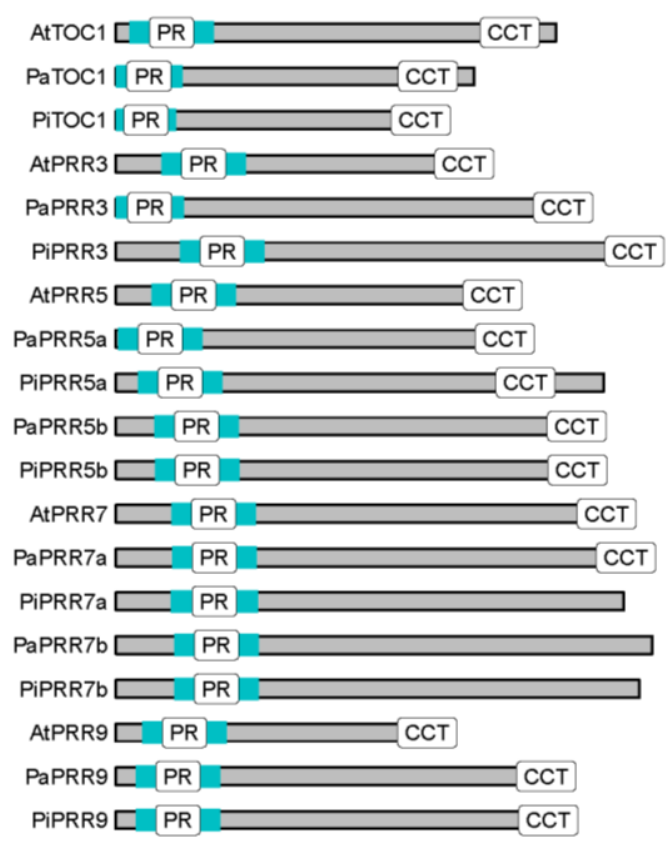

300

Amino acid number

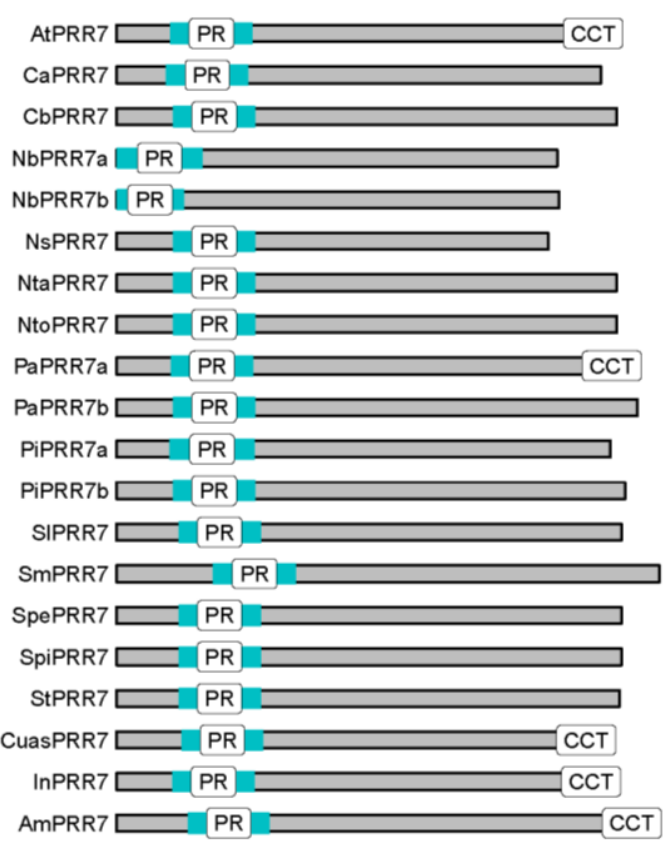

300 - 600

Amino acid number

Figure S3: (A) Domain structure of PRRs proteins in Arabidopsis thaliana (At), Petunia axillaris (Pa) and P. inflata (Pi). (B) Domain structure of PRR7s proteins in Arabidopsis thaliana (At), Capsicum annuum (Ca), C.baccatum (Cb),

Nicotiana benthamiana (Nb), N.sylvestris (Ns), N.tabacum (Nta), N.tomentosiformis (Nto), Petunia axillaris (Pa), P. inflata (Pi), Solanum lycopersicum (sl), S.melongena (Sm), S.pennellii (Spe), S.pimpinellifolium (Spi), S.tuberosum (St), Cuscuta australis (Cuas), Ipomea nil (In) and Antirrhinum majus (Am). 
Figure S4: Local alignment of repression motifs of PRR5 proteins. Arabidopsis thaliana (A.thaliana), Capsicum annuum (C.annuum), Nicotiana benthamiana (N.benthamiana), N. tomentosiformis (N.tomentosiformis), $N$. sylvestris (N.sylvestris), Petunia axillaris (P.axillaris), P. inflata (P.inflata), Solanum lycopersicum (S.lycopersicum) and S. tuberosum (S.tuberosum).

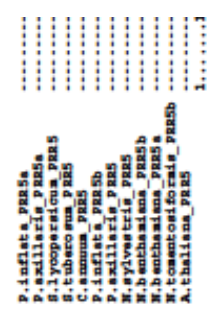




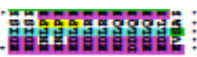

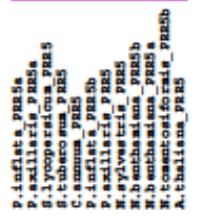


Chapter I- 83

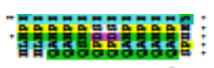

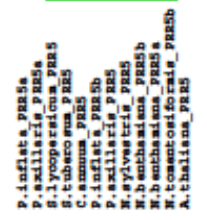


Chapter I - 84

Figure S5: Local alignment of GIGANTEA proteins.

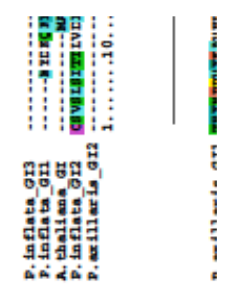


Chapter I- 85

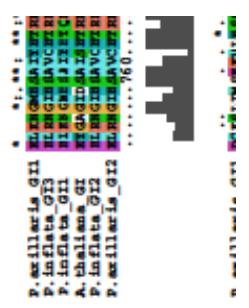



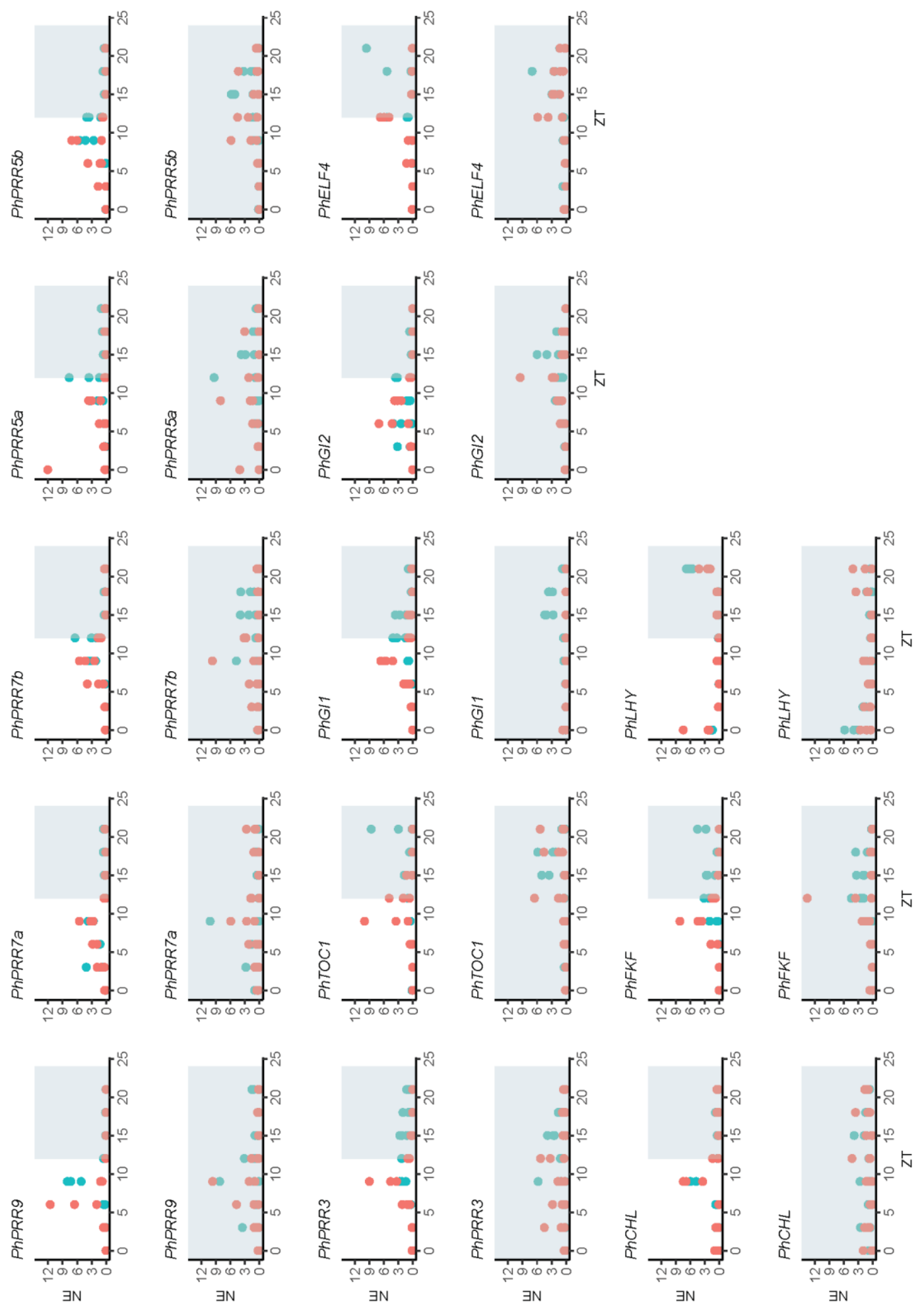

Figure S6. Normalized expression (NE) for biological replicates. Expression of clock genes and associatedgenes in leaves (red dots) and petals (blue dots) under a light:dark (LD) and constant darkness (DD). Gene expression was normalized to PhACT, the value of every single biological replicate is shown here. Grey areas indicate dark periods. ZT denotes zeitgeber time. 
Table S1: PSEUDO-RESPONSE REGULATORS (PRRs) accessions.

\begin{tabular}{|c|c|c|}
\hline Species & Protein & Accession \\
\hline \multirow[t]{3}{*}{ Antirrhinum majus } & PRR5 & Am07g14220 \\
\hline & PRR7 & Am07g35120 \\
\hline & TOC1 & Am01g23590 \\
\hline \multirow[t]{5}{*}{ Arabidopsis thaliana } & PRR3 & AT5G60100.2 \\
\hline & PRR5 & NP_568446.2 \\
\hline & PRR7 & AT5G02810.1 \\
\hline & PRR9 & AT2G46790 \\
\hline & TOC1 & AT5G61380.1 \\
\hline \multirow[t]{4}{*}{ Amborella trichopoda } & PRR37 & XP_006828277.1 \\
\hline & PRR73 & XP_020529326.1 \\
\hline & PRR9 & XP_011629028.1 \\
\hline & TOC1 & XP_011625651.1 \\
\hline \multirow[t]{4}{*}{ Capsicum annuum } & PRR5 & CA03g21230 \\
\hline & PRR9 & CA10g05550 \\
\hline & PRR7 & CA10g11870 \\
\hline & TOC1 & CA03g29830 \\
\hline \multirow{10}{*}{$\begin{array}{l}\text { Nicotiana attenuata } \\
\text { N. benthamiana }\end{array}$} & TOC1 & XP19229967 \\
\hline & PRR3a & Niben101Scf05009g04012.1 \\
\hline & PRR5a & Niben101Scf00225g05002.1 \\
\hline & PRR5b & Niben101Scf01109g04021.1 \\
\hline & PRR7a & Niben101Scf00294g03009.1 \\
\hline & PRR7b & Niben101Scf01994g01007.1 \\
\hline & PRR9a & Niben101Scf11670g02004.1 \\
\hline & PRR9b & Niben101Scf02026g04007.1 \\
\hline & TOC1a & Niben101Scf11469g00017.1 \\
\hline & TOC1b & Niben101Scf00063g06009.1 \\
\hline \multirow[t]{4}{*}{ N. sylvestris } & PRR3 & gi|698444565| \\
\hline & PRR5 & gi|698515802| \\
\hline & PRR7 & gi|698585162| \\
\hline & TOC1 & XP_009791525.1 \\
\hline \multirow[t]{6}{*}{ N. tomentosiformis } & PRR3a & gi|̄697159824| \\
\hline & PRR5a & XP_018627531.1 \\
\hline & PRR5b & gi|697192415| \\
\hline & PRR7 & gi|697100515| \\
\hline & PRR9 & mRNA_36525_cds \\
\hline & TOC1 & gi|697126282| \\
\hline \multirow{7}{*}{ Petunia axillaris } & PRR37 & Peaxi162Scf01024g00009.1 \\
\hline & PRR5b & Peaxi162Scf00912g00022.1 \\
\hline & PRR5a & Peaxi162Scf00542g03011.1 \\
\hline & PRR7a & Peaxi162Scf01517g00133.1 \\
\hline & PRR7b & Peaxi162Scf00146g01328.1 \\
\hline & PRR9 & Peaxi162Scf00313g00210.1 \\
\hline & TOC1 & Peaxi12Scf00274g00351.1 \\
\hline \multirow{6}{*}{ P. inflata } & PRR3 & Peinf101Scf02768g00025.1 \\
\hline & PRR5a & Peinf101Scf00223g03002.1 \\
\hline & PRR5b & Peinf101Scf01482g12029.1 \\
\hline & PRR7a & Peinf101Scf00931g05033.1 \\
\hline & PRR7b & Peinf101Scf00756g02019.1 \\
\hline & PRR9 & Peinf101Scf00559g10011.1 \\
\hline
\end{tabular}




\begin{tabular}{ccc}
\hline & TOC1 & Peinf101Scf01556g09043.1 \\
Physcomitrella patens & PRR37 & XP_024364994.1 \\
Solanum lycopersicum & PRR3 & Solyc04g049670.2 \\
& PRR5 & Solyc03g081240.2 \\
& PRR7 & Solyc10g086000.1 \\
& PRR9 & Solyc10g005030.2 \\
& TOC1 & Solyc03g115770.2 \\
S. tuberosum & PRR5 & PGSC0003DMP400001175 \\
& PRR7 & PGSC0003DMP400001175 \\
Vitis vinifera & PRR9 & XP_006352628 \\
& TOC1 & GSVIVG01007965001 \\
& PRR3 & GSVIVT01025088001 \\
& PRR5 & GSVIVG01027443001 \\
& PRR7 & GSVIVG01032644001 \\
& PRR9 & GSVIVT01038647001 \\
\hline
\end{tabular}


Table S2: GIGANTEA (GI) protein accessions used in the phylogenetic reconstruction.

\begin{tabular}{|c|c|c|}
\hline Species & Protein & Accession \\
\hline Arabidopsis thaliana & GI & AAT80910.1 \\
\hline Amborella trichopoda & GI & PRGDB24499 \\
\hline Antirrhinum majus & GI & Am06g07460.P03 \\
\hline Brachypodium distachyon & GI & XP_003564357.1 \\
\hline \multirow[t]{2}{*}{ Cicer arietinum } & GI1 & XP_004496435.1 \\
\hline & GI2 & XP_004496436.1 \\
\hline Fragaria vesca & GI & XP_004290483.1 \\
\hline \multirow[t]{3}{*}{ Glycine max } & GI1 & BAJ22595.1 \\
\hline & GI2 & BAN82589.1 \\
\hline & GI3 & ACA24490.1 \\
\hline Marchantia polymorpha & GI & Mapoly0019s0145.1 \\
\hline Medicago truncatula & GI & XP_003592048.2 \\
\hline \multirow[t]{4}{*}{ Nicotiana benthamiana } & GI1 & NbS00010804g0011.1 \\
\hline & GI2 & NbS00006512g0008.1 \\
\hline & GI3 & Niben101Scf09649g01002.1 \\
\hline & GI4 & NbS00010805g0006.1 \\
\hline Oryza sativa & GI & XP_015649578.1 \\
\hline Panicum hallii & GI & Pahal.E04224.2 \\
\hline \multirow[t]{2}{*}{ Petunia axillaris } & GI1 & Peaxi162Scf00360g00418.1 \\
\hline & GI2 & Peaxi162Scf00160g01744.1 \\
\hline \multirow[t]{3}{*}{ P.inflata } & GI1 & Peinf101Scf00386g02019.1 \\
\hline & GI2 & Peinf101Scf02877g01057.1 \\
\hline & GI3 & Peinf101Scf02652g00046.1 \\
\hline Pisum sativum & GI & ABP81863.1 \\
\hline Selaginella moellendorffii & GI & XP_024528715.1 \\
\hline Setaria italica & GI & Seita.5G129500.1 \\
\hline S.viridis & GI & Sevir.5G127000.1 \\
\hline \multirow[t]{2}{*}{ Solanum lycopersicum } & GI1 & Solyc04g071990.2.1 \\
\hline & GI2 & Solyc12g056650.1.1 \\
\hline S.tuberosum & GI & XP_006359039.1 \\
\hline Triticum aestivum & GI3 & AAT79487.1 \\
\hline Vigna radiata & GI & XP_014514153.1 \\
\hline V.unguiculata & GI & Vun_T01130.1_6 \\
\hline Vitis vinifera & GI & XP_010665061.1 \\
\hline \multirow[t]{2}{*}{ Zea mays } & GI1 & GRMZMM2G107101_T03 \\
\hline & GI2 & GRMZM5G844173_T01 \\
\hline
\end{tabular}


Table S3: Primers used for qPCR.

\begin{tabular}{ccc}
\hline Gene & Forward primer & Reverse primer \\
\hline$P h C H L$ & TGCATCTGTTGGCTCTGTTT & CCCCAACCCAATCTCTTAGC \\
$P h F K F$ & CTGGGCAACCTCCAAAGTT & CATGGATCAGAATCTTGTTTGCT \\
$P h G I 1$ & TGGAGAAAGGGCAGAGACAT & GTGGAGCCACCCTTACGTT \\
$P h G I 2$ & TTTAGAGTCCTTTCACTCATCCATC & AATACAGCATTTGTTACATGGAGGT \\
$P h L H Y$ & CGACGTGGTAGGAATTGCATC & GCAAGAAATGGTCATCAAAGGAC \\
$P h P R R 3$ & GTGGAAGTGGTGATCGCTCT & TCCATCCTGACGCACAAAT \\
$P h P R R 5 a$ & CCAATGATGCCCATCTTCAT & ACGCTGCTCTGCAAGTTGTT \\
$P h P R R 5 b$ & GGAACTCCCATCGATCTCAA & GGAGCCTCACTAGGTAATTGACG \\
$P h P R R 7 a$ & CAGAAGAGGAAGGAGCGATG & AGGGAAAGTAGGAAGGAAAGCA \\
$P h P R R 7 b$ & AGGTGCAAATGCGGAAAGT & AGCATCTATCTTTCTTCTTGTGACG \\
$P h P R R 9$ & GAGCTCATGTTTCCGAGAGC & GGTCGCTGTTCTGCAAGTCT \\
$P h T O C 1$ & TGATGGTAAGGGGAGCAAAG & CTGAAGCAGGATGCCCATTA \\
$P h A C T$ & TGCACTCCCACATGCTATCCT & TCAGCCGAAGTGGTGAAAGAG \\
\hline
\end{tabular}




Chapter II: The Petunia CHANEL Gene is a ZEITLUPE Ortholog Coordinating Growth and Scent Profiles. 



\section{Graphical abstract} - Genes and proteins identification $\begin{aligned} & \text { P.axillaris GII THYNRPVYRAVHRDGGADRSSRGSI } \\ & \text { P.inflata GI } 3\end{aligned}$ (Arabidopsis as query sequence) P. inflata GI

Primer design

- Phylogeny

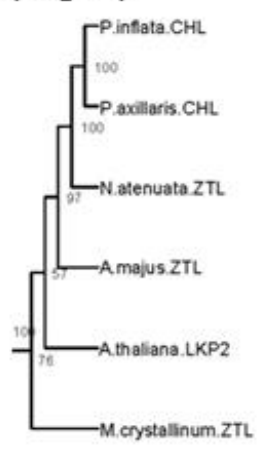

P.inflata GI2 P.axillaris GI2

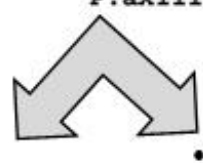

- Silencing target gene. Petunia

transformation: pHELLSGATE12

THYNRPLFKVDRQDKGADRSTSGS

- Petunia: growth and acclimation (light:dark)

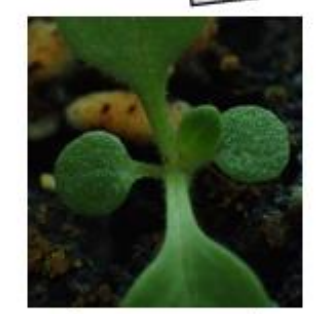

- Sampling: leaves and petals (time course)

- DNA for PCR (OMGs identification)

- RNA for qPCR: validation of reference genes and gene expression

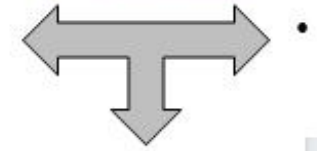

- Phenotype

- Growth
THYNRPVYKAVHRDIGADRSSRGSI

HYNRP I YKTBQQNGDTERN - CLSI

THYNRPLFKVDRQDKGGDRSTSGSS

.....160.....170....170.

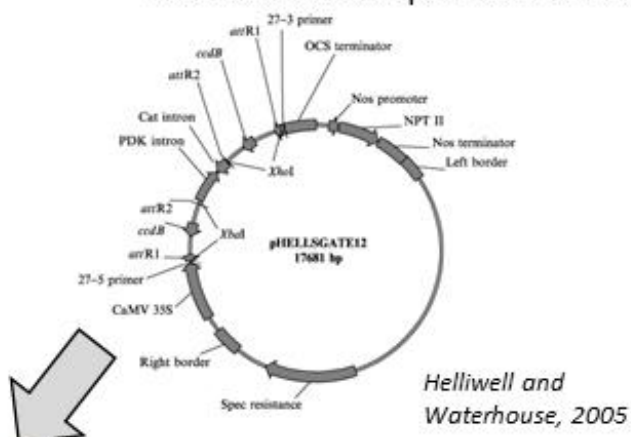

Waterhouse, 2005

Collection and identification of volatiles (time course)

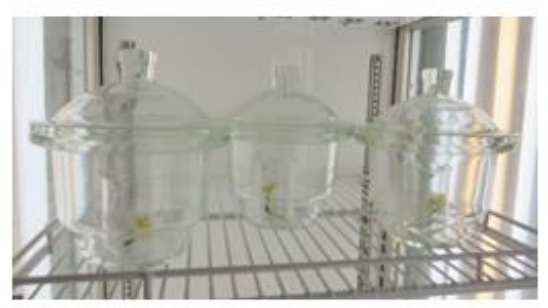


Chapter II - 96 


\title{
cells
}

Article

\section{The Petunia CHANEL Gene is a ZEITLUPE Ortholog Coordinating Growth and Scent Profiles}

\author{
by Marta I. Terry ${ }^{1}$, Fernando Pérez-Sanz ${ }^{2}$, M. Victoria Díaz-Galián ${ }^{1}$, Felipe Pérez de los Cobos $^{3}$, \\ Pedro J. Navarro ${ }^{4}$, Marcos Egea-Cortines ${ }^{1}$ and Julia Weiss ${ }^{1, *}$ \\ ${ }^{1}$ Genética Molecular, Instituto de Biotecnología Vegetal, Edificio I+D+I, Plaza del Hospital s/n, \\ Universidad Politécnica de Cartagena, 30202 Cartagena, Spain \\ ${ }^{2}$ Biomedical Informatic and Bioinformatic Platform, Biomedical Research Institute of Murcia, \\ University Clinical Hospital 'Virgen de la Arrixaca', University of Murcia, 30120 Murcia, Spain \\ ${ }^{3}$ Plant Breeding Department, Center of Edafology and Applied Biology of Segura-High Council \\ for Scientific Research (CEBAS-CSIC), Espinardo University Campus, Espinardo, 30100 Murcia, \\ Spain \\ ${ }^{4}$ Escuela Técnica Superior de Ingeniería de Telecomunicación (DSIE), Campus Muralla del Mar, \\ s/n., Universidad Politécnica de Cartagena, 30202 Cartagena, Spain \\ ${ }^{*}$ Author to whom correspondence should be addressed.
}

Received: 4 March 2019 / Accepted: 9 April 2019 / Published: 11 April 2019

\begin{abstract}
:
The floral perianth, comprising sepals and petals, conceals the sexual organs and attracts pollinators. The coordination of growth and scent emission is not fully understood. We have analyzed the effect of knocking down CHANEL (PhCHL), the ZEITLUPE ortholog in petunia $(P h C H L)$ by hairpin RNAs. Plants with low PhCHL mRNA had overall decreased size. Growth evaluation using time lapse image analysis showed that early leaf movement was not affected by RNAi:PhCHL, but flower angle movement was modified, moving earlier during the day in knockdown plants than in wild types. Despite differences in stem length, growth rate was not significantly affected by loss of $P h C H L$. In contrast, petal growth displayed lower growth rate in RNAi:PhCHL. Decreased levels of PhCHL caused strongly modified scent profiles, including changes in composition and timing of emission resulting in volatile profiles highly divergent from the wild type. Our results show a role of $P h C H L$ in controlling growth and development of vegetative and reproductive organs in petunia. The different effects of $P h C H L$ on organ development indicate an organ-specific interpretation of the down regulation of $P h C H L$. Through the control of both timing and quantitative volatile emissions, $P h C H L$ appears to be a major coordinator of scent profiles.
\end{abstract}

Keywords: floral scent; petal development; growth rate; phenomics; circadian clock; ZEITLUPE; image analysis; hairpin RNA 


\section{Introduction}

Plant aerial organs grow from lateral primordia that form in the shoot apical meristem [1]. The type of organs produced, i.e., leaves or flowers, are the result of a vegetative or reproductive developmental program. The formation of flowers is the result of the activation of the so-called floral organ identity genes. They comprise a set of MADS-BOX proteins that in a combinatorial fashion allow the formation of the different organs [2]. The interaction of different MADS-box proteins occur via formation of protein complexes that activate the different organ identity programs leading to the formation of sepals and petals in the perianth and stamens and carpels $[3,4]$.

Floral organs play an important role in reproductive success in many plants. Proper floral size is a key component of flower-pollinator interaction [5]. Floral size, like in leaves, is controlled by coordinated cell division and expansion processes [6]. The genes controlling lateral organ size appear to be conserved. Indeed, general regulators of lateral growth such as AINTEGUMENTA control floral size in Arabidopsis, petunia, Antirrhinum and tobacco [7,8,9].

During late flower development and maturation there is a major transcriptional reprogramming and scent emission starts with flower opening $[10,11]$. Scent emission takes place when the floral organ identity genes are not fully active, indicating a quantitative effect of the DEFICIENS/GLOBOSA MADS box proteins and downstream factors on scent emission [11].

There are a large number of plants that emit floral volatiles with significantly larger outputs during the day or during the night $[12,13,14,15,16]$, suggesting a circadian regulation of scent emission. The circadian clock genes LATE ELONGATED HYPOCOTYL in petunia (PhLHY) and NaLHY and ZEITLUPE (NaZTL) in Nicotiana attenuata have been investigated and control the timing of emission of methyl benzoate and benzyl benzoate in petunia and benzyl acetone in $\mathrm{N}$. attenuata $[17,18]$. Thus, a default pathway controlled by petal identity may activate floral scent emission, and the fine tuning in terms of emission timing should be regulated by the clock. However, this emerging hypothesis requires further experimental support; the studies mentioned have analyzed a small number of volatile organic compounds (VOCs), but the effect, if any, of the circadian clock on scent profiles is not known.

In this work, we have analyzed the down-regulation of the petunia gene ortholog of ZTL and its effect on growth and scent emission. We found that PhZTL plays a differential role in stem and floral size and is a major coordinator of floral scent profiles in petunia. As a result, we named the gene CHANEL (PhCHL).

\section{Materials and Methods}

\section{Gene Identification and Phylogenetic Analysis}

We identified ZTL orthologs and paralogs in the Petunia genome using BLAST [19]. The identified scaffolds and cDNAs were used to confirm the genome annotation using Genewise [20]. Protein alignment was performed with CLUSTALX [21]. Phylogenetic analysis was performed with the $\mathrm{R}$ libraries ape and phangorn [22,23], using the Maximum Likelihood as statistical method, JTT (Jones, Taylor and Thornton) as model of amino acid substitution, and 1000 bootstrap replicates. Trees were visualized and annotated with ggtree [24] using R, ( $R$ version 3.5.1). Protein accessions are listed in Table S1. 


\section{Silencing of PhCHL}

We obtained sequence information from the genomic clone of PhCHL (Peaxi162Scf01124g00126.1) found in W115 (or Mitchell) and amplified 255 bp encompassing the last nine coding codons and 3'untranslated region. As the major effect of silencing of ZTL in petunia was a major disruption of scent profiles, we called it CHANEL, a famous perfume. The specific sequence of $P h C H L$ was:

$>\mathrm{PhCHL}$

TGAACTATCTTTAGCAAGCTCTGTCATTTGAATAAAGAAAAAAGTAATGATGAAGAGAAGGTGTTGTGC AGTATTCATAATGAAAATTTTGCCTCAAGAATAAAGAGAGTCCCGAGCAAACTATTGCAGTGCGGTTTT TGCATTGCACCAAATGCATAAATGACTAGCAAGTACCTGTGAGTTAGTGGCTGTCTTGTTTATTCTTGTG TGGCTCATATGCCATGGTGAGCAAATGGTCCTATTGAGCAGATGGTC

We used primers, introducing a partial attb1 and attb2 recombination site for GATEWAY cloning using PhCHLrnaiaattb1 and PhCHLrnaiattb2 (Table S2). We performed a second PCR using attb1 and attb2 to add the corresponding sequences for recombination. The amplified fragment was recombined into pDONR221 and into the GATEWAY vector pHELLSGATE12 to obtain a hairpin construct [25]. The pHELLSGATE12 drives the hairpin construct using a standard 35S promoter. The W115 Mitchell double haploid was transformed as described previously [7].

Transformed plants were identified by PCR with primers amplifying NPTII. The completeness of the construct was tested with the Agri 51 and Agri 56 primers [26] (see Table S2). The PCR conditions were $3 \mathrm{~min}$ at $95^{\circ} \mathrm{C}$ followed by 35 cycles of $15 \mathrm{~s}$ at $95^{\circ} \mathrm{C}, 15 \mathrm{~s}$ at $55^{\circ} \mathrm{C}$ and $15 \mathrm{~s}$ at 72 ${ }^{\circ} \mathrm{C}$, and terminated by $5 \mathrm{~min}$ at $72{ }^{\circ} \mathrm{C}$ (Kapa Biosistems). The PCR reactions were loaded on $1 \%$ agarose gel containing ethydium bromide. PCR products from $\mathrm{T} 2$ plants were purified and sequenced.

\section{Plant Growth Conditions and Sampling}

Petunia plants were grown using a commercial substrate in a greenhouse under natural conditions. All experiments were conducted with at least three biological replicates. To study the expression of $P h C H L$, non-transgenic siblings and two independent RNAi:PhCHL T2 lines (RNAi:PhCHL3 and RNAi:PhCHL10) were transferred to a climate chamber with $12 \mathrm{~h}$ of light and $12 \mathrm{~h}$ of dark (12LD) or 8L:16D and $23^{\circ} \mathrm{C}$ and $18^{\circ} \mathrm{C}$ for day and night, respectively. Plants were acclimated for 4-5 days. Young leaves and petals from 2-3 day-old flowers were sampled every three $\mathrm{h}$ for $24 \mathrm{~h}$; tissues were immediately frozen in liquid nitrogen and stored at $-80{ }^{\circ} \mathrm{C}$ until further analysis.

To analyze the floral scent of non-transgenic and transgenic petunia flowers, we took at least three biological replicates of 2-3 day-old flowers (one flower per plant) every three $\mathrm{h}$.

\section{Housekeeping Genes and Gene Expression Analysis by qPCR}

RNA was extracted from three biological replicates per time point of leaves and corollas using acid phenol [27]. Concentrations were measured using NanoDrop (Thermo-Fisher). Equal amounts of total RNA were used to obtain cDNA using Maxima kits (Thermo-Fisher) according to the user manual.

Previously, we performed a study to validate the housekeeping gene or genes, in two tissue samples, petal and leaf, for time course studies according to [28]. The candidate genes were ACTIN 11 (ACT), CYCLOPHILIN (CYP), ELONGATION FACTOR 1 $\alpha$ (EF1 $\alpha)$, GLYCALDEHYDE- 
3-PHOSPHATE DEHYDROGENASE (GADPH), RIBOSOMAL PROTEIN S13 (RPS13), GTPNUCLEAR BINDING PROTEIN (RAN1) and POLYUBIQUITIN (UBQ) (Table S2). PCR analysis was performed as described previously [28]. The following protocol was used for 40 cycles: $95^{\circ} \mathrm{C}$ for $5 \mathrm{~s}, 60^{\circ} \mathrm{C}$ for $20 \mathrm{~s}$ and $72{ }^{\circ} \mathrm{C}$ for $15 \mathrm{~s}$ (Clontech SYBR Green Master Mix and Mx3000P qPCR Systems, Agilent Technologies), samples were run in duplicate. Cycle threshold (Ct) values were analyzed by BestKeeper [29], NormFinder [30], geNorm [31] and comparative $\Delta \mathrm{Ct}$ methods [32] implemented in the web-based tool RefFinder [33] at different time points (Figure S1).

Analyzing all tissues, the most stable genes were $\mathrm{PhCYP}$ and $\mathrm{PhEF1} \alpha$ (Figure S2A). Moreover, for individual tissues, results were slightly different: the best genes for normalization in leaves were $P h A C T$ and $P h E F 1 \alpha$, and for petals, PhACT and PhCYP (Figure S2B,C).

We used $P h A C T$ to normalize the expression of clock genes in petunia leaves and petals as described [34]. Normalized expression was calculated as described [34] using the REST program [29] and PhACT as internal control gene.

Primers for circadian clock genes were designed using pcrEfficiency [35] (Table S2) and the following protocol was used for 40 cycles: $95^{\circ} \mathrm{C}$ for $5 \mathrm{~s}, 60^{\circ} \mathrm{C}$ for $20 \mathrm{~s}$ and $72{ }^{\circ} \mathrm{C}$ for $15 \mathrm{~s}$. Samples were run in duplicate. Primer combinations were tested with genomic DNA from Mitchell, and we found that all of them gave a single copy DNA on agarose gels. The endpoint PCR was further verified by melting point analysis where all primer combinations gave a single peak of melting (Figure S3).

\section{Image Acquisition}

We used an image acquisition system described previously [36]. Plants were grown inside a growth chamber comprising LED lights covering from UV to red light. Day and night images were taken by activating an Infrared light at $840 \mathrm{~nm}$ wavelength during short intervals of time (3 s). Images were acquired every ten minutes with an artificial vision camera comprising two CCD sensors, a multichannel 24-bit RGB absorbing at $610 \mathrm{~nm}, 540 \mathrm{~nm}$ and $460 \mathrm{~nm}$, and a monochromatic sensor capturing at $800 \mathrm{~nm}$. The acquired images have a resolution of $1296 \times 966$ pixels.

We obtained data using transgenic lines and compared them to the segregating siblings. Leaf growth and movement in seedlings was recorded for a period of 12 days with a total of 1728 images. Stem and flower growth was recorded for a period of 5 days and $16 \mathrm{~h}$ for line 3 and 3 days for line 10, for a total of 822 images and 432 images respectively. Using a semi-automatic procedure, we measured the length and angle of the longitudinal axis as referred to the horizontal plane of the flowers, as well as the length of the stem. The acquisition intervals were 1 hour for line 3 and $2 \mathrm{~h}$ for line 10, to explore differences in flower and stem growth patterns between wildtype and transgenic individuals. Analysis of growth was performed using the R package grofit [37]. Graphics were done using the color-blind friendly palette.

\section{Scent Analysis}

Flowers were placed in a glass beaker with a solution $4 \%$ of glucose inside a desiccator. Emitted volatiles were collected with twisters from the headspace every three $h$ and analyzed by GM/CS as described [16]. Total and relative amounts were calculated using total integrated area divided by fresh weight as described before [38]. Detection of rhythmic scent emission was performed 
using the JTK_CYCLE algorithm [39] implemented in the R package MetaCycle [40]. Scent profile figures were plotted using the $\mathrm{R}$ library ggplot2 [41], using color palettes providing by the package viridis [42].

\section{Results}

\section{The Petunia Genomes Have a Single ZTL Gene}

We mined the petunia genomes to identify ZEITLUPE/FLAVIN-BINDING KELCH REPEAT F$B O X$ (ZTL/FKF) orthologs and paralogs using BLAST. We found two genes with homology to the Arabidopsis genome in P. axillaris: Peaxi162Scf01124g00126.1 and Peaxi162Scf00655g00114.1; and three in P. inflata: Peinf101Scf01230g02037.1, Peinf101Scf02808g00015.1 and Peinf101Scf04186g00007.1 (Table S3).

We performed a phylogenetic reconstruction of the genes found in petunia and compared them to the LOV-F-box-KELCH proteins from several monocots, dicots and the basal plant Marchantia polymorpha (Figure S4). As previously mentioned, the silencing of $\mathrm{PhCHL}$ caused a major change in the composition of floral scent. Thus, we named the gene CHANEL (PhCHL) (see below).

The phylogenetic reconstruction shows two major clades, one containing all the $F K F$-like genes and a second one comprising the ZTL and the Arabidopsis LOV KELCH PROTEIN2 (LKP2). In both clades, two subclades separate monocots from dicots. The Marchantia FKF like gene [43] falls somewhere between the FKF group of coding genes and the ZTL coding set of genes. The genomes of $P$. axillaris and $P$. inflata appear to have one gene corresponding to $P h C H L$, but differ in the copy number of $F K F$ that is found in two copies in P. inflata. According to the ancestral region by gene analysis of Petunia hybrida W115, the ZTL-FKF genes present in P. hybrida correspond to P. axillaris [19]. Thus, based on the phylogenetic reconstruction, we identified Peaxi162Scf01124g00126.1 as PhCHL and Peaxi162Scf00655g00114.1 as PhFKF.

\section{The Expression of PhCHL is Organ Specific and Affected by Day Length}

The PhCHL expression has been studied in leaves and seedlings of Nicotiana attenuata and Arabidopsis $[17,44,45]$. In these plants and tissues, $P h C H L$ does not show rhythmic expression. We determined the set of reference genes for circadian expression in leaves and petals in order to establish the circadian gene expression patterns in petunia (see Materials and Methods). We analyzed the expression of $P h C H L$ in petunia corolla using a 12:12 LD light regime and found that the expression had its maximum at ZT9 (Figure 1A). We found that the expression at ZT9 was significantly higher, and the lowest expression occurred at ZT15. Although the expression of $\mathrm{PhCHL}$ in corollas showed a peak at ZT9, the mathematical analysis for circadian oscillation using the JTK_CYCLE algorithm indicated that the expression of PhCHL in petunia corollas was not rhythmic $(\mathrm{p}=1)$. We also analyzed the expression of $\mathrm{PhCHL}$ in leaves and the pattern was similar to corollas: PhCHL increased at ZT9 (Figure 1A), and its expression was not rhythmic $(\mathrm{p}=1)$. Under short days (8L:16D), the expression of $\mathrm{PhCHL}$ in leaves reached its maximum at midnight (ZT17) while the maximum expression in petals was detected during the afternoon (ZT5) (Figure 1B). As observed under 12L:12D, PhCHL did not display a rhythmic expression either in leaves or petals $(\mathrm{p}>0.05)$. 

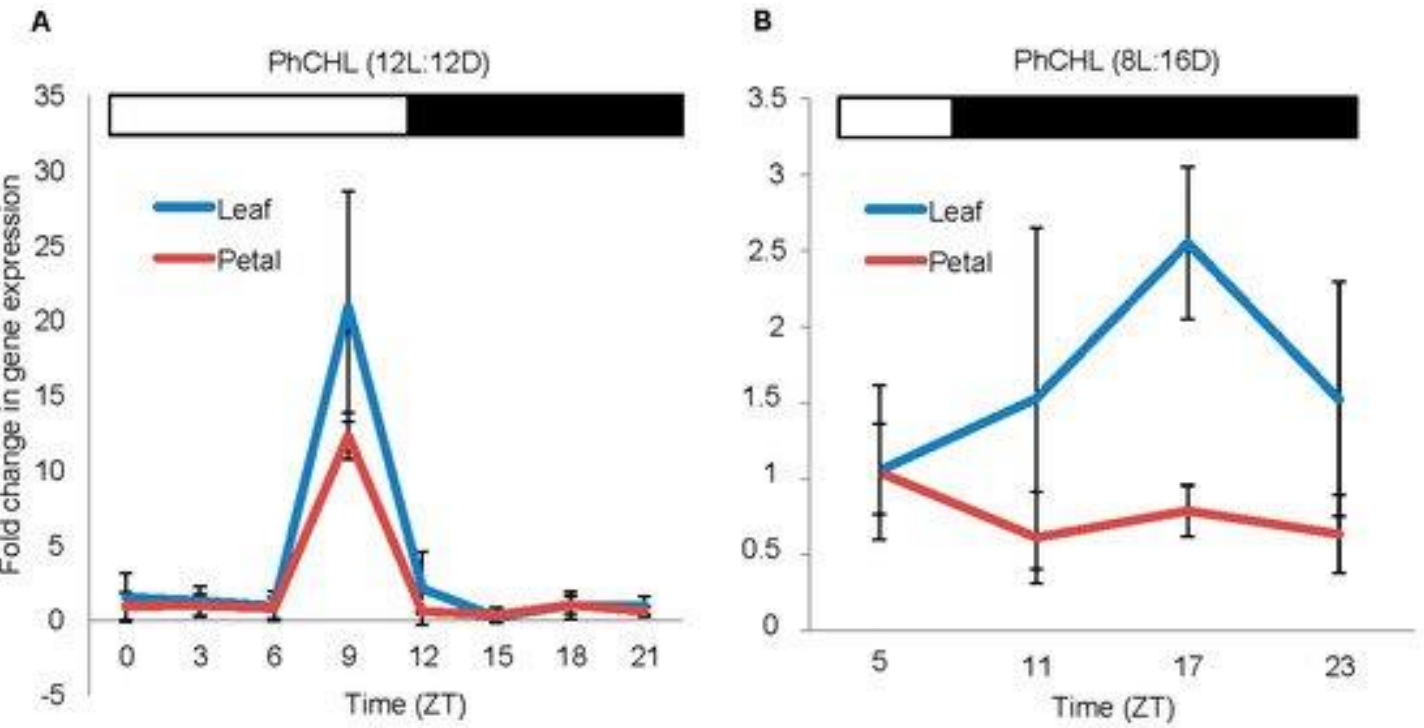

Figure 1: PhCHL expression in W115 petunia under 12LD (A) and 8L16D cycle (B) in leaves (blue line) and petals (red line) revealed a different pattern depending on light conditions. The maximum expression ocurred before the dark period (ZT9) in leaves and petals under a 12LD cycle (A). This maximum was delayed in leaves under short days. PhCHL maintained its peak before dusk in petals (B). Results represent average \pm standard deviation from three replicates. White bar indicates the light period and black bar, the dark period.

\section{Silencing PhCHL Does Not Affect PhFKF}

We knocked down $\mathrm{PhCHL}$ using a RNAi hairpin construct and found significant down regulation of ZTL in several lines. We used two lines for further analysis. RNAi:PhCHL10 showed a down regulation of $80 \%(\mathrm{p}=0.032)$, while RNAi:PhCHL3 showed a downregulation of $68 \%(\mathrm{p}=0.047)$ (Figure 2A). We also analyzed the expression of FLAVIN-BINDING KELCH REPEAT F-BOX 1 (PhFKF), to discard co-silencing of the paralogous genes (ZT5). The expression of PhFKF did not differ significantly between transgenic and non-transgenic petunias (Figure 2B).
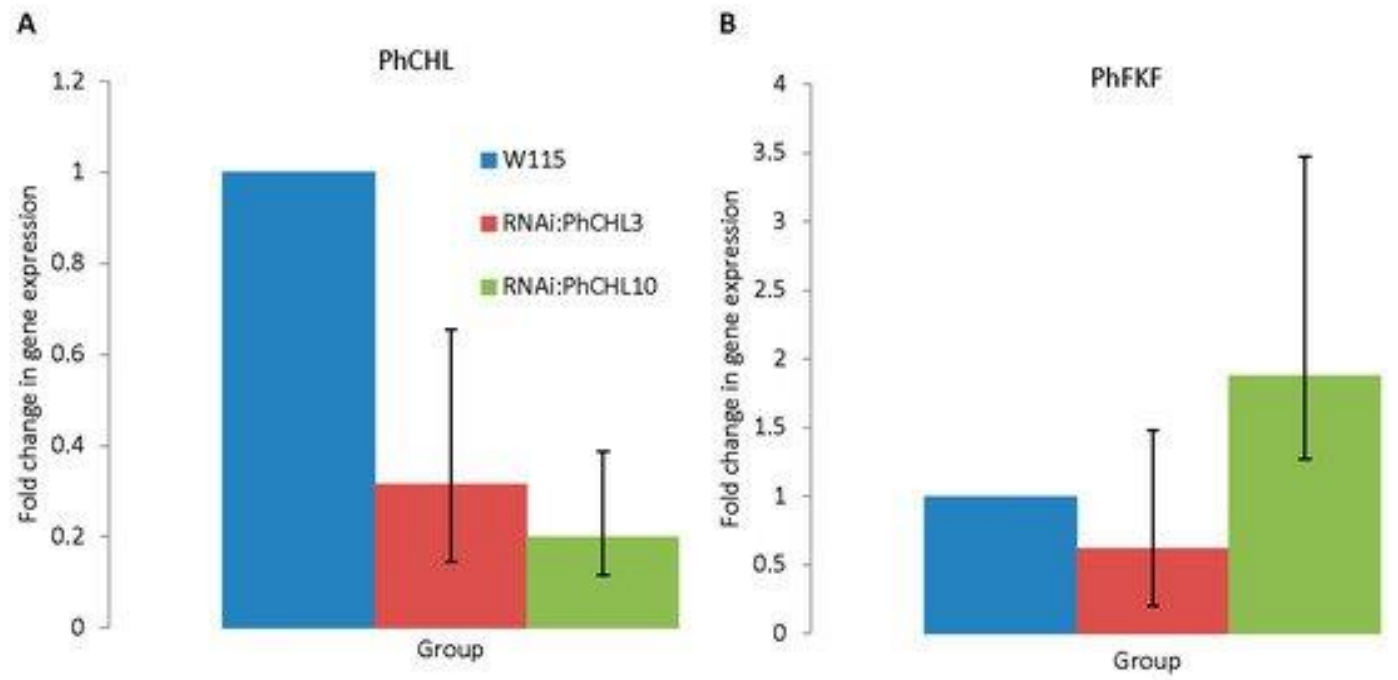

Figure 2: PhCHL (A) and PhFKF (B) expression in wild-type (blue bar) and RNAi:PhCHL plants (red bar and green bar) petals. PhCHL expression was significantly down-regulated in RNAi:PhCHL3 (p = 0.047) and RNAi:PhCHL10 ( $\mathrm{p}=0.032$ ) compared to the wild-type (A). Silencing PhCHL did not affect PhFKF expression RNAi:PhCHL3 ( $p$ value $=0.6)$ RNAi:PhCHL10 $(p$ value $=0.06)(B)$. 


\section{PhCHL Is a Positive Regulator of Lateral Organ Growth}

We quantified the effect of RNAi:PhCHL on plant development and found that while not all parameters analyzed showed statistically significant changes, in general terms, $P h C H L$ appears to play a role in the production of above ground biomass affecting organ size (Table 1). Thus, RNAi:PhCHL plants were significantly shorter than the non-transgenic siblings by roughly $23 \%$. We analyzed floral size by measuring the length of the tube and the maximum expansion of the limb and found that, while the tube length was not always affected, the limb expansion was significantly reduced by RNAi:PhCHL, with size changes in the range of $12-18 \%$ (Table 1). Finally, we did not find differences in chlorophyll content (Table 1) or in the general canopy architecture i.e., number of branches (data not shown).

Table 1: Phenotypic analysis of RNAi:PhCHL lines 3 and 10 and comparison to non-transgenic siblings in T2 generation. Plant height, floral limb and floral tube length were measured from $R N A i$ :PhCHL lines $(3,10)$ and the wild-type W115. Results, in centimeters, represent average \pm standard deviation. p-value $<0.05$ indicates a significant difference between non-transgenic and transgenic plants, significance levels are indicated with one asterisks ( ${ }^{*}$ for $\left.\mathrm{p}<0.05\right)$, two asterisks $\left({ }^{* *}\right.$ for $\mathrm{p}<0.001$ ) and three asterisks $\left({ }^{* *}\right.$ for $\mathrm{p}<$ 0.0001). NS indicates not significant differences.

\begin{tabular}{llllll}
\hline \multirow{2}{*}{ Measure } & \multicolumn{2}{l}{ RNAi:PhCHL } & W115 & p-value \\
& Line 3 & Line 10 & & RNAi:PhCHL3 & RNAi:PhCHL10 \\
\hline Plant height & $25.1 \pm 1.89$ & $21.7 \pm 4.18$ & $37.33 \pm 3.0$ & 0.07 & $0.022^{*}$ \\
Floral limb & $4.37 \pm 0.44$ & $4.76 \pm 0.55$ & $5.38 \pm 0.29$ & $0.00009^{* * *}$ & $0.0038^{* *}$ \\
Floral tube & $4.07 \pm 0.37$ & $4.81 \pm 0.51$ & $4.82 \pm 0.35$ & $0.00055^{* * *}$ & NS \\
Chlorophyll & $39.43 \pm 6.32$ & $36.65 \pm 9.77$ & $39.30 \pm 9.80$ & NS & NS \\
\hline
\end{tabular}

We can conclude that $R N A i: P h C H L$ is a positive regulator of lateral organ size with a pleiotropic effect causing a decrease in shoot and flower size.

\section{PhCHL Is Involved in Flower Angle Changes but Not Leaf Movement}

As size was negatively affected by RNAi:PhCHL (Table 1), we used a phenomics approach with time lapse image acquisition to identify the effects on growth kinetics [46]. We tried to analyze leaf growth in seedlings; however, leaf movement, a trait under light and circadian control, was so extreme that we could not obtain reliable data for growth (Movie S1). Changes in leaf position appeared to correspond to day/night changes. We measured the changes in leaf position every hour for a period of four days. We found that both non-transgenic and transgenic lines had open leaves during the day and closed leaves during the night (Movie S1). The changes in leaf opening and closing, in terms of speed or timing were not affected by the PhCHL expression levels (Figure 3A). Indeed, a mathematical analysis of the period, lag phase and amplitude did not show significant differences between RNAi:PhCHL and wild type (Table S4). 

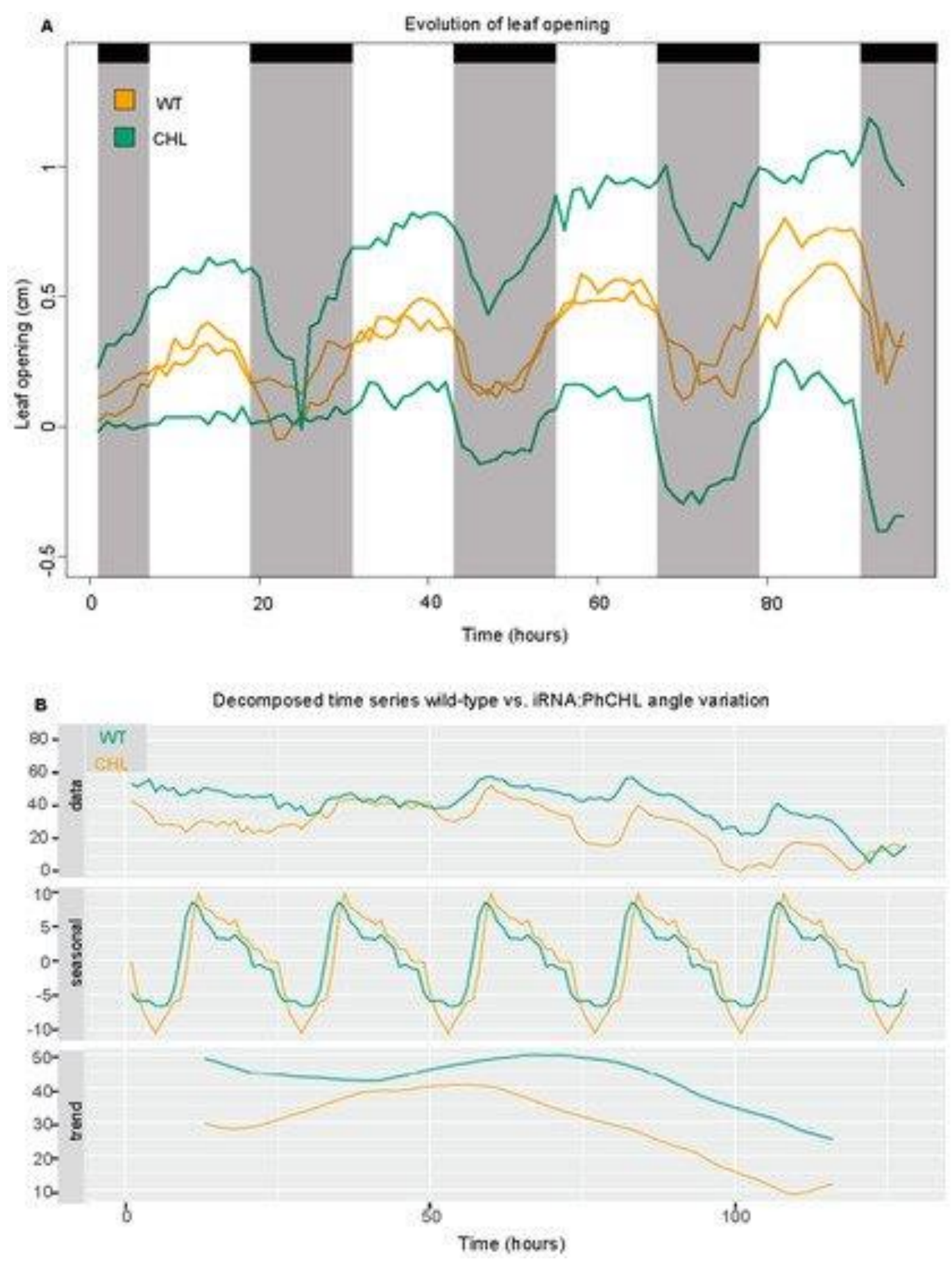

Figure 3: Down regulation of $\mathrm{PhCHL}$ does not affect leaf movement (A). The distance between the center of the plant and the end of each leaf is shown. Furthermore, these data correspond to the distance in the $\mathrm{X}$ axis. Negative values correspond to leaf positions where the tip of the leaf passed the center of the plant. Down regulation of $\mathrm{PhCHL}$ causes increased flower angles and advanced daily changes (green line, B). Orange line represents WT plants, green line represents RNAi:PhCHL plants.

We analyzed flower angle against the horizontal axis, as it is a parameter related to pollination that is regulated by NaZTL in Nicotiana attenuata [17]. Both wild-type and transgenic lines had a similar daily pattern of flower movement; however, RNAi line 3 flowers had always higher 
angles than the non-transgenic siblings. A decomposed time series showed that their daily changes in angle were slightly advanced compared to wild type (Figure 3B).

\section{Differential Effect of PhCHL on Stem and Flower Growth Rate}

The difference in overall plant size indicated a role of $\mathrm{PhCHL}$ in plant growth. We analyzed stem growth and found that growth curves (Table 2) were similar in wild-type and transgenic plants (Figure 4A; Table 2). Still, maximal growth speed in transgenic line 3 was $80.7 \%$ compared to wild type and area under the curve was $82 \%$. The data indicates that stems are shorter because growth occurs during shorter periods of time, but growth speed appears to be less affected in the stem (see discussion).

Table 2: Growth rate of petunia stems and flowers. Maximal growth is expressed in $\mathrm{mm}$. Stems grew from day 0 and total growth refers to size achieved after 5 days and $16 \mathrm{~h}$ taking as reference the stem at time zero. Maximum growth for flowers refers to the same period but comprises the overall floral size. The maximum slope depicts growth rate while the area under the model (integral) gives an estimation of the overall difference in accumulated growth.

\begin{tabular}{llccc}
\hline Group & Rate & $\begin{array}{c}\text { Max.Growth/ } \\
\text { Std.Error }\end{array}$ & $\begin{array}{c}\text { Max.Slope/ } \\
\text { Std.Error }\end{array}$ & $\begin{array}{c}\text { Area under } \\
\text { Model }\end{array}$ \\
\hline WT & Stem growth & $16.084 / 0.142$ & $0.121 / 0.005$ & 1778.3 \\
RNAi:PhCHL & Stem growth & $12.984 / 0.096$ & $0.118 / 0.006$ & 1471.53 \\
WT & Flower growth & $57.698 / 0.403$ & $0.798 / 0.013$ & 3598.88 \\
RNAi:PhCHL & Flower growth & $39.677 / 0.344$ & $0.566 / 0.011$ & 2328.95 \\
\hline
\end{tabular}



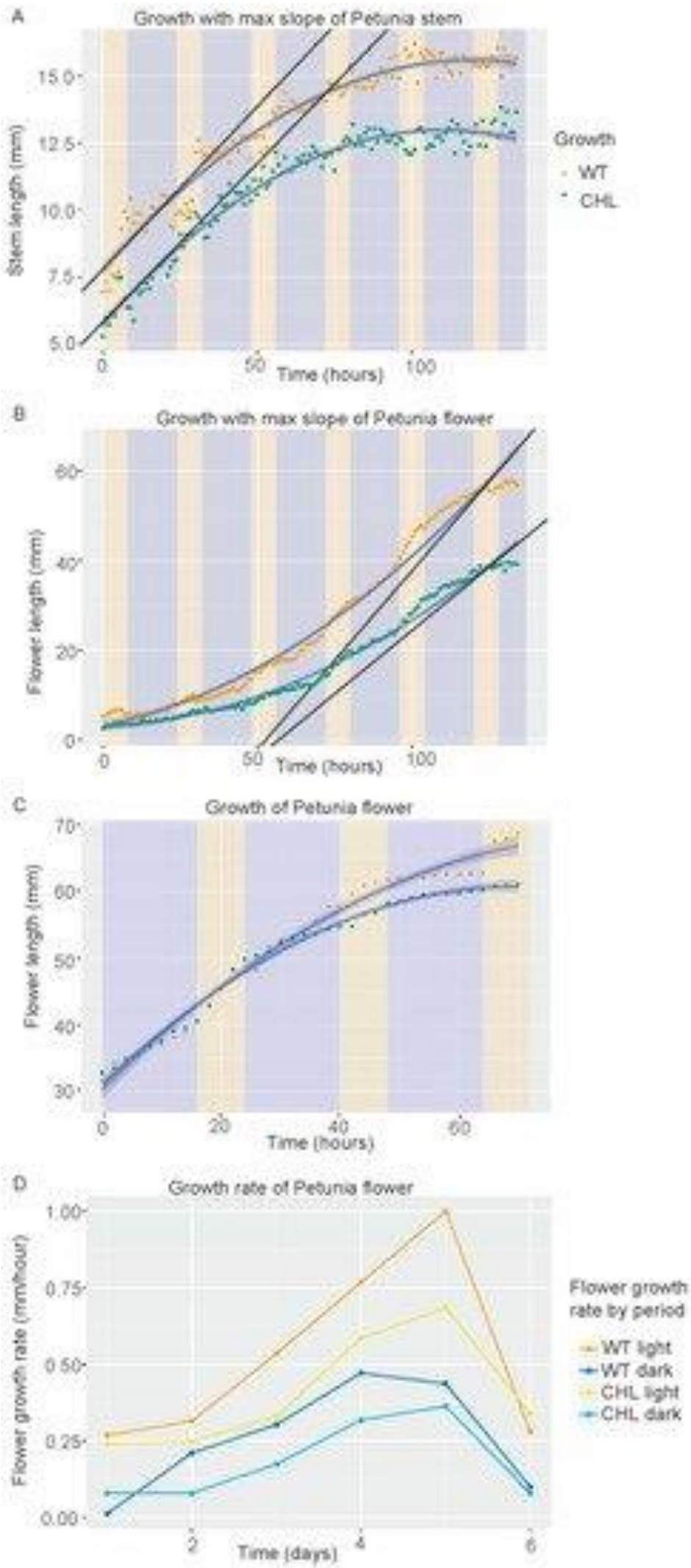

Figure 4: Down regulation of $\mathrm{PhCHL}$ affects growth length in stems (A) and growth rate in flowers (B,C). Graphics show the raw data (points), the adjusted curve and confidence interval (grey shade). Orange line represents WT plants, green line represents RNAi:PhCHL plants. Yellow and blue areas indicated light and dark period, respectively. (D) Flower growth rate by period, day versus night in wild-type and RNAi:PhCHL transgenic lines. 
We analyzed the increase in flower length. Down regulation of $P h C H L$ caused a strong decrease in flower growth speed in line 3 (Movie S2). The wild-type flowers had an overall growth speed that was always higher than in transgenic lines (Figure 4B). We calculated the differences in growth speed and found that the maximal slope indicating growth speed was 1.4-fold higher in wild type compared to transgenic line 3 (Table 2). We analyzed line 10, but due to flowering time differences, we were able to obtain data only from older flowers. These flowers also grew at a lower speed than wild type, but differences were not so pronounced (Movie S3) (Figure 4C).

Growth of hypocotyls in Arabidopsis is gated by the plant circadian clock [47]. We tested the hypothesis that petunia flowers may grow at different speeds during day and night. Indeed, we found that overall flower growth speed was higher during the day than during the night, coming to a sharp decrease in growth speed when flowers open (Figure 4D). The flowers corresponding to RNAi:PhCHL always grew slower than the wild types, but the time required to become fully developed was not affected by PhCHL (Figure 4D). Altogether, our data shows that PhCHL plays a role in organ growth speed and duration that is organ-specific.

\section{PhCHL Coordinates Daily Changes in Scent Profiles}

Petunia flowers emit mostly benzenoids/phenylpropanoids, including methyl benzoate, benzaldehyde and benzyl benzoate [48]. We also identified emission of terpenoids, cadinene and limonene. We selected 17 volatile organic compounds (VOCs) to analyze the effect of PhCHL silencing in volatile emission for a 24-hour period (Table 3). The major VOC emitted by P. hybrida was methyl benzoate $(74.90 \%$ of selected volatiles) whereas cadinene was the volatiles with the lowest emission ( $0.02 \%$ of selected compounds). Methyl benzoate was also the principal emitted volatile in transgenic lines: $79.1 \%$ in RNAi:PhCHL3 and $58.51 \%$ in RNAi:PhCHL10 petunia flowers. The volatile with the lowest emission was acetophenone for RNAi:PhCHL3 $(0.01 \%)$ and cadinene for RNAi:PhCHL10 (0.018\%). Due to the high emission of methyl benzoate in all petunia lines, we analyzed the volatile profile excluding this compound (Figure 5, Figure S5A).

Table 3: Retention time (RT) expressed in minutes, name and CAS number (assigned by the Chemical Abstract Services) of selected volatiles.

\begin{tabular}{ccc}
\hline RT & Name & CAS \\
\hline 4.873 & Benzaldehyde & $100-52-7$ \\
6.435 & Limonene & $138-86-3$ \\
6.539 & Benzyl alcohol & $100-51-6$ \\
6.735 & Phenylacetaldehyde & $122-78-1$ \\
7.230 & Acetophenone & $98-86-2$ \\
7.825 & Methyl benzoate & $93-58-3$ \\
8.149 & Phenylethyl alcohol & $60-12-8$ \\
9.125 & Benzyl acetate & $140-11-4$ \\
9.244 & Ethyl benzoate & $93-89-0$ \\
9.668 & Methyl salicylate & $119-36-8$ \\
10.720 & Phenylethyl acetate & $103-45-7$ \\
12.287 & Eugenol & $97-53-0$ \\
12.711 & Benzyl 2-methylbutyrate & $56423-40-6$ \\
13.587 & Isoeugenol (isomers) & $97-45-1 ; 5932-68-3$ \\
14.254 & Benzyl tiglate & $37526-88-8$ \\
14.625 & Cadinene & $483-76-1$ \\
17.525 & Benzyl benzoate & $120-51-4$ \\
\hline
\end{tabular}



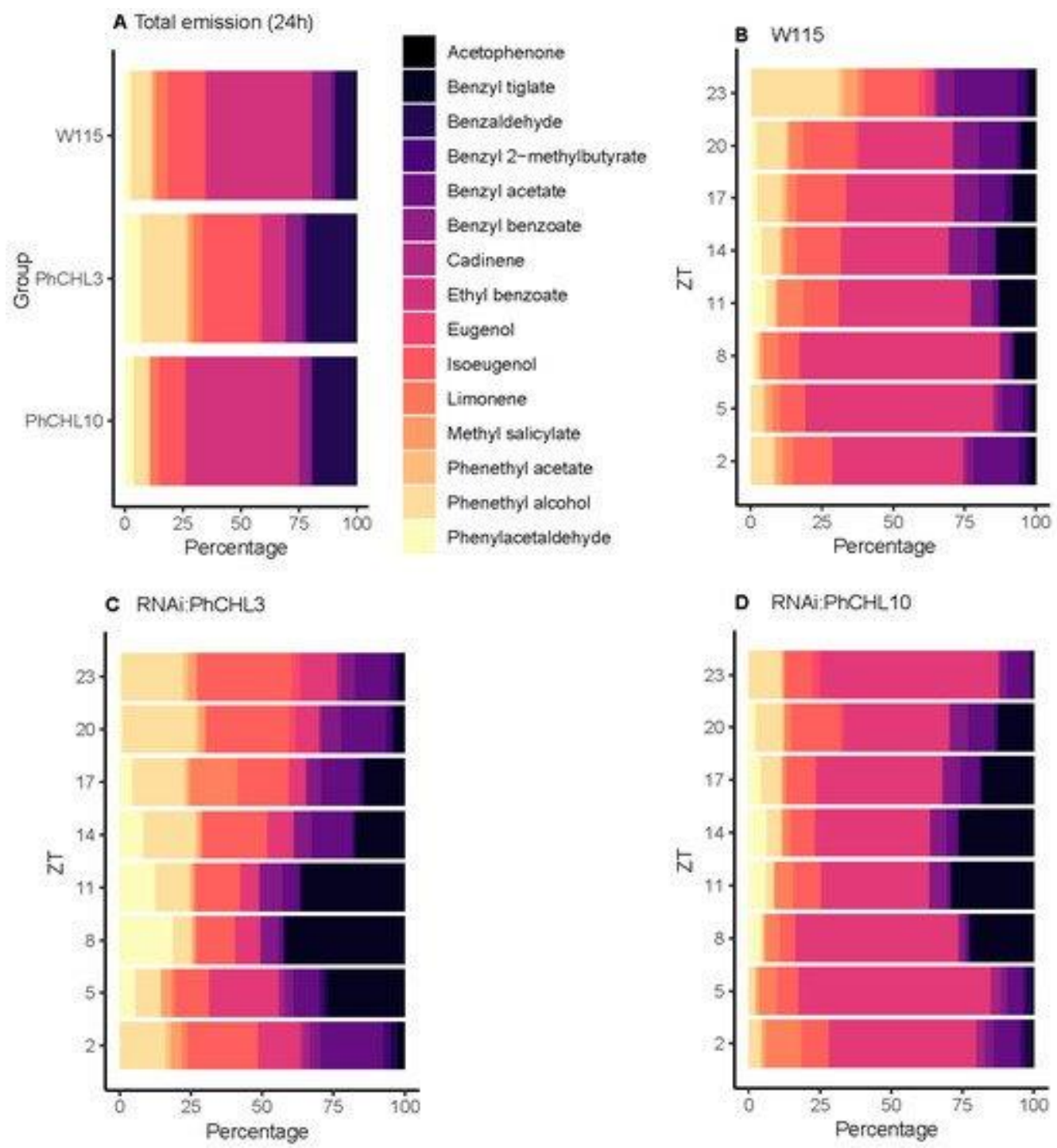

Figure 5: Petunia scent profiles expressed as percentage. Due to its high emission, methyl benzoate was excluded to visualize the remaining volatiles. Profiles were determined for $24 \mathrm{~h}$ emission under a 8L:16D cycle for the wild-type (first bar) and the transgenic lines (second and third bar) (A) and in a time-course (B-D), where each bar represent one sampling point (in ZT h) for wild-type (B), RNAi:PhCHL3 (C) and RNAi:PhCHL10 (D) petunia flowers.

Excluding methyl benzoate (Figure S5A), the second-highest emitted volatile was ethyl benzoate in wild-type petunia and RNAi:PhCHL10 line $(45.72 \%$ and $48.61 \%$ of selected compounds, respectively). In contrast, the emission of ethyl benzoate was lower in RNAi:PhCHL3 (10.23\%) and the second major volatile in this transgenic line was isoeugenol (24.38\%). Isoeugenol represented $15.84 \%$ in wild type and $10.92 \%$ in RNAi:PhCHL10 (Figure 5A). We found that certain volatiles increased their emission in both RNAi:PhCHL lines: benzaldehyde, phenylacetaldehyde, benzyl tiglate and benzyl 2-methylbutyrate (Figure 5A). The volatiles limonene, benzyl benzoate and acetophenone decreased their emission in RNAi:PhCHL3 and RNAi:PhCHL10 petunia flowers (Figure 5A) Finally, the quantities of some emitted volatiles varied among lines; the emission of benzyl acetate, cadinene, methyl salicylate, phenethyl acetate and phenethyl alcohol was higher 
in RNAi:PhCHL3, whereas the quantities of these compounds decreased in the RNAi:PhCHL10 line (Figure 5A).

As the quantitative changes in scent could occur at different times of the day, we collected scent every three $\mathrm{h}$ in an 8L:16D cycle. The profile analysis of floral compounds throughout $24 \mathrm{~h}$ revealed modifications in the contribution of single compounds to the scent profile.

Methyl benzoate was the major emitted compound by non-transgenic and transgenic petunia flowers. Its contribution to the floral scent varied from 69 to $79 \%$ in wild-type petunias, (Figure S5B), from 73 to $87 \%$ in RNAi line 3 (Figure S5C) and from $46 \%$ to $71 \%$ in RNAi line 10 (Figure S5D). Methyl benzoate tended to decrease during the light period in wild-type and RNAi:PhCHL10 plants, in contrast in RNAi:PhCHL3 the highest contribution to the floral scent occurred at ZT5 (Figure S5B-D).

As mentioned above, we excluded methyl benzoate to analyze the temporal variation in scent emission profiles of those volatiles with lower emission. Briefly, in the wild-type plants, benzyl 2-methylbutyrate contribution to the scent profile increased during the light period (ZT2, ZT5). Cadinene, had the highest contribution at dawn and transition to day light (ZT23-ZT2). In contrast, the VOCs benzaldehyde, ethyl benzoate, limonene and phenylacetaldehyde showed their major contribution to the scent composition at dusk and early night (ZT8, ZT11). Acetophenone and benzyl benzoate displayed their highest contribution to the flower aroma at midnight (ZT14, ZT17). Finally, benzyl alcohol, benzyl acetate, eugenol, isoeugenol, methyl salicylate, phenethyl alcohol and phenethyl acetate percent composition was higher at late night (ZT20, ZT23) (Figure 5B).

When we analyzed the floral scent composition in RNAi petunias, three types of changes in the scent profile were observed. A set of volatiles showed similar profiles to the wild type (Figure 5B-D). These included of benzaldehyde, benzyl 2-methylbutyrate, cadinene, eugenol, isoeugenol and phenethyl alcohol. A second set of volatiles showed increased production during th late night and dawn (ZT23) as in wild type but did not decay during the light period (ZT2). Finally, acetophenone that had its maximal emission at midnight (ZT14-ZT17) and methyl salicylate (ZT20-ZT23) shifted their maxima to the light period at ZT2-ZT5.

These changes in timing of emission are reflected in the different quantitative combinations of VOCs found between wild-type and transgenic lines. Indeed, at the time when lights went off at ZT8, ethyl benzoate was the second important emitted volatile in W115 (70\% of selected volatiles), decreasing in RNAi:PhCHL10 to 57\% and RNAi:PhCHL3 to 8.7\%. The VOCs acetophenone and phenenthyl alcohol also decreased their emission in both transgenic lines. In contrast, benzaldehyde emission increased in both transgenic lines from $6.85 \%$ W115 (6.85\%) to $41.8 \%$ in RNAi:PhCHL3 and 22.1\% t in RNAi:PhCHL10. Phenylacetaldehyde also increased its emission in both RNAi:PhCHL3 (18.7\%) and RNAi:PhCHL10 (4.3\%) as petunia this volatile only represented a $1.4 \%$ of the profile in the wild-type (Figure $5 \mathrm{~B}-\mathrm{D}$ ). When the lights went on at ZT0, scent also differed in transgenic and non-transgenic petunia flowers. The predominant compounds in the wild-type scent profile were phenethyl alcohol $(30.5 \%)$, benzyl alcohol $(21.9 \%)$ and isoeugenol (19.3\%). In contrast, the major compounds in RNAi:PhCHL3 were isoeugenol (33\%), phenethyl 
alcohol (21.8\%) ethyl benzoate (12.7\%) meanwhile in RNAi:PhCHL10 were ethyl benzoate (62.7\%), phenethyl alcohol (11.4\%) and isoeugenol (9.6\%) (Figure 5B-D).

\section{PhCHL Is Required for Timing of Scent Profiles}

Petunia is considered a nocturnal plant; its scent emission is synchronized with pollinator activity. We analyzed the circadian rhythmicity of scent emission and the effect of silencing the gene PhCHL. In wild-type plants, benzaldehyde, benzyl acetate, benzyl alcohol, benzyl benzoate, eugenol, isoeugenol, methyl benzoate, phenylacetaldehyde, phenethyl acetate and phenethyl alcohol were rhythmically emitted $(\mathrm{p}<0.05)$, while acetophenone, benzyl 2-methylbutyrate, benzyl tiglate, cadinene, limonene, ethyl benzoate and methyl salicylate turned out to be arrhythmic ( $p$ > 0.05) (Table 4). In the RNAi plants, most compounds emitted in a rhythmic fashion in wild type were emitted in a rhythmic manner (Table 4). Moreover, benzyl tiglate, benzyl 2-methylbutyrate and methyl salicylate were not rhythmically emitted both in W115 and RNAi:PhCHL10 line oscillated significantly in RNAi:PhCHL3 petunias (Table 4).

Table 4: Analysis of emitted volatiles with MetaCycle. The JTK_CYCLE algorithm implemented in the R library "MetaCycle" was used to detect rhythms in emitted volatiles of petunia wild-type (W115) and transgenic RNAi:PhCHL lines (PhCHL3, PhCHL10). Volatiles with significant $\mathrm{p}$ value ( $\mathrm{p}$ value $<0.05$ ) showed a rhythmic emission. Phase is defined as the time point, in ZT $h$, with the highest emission.

\begin{tabular}{|c|c|c|c|c|c|c|}
\hline Volatile & $\begin{array}{c}\text { W115 } \\
\text { p value }\end{array}$ & Phase & $\begin{array}{l}\text { PhCHL3 } \\
\text { p value }\end{array}$ & Phase & $\begin{array}{l}\text { PhCHL10 } \\
\text { p value }\end{array}$ & Phase \\
\hline Benzyl tiglate & 1.000 & 2 & 0.014 & 0.5 & 0.476 & 5 \\
\hline Cadinene & 0.445 & 5 & 0.246 & 23 & 1.000 & 9.5 \\
\hline Ethyl benzoate & 1.000 & 11 & 1.000 & 20 & 1.000 & 20 \\
\hline Acetophenone & 1.000 & 12.5 & 1.000 & 8 & 0.210 & 11 \\
\hline Benzaldehyde & 0.000 & 15.5 & 0.000 & 12.5 & 0.000 & 15.5 \\
\hline Benzyl benzoate & 0.001 & 15.5 & 0.023 & 17 & 0.001 & 17 \\
\hline Limonene & 0.165 & 15.5 & 0.280 & 17 & 1.000 & 11 \\
\hline Phenylacetaldehyde & 0.001 & 15.5 & 0.000 & 12.5 & 0.000 & 20 \\
\hline Methyl benzoate & 0.017 & 17 & 0.003 & 15.5 & 0.011 & 17 \\
\hline Isoeugenol & 0.001 & 18.5 & 0.007 & 18.5 & 0.014 & 17 \\
\hline Benzyl acetate & 0.003 & 20 & 0.001 & 20 & 0.005 & 20 \\
\hline Eugenol & 0.001 & 20 & 0.000 & 20 & 0.019 & 20 \\
\hline Methyl salicylate & 1.000 & 20 & 0.009 & 20 & 1.000 & 15.5 \\
\hline Phenylethyl acetate & 0.048 & 20 & 0.002 & 20 & 0.000 & 20 \\
\hline Phenylethyl alcohol & 0.000 & 20 & 0.000 & 18.5 & 0.000 & 15.5 \\
\hline Benzyl alcohol & 0.000 & 21.5 & 0.007 & 20 & 0.000 & 20 \\
\hline $\begin{array}{c}\text { Benzyl 2- } \\
\text { methylbutyrate }\end{array}$ & 1.000 & 23 & 0.011 & 23 & 0.194 & 2 \\
\hline
\end{tabular}

We also analyzed the phase or time point with the highest emission of selected volatiles. Most compounds increased their emission during the dark period, and we classified the volatiles according to their maximum emission. In the wild-type petunia, first group comprised benzyl tiglate and cadinene, which showed their peaks during the subjective day (ZT2 and ZT5, respectively). The second group included the volatiles ethyl benzoate and acetophenone, that reached its maximum emission at early night (ZT11 and ZT12.5, respectively). The third group consisted of those VOCs which peaked at midnight, from ZT15 to ZT18.5: benzaldehyde, benzyl acetate, limonene, isoeugenol, methyl benzoate and phenylacetaldehyde. Finally, the fourth 
group included benzyl 2-methylbutyrate, benzyl acetate, benzyl alcohol, eugeno, methyl salicylate, phenethyl acetate and phenethyl alcohol, that showed their maximum emission at late night (ZT20 to ZT23) (Table 4).

Analyzing the phase of emitted volatiles in transgenic lines revealed important differences. We found four types of behavior. First, the volatiles benzyl acetate, eugenol and phenethyl acetate did not change their peak in wild-type and transgenic petunias (Table 4). Second, benzyl benzoate, cadinene and ethyl benzoate delayed their maximum emission in both transgenic lines (Table 4). Third, acetophenone, benzyl alcohol and phenethyl alcohol displayed an advanced phase in RNAi:PhCHL plants (Table 4). Finally, a group of volatiles did not follow the same pattern in RNAi:PhCHL3 and RNAi:PhCHL10 lines; benzyl 2-methylbutirate and isoeugenol did not change their peak in RNAi:PhCHL3 compared to W115 petunias whereas these compounds were emitted in advanced in the line RNAi:PhCHL10; on the other hand, the compounds benzaldehyde and methyl benzoate peaked at the same time in non-transgenic and RNAi:PhCHL10 petunias but in the RNAi:PhCHL3 line this peak was advanced (Table 4).

Altogether, $\mathrm{PhCHL}$ plays a fundamental role in coordinating floral scent profile of petunia that could be related to the timing of maximal production of different VOCs. The effect on single compounds appears to be opposite in some cases, suggesting a control of scent pathway at one of several points that we do not understand yet.

\section{Discussion}

The ZTL gene in Arabidopsis plays a central role in the circadian clock regulation and affects several traits such as flowering time [45], and in Nicotiana it also controls flower daily movement and the emission of benzyl acetone [17]. Here we have performed a systematic study of $P h C H L$, the ortholog of ZTL, and its outputs in Petunia hybrida, uncovering several unreported functions.

The ZTL/FKF/LKP2 proteins are blue light receptors in Arabidopsis. The expression of ZTL is not rhythmic in Arabidopsis or Nicotiana [44,45]. While PhCHL showed a clear peak of expression in 12L:12D, we could not find a significant rhythm, indicating a conserved expression pattern with other plants where it has been analyzed. This is the first time that PhCHL, a ZTL ortholog, has been analyzed in petals. The similarity of expression of $\mathrm{PhCHL}$ in leaves and petals indicates that the leaf and petal clock may be partly conserved. However, this needs further analysis with more genes, as clock transcriptional structure has been shown to change in roots, pods or seeds $[49,50]$.

One of the classical experiments in Chronobiology in plants was performed by d'Ortous de Mairan. He demonstrated that leaf movement was rhythmic and endogenous [51]. Leaf angle and leaf movement have been widely studied in crops, including soybean and maize [52,53] and in the canonical model Arabidopsis. The analysis of circadian clock mutants in Arabidopsis revealed that the clock genes GIGANTEA (GI) and EARLY FLOWERING 4 (ELF4) are required to maintain leaf movement rhythmicity [54,55]. In petunia, we detected periodic changes in leaf position but diel changes in position were not affected by the down-regulation of PhCHL. This result suggests that $P h C H L$ did not play a critical role in leaf rhythms at early stages of development.

The first apparent effect of down-regulating $\mathrm{PhCHL}$ was a decrease in plant body size. A detailed analysis using time lapse images showed that the stem of wild-type plants and siblings knocked down for PhCHL grew at similar speed. This suggests that the identified decrease in shoot length 
maybe the result of smaller primordia, decreased growth duration or a combination of both phenomena. In contrast, petal development appeared to be affected in growth rate. Furthermore, petal growth occurred at higher rates during the day than during the night both in wild-type and transgenic plants, suggesting that gated growth of flowers was independent of PhCHL. Work in Arabidopsis and maize has shown that the process of growth rate and duration maybe differentially affected by mutations $[56,57,58]$. Our results show that measuring two different organs may yield different results related to growth rate and duration. The plant circadian clock appears to have an organ specific resetting in roots, pods and seeds [50,59,60,61]. In this context, shoot growth is driven by the shoot apical meristem while flowers have undergone major organ identity reprogramming. As both cell division and expansion are under direct control of the clock $[62,63]$, our results indicate a somewhat different interpretation of loss of PhCHL in stems and flowers.

We performed a complete scent profile analysis in wild-type and knockdown lines. Floral scent comprised $98.66 \%$ benzenoids/phenylpropanoids and $1.34 \%$ terpenoids in wild-type petunias. This composition was somewhat similar in transgenic lines, indicating that the effects of $\mathrm{PhCHL}$ are not specific for a single volatile family of compounds. The emission of several phenylpropanoids/benzenoids compounds, such as methyl benzoate, benzyl alcohol, benzyl benzoate o benzaldehyde, displayed a rhythmic oscillation whereas acetophenone or ethyl benzoate (phenylpropranoids/benzenoids) and the terpenoids cadinene and limonene did not. In addition, the amount of emitted volatiles tended to increase and peak during the dark phase, coinciding with petunia pollinators activity [64]. These results are similar to those described previously for whole flowers, indicating that petal volatiles and those emitted by other organs have similar control mechanism [14]. This suggests that the circadian clock plays a key role in the regulation of biosynthesis and emission of certain compounds that interacts and/or attracts pollinators. In contrast, volatiles which did not oscillate such as acetophenone, or terpenoids may play a role in defense $[65,66]$.

The disruption of PhCHL shifted the maximum emission of benzyl alcohol was advanced whereas the peaks of benzyl benzoate and ethyl benzoate were delayed. Other volatiles, such as benzyl alcohol, eugenol and phenethyl acetate, were not affected by the knockdown of PhCHL. These results suggest that $\mathrm{PhCHL}$ was involved, directly or indirectly, in the emission pattern of certain volatiles. However complete knockouts for PhCHL may show a stronger effect in the volatiles affected and/or additional effects on those that appear to remain stable.

Flower fragrances play a complex biological role. The dominant nocturnal emitted volatiles of Petunia axillaris, benzaldehyde, benzyl alcohol and methyl benzoate, act as attractant of its nocturnal pollinator [64] whereas benzaldehyde has been described as a mild repellent [67]. On the other hand, the highest emitted compound by P. integrifolia is benzaldehyde [64]. In Petunia hybrida, the three major compounds were methyl benzoate, ethyl benzoate and isoeugenol. In contrast, the three principal released VOCs in RNAi:PhCHL3 were methyl benzoate, isoeugenol and benzaldehyde, while in RNAi:PhCHL10, they were methyl benzoate, ethyl benzoate and benzaldehyde. In addition, in the present work, we described how the proportion of the compounds emitted by wild-type and RNAi:PhCHL petunias changed throughout a $24 \mathrm{~h}$ period. Previous studies that covered the down-regulation of the clock genes LHY and ZTL in petunia and wild tobacco, have report a reduction in volatile emission and production $[17,18]$. Our results 
showed that silencing PhCHL modified blend ratios, resulting in a different scent profile. Changes in emission pattern and fragrance composition may have an effect in pollinator attraction, plant defense against herbivores and pathogens or plant-plant signaling $[68,69,70]$. Our work shows that PhCHL plays a major role in the quantities and timing of VOC emission, thus coordinating the proper composition and daily changes of scent blends.

Supplementary Materials: Supplementary materials are available online.

Author Contributions: M.I.T. designed experiments, performed experiments, performed formal data analysis, wrote, revised and edited the paper. F.P.S. designed experiments, developed the software, performed experiments, performed formal data analysis and revised and edited the paper. M.V.D.G. performed formal data analysis and revised and edited the paper. F.P.C. performed formal data analysis and revised and edited the paper.

P.J.N. conceived and coordinated the study, designed experiments, developed the software, performed formal data analysis, revised and edited the paper, supervised this work and acquired funding. M.E.C. conceived and coordinated the study, designed experiments, performed formal data analysis, wrote, revised and edited the paper, supervised this work and acquired funding. J.W. conceived and coordinated the study, designed experiments, performed experiments, performed formal data analysis, revised and edited the paper, supervised this work and acquired funding. All authors revised and approved the finaldraft.

Funding: This research was funded by Fundación Seneca 19398/PI/14, 19895/GERM/15 and MC BFU-2017 88300C2-1-R and BFU-2017 88300-C2-2-R.

Acknowledgments: We would like to acknowledge María José Roca for technical assistance.

Conflicts of Interest: The authors declare no conflict of interest. The funders had no role in the design of the study; in the collection, analyses, or interpretation of data; in the writing of the manuscript, or in the decision to publish the results. 


\section{References}

1. Barton, M.K. Twenty years on: The inner workings of the shoot apical meristem, a developmental dynamo. Dev. Biol. 2010, 341, 95-113. [CrossRef] [PubMed]

2. Angenent, G.C.; Immink, R.G.H.; Kaufmann, K. The "ABC" of MADS domain protein behaviour and interactions. Semin. Cell Dev. Biol. 2010, 21, 87-93.

3. Egea-Cortines, M.; Saedler, H.; Sommer, H. Ternary complex formation between the MADS-box proteins SQUAMOSA, DEFICIENS and GLOBOSA is involved in the control of floral architecture in Antirrhinum majus. EMBO J. 1999, 18, 5370-5379. [CrossRef] [PubMed]

4. Honma, T.; Goto, K. Complexes of MADS-box proteins are sufficient to convert leaves into floral organs. Nature 2001, 409, 525-529. [CrossRef] [PubMed]

5. Bernardello, G.; Anderson, G.J.; Stuessy, T.F.; Crawford, D.J. A survey of floral traits, breeding systems, floral visitors, and pollination systems of the angiosperms of the Juan Fernandez Islands (Chile). Bot. Rev. 2001, 67, 255-308. [CrossRef]

6. Hepworth, J.; Lenhard, M. Regulation of plant lateral-organ growth by modulating cell number and size. Curr. Opin. Plant Biol. 2014, 17, 36-42. [CrossRef] [PubMed]

7. Manchado-Rojo, M.; Weiss, J.; Egea-Cortines, M. Validation of Aintegumenta as a gene to modify floral size in ornamental plants. Plant Biotechnol. J. 2014, 12, 1053-1065. [CrossRef] [PubMed]

8. Krizek, B.A. Ectopic expression AINTEGUMENTA in Arabidopsis plants results in increased growth of floral organs. Dev. Genet. 1999, 25, 224-236. [CrossRef]

9. Kuluev, B.; Avalbaev, A.; Nurgaleeva, E.; Knyazev, A.; Nikonorov, Y.; Chemeris, A. Role of AINTEGUMENTA- like gene NtANTL in the regulation of tobacco organ growth. J. Plant Physiol. 2015, 189, 11-23. [CrossRef] [PubMed]

10. Muhlemann, J.K.; Maeda, H.; Chang, C.Y.; Miguel, P.S.; Baxter, I.; Cooper, B.; Perera, M.A.; Nikolau, B.J.; Vitek, O.; Morgan, J.A.; et al. Developmental Changes in the Metabolic Network of Snapdragon Flowers. PLoS ONE 2012, 7, e40381. [CrossRef] [PubMed]

11. Manchado-Rojo, M.; Delgado-Benarroch, L.; Roca, M.J.; Weiss, J.; Egea-Cortines, M. Quantitative levels of Deficiens and Globosa during late petal development show a complex transcriptional network topology of $B$ function. Plant J. 2012, 72, 294-307. [CrossRef] [PubMed]

12. Fenske, M.P.; Imaizumi, T. Circadian Rhythms in Floral Scent Emission. Front. Plant Sci. 2016, 7, 462. [CrossRef] [PubMed]

13. Dudareva, N.; Murfitt, L.M.; Mann, C.J.; Gorenstein, N.; Kolosova, N.; Kish, C.M.; Bonham, C.; Wood, K. Developmental regulation of methyl benzoate biosynthesis and emission in snapdragon flowers. Plant Cell 2000, 12, 949-961. [CrossRef] [PubMed]

14. Verdonk, J.C.; Ric de Vos, C.H.; Verhoeven, H.A.; Haring, M.A.; van Tunen, A.J.; Schuurink, R.C.; de Vos, C.H.R. Regulation of floral scent production in petunia revealed by targeted metabolomics. Phytochemistry 2003, 62, 997-1008. [CrossRef]

15. Hendel-Rahmanim, K.; Masci, T.; Vainstein, A.; Weiss, D. Diurnal regulation of scent emission in rose flowers. Planta 2007, 226, 1491-1499. [CrossRef]

16. Ruíz-Ramón, F.; Águila, D.J.; Egea-Cortines, M.; Weiss, J. Optimization of fragrance extraction: Daytime and flower age affect scent emission in simple and double narcissi. Ind. Crops Prod. 2014, 52, 671-678. [CrossRef]

17. Yon, F.; Joo, Y.; Cort, L.; Rothe, E.; Baldwin, I.T.; Kim, S.; Kim, S. Silencing Nicotiana attenuata LHY and ZTL alters circadian rhythms in flowers. New Phytol. 2015, 203, 1058-1066. [CrossRef]

18. Fenske, M.P.; Hewett Hazelton, K.D.; Hempton, A.K.; Shim, J.S.; Yamamoto, B.M.; Riffell, J.A.; Imaizumi, T. Circadian clock gene LATE ELONGATED HYPOCOTYL directly regulates the timing of floral scent emission in Petunia. Proc. Natl. Acad. Sci. USA 2015, 112, 9775-9780. [CrossRef]

19. Bombarely, A.; Moser, M.; Amrad, A.; Bao, M.; Bapaume, L.; Barry, C.C.S.; Bliek, M.; Boersma, M.R.M.; Borghi, L.; Bruggmann, R.; et al. Insight into the evolution of the Solanaceae from the parental genomes of Petunia hybrida. Nat. Plants 2016, 2, 1-9. [CrossRef]

20. Birney, E.; Clamp, M.; Durbin, R. GeneWise and Genomewise. Genome Res. 2004, 14, 988-995. [CrossRef] 
21. Larkin, M.A.; Blackshields, G.; Brown, N.P.; Chenna, R.; McGettigan, P.A.; McWilliam, H.; Valentin, F.; Wallace, I.M.; Wilm, A.; Lopez, R.; et al. Clustal W and clustal X version 2.0. Bioinformatics 2007, 23, 2947-2948. [CrossRef] [PubMed]

22. Paradis, E.; Claude, J.; Strimmer, K. APE: Analyses of Phylogenetics and Evolution in R language. Bioinformatics 2004, 20, 289-290. [CrossRef] [PubMed]

23. Schliep, K.P. Phangorn: Phylogenetic analysis in R. Bioinformatics 2011, 27, 592-593. [CrossRef]

24. Yu, G.; Smith, D.K.; Zhu, H.; Guan, Y.; Lam, T.T.-Y. Ggtree: An r package for visualization and annotation of phylogenetic trees with their covariates and other associated data. Methods Ecol. Evol. 2017, 8, 28-36. [CrossRef]

25. Helliwell, C.; Waterhouse, P. Constructs and methods for high-throughput gene silencing in plants. Methods 2003, 30, 289-295. [CrossRef]

26. Hilson, P.; Allemeersch, J.; Altmann, T.; Aubourg, S.; Avon, A.; Beynon, J.; Bhalerao, R.P.; Bitton, F.; Caboche, M.; Cannoot, B.; et al. Versatile gene-specific sequence tags for Arabidopsis functional genomics: Trancript profiling and reverse genetics applications. Genome Res. 2004, 14, 26-2189. [CrossRef] [PubMed]

27. Box, M.S.; Coustham, V.; Dean, C.; Mylne,J.S. Protocol: A simple phenol-based method for 96-well extraction of high quality RNA from Arabidopsis. Plant Methods 2011, 7, 7. [CrossRef]

28. Mallona, I.; Lischewsky, S.; Weiss, J.; Hause, B.; Egea-Cortines, M. Validation of reference genes for quantitative real-time PCR during leaf and flower development in Petunia hybrida. BMCPlant Biol. 2010, 10, 4. [CrossRef] [PubMed]

29. Pfaffl, M.W.; Tichopad, A.; Prgomet, C.; Neuvians, T.P. Determination of stable housekeeping genes, differentially regulated target genes and sample integrity: BestKeeper-Excel-based tool using pair-wise correlations. Biotechnol. Lett. 2004, 26, 509-515. [CrossRef] [PubMed]

30. Andersen, C.L.; Jensen, J.L.; Orntoft, T.F. Normalization of real-time quantitative reverse transcription-PCR data: A model-based variance estimation approach to identify genes suited for normalization, applied to bladder and colon cancer data sets. Cancer Res. 2004, 64, 5245-5250. [CrossRef]

31. Vandesompele, J.; De Preter, K.; Pattyn, F.; Poppe, B.; Van Roy, N.; De Paepe, A.; Speleman, F. Accurate normalization of realtime quantitative RT-PCR data by geometric averaging of multiple internal control genes. Genome Biol. 2002, 3, RESEARCH0034. [CrossRef] [PubMed]

32. Silver, N.; Best, S.; Jiang, J.; Thein, S.L. Selection of housekeeping genes for gene expression studies in human reticulocytes using real-time PCR. BMC Mol. Biol. 2006, 7, 33. [CrossRef] [PubMed]

33. Xie, F.; Xiao, P.; Chen, D.; Xu, L.; Zhang, B. miRDeepFinder: A miRNA analysis tool for deep sequencing of plant small RNAs. Plant Mol. Biol. 2012, 80, 75-84. [CrossRef] [PubMed]

34. Schmittgen, T.D.; Livak, K.J. Analyzing real-time PCR data by the comparative CT method. Nat. Protoc. 2008, 3, 1101-1108. [CrossRef]

35. Mallona, I.; Weiss, J.; Egea-Cortines, M. pcrEfficiency: A Web tool for PCR amplification efficiency prediction. BMC Bioinform. 2011, 12, 404. [CrossRef]

36. Navarro, P.J.; Pérez, F.; Weiss, J.; Egea-Cortines, M. Machine learning and computer vision system for phenotype data acquisition and analysis in plants. Sensors 2016, 16, 641. [CrossRef]

37. Kahm, M.; Hasenbrink, G.; Ludwig, J. Grofit: Fitting Biological Growth Curves with R. J. Stat. Softw. 2010, 33, 1-21. [CrossRef]

38. Ruiz-Hernández, V.; Roca, M.J.; Egea-Cortines, M.; Weiss, J. A comparison of semi-quantitative methods suitable for establishing volatile profiles. Plant Methods 2018, 14, 67. [CrossRef] [PubMed]

39. Hughes, M.E.; Hogenesch, J.B.; Kornacker, K. JTK_CYCLE: An efficient nonparametric algorithm for detecting rhythmic components in genome-scale data sets. J. Biol. Rhythm. 2010, 25, 372-380. [CrossRef] [PubMed]

40. Wu, G.; Anafi, R.C.; Hughes, M.E.; Kornacker, K.; Hogenesch, J.B. MetaCycle: An integrated R package to evaluate periodicity in large scale data. Bioinformatics 2016, 32, 3351-3353. [CrossRef]

41. Wickham, H. Ggplot2: Elegant Graphics for Data Analysis; Springer: Berlin/Heidelberg, Germany, 2016; ISBN 978-3-319-24277-4. 
42. Garnier, S.; Ross, N.; Rudis, B.; Sciaini, M.; Scherer, C. Viridis: Default Color Maps from "Matplotlib"; R Project: Vienna, Austria, 2018; R Package Version 0.5; Available online: https://cran.r-project.org/web/packages/ viridis/index.html (accessed on 11 April 2019)

43. Kubota, A.; Kita, S.; Ishizaki, K.; Nishihama, R.; Yamato, K.T.; Kohchi, T. Co-option of a photoperiodic growthphase transition system during land plant evolution. Nat. Commun. 2014, 5, 3668. [CrossRef] [PubMed]

44. Yon, F.; Seo, P.-J.; Ryu, J.Y.; Park, C.-M.; Baldwin, I.T.; Kim, S.-G. Identification and characterization of circadian clock genes in a native tobacco, Nicotiana attenuata. BMC Plant Biol. 2012, 12, 172. [CrossRef] [PubMed]

45. Somers, D.E.;Schultz, T.F.;Milnamow, M.; Kay, S.A.ZEITLUPE encodes a novel clock-associated PASprotein from Arabidopsis. Cell 2000, 101, 319-329. [CrossRef]

46. Navarro, P.J.; Fernández, C.; Weiss, J.; Egea-Cortines, M. Development of a configurable growth chamber with a vision system to study circadian rhythm in plants. Sensors 2012, 12, 15356-15375. [CrossRef] [PubMed]

47. Nusinow, D.A.; Helfer, A.; Hamilton, E.E.; King, J.J.; Imaizumi, T.; Schultz, T.F.; Farré, E.M.; Kay, S.A.; Farre, E.M. The ELF4-ELF3-LUX complex links the circadian clock to diurnal control of hypocotyl growth. Nature 2011, 475, 398. [CrossRef] [PubMed]

48. Amrad, A.; Moser, M.; Mandel, T.; de Vries, M.; Schuurink, R.C.; Freitas, L.; Kuhlemeier, C. Gain and Loss of Floral Scent Production through Changes in Structural Genes during Pollinator-Mediated Speciation. Curr. Biol. 2016, 26, 3303-3312. [CrossRef] [PubMed]

49. Endo, M. Tissue-specific circadian clocks in plants. Curr. Opin. Plant Biol. 2016, 29, 44-49. [CrossRef]

50. Weiss, J.; Terry, M.I.; Martos-Fuentes, M.; Letourneux, L.; Ruiz-hernández, V.; Fernández, J.A.; Egea-cortines, M. Diel pattern of circadian clock and storage protein gene expression in leaves and during seed filling in cowpea (Vigna unguiculata). BMC Plant Biol. 2018, 18, 33-53. [CrossRef]

51. De Mairan, J.-J. Observation Botanique; Histoire de l'Académie Royale des Sciences Paris; Institut de France: Paris, France, 1729; p. 35.

52. Ku, L.; Wei, X.; Zhang, S.; Zhang, J.; Guo, S.; Chen, Y. Cloning and Characterization of a Putative TAC1 Ortholog Associated with Leaf Angle in Maize (Zea mays L.). PLoS ONE 2011, 6, e20621. [CrossRef] [PubMed]

53. Kao, W.-Y.; Tsai, T.-T. Tropic leaf movements, photosynthetic gas exchange, leaf $\delta 13 \mathrm{C}$ and chlorophyll a fluorescence of three soybean species in response to water availability. Plant Cell Environ. 1998, 21, 10551062. [CrossRef]

54. Park, D.H. Control of Circadian Rhythms and Photoperiodic Flowering by the Arabidopsis GIGANTEA Gene. Science 1999, 285, 1579-1582. [CrossRef] [PubMed]

55. Doyle,M.R.;Davis, S.J.;Bastow, R.M.;McWatters,H.G.;Kozma-Bognar, L.;Nagy,F.;Millar, A.J.;Amasino, R.M. The ELF4 gene controls circadian rhythms and flowering time in Arabidopsis thaliana. Nature 2002, 419, 74-77. [CrossRef] [PubMed]

56. Kennaway, R.; Coen, E.; Green, A.; Bangham, A. Generation of diverse biological forms through combinatorial interactions between tissue polarity and growth. PLoS Comput. Biol. 2011, 7, e1002071. [CrossRef]

57. Beemster, G.T.S.; De Vusser, K.; De Tavernier, E.; De Bock, K.; Inze, D. Variation in growth rate between Arabidopsis ecotypes is correlated with cell division and A-type cyclin-dependent kinase activity. Plant Physiol. 2002, 129, 854-864. [CrossRef]

58. Feys, K.; Demuynck, K.; De Block, J.; Bisht, A.; De Vliegher, A.; Inzé, D.; Nelissen, H. Growth rate rather than growth duration drives growth heterosis in maize B104 hybrids. Plant Cell Environ. 2017, 41, 374-382. [CrossRef] [PubMed]

59. Thain, S.C.; Murtas, G.; Lynn, J.R.; McGrath, R.B.; Millar, A.J. The circadian clock that controls gene expression in Arabidopsis is tissue specific. Plant Physiol. 2002, 130, 102-110. [CrossRef] [PubMed]

60. Bordage, S.; Sullivan, S.; Laird, J.; Millar, A.J.; Nimmo, H.G. Organ specificity in the plant circadian system is explained by different light inputs to the shoot and root clocks. New Phytol. 2016, 212, 136-149. [CrossRef] [PubMed]

61. Voß, U.; Wilson, M.H.; Kenobi, K.; Gould, P.D.; Robertson, F.C.; Peer, W.A.; Lucas, M.; Swarup, K.; Casimiro, I.; Holman, T.J.; et al. The circadian clock rephases during lateral root organ initiation in Arabidopsis thaliana. Nat. Commun. 2015, 6, 7641. [CrossRef] [PubMed]

62. Farré, E.M. The regulation of plant growth by the circadian clock. Plant Biol. 2012, 14, 401-410. [CrossRef]

63. Fung-Uceda, J.; Lee, K.; Seo, P.J.; Polyn, S.; De Veylder, L.; Mas, P. The Circadian Clock Sets the Time of DNA Replication Licensing to Regulate Growth in Arabidopsis. Dev. Cell 2018, 45, 101-113. [CrossRef] [PubMed]

64. Hoballah, M.E.; Stuurman, J.; Turlings, T.C.J.; Guerin, P.M.; Connétable, S.; Kuhlemeier, C.; Connetable, S.; 
Kuhlemeier, $\mathrm{C}$. The composition and timing of flower odour emission by wild Petunia axillaris coincide with the antennal perception and nocturnal activity of the pollinator Manduca sexta. Planta 2005, 222, 141-150. [CrossRef] [PubMed]

65. Unsicker, S.B.; Kunert, G.; Gershenzon, J. Protective perfumes: The role of vegetative volatiles in plant defense against herbivores. Curr. Opin. Plant Biol. 2009, 12, 479-485. [CrossRef]

66. Pichersky, E.; Gershenzon, J. The formation and function of plant volatiles: Perfumes for pollinator attraction and defense. Curr. Opin. Plant Biol. 2002, 5, 237-243. [CrossRef]

67. Junker, R.R.; Blüthgen, N. Floral scents repel potentially nectar-thieving ants. Evol. Ecol. Res. 2008, 10, 295308.

68. Aharoni, A. Terpenoid Metabolism in Wild-Type and Transgenic Arabidopsis Plants. Plant Cell Online 2003, 15, 2866-2884. [CrossRef] [PubMed]

69. Yon, F.; Kessler, D.; Joo, Y.; Cortés Llorca, L.; Kim, S.G.; Baldwin, I.T. Fitness consequences of altering floral circadian oscillations for Nicotiana attenuata. J. Integr. Plant Biol. 2017, 59, 180-189. [CrossRef] [PubMed]

70. Bhatia, V.; Maisnam, J.; Jain, A.; Sharma, K.K.; Bhattacharya, R. Aphid-repellent pheromone E- $\beta$-farnesene is generated in transgenic Arabidopsis thaliana over-expressing farnesyl diphosphate synthase2. Ann. Bot. 2015, 115, 581-591. [CrossRef] [PubMed]

C 2019 by the authors. Licensee MDPI, Basel, Switzerland. This article is an open access article distributed under the terms and conditions of the Creative Commons Attribution (CC BY) license (http://creativecommons.org/licenses/by/4.0/). 


\section{Supplementary material}

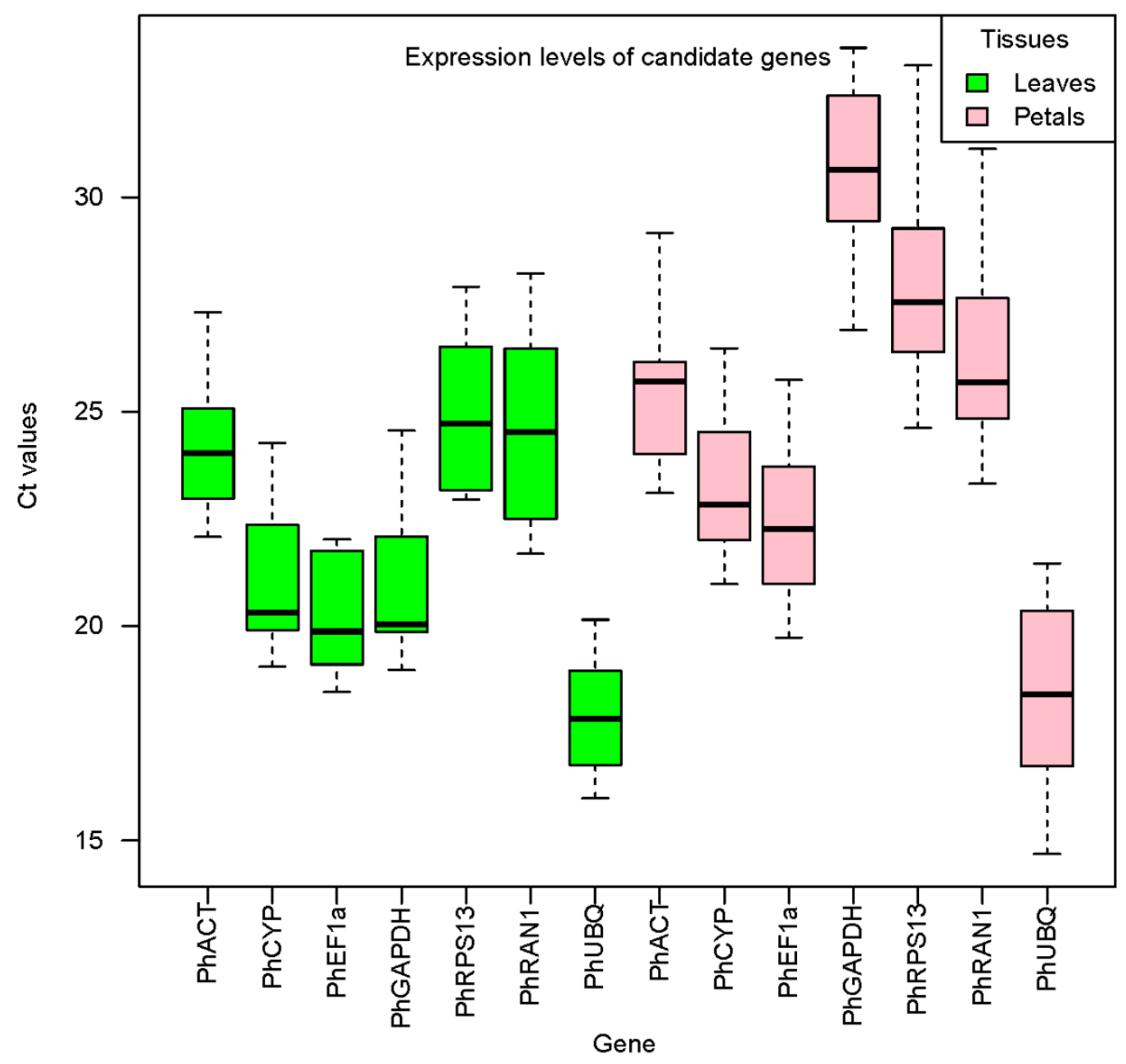

Figure S1: Expression levels of candidate housekeeping genes (PhACT, PhCYP, PhEF1 $\alpha, P h G A D P H$, PhRPS13, PhRAN1 and PhUBI), represented as cycle threshold values (Ct) for petunia leaves (green boxes) and petals (pink boxes) from qPCR. Box represents first and third quartile, the line across the box is the median and whiskers indicate minimum and maximum. 


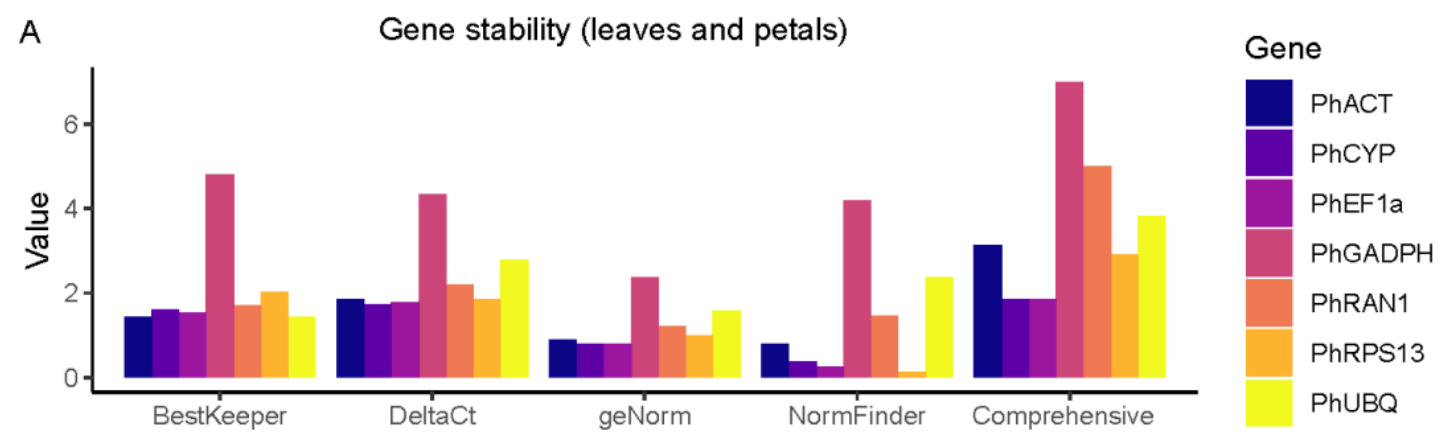

B Gene stability (leaves)

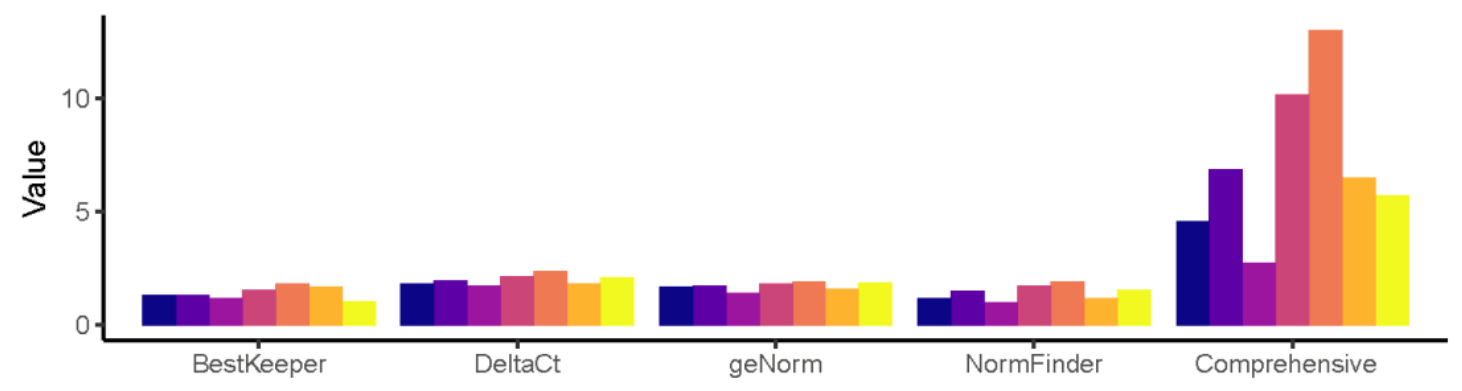

C

Gene stability (petals)

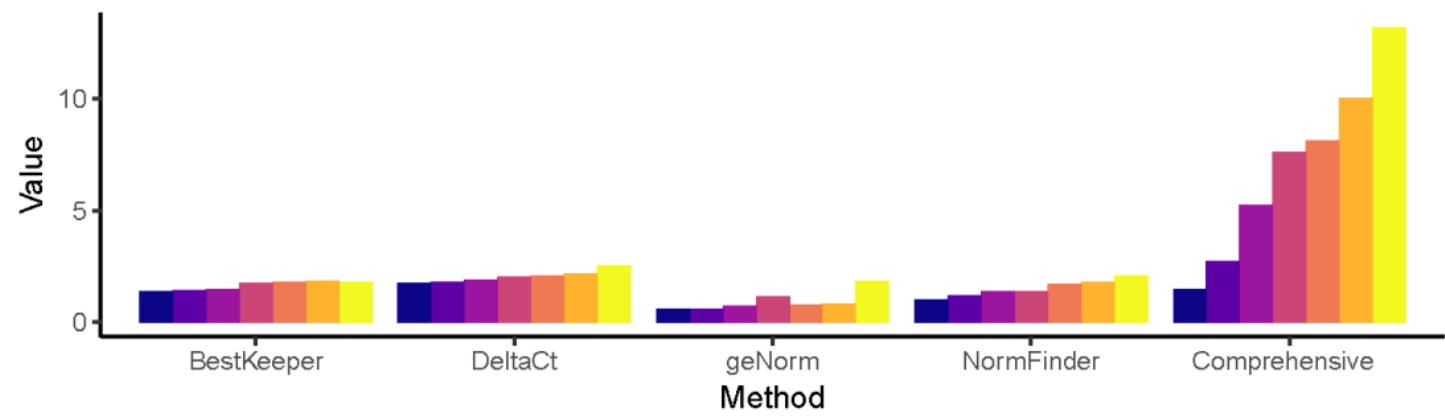

Figure S2: Gene stability for both tissues (leaves and petals) (A), leaves (B) and petals (C) by Delta CT $(\Delta \mathrm{Ct})$, BestKeeper, NormFinder and geNorm method for candidate reference genes $P h A C T, P h C Y P, P h E F 1 \alpha$, PhGADPH, PhRAN1, PhRPS13 and PhUBI. Furthermore, comprehensive gene stability offers the average expression stability values for all genes. Most stable genes displayed the lowest values and least stable genes showed the highest values. 

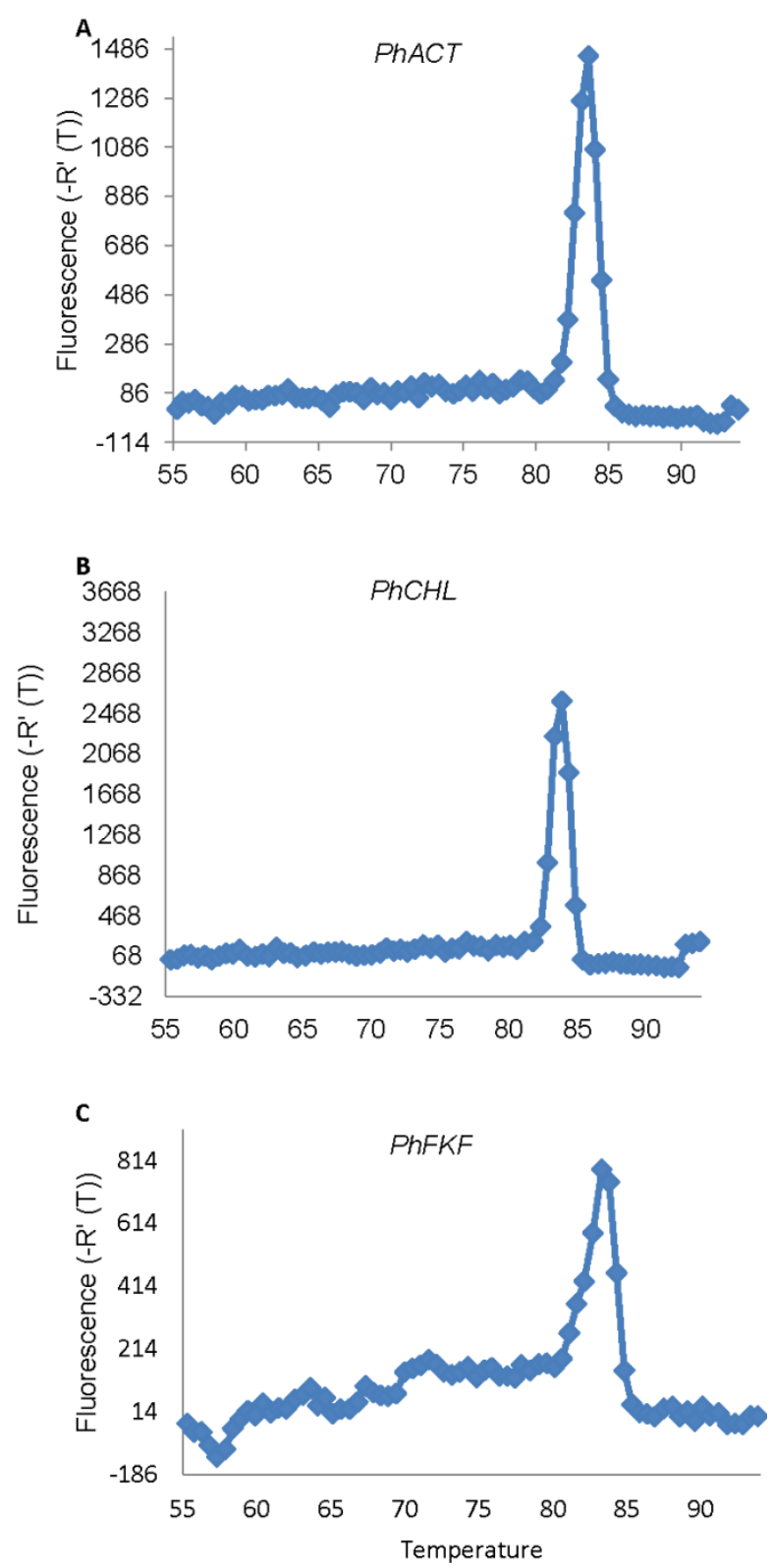

Figure S3: Melt or dissociation curve analysis of petunia genes PhACT (A), PhCHL (B) and PhFKF (C). 
A
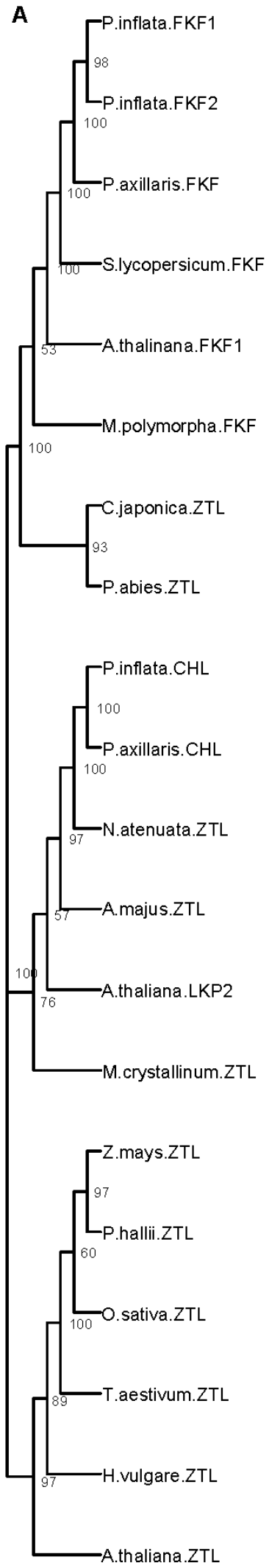

B

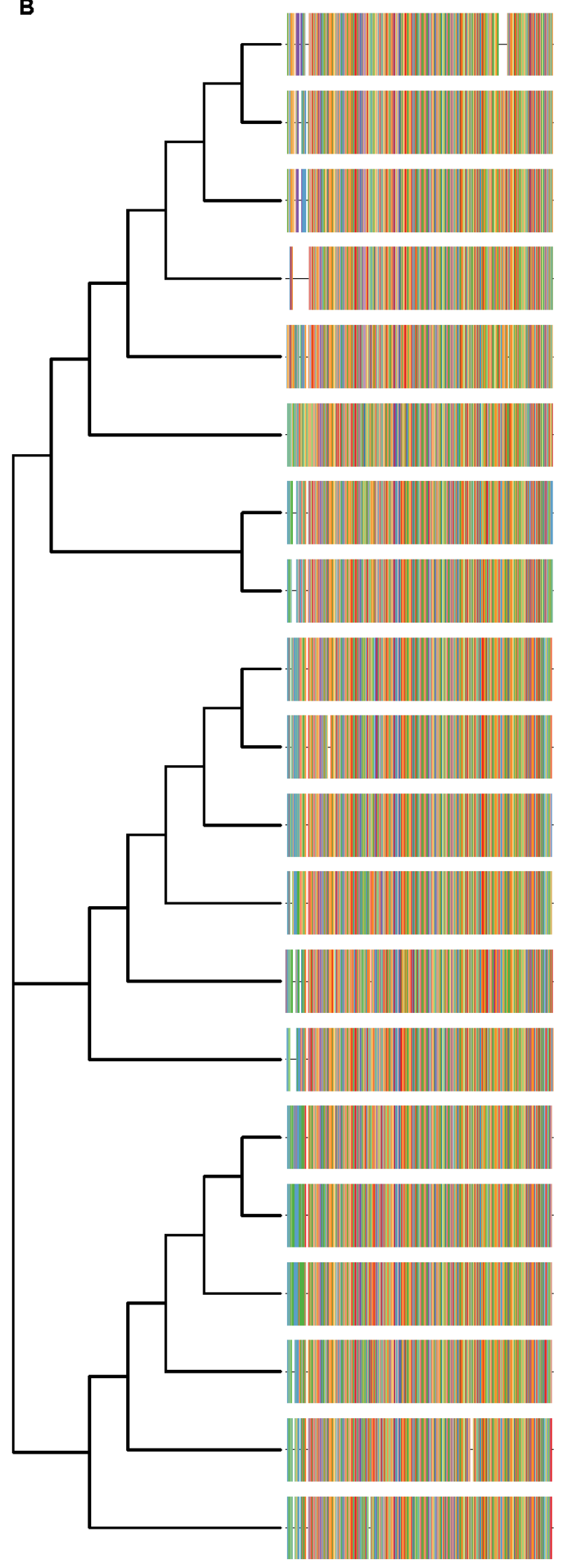

Figure S4: Phylogenetic tree of CHL, FKF, LKP2 and ZTL genes in Antirhinum majus (A.majus), Arabidopsis thaliana (A.thaliana), Cryptomeria japonica (C.japonica), Hordeum vulgare (H.vulgare), Marchantia polymorpha (M.polymorpha), Mesembryanthemum crystallinum (M.crystallinum), Nicotiana attenuata (N.attenuata), Oryza sativa (O.sativa), Petunia axillaris (P.axillaris), Petunia inflata (P.inflata), Picea abies (P.abies), Solanum lycopersicum (S.lycopersicum), Triticum aestivum (T.aestivum) and Zea mays (Z.mays). Amino acid sequences 
were aligned using CLUSTALX. Phylogenetic analysis was performed with the R libraries ape and phangorn using the Maximum Likelihood as statistical method, JTT as model of amino acid substituion and 1000 bootstrap replicates, indicated (as percentage) with the numbers next to the branches (A). Protein alignment is shown in B. 

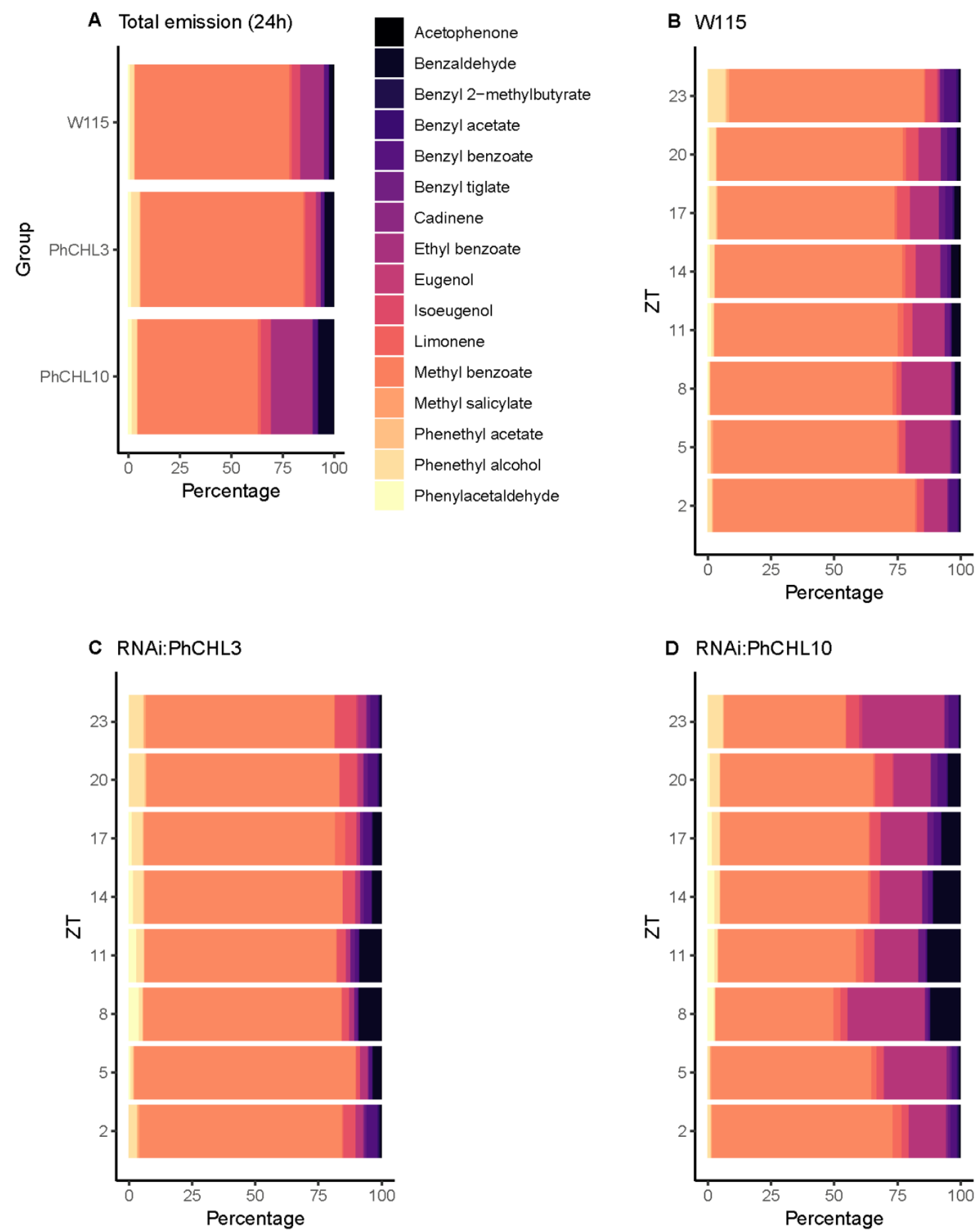

Figure S5: Petunia scent profiles expressed as percentage, including methyl benzoate. Profiles were determined for $24 \mathrm{~h}$ emission under a $8 \mathrm{~L}: 16 \mathrm{D}$ cycle for the wild-type (first bar) and the transgenic lines (second and third bar) (A) and in a time-course (B-D), where each bar represent one sampling time point (in ZT hours) for wild-type (B), RNAi:PhCHL3 (C) and RNAi:PhCHL10 (D) petunia flowers. 
Table S1: GenBank, Snapdragon Genome Sol Genomics Network Database accession numbers of proteins used in phylogenetic reconstruction.

\begin{tabular}{cccc}
\hline Species & Protein & Accession & Database \\
\hline Antirrhinum majus & ZTL & Am01g33620 & Snapdragon \\
Arabidopsis thaliana & FKF1 & OAP14729.1 & GenBank \\
& LKP2 & NP_849983.1 & GenBank \\
& ZTL & OAO90691.1 & GenBank \\
Cryptomeria japonica & ZTL & BAP76060.1 & GenBank \\
Hordeum vulgare & ZTL & ACR15149.1 & GenBank \\
Marchantia polymorpha & FKF & BAO66508.1 & GenBank \\
Mesembryanthemum crystallinum & ZTL & AAQ73527.1 & GenBank \\
Nicotiana attenuata & ZTL & AFA35963.1 & GenBank \\
Oryza sativa & ZTL & XP_015643178.1 & GenBank \\
Panicum hallii & ZTL & XP_025810803.1 & GenBank \\
Petunia axillaris & CHL & Peaxi162Scf01124g00126.1 & Sol Genomics \\
& FKF & Peaxi162Scf00655g00114.1 & Sol Genomics \\
Petunia inflata & CHL & Peinf101Scf01230g02037.1 & Sol Genomics \\
& FKF1 & Peinf101Scf04186g00007.1 & Sol Genomics \\
Picea abies & FKF2 & Peinf101Scf02808g00015.1 & Sol Genomics \\
Solanum lycopersicum & ZTL & AGH20050.1 & GenBank \\
Triticum aestivum & FKF & Solyc01g005300.3 & Sol Genomics \\
Zea mays & ZTL & ABR14627.1 & GenBank \\
& ZTL & PWZ17109.1 & GenBank \\
\hline
\end{tabular}


Table S2: Primers for PCR (attb1, attb2, PhCHLrnaiaattb1, PhCHLrnaiaattb2, Agri51, Agri 56, NPTII and specific fragment of PhCHL for transformation, RNAi:PhCHL) and qPCR (PhACT, PhCYP, PhEF1 $\alpha$, PhGADPH, PhFKF, PhRAN1, PhRPS13, PhUBQ and PhCHL.

\begin{tabular}{|c|c|c|}
\hline Gene & Forward & Reverse \\
\hline attb1, attb2 & $\begin{array}{l}\text { GGGGACAAGTTTGTACAAAAAAGCAGG } \\
\text { СT }\end{array}$ & $\begin{array}{l}\text { GGGGACCACTTTGTACAAGAAAG } \\
\text { CTGGGTA }\end{array}$ \\
\hline PhCHLrnaiaattb1 & $\begin{array}{l}\text { TACAAAAAAGCAGGCTCTGCATGAACTAT } \\
\text { CTTTAGCAAGC }\end{array}$ & \\
\hline PhCHLrnaiaattb2 & $\begin{array}{l}\text { CAAGAAAGCTGGGTAATTCAGACCATCTG } \\
\text { CTCAATAGG }\end{array}$ & \\
\hline Agri51,Agri56 & CAACCACGTCTTCAAAGCAA & CTGGGGTACCGAATTCCTC \\
\hline NPTII & СCTGCTTGCCGAATATCATGGTGG & $\begin{array}{l}\text { CGAAATCTCGTGATGGCAGGTTG } \\
\text { G }\end{array}$ \\
\hline RNAi:PhCHL & TGCATCTGTTGGCTCTGTTT & ССССААСССААТСТСТТАGС \\
\hline PhACT & TGCACTCCCACATGCTATCCT & TCAGCCGAAGTGGTGAAAGAG \\
\hline $\mathrm{PhCHL}$ & TGCATCTGTTGGCTCTGTTT & ССССААСССААТСТСТTAGC \\
\hline $\operatorname{PhCYP}$ & AGGCTCATCATTCCACCGTGT & TCATCTGCGAACTTAGCACCG \\
\hline$P h E F 1 \alpha$ & CCTGGTCAAATTGGAAACGG & CAGATCGCCTGTCAATCTTGG \\
\hline PhGADPH & AАCAАCTCACTCCTACACCGG & GGTAGCACTAGAGACACAGCCTT \\
\hline PhFKF & CTGGGCAACCTCCAAAGTT & CATGGATCAGAATCTTGTT \\
\hline PhRAN1 & AAGCTCCCACCTGTCTGGAAA & TGCTAACAGATTGCCGGAAGCC \\
\hline PhRPS13 & CAGGCAGGTTAAGGCAAAGC & ACTAGCAAGGTACAGAAACGGC \\
\hline$P h U B Q$ & TGGAGGATGGAAGGACTTTGG & CAGGACGACAACAAGCAACAG \\
\hline
\end{tabular}


Table S3: Results from BLAST of the Petunia genomes and major features of homology of the $\mathrm{CHL} / \mathrm{FKF} / \mathrm{ZTL}$ protein family. Comparisons are made against the Arabidopsis ortholog. The homology refers to the number of identical annealed amino acids in relation to the total coded protein.

\begin{tabular}{cccc}
\hline Petunia gene & BLAST values & $\begin{array}{c}\text { Predicted } \\
\text { protein length }\end{array}$ & $\begin{array}{c}\text { Homology to } \\
\text { Arabidopsis }\end{array}$ \\
\hline $\begin{array}{c}\text { PhCHL } \\
\text { Peaxi162Scf01124g00126.1 }\end{array}$ & 0.0 & 616 & $489 / 610$ \\
$\begin{array}{c}\text { PhFKF } \\
\text { Peaxi162Scf00655g00114.1 } \\
\text { PinfZTL }\end{array}$ & 0.0 & 617 & $478 / 582$ \\
$\begin{array}{c}\text { Peinf101Scf01230g02037.1 } \\
\text { PinfFKF1 }\end{array}$ & 0.0 & 623 & $502 / 610$ \\
$\begin{array}{c}\text { Peinf101Scf04186g00007.1 } \\
\text { PinfFKF2 }\end{array}$ & 0.0 & 593 & $479 / 582$ \\
Peinf101Scf02808g00015.1 & 0.0 & 618 & $461 / 577$ \\
\hline
\end{tabular}


Table S4: Analysis of leaf movement in RNAi:PhCHL and non-transgenic segregating siblings (PhWT). Images were analyzed using the JTK algorithm in the Metacycle package. Significant rhythms were tested using the Bejamini-Hochberg critical value (BH.Q). Adjusted P-value (ADJ.P) was used as a cut-off to identify clock-regulated transcripts. When both of them are less than 0.05 , the circadian rhythm is accepted. Period is the time lapse between to peaks. LAG is the time of the first peak. Amplitude is the distance between the average of an oscillation and the peak.

\begin{tabular}{ccccccc}
\hline Group & Tissue & BH.Q & ADJ.P & Period (h) & LAG (phase) & Amplitude \\
\hline PhWT & Leaf 1 & $6.38 \mathrm{e}^{-14}$ & $3.19 \mathrm{e}^{-14}$ & 25 & 11 & 0.1160 \\
& Leaf 2 & $4.30 \mathrm{e}^{-13}$ & $4.30 \mathrm{e}^{-13}$ & 24 & 12.5 & 0.2106 \\
RNAi:CHL & Leaf 1 & $9.663 \mathrm{e}^{-05}$ & $9.66 \mathrm{e}^{-05}$ & 25 & 12.5 & 0.1615 \\
& Leaf 2 & $1.64 \mathrm{e}^{-14}$ & $8.21 \mathrm{e}^{-05}$ & 24 & 11.5 & 0.1283 \\
\hline
\end{tabular}


Chapter II - 128 
Chapter III: The snapdragon LATE ELONGATED HYPOCOTYL plays a dual role in activating floral growth and scent emission. 



\section{Graphical abstract}

- Genes and proteins identification (Arabidopsis as query sequence)

- Primer design

- Phylogeny

- Domain identification

$$
\text { AtLHY }
$$

- Snapdragon: growth and acclimation (light:dark)

- Sampling: leaves and petals (time course)

- DNA for PCR (OMGs identification)

- RNA for qPCR (gene expression)

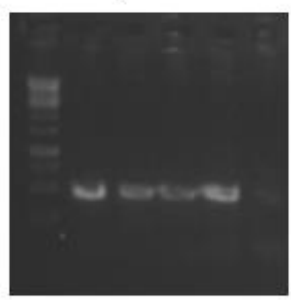

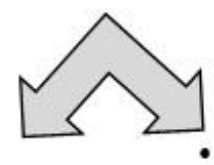

- Silencing target gene. Snapdragon transformation: pHELLSGATE12
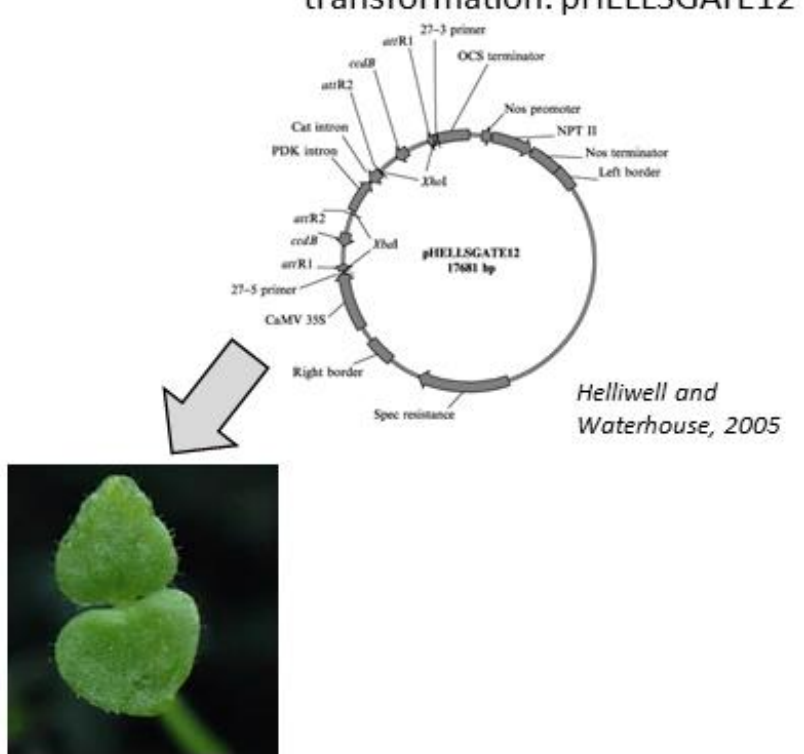

Waterhouse, 2005

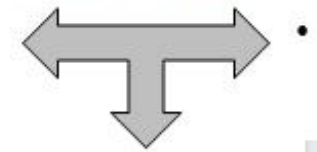

- Collection and identification of volatiles (time course)

- Phenotype

- Growth

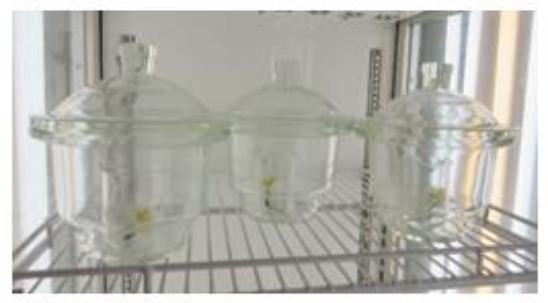


Chapter III - 132 


\title{
cells
}

Article

\section{The Snapdragon LATE ELONGATED HYPOCOTYL Plays A Dual Role in Activating Floral Growth and Scent Emission}

\author{
Marta I. Terry ${ }^{1}$, Fernando Pérez-Sanz ${ }^{2}$, Pedro J. Navarro ${ }^{3}$, Julia Weiss ${ }^{1}$ and Marcos Egea- \\ Cortines 1, * \\ 1 Genética Molecular, Instituto de Biotecnología Vegetal, Edificio I+D+I, Plaza del Hospital s/n, \\ Universidad Politécnica de Cartagena, 30202 Cartagena, Spain \\ ${ }^{2}$ Biomedical Informatic and Bioinformatic Platform, Biomedical Research Institute of Murcia, University \\ C linical Hospital 'Virgen de la Arrixaca', University of Murcia, 30120 Murcia, Spain \\ ${ }^{3}$ Escuela Técnica Superior de Ingeniería de Telecomunicación (DSIE), Campus Muralla del Mar, s/n, \\ Universidad Politécnica de Cartagena, 30202 Cartagena, Spain \\ * Correspondence: marcos.egea@upct.es; Tel.: +34-868-071-077
}

Received: 17 July 2019; Accepted: 16 August 2019; Published: 17 August 2019

\begin{abstract}
:
The plant circadian clock controls a large number of internal processes, including growth and metabolism. Scent emission displays a circadian pattern in many species such as the snapdragon. Here we show that knocking down LATE ELONGATED HYPOCOTYL in Antirrhinum majus affects growth and scent emission. In order to gain an understanding of the growth kinetics, we took a phenomic approach using in-house artificial vision systems, obtaining time-lapse videos. Wild type flowers showed a higher growth speed than knockdown plants. The maximal growth rate was decreased by $22 \%$ in plants with lower LHY expression. Floral volatiles were differentially affected as RNAi plants showed advanced emission of compounds synthesized from cinnamic acid and delayed emission of metabolites of benzoic acid. The monoterpenes myrcene and ocimene were delayed, whereas the sesquiterpene farnesene was advanced. Overall, transgenic lines showed an altered volatile emission pattern and displayed a modified scent profile. Our results show that AmLHY plays an important role in the quantitative and qualitative control of floral growth and scent emission.
\end{abstract}

Keywords: antirrhinum; aroma; artificial vision; biological rhythm; flower development; growth rate; phenomics; RNA interference; volatile organic compounds Cells 2019, 8, 920; doi:10.3390/cells8080920 www.mdpi.com/journal/cells 


\section{Introduction}

Floral organs are arranged in whorls of sepals, petals, stamens, and carpels. They acquire their identities when a set of genes called floral organ identity genes are activated. These organ identity genes activate the morphogenetic program in combinations [1]. The MADS-BOX genes DEFICIENS and GLOBOSA form protein complexes that drive petal and stamen development [2,3]. The so-called C-function genes are involved in the organ identity of the stamens and carpels [4] and cause the termination of the floral meristem development $[5,6]$.

Floral organ size is primarily controlled by the organ identity genes in a quantitative way $[7,8]$. Changes in floral organ size occur by changes in the time and/or rate of cell division and expansion $[9,10]$. Lateral organs grow by a combination of cell division and expansion. Several genes controlling these processes also play a role in the final size of the flower. Amongst them are the transcription factor AINTEGUMENTA [1-4], affecting both cell division and expansion and EXPANSINS, which control primarily cell expansion [11,12].

The emission of floral scent occurs in many cases from petal tissues [13] and has several functions including the attraction and guidance of pollinators and the repulsion of non-beneficial insects $[14,15]$. Apart of the important role of Volatile Organic Compounds (VOCs) emission in plant reproduction and protection, the general floral bouquet, which is perceived by the human olfactory system, is also of aesthetic value $[16,17]$. Floral volatiles are emitted in a circadian fashion and this fact characterizes some plants as day emitters, like Antirrhinum or roses, or night emitters, like Petunia or Silene [18-20], indicating that the majority of the volatiles are released during a given timeframe.

The circadian clock has been extensively studied in Arabidopsis [21]. Research on circadian clock in other species is increasingly contributing to the understanding of the genetics of the circadian clock in plants and the importance of its restructuring for optimal outputs in adaptation to the environment [22-24]. Cell expansion is controlled by the circadian clock through the coordination of DELLA (aspartic acid-glutamic acid-leucine-leucine-alanine) proteins and the PHYTOCHROME INTERACTING FACTOR (PIF) transcription factors [25]. Cell division is also under the direct control of the clock via binding of TIMING OF CAB 1 to the promoter of CDC6 in Arabidopsis [26]. Scent emission is also directly controlled by the clock. Knocking down the LATE ELONGATED HYPOCOTYL (LHY) in Petunia causes the down regulation of the benzenoid/ phenylpropanoid pathway [27], limiting the timing of floral volatile emission to the evening. Additional evidence for a direct role of the circadian clock on the regulation of floral scent emission has been found in Nicotiana attenuate, where knockdown of LHY or ZEITLUPE cause changes in the emission of the attractant benzyl acetone [28]. Recent work has shown that the ortholog of ZEITLUPE in Petunia, PhCHANEL, coordinates scent profiles [29].

In this work, we have addressed the function of the core clock gene LHY on flower development in Antirrhinum majus using RNA interference. Using a phenomics approach we analyzed the effect of knocking down AmLHY on growth. We also analyzed in detail the function of AmLHY on scent emission. Our results indicate a non-linear and complex control of the floral scent synthesis and emission process by AmLHY. 


\section{Material and methods}

\section{Phylogenetic Analysis}

We obtained the AmLHY gene by BLAST (Basic Local Alignment Search Tool) against a set of genomic scaffolds using the Arabidopsis $L H Y$ as a query. We used the close relative gene from Mimulus gutattus (Migut.N01518.2.p) downloaded from Phytozome to obtain a cDNA model using Genewise [30]. The EMBL-EBI accession number was PRJEB24602.

LHY/CCA1 protein sequences were obtained from National for Biotechnology Information (NCBI) using BLASTp (Table S1). REVEILLE (RVE) Arabidopsis protein sequences were used as a query to identify these proteins in Antirrhinum majus, using the program tblastn and the genome version 3 in the Snapdragon Genome Database (http://bioinfo.sibs.ac.cn/Am/index.php), that had been recently released [31]. Protein alignment was performed by CLUSTAL X, a Windows interface for the ClustalW multiple sequence alignment software [32]. Phylogenetic trees were built with the R libraries "ape" and "phangorn" [33,34], Maximum Likelihood was used as a statistical method and Jones, Taylor, and Thornton (JTT) as a model of amino acids substitution [35] with 1000 bootstrap replicates. Trees were visualized with the R package "ggtree" [36]. Protein domains and functional sites were inferred using the web-based tool "PROSITE" (https://prosite.expasy.org/) [37] and the schematic structure of proteins was plotted with the Bioconductor package "drawProteins" [38]. All libraries were built under $\mathrm{R}$ version 3.5.1.

\section{Plant Material and Transformation}

We used the pHELLSGATE12 plasmid [39] to obtain a construct encompassing $156 \mathrm{bp}$, starting $45 \mathrm{bp}$ before the predicted ATG. Antirrhinum majus hypocotyls of the Sippe 50 (Max-Planck-Institut für Pflanzenzüchtungsforschung, Köln, Germany) line were transformed using the Agrobacterium tumefaciens strain EHA105 as described previously [8]. Sippe 50 was an inbred line that had been used for genetic analysis since $1910[40,41]$. As it has been selfed since then it can be considered completely homozygous. Transgenic plants were confirmed by polymerase chain reaction (PCR) based on the amplification of the gene NPTII. Genomic DNA was isolated from leaves using a kit (NucleoSpin ${ }^{\circledR}$ Plant II, Düren, Germany). PCR was conducted with OneTaq ${ }^{\circledR}$ DNA Polymerase (see Table S3 for primers details). The PCR conditions were $30 \mathrm{~s}$ at $94{ }^{\circ} \mathrm{C}$ followed by 40 cycles of $15 \mathrm{~s}$ at $94{ }^{\circ} \mathrm{C}, 30 \mathrm{~s}$ at 60 ${ }^{\circ} \mathrm{C}$, and $30 \mathrm{~s}$ at $72{ }^{\circ} \mathrm{C}$ and terminated by $5 \mathrm{~min}$ at $72{ }^{\circ} \mathrm{C}$.

A. majus Sippe 50 and transgenic snapdragon seeds were germinated in vermiculite and were placed in a growth chamber with $16 \mathrm{~h}$ light $/ 8 \mathrm{~h}$ dark cycle conditions at $23 / 18^{\circ} \mathrm{C}$ during day and night, respectively. Transgenic plants were detected by PCR (NEB, One Taq DNA Polymerase, Ipswich, MA, USA) using NPTII primers (Table S3). We selected 3 independent lines: RNAi:AmLHY14, RNAi:AmLHY26, and RNAi:AmLHY27. Later, seedlings were transferred to pots with a mixture of peat, vermiculite, and perlite 1.1:1 in a greenhouse under natural conditions. Finally, seven days before sampling, plants were placed in a growth chamber with $12 \mathrm{~h}$ light/ $12 \mathrm{~h}$ dark cycles with $23 / 18{ }^{\circ} \mathrm{C}$ temperature cycles. Zeitgeber time 0 (ZT 0) was defined by the time when the lights turnedon.

\section{Gene Expression Analysis}

Fully expanded leaves were collected from 3 to 4 plants at $6 \mathrm{~h}$ intervals for a complete day

h). Leaves were immediately frozen in liquid $\mathrm{N}_{2}$ and stored at $-80^{\circ} \mathrm{C}$ until use. Total RNA from leaves was extracted using a phenol-based method as described in reference [42] and treated with DNase I (Fermentas-ThermoFisher, Waltham, MA, USA). Equal amounts of total RNA (ThermoFisher, NanoDrop 2000, Waltham, MA, USA) were used for cDNA synthesis (ThermoFisher, Maxima First Strand cDNA Synthesis Kit, Waltham, MA, USA). 
AmLHY expression levels were analyzed by quantitative polymerase chain reaction (qPCR) (AgilentMx3000PQPCRSystem, Santa Clara, CA, USA) with SYBR Green (TaKaRa, SYBR Green Master Mix, Kusatsu, Shiga, Japan) according to manufacture manuals, and the following protocol was used for 40 cycles: $95{ }^{\circ} \mathrm{C}$ for 4 min and then cycling at $95{ }^{\circ} \mathrm{C}$ for $15 \mathrm{~s}, 60{ }^{\circ} \mathrm{C}$ for $15 \mathrm{~s}$, and $72{ }^{\circ} \mathrm{C}$ for $30 \mathrm{~s}$. UBIQUITIN (AmUBQ) was used as an internal control and samples were run in duplicate (Table S3). Normalized expression was expressed as $2^{-\Delta \Delta C t}$, thus we used an efficiency of 2 for data analysis [43]. Daily gene expression of $A m L H Y$ was normalized by the average expression level across the timecourse; AmLHY expression in RNAi lines was normalized to WT. To test differences in expression between wild-type and transgenic plants we performed a Student's $t$-test using the package "stats" in $\mathrm{R}$ ( $\mathrm{R}$ version3.5.1).

\section{Flower Measurements}

Flowers from A. majus Sippe 50 non-transgenic siblings and T2 generations were measured 2 to 3 days post-anthesis according to reference [44]. Flowers were sampled from 3 to 4 different plants per group. In total, we measured 8 flowers from non-transgenic siblings, 9 flowers from RNAi:AmLHY14, 4 flowers from RNAi:AmLHY26, and 7 flowers from RNAi:AmLHY27 line. Floral parameters were compared between non-transgenic and transgenic siblings with the Student's t-test performed in $R(R$ version 3.5.1).

\section{Growth Analysis and Artificial Vision}

We used an image acquisition system described previously [45,46]. Plants were grown inside a growth chamber comprising LED day lights covering from UV to red light. Night images were taken by activating an infrared light at $840 \mathrm{~nm}$ wavelength during short intervals of time (3 s). Images were acquired with an artificial vision camera comprising two CCD sensors, a multichannel 24-bits RGB absorbing at $610 \mathrm{~nm}, 540 \mathrm{~nm}$, and $460 \mathrm{~nm}$, and a monochromatic sensor capturing at $800 \mathrm{~nm}$. The acquired images have a resolution of $1296 \times 966$ pixels.

We obtained data using a light/dark $12 \mathrm{~h} / 12 \mathrm{~h}$ period of $A$. majus Sippe 50 and the segregating siblings of RNAi:AmLHY for a period of 8 days and $7 \mathrm{~h}$. Images were acquired every $10 \mathrm{~min}$ for a total of 1196 images comprising 3 wild type and 3 transgenic flowers. Using a semiautomatic process, we measured the length every two hours. A curve was fitted to the raw data using a GENERAL ADDITIVE MODEL (GAM) using the package " $\mathrm{mgcv}$ " from $\mathrm{R}$. The maximum growth corresponded to the maximal size of the flowers, corresponding to the maximal value of the curve. We obtained the maximal slope that would correspond to the maximum growth rate by deriving 200 points of the curve and obtaining the highest number. The area under the curve was obtained by integrating the fitted curve using the integrative function from the "stats" package. 


\section{Volatiles Collection, Gas Chromatography Mass Spectrometry, and Scent Analysis}

Non-transgenic plants and plants belonging to T2 generations were sampled. Three or four flowers per line from 2 to 3 days post anthesis were used as described previously [47]. We collected volatiles starting at ZT3, for a period of $6 \mathrm{~h}$ during $24 \mathrm{~h}$. All plants were acclimated to $12 \mathrm{~h}$ light $/ 12 \mathrm{~h}$ dark (12LD) and $18 / 23^{\circ} \mathrm{C}$ cycle. The volatiles captured were analyzed by gas chromatography mass spectrometry (GC/MS) as described in reference [8]. Flower scent was analyzed by the R package "gcProfileMakeR" (unpublished results), selecting a 60\% frequency and default quality. Selected volatiles amount was expressed as an integrated area divided by flower fresh weight [48]. The phase was calculated using the JTK-CYCLE implemented in "MetaCycle" [49] (R version 3.5.1). Graphs were plotted with "ggplot2" [50] using a color blind-friendly palette provided by "viridis" [51]. Volatile pathways were represented using the software "PathVisio" (version 3.3.0) [52].

\section{Results}

\section{The Antirrhinum majus $L H Y$}

We obtained a single scaffold that had high similarity to the LHY gene from Arabidopsis. A multiple sequence alignment of the translated proteins showed a high level of homology of snapdragon LHY (AmLHY) to other LHY and REVEILLE (RVE) coding genes (Figure S1, Table S1). In total, we identified seven RVEs genes in snapdragon and one LHY by BLAST, with high similarity to Arabidopsis (Table S2). A phylogenetic reconstruction using predicted proteins showed that the AmLHY clusters with other LHY proteins and they were clearly separated from the RVE clade (Figure S1). Moreover, CCA1a and CCA1b from Physcomitrella patens clustered between the RVE1/2/7 and RVE4/8 clades. LHY/CCA1/RVE (AtLHY, AtCCA1, and AtRVE in Arabidopsis) are MYB proteins, which are characterized by a conserved DNA-binding domain [53-55].

We identified the MYB domain and the HTH DNA-binding domain (helix-turn-helix motif) in AmLHY, which were highly conserved in size and position, as observed in other species such as Petunia or Vigna (Figure S1C). The coding region of AmLHY differed compared to AtLHY. AmLHY showed additional aminoacids that resulted in a longer protein (Figure S2). As mentioned above, we identified seven genes related to the RVE family in snapdragon, which shared a high homology with Arabidopsis except for three genes. We could not identify the MYB domain in AmRVE1/2/7A and AmRVE1/2/7B, while AmRVE1/2/7D showed two MYB domains (Figure S1C), suggesting an internal gene duplication.

\section{The AmLHY Shows A Diurnal Expression Pattern}

Weanalyzed the expression of $A m L H Y$ in leaves of wild-type plants under a 12LD cycle. Wefound that $A m L H Y$ expression increased at the end of the subjective night, peaking in the early morning. AmLHY showed a robust and significant oscillation (Figure 1a, $p$ value $=3.3 \times 10^{-06}$ ), as described in other species including Arabidopsis, cowpea, or wild tobacco [54,56,57]. We selected T1 plants from three independent lines (RNAi:AmLHY14, RNAi:AmLHY26 and RNAi:AmLHY27). In T2, all selected lines displayed a significant lower transcript level of AmLHY (Figure 1b, Table 1). RNAi:AmLHY14 showed an average of $90 \%$ reduction in AmLHY expression levels, RNAi:AmLHY26 of 65\% and finally, RNAi:AmLHY 27 of $74 \%$. 
a) AmLHY daily expression

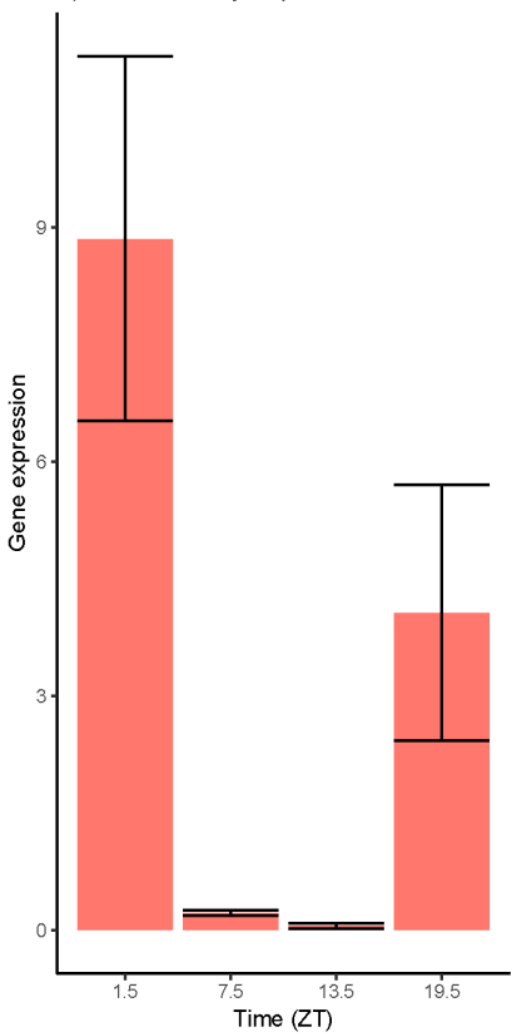

b) AmLHY expression

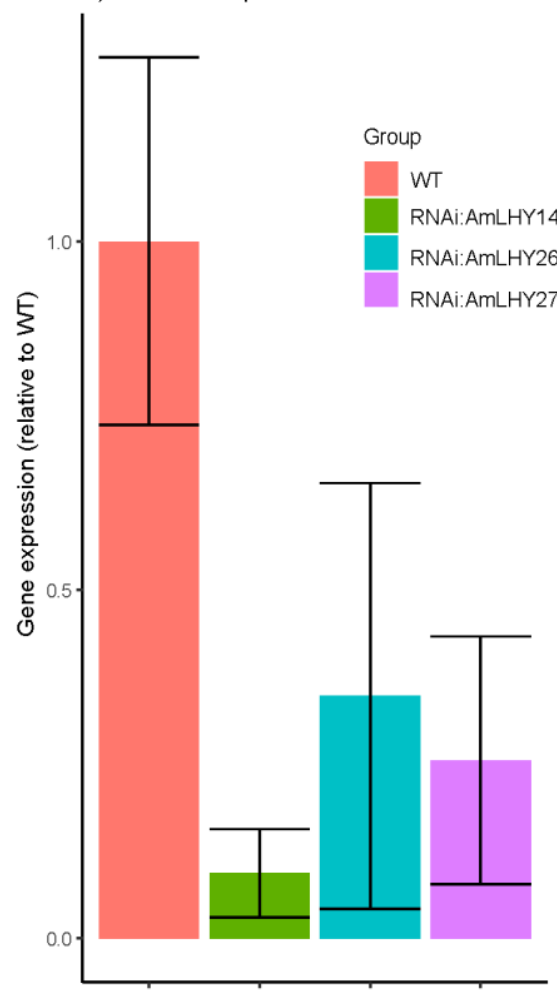

Figure 1: AmLHY expression (a) Daily expression in wild-type plants under a $12 \mathrm{~h}$ light/12 h dark (12LD) cyle; (b) AmLHY expression at ZT1.5 in wild-type (red) and transgenic lines RNAi:AmLHY14 (green), RNAi:AmLHY26 (blue) and RNAi:AmLHY27 (purple). Expression was determined by the $\triangle \mathrm{C}$ method using the wild-type as a control. Reference gene was AmUBI. Each bar represents the average \pm standard deviation from 3 to 4 biological replicates.

Table 1: AmLHY expression in wild-type and RNAi lines at ZT 1.5. Expression was normalized by WT. Average and standard deviation (SD) represents 3 to 4 biological replicates. The knock down percentage in RNAi lines is shown in the $\%$ KD column. Differences were tested by a Student's $t$-test; a $p$-value $<0.05$ indicates a significant down-regulation.

\begin{tabular}{ccccc}
\hline Group & Average & SD & \% KD & $p$-Value \\
\hline WT & 1 & 0.263 & & \\
RNAi:AmLHY14 & 0.093 & 0.063 & 90.66 & 0.001 \\
RNAi:AmLHY26 & 0.348 & 0.306 & 65.23 & 0.006 \\
RNAi:AmLHY27 & 0.256 & 0.17 & 74.44 & 0.003 \\
\hline
\end{tabular}

\section{AmLHY Does Not Affect Flower Morphology and Size}

The typical snapdragon flower has five sepals and five petals, these petals are fused resulting in a tubular and bilaterally symmetrical flower. We did not observe changes in organ identity or aberrant growth. All plants showed fully opened flowers.

We characterized snapdragon flowers analyzing 11 floral parameters, comparing the wild-type Sippe 50 and RNAi:AmLHY lines. These measurements included sepals, petals, and reproductive organs. The down regulation of $L H Y$ did not significantly affect the flower size, with the exception of petal height, lower petal expansion, and palate, which decreased in RNAi:AmLHY14 line (Figure S3, TableS4). 


\section{AmLHY Enhances Growth Speed}

The study of mutants affecting floral size in Arabidopsis, Antirrhinum, and other species have relied mostly on endpoint analysis of mutants [10,58]. There is very little information about the growth kinetics that causes the final changes in terms of size. Modifications in growth leading to differences in final size may occur as a result of the duration of the growth period, changes in growth speed, or a combination of both parameters. We used a previously described in-house artificial vision system to obtain time lapse pictures of line RNAi:AmLHY27 and an azygote segregating sibling (Movie S1). We obtained growth curves for wildtype and transgenic siblings and results showed a very strong effect of the down regulation of $A m L H Y$ on flower growth rate (Figure 2). The maximal growth speed achieved by the RNAi:AmLHY line was roughly $78 \%$ of the non-transgenic sibling, and the area under the growth curve model was $73 \%$ of the non-transgenic sibling (Table 2). The maximal slope used to calculate growth rate [59] suggested that the overall growth rate was only $51 \%$ as compared to wild type. As far as we could analyze, the length of the flower growth period was similar in WT and in RNAi:AmLHY27, indicating that modifying the plant circadian clock affected growth speed in the petals.

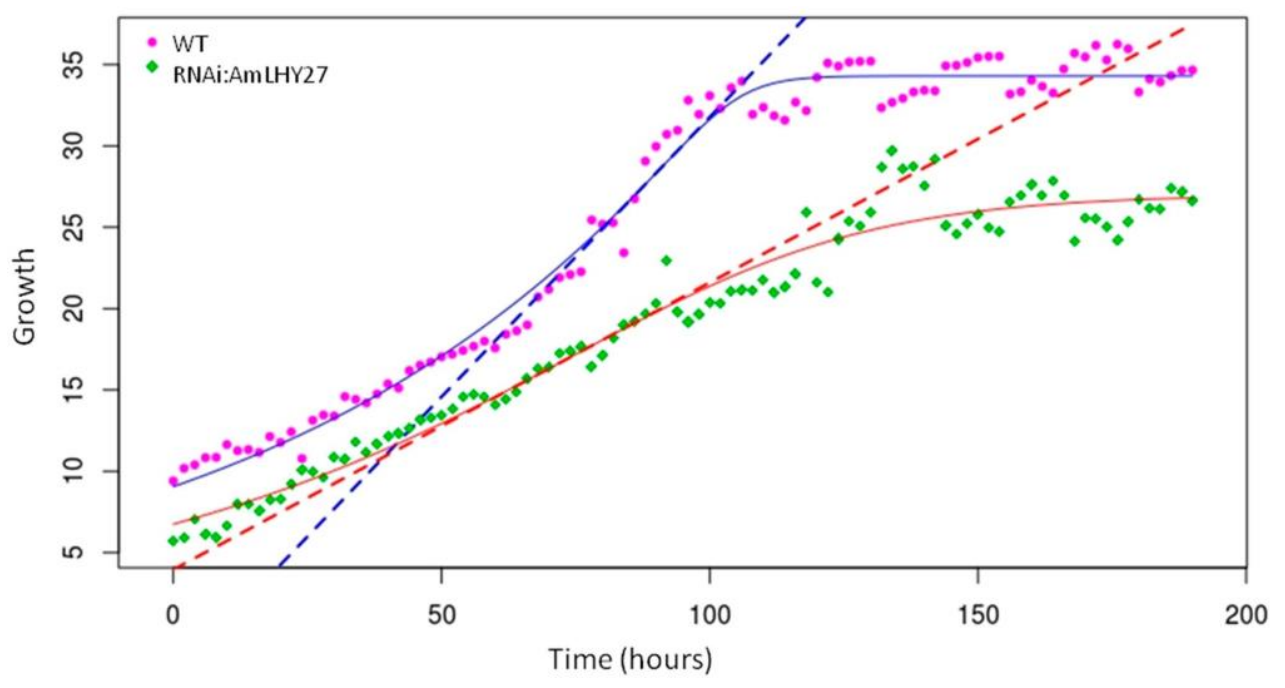

Figure 2: Growth curve expressed in mm, of flowers of non-transgenic (WT, purple) and RNAi.AmLHY27 (green). Dots represent the raw data, solid lines indicate the adjusted curve and dashed lines denote the maximum slope, that corresponds to the maximum growth rate.

Table 2: Parameters obtained from the phenomic analysis. Maximum growth corresponds to final maximum of the curve in $\mathrm{mm}$. The maximum slope indicates the growth rate. The area under the model is an estimation of the difference in accumulated growth.

\begin{tabular}{cccc}
\hline Group & Max. Growth/Std. & Max. Slope/Std. & Area \\
\hline WT & $34.301 / 0.191$ & $0.344 / 0.021$ & 4892.457 \\
RNAi:AmLHY27 & $27.014 / 0.531$ & $0.176 / 0.0078$ & 3604.565 \\
\hline
\end{tabular}

\section{$A m L H Y$ is Required for Major Volatile Production}

We analyzed the floral scent emitted by wild-type and RNAi:AmLHY flowers using a time course with sampling six hours apart. A collection of volatiles was performed under a 12LD cycle. We detected 15 compounds during the time-course sampling (Table S5). Most detected volatiles belonged to the phenylpropanoid/benzenoid pathway but we also found terpenes as described previously [60]. 
We divided the volatile organic compounds into two groups. The first group comprised those VOCs, which contributed to the scent profile above $2 \%$ (major volatiles) and the second group contained the remaining compounds (minor volatiles). The major group comprised five compounds: Acetophenone, methyl benzoate, 3,5-dimethoxytoluene, ocimene, and linalool. We found major changes in the overall profile $(24 \mathrm{~h})$ in RNAi:AmLHY. The monoterpenes ocimene and linalool increased their levels in transgenic lines by $34.5 \%$ and $46.16 \%$, respectively. In contrast, the volatile 3,5-dimethoxytoluene contribution to the scent profile was reduced by $23.6 \%$ in RNAi plants. Acetophenone and methyl benzoate, the two major compounds, decreased but not significantly in RNAi lines (2.6 and 7.5\% respectively) (Figure S4). These five compounds comprised $98.35 \%$ of the profile in wild-type plants and an average of $97.81 \%$ in RNAi:AmLHY lines. Interestingly, the minor volatiles, whose contribution to the fragrance aroma was 1.65\% in WT and $2.19 \%$ in transgenic lines, revealed the highest complexity of the snapdragon aroma. Weclassified the volatiles into two groups. The first group comprised compounds which decreased in the profile: The aldehydes nonanal and decanal. The second group included the benzenoids/phenylpropanoids 2-hydroxyacetophenone, benzaldehyde, cinnamylalcohol, ethyl benzoate, methyl cinnamate, and methyl salicylate, and the terpenes farnesene and myrcene, which increased their contribution to the odour (FigureS4).

Daily emission also revealed changes in the scent profile. In major compounds, we found that the contribution of the benzenoids acetophenone and 3,5-dimethoxytoluene to the scent profile was lower in RNAi lines along all the time points analyzed. Methyl benzoate level was lower in all time points, except at ZT15, which increased its contribution slightly. In contrast, the monoterpenes linalool and ocimene were higher in transgenic lines (Figure3).

a) Wild-type

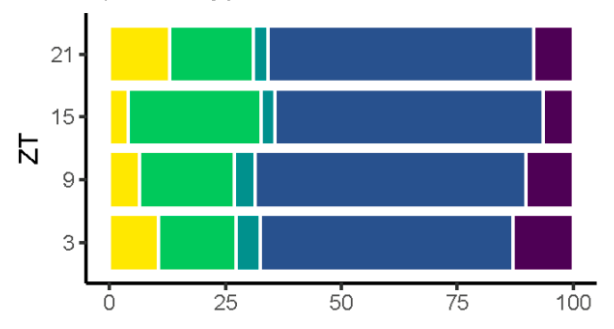

c) RNAi:AmLHY26

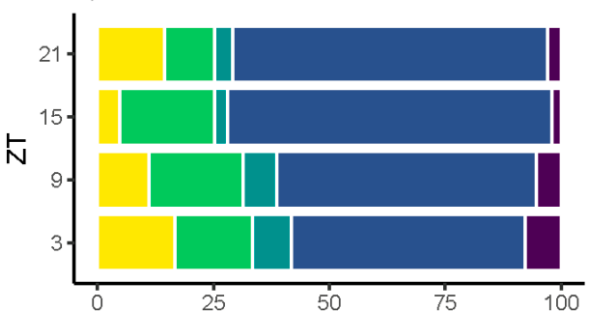

e) RNAi (average)

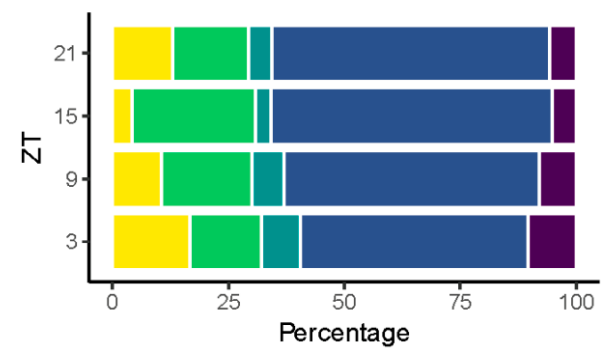

b) RNAi:AmLHY14

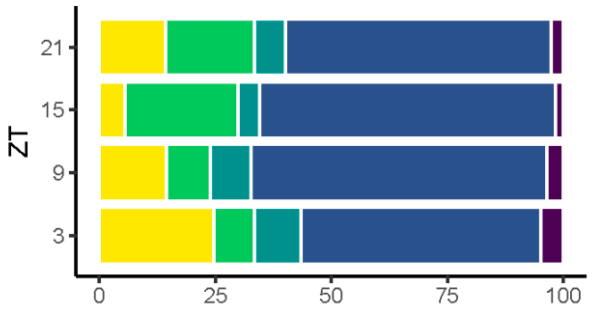

d) RNAi:AmLHY27

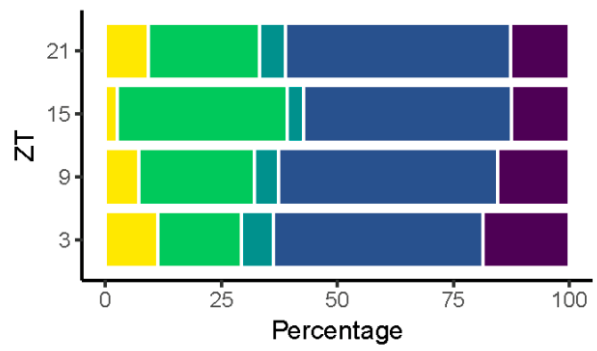

VOC

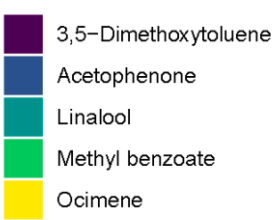

Figure 3: Daily scentemission of major compounds in wild type (a), and transgenic lines RNAi:AmLHY14 (b), RNAi:AmLHY26 (c), RNAi:AmLHY27 (d). An average of RNAi lines is represented in (e). ZT indicates zeitgeber time. 
We also observed changes in minor volatiles. The aldehydes nonanal and decanal contribution werelower in transgenic lines. Furthermore, the benzenoid/phenylpropanoids benzadelhyde, cinnamyl alcohol, and methyl salicylate levels were higher in RNAi:AmLHY lines. The remaining compounds, 2-hydroxyacetophenone, ethyl benzoate, methyl cinnamate, and myrcene did not show a robust pattern as myrcene, that showed the highest increment by $668 \%$ at ZT9, but decreased by $33 \%$ at ZT15 and by $37 \%$ at ZT21 (Figure 4 ).

a) Wild-type

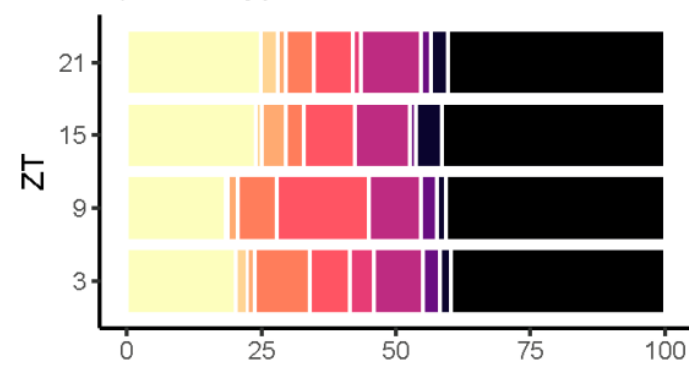

c) RNAi:AmLHY26

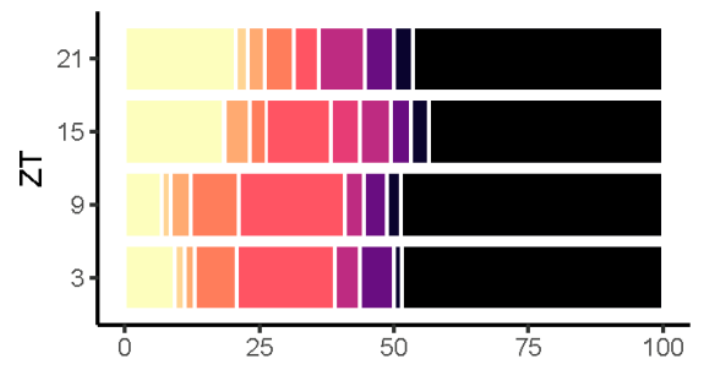

e) RNAi (average)

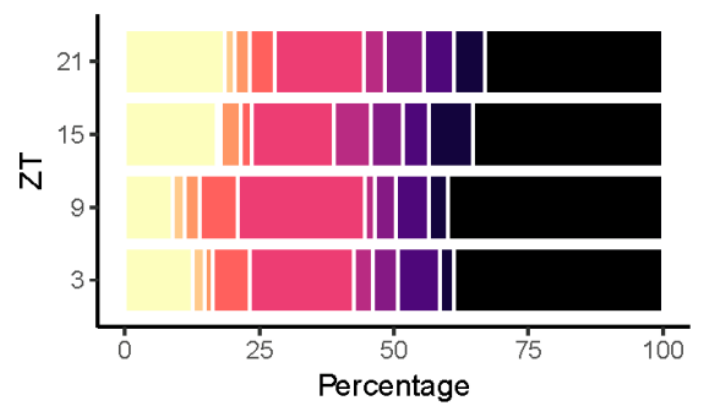

b) RNAi:AmLHY14

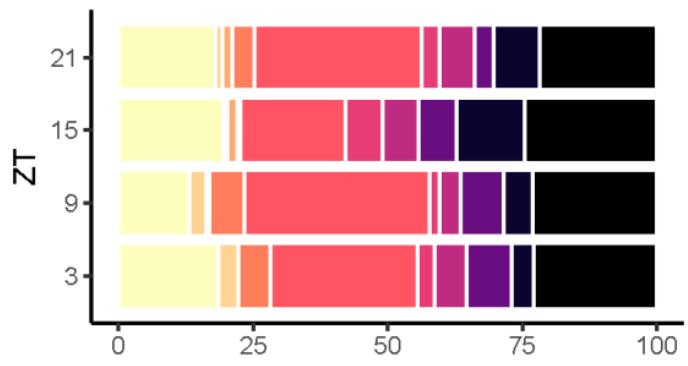

d) RNAi:AmLHY27

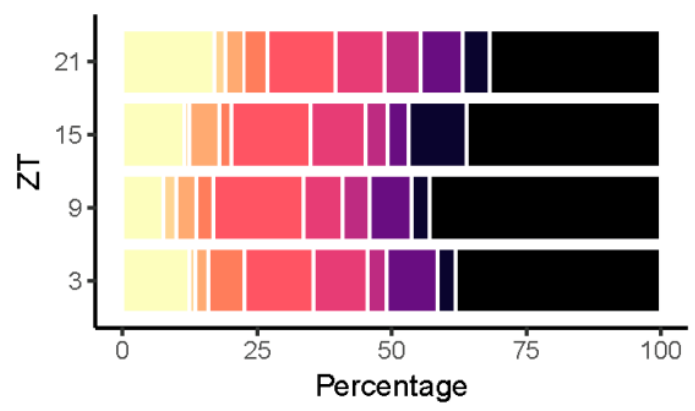

Figure 4: Daily scentemission of minor compounds in wild type (a), and transgenic lines RNAi:AmLHY14 (b), RNAi:AmLHY26 (c), RNAi:AmLHY27 (d). An average of RNAi lines is represented in (e). ZT indicates zeitgeber time.

Altogether these results suggest a complex regulation of synthesis and/or emission of volatile organic compounds by $A m L H Y$, acting at different levels over the phenylpropanoid/benzenoid and terpene pathways. All these changes resulted in a different and new flower-odour blend.

\section{AmLHY Controls the Timing of ScentEmission}

We detected 15 volatile organic compounds (Table S5; Figures 3 and 4). In wild-type flowers, most selected volatiles showed a diurnal pattern. The release of VOCs started in the early morning, reaching their maximum emission at midday or before dusk. We classified the emitted VOCs in three groups based on their time of maximum emission. The first group comprises myrcene, ocimene, linalool, 
decanal, nonanal, 3,5-dimethoxytoluene, 2-hydroxiacetophenone, and methyl cinnamate, that reached their maximum emission at early day and midday. A second group included cinnamyl alcohol and farnesene that peaked at the end of the light period. Finally, the third group covered acetophenone, methyl benzoate, and methyl salicylate, which increased their emission at midnight (Table S6).

In contrast, we found that the maximum emission of some VOCs shifted in RNAi lines, and we divided the volatiles into three groups. First, the monoterpene linalool, the aldehydes nonanal and decanal and the benzenoids/phenylpropanoids cinnamyl alcohol, 3,5-dimethoxytoluene, and 2hydroxyacetophenone did not present any differences with wild-type flowers, showing its maximum emission at the same time. The second group comprised the derivatives of benzoic acid methyl benzoate and methyl salicylate, and the monoterpenes myrcene and ocimene, which delayed their maximum emission. Finally, acetophenone, benzaldehyde, methyl cinnamate (except in line RNAi:AmLHY26, which did not show any difference) and the sesquiterpene farnesene peaked early in transgenic lines (Table S6). We could not determine the phase of the ethyl benzoate, due to their irregular emission (Table S6).

Based on the known phenylpropanoid/benzenoid pathway we divided it into two principal branches, which have a common precursor, L-phenylalanine. The first branch included those compounds that derived from trans-cinnamic acid, as methyl cinnamate. The second branch covered benzoic acid derivatives, methyl salicylate, and methyl benzoate (Figure 5). Our results showed that the down-regulation of $A m L H Y$ advanced the maximum emission of acetophenone, benzaldehyde, and methyl cinnamate, while it caused a delayed peak of methyl salicylate and methyl benzoate.

a)

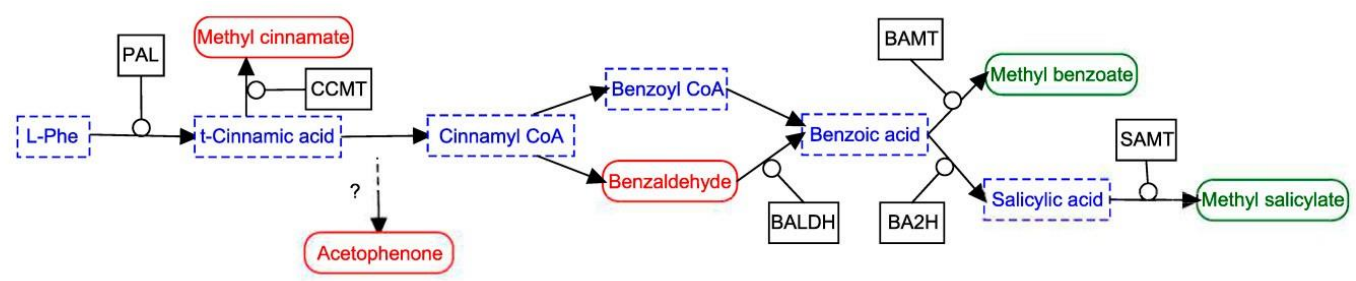

b)

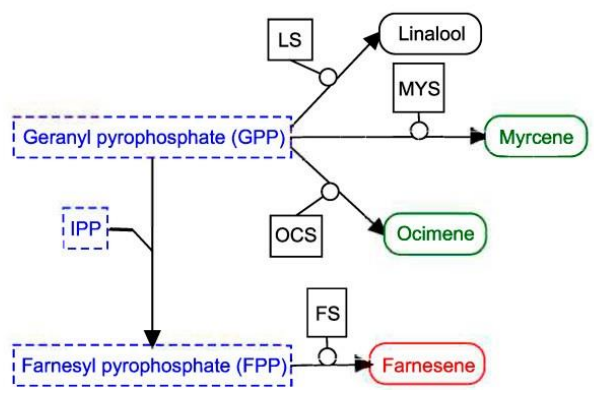

Legend

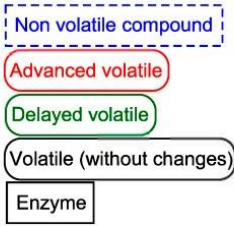

Figure 5: Schematic view of some phenylpropanoids/benzenoids (a), monoterpenes (b) and sesquiterpenes (c) pathway. Non-volatile compounds are represented in a dashed and blue rectangle and volatile compounds with a solid line and a rounded rectangle, the green color indicates a volatile that displays a delayed emission and the red color, an advanced emission. Enzymes and the $\mathrm{C}_{5}$ unit IPP (isopentyl diphosphate) are shown over the arrows. Enzyme abbreviations: BA2H (benzoic acid 2-hydroxylase), BALDH (benzaldehyde dehydrogenase), BAMT (benzoic acid carboxyl methyl transferase), CCMT (cinnamic acid carboxyl methyl transferase), FS (farnesene synthase), LS (linalool synthase), MYS (myrcene synthase), OCS (ocimene synthase), PAL (phenylalanine ammonia lyase) and SAMT (salicylic acid carboxyl methyl transferase).

We found a similar pattern in terpene emission. Geranyl pyrophosphate (GPP) is the precursor of the monoterpenes linalool, myrcene, and ocimene [61], whose reactions are catalyzed by linalool synthase (LS), myrcene synthase (MYS) and ocimene synthase (OCS), respectively. RNAi flowers displayed a delayed emission of myrcene and ocimene, peaking at midday (ZT6). 
In contrast, linalool was not affected. The emission of farnesene, a sesquiterpene that derives from farnesyl pyrophosphate (FPP) by addition of isopentyl diphosphate (IPP) to GPP [62], was advanced in transgenic snapdragons (Figure 5, Table S6).

Altogether, our results suggest that AmLHY regulates the synthesis and/or emission of volatile compounds at different levels. First, principal changes were found in minor compounds contribution, which comprises the highest diversity fraction of snapdragon aroma. Second, the emission of those VOCs derived from trans-cinnamic acid (benzaldehyde and methyl cinnamate) started earlier, whereas the compounds that derived from benzoic acid (methyl benzoate and methyl salicylate) started later. The terpenes myrcene and ocimene, which shared the precursor GPP, also displayed a delayed emission phenotype, while farnesene peaked early in RNAilines.

\section{Discussion}

In this work, we have performed a functional analysis of the Antirrhinum majus LHY gene. The LHY gene is found as a single copy gene in many plants such as Petunia, Arabidopsis, tomato, or Nicotiana attenuata [23,57]. Our results indicate that in Antirrhinum there is a single gene that may have similar functions to the ones described in Arabidopsis, Petunia, or Nicotiana, including control of growth and scent emission. In this work, we have uncovered a function in floral development where it enhances growth speed.

We found that loss of function of $L H Y$ in Antirrhinum does not affect organ identity. Despite the importance of the plant circadian clock on the maintenance of the photosynthetic apparatus $[63,64]$, our results indicate that the plant circadian clock is not involved in the degradation of the chlorophyll machinery during petal development. Sepaloid petals result from decreased activity of B function genes and their targets [65], but we could not find evidence for an effect of AmLHY on petal identity. The transcriptional structure of the plant circadian clock varies between tissues and possible changes of the plant clock in petals versus other tissues or organs remains to be determined.

The size of plant lateral organs is the result of a combination of cell division and expansion. A variety of mutants affecting these processes in Antirrhinum show that petal growth can be differentially affected by genes indicating an intricate coordination of cell division, cell expansion, and compensation mechanisms [66]. The plant circadian clock is known to control cell expansion, our results demonstrate that $A m L H Y$ did not affect equally all the floral parameters analyzed. Our results did not differ from the findings in nightshades as down regulation of $L H Y$ does not affect floral size, petal junction distance, and corolla length, in Nicotiana attenuata or Petunia[27,28].

The temporal timing of cell division and expansion plays a key role in plant development. Both the length of the growth period and growth rate determine the final size of an organ. Our phenomic analysis of the Antirrhinum flower shows that the growth period is not controlled by AmLHY whereas the growth rate is substantially reduced. We may conclude that the period between cell divisions could be elongated in RNAi:AmLHY plants, resulting in organs with fewer and/or smaller cells. This hypothesis may require additional testing. Recent studies indicate that $L H Y$ represses abscisic acid (ABA) synthesis and signaling pathways [61], indicating that the newly identified effect of AmLHY on growth may occur via modulation of ABA. Our results are congruent due to the slow growth rate observed in RNAi plants highlighting the role of the circadian clock in flower development. The fact that floral organ size is not significantly reduced but growth speed is slowed in AmLHY knockdown lines indicates that compensation in terms of growth time may be occurring in order to achieve wild type organ size.

Floral scent profiles play a key role in the interaction of plants with both pollinators and pests [14]. The volatile blend is thought to be a complex interphase of interaction, and it is specific for a species [60]. The A. majus scent profile is highly complex as it comprises phenylpropanoids/benzenoids, and terpenes amongst the major VOCs. Previous studies showed that silencing ZTL in Nicotiana atenuatta causes a major reduction of benzyl acetone while $L H Y$ causes an early emission. The down regulation of $P h L H Y$ causes an earlier emission and reduction of methyl benzoate and benzyl benzoate [27,28]. 
Interestingly, bumblebees, one of the A. majus pollinators, are capable of detecting variations in aroma blends among snapdragon species, and wild Antirrhinum emitting different scent blends appear to have specialized pollinators $[67,68]$. As silencing AmLHY resulted in new aroma ratios, it may alter pollinators behaviour. Future studies may address the effect of silencing $A m L H Y$ and the interaction with pollinators as well as pests and/or pathogens.

Wefound that AmLHY plays a complex and central role in the coordination of floral scent emission, affecting timing and scent profile. While it does not have a major effect on the total emission, it has a profound effect on the emission of single volatiles. An important difference between Antirrhinum and the Solanaceae Nicotiana and Petunia is that it emits floral volatiles preferentially during the day. In contrast to previously published work in Petunia [27], we found that the down regulation of $A m L H Y$ caused a delayed emission of methyl benzoate (Figure 5). We can conclude that as the expression patterns of AmLHY and PhLHY are identical, the opposite effect on individual scent components emission timing is probably coordinated by a second layer of transcription factors. As the emission of single volatiles from the phenylpropanoids/benzenoids and monoterpene/sesquiterpenes is advanced or delayed in a consistent manner it appears that there might be either a difference at the transcriptional level or at the actual metabolic flux, giving rise to the observed differences. These two scenarios are not mutally exclusive and future research should help us understand the fine tuning of scent emission by AmLHY.

\section{Conclusions}

Our work shows that AmLHY plays a role in growth and scent emission. The combination of floral organ identity and circadian control are main factors required for proper flower development. Our results also revealed that the complexity of floral aroma depends on timing emission, which is under circadian clock regulation, and the contribution (or amount) of every single volatile. Interestingly, the down-regulation of $A m L H Y$ affected volatiles biosynthesis pathways at different branches. Timing of emission is an additional variable that may be well worth testing in plant-insect interactions.

Supplementary Materials: The following are available online at http://www.mdpi.com/2073-4409/8/8/920/s1, Movie S1: Snapdragon flowers growth, Figure S1: Phylogenetic reconstruction of AmLHY, LHY, and RVE predicted proteins, Figure S2: AtLHY and AmLHY protein alignment, Figure S3: Floral parameters in non-transgenic (WT) and transgenic lines (RNAi:AmLHY), Figure S4: $24 \mathrm{~h}$ scent profile, Figure S5: Total volatile amounts, Table S1: Accession numbers of proteins used in phylogenetic reconstruction, Table S2: BLAST analysis, Table S3: PCR primers used in the current study, Table S4: Analysis of floral parameters in non-transgenic and transgenic lines, Table S5: Retention time in minutes Table S6: Analysis of daily emitted volatiles with the algorithm JTK_CYCLE.

\section{Author Contributions:}

Conceptualization, M.I.T., F.P.-S., P.J.N., J.W. and M.E.-C.; data curation, M.I.T., F.P.-S., J.W., and M.E.-C.; formal analysis, M.I.T., F.P.-S., P.J.N., J.W., and M.E.-C.; funding acquisition, P.J.N., J.W. and M.E.-C.; investigation, M.I.T., F.P.-S., P.J.N., J.W., and M.E.-C.; Methodology, M.I.T., F.P.-S., P.J.N., and M.E.-C.; project administration, P.J.N., J.W., and M.E.-C.; resources, J.W. and M.E.-C.; software, F.P.-S. and P.J.N.; supervision, P.J.N., J.W., and M.E.C.; validation, M.E.-C.; writing-original draft, M.I.T., J.W. and M.E.-C.; writing-review and editing, M.I.T., F.P.S., P.J.N., J.W., and M.E.-C.

Funding: This research was funded by Ministerio de Ciencia, Innovación y Universidades MICINN grants BFU-2017- 88300C2-1-R (JW and MEC) and BFU-2017- 88300-C2-2-R (PJN).

Conflicts of Interest: The authors declare no conflict of interest. 


\section{References}

1. Irish, V. The ABC model of floral development. Curr. Biol. 2017, 27, R887-R890. [Google Scholar] [CrossRef] [PubMed]

2. Davies, B.; Egea-Cortines, M.; de Andrade Silva, E.; Saedler, H.; Sommer, H. Multiple interactions amongst floral homeotic MADS box proteins. EMBO J. 1996, 15, 4330-4343. [Google Scholar] [CrossRef] [PubMed]

3. Egea-Cortines, M.; Saedler, H.; Sommer, H. Ternary complex formation between the MADS-box proteins SQUAMOSA, DEFICIENS and GLOBOSA is involved in the control of floral architecture in Antirrhinum majus. EMBO J. 1999, 18, 5370-5379. [Google Scholar] [CrossRef] [PubMed]

4. Bradley, D.; Carpenter, R.; Sommer, H.; Hartley, N.; Coen, E. Complementary floral homeotic phenotypes result from opposite orientations of a transposon at the plena locus of antirrhinum. Cell 1993, 72, 85-95. [Google Scholar] [CrossRef]

5. Lenhard, M.; Bohnert, A.; Jürgens, G.; Laux, T. Termination of Stem Cell Maintenance in Arabidopsis Floral Meristems by Interactions between WUSCHEL and AGAMOUS. Cell 2001, 105, 805-814. [Google Scholar] [CrossRef]

6. Lohmann, J.U.; Hong, R.L.; Hobe, M.; Busch, M.A.; Parcy, F.; Simon, R.; Weigel, D. A Molecular Link between Stem Cell Regulation and Floral Patterning in Arabidopsis. Cell 2001, 105, 793-803. [Google Scholar] [CrossRef]

7. Bey, M.; Stüber, K.; Fellenberg, K.; Schwarz-Sommer, Z.; Sommer, H.; Saedler, H.; Zachgo, S. Characterization of Antirrhinum Petal Development and Identification of Target Genes of the Class B MADS Box Gene DEFICIENS. Plant Cell 2004, 16, 3197-3215. [Google Scholar] [CrossRef]

8. Manchado-Rojo, M.; Delgado-Benarroch, L.; Roca, M.J.; Weiss, J.; Egea-Cortines, M. Quantitative levels of Deficiens and Globosa during late petal development show a complex transcriptional network topology of B function. Plant J. 2012, 72. [Google Scholar] [CrossRef]

9. Reale, L.; Porceddu, A.; Lanfaloni, L.; Moretti, C.; Zenoni, S.; Pezzotti, M.; Romano, B.; Ferranti, F. Patterns of cell division and expansion in developing petals of Petunia hybrida. Sex. Plant Reprod. 2002, 15, 123-132. [Google Scholar] [CrossRef]

10. Weiss, J.; Delgado-Benarroch, L.; Egea-Cortines, M. Genetic control of floral size and proportions. Int. J. Dev. Biol. 2004, 49, 513-525. [Google Scholar] [CrossRef]

11. Zenoni, S.; Fasoli, M.; Tornielli, G.B.; Santo, S.D.; Sanson, A.; de Groot, P.; Sordo, S.; Citterio, S.; Monti, F.; Pezzotti, M. Overexpression of PhEXPA1 increases cell size, modifies cell wall polymer composition and affects the timing of axillary meristem development in Petunia hybrida. New Phytol. 2011, 191, 662-677. [Google Scholar] [CrossRef]

12. Zenoni, S.; Reale, L.; Tornielli, G.B.; Lanfaloni, L.; Porceddu, A.; Ferrarini, A.; Moretti, C.; Zamboni, A.; Speghini, A.; Ferranti, F.; et al. Downregulation of the Petunia hybrida $\alpha$-Expansin Gene PhEXP1 Reduces the Amount of Crystalline Cellulose in Cell Walls and Leads to Phenotypic Changes in Petal Limbs. Plant Cell 2004, 16, 295-308. [Google Scholar] [CrossRef]

13. Adebesin, F.; Widhalm, J.R.; Boachon, B.; Lefèvre, F.; Pierman, B.; Lynch, J.H.; Alam, I.; Junqueira, B.; Benke, R.; Ray, S.; et al. Emission of volatile organic compounds from petunia flowers is facilitated by an ABC transporter. Science 2017, 356, 1386-1388. [Google Scholar] [CrossRef]

14. Kessler, D.; Diezel, C.; Clark, D.G.; Colquhoun, T.A.; Baldwin, I.T. Petunia flowers solve the defence/apparency dilemma of pollinator attraction by deploying complex floral blends. Ecol. Lett. 2013, 16, 299-306. [Google Scholar] [CrossRef] 
15. Turlings, T.C.; Ton, J. Exploiting scents of distress: The prospect of manipulating herbivore-induced plant odours to enhance the control of agricultural pests. Curr. Opin. Plant Biol. 2006, 9, 421-427. [Google Scholar] [CrossRef]

16. Verhoeven, H.A.; Blaas, J.; Brandenburg, W.A. Fragrance Profiles of Wild and Cultivated Roses. In Reference Module in Life Sciences; Elsevier: Amsterdam, The Netherlands, 2017; ISBN 978-0-12-809633-8. [Google Scholar]

17. Pichersky, E.; Dudareva, N. Scent engineering: Toward the goal of controlling how flowers smell. Trends Biotechnol. 2007, 25, 105-110. [Google Scholar] [CrossRef]

18. Kolosova, N.; Gorenstein, N.; Kish, C.M.; Dudareva, N. Regulation of Circadian Methyl Benzoate Emission in Diurnally and Nocturnally Emitting Plants. Plant Cell 2001, 13, 2333-2347. [Google Scholar] [CrossRef]

19. Dötterl, S.; Wolfe, L.M.; Jürgens, A. Qualitative and quantitative analyses of flower scent in Silene latifolia. Phytochemistry 2005, 66, 203-213. [Google Scholar] [CrossRef]

20. Hendel-Rahmanim, K.; Masci, T.; Vainstein, A.; Weiss, D. Diurnal regulation of scent emission in rose flowers. Planta 2007, 226, 1491-1499. [Google Scholar] [CrossRef]

21. de Montaigu, A.; Tóth, R.; Coupland, G.; Toth, R.; Coupland, G. Plant development goes like clockwork. Trends Genet 2010, 26, 296-306. [Google Scholar] [CrossRef]

22. Müller, N.A.; Wijnen, C.L.; Srinivasan, A.; Ryngajllo, M.; Ofner, I.; Lin, T.; Ranjan, A.; West, D.; Maloof, J.N.; Sinha, N.R.; et al. Domestication selected for deceleration of the circadian clock in cultivated tomato. Nat. Genet. 2016, 48, 89-93. [Google Scholar] [CrossRef]

23. Bombarely, A.; Moser, M.; Amrad, A.; Bao, M.; Bapaume, L.; Barry, C.; Bliek, M.; Boersma, M.; Borghi, L.; Bruggmann, R.; et al. Insight into the evolution of the Solanaceae from the parental genomes of Petunia hybrida. Nat. Plants 2016, 2, 1-9. [Google Scholar] [CrossRef]

24. Marcolino-Gomes, J.; Rodrigues, F.A.; Fuganti-Pagliarini, R.; Bendix, C.; Nakayama, T.J.; Celaya, B.; Molinari, H.B.C.; de Oliveira, M.C.N.; Harmon, F.G.; Nepomuceno, A. Diurnal Oscillations of Soybean Circadian Clock and Drought Responsive Genes. PLoS ONE 2014, 9, e86402. [Google Scholar] [CrossRef]

25. de Lucas, M.; Prat, S. PIFs get BRright: PHYTOCHROME INTERACTING FACTORs as integrators of light and hormonal signals. New Phytol. 2014, 202, 11261141. [Google Scholar] [CrossRef]

26. Fung-Uceda, J.; Lee, K.; Seo, P.J.; Polyn, S.; De Veylder, L.; Mas, P. The Circadian Clock Sets the Time of DNA Replication Licensing to Regulate Growth in Arabidopsis. Dev. Cell 2018, 45, 101-113. [Google Scholar] [CrossRef]

27. Fenske, M.P.; Hewett Hazelton, K.D.; Hempton, A.K.; Shim, J.S.; Yamamoto, B.M.; Riffell, J.A.; Imaizumi, T. Circadian clock gene LATE ELONGATED HYPOCOTYL directly regulates the timing of floral scent emission in Petunia. Proc. Natl. Acad. Sci. USA. 2015, 112, 9775-9780. [Google Scholar] [CrossRef]

28. Yon, F.; Joo, Y.; Cort, L.; Rothe, E.; Baldwin, I.T.; Kim, S.; Kim, S. Silencing Nicotiana attenuata LHY and ZTL alters circadian rhythms in flowers. New Phytol. 2015, 209, 1058-1066. [Google Scholar] [CrossRef]

29. Terry, M.I.; Pérez-Sanz, F.; Díaz-Galián, M.V.; Pérez de los Cobos, F.; Navarro, P.J.; Egea-Cortines, M.; Weiss, J. The Petunia CHANEL Gene is a ZEITLUPE Ortholog Coordinating Growth and Scent Profiles. Cells 2019, 8, 343. [Google Scholar] [CrossRef]

30. Birney, E.; Clamp, M.; Durbin, R. GeneWise and Genomewise. Genome Res. 2004, 14, 988-995. [Google Scholar] [CrossRef]

31. Li, M.; Zhang, D.; Gao, Q.; Luo, Y.; Zhang, H.; Ma, B.; Chen, C.; Whibley, A.; Zhang, Y.; Cao, Y.; et al. Genome structure and evolution of Antirrhinum majus L. Nat. Plants 2019, 5, 174. [Google Scholar] [CrossRef] 
32. Thompson, J.D.; Gibson, T.J.; Higgins, D.G. Multiple Sequence Alignment Using ClustalW and ClustalX. Curr. Protoc. Bioinforma. 2003, 2-3. [Google Scholar] [CrossRef]

33. Paradis, E.; Claude, J.; Strimmer, K. APE: Analyses of Phylogenetics and Evolution in R language. Bioinformatics 2004, 20, 289-290. [Google Scholar] [CrossRef]

34. Schliep, K.P. phangorn: Phylogenetic analysis in R. Bioinformatics 2011, 27, 592593. [Google Scholar] [CrossRef]

35. Jones, D.T.; Taylor, W.R.; Thornton, J.M. The rapid generation of mutation data matrices from protein sequences. Bioinformatics 1992, 8, 275-282. [Google Scholar] [CrossRef]

36. Yu, G.; Smith, D.K.; Zhu, H.; Guan, Y.; Lam, T.T.-Y. ggtree: An r package for visualization and annotation of phylogenetic trees with their covariates and other associated data. Methods Ecol. Evol. 2017, 8, 28-36. [Google Scholar] [CrossRef]

37. Hulo, N.; Bairoch, A.; Bulliard, V.; Cerutti, L.; De Castro, E.; Langendijk-Genevaux, P.S.; Pagni, M.; Sigrist, C.J.A. The PROSITE database. Nucleic Acids Res. 2006, 34, D227-D230. [Google Scholar] [CrossRef]

38. Brennan, P. drawProteins: A Bioconductor/R package for reproducible and programmatic generation of protein schematics. F1000Research 2018, 7, 1-15. [Google Scholar] [CrossRef]

39. Helliwell, C.; Waterhouse, P. Constructs and methods for high-throughput gene silencing in plants. Methods 2003, 30, 289-295. [Google Scholar] [CrossRef]

40. Stubbe, H. Genetik und Zytologie von Antirrhinum L. sect. Antirrhinum; Veb Gustav Fisher Verlag: Jena, Germany, 1966. [Google Scholar]

41. Schwarz-Sommer, Z.; Gubitz, T.; Weiss, J.; Gomez-di-Marco, P.; Delgado-Benarroch, L.; Hudson, A.; Egea-Cortines, M. A molecular recombination map of Antirrhinum majus. BMC Plant Biol. 2010, 10, 275. [Google Scholar] [CrossRef]

42. Box, M.S.; Coustham, V.; Dean, C.; Mylne, J.S. Protocol: A simple phenol-based method for 96-well extraction of high quality RNA from Arabidopsis. Plant Methods 2011, 7, 7. [Google Scholar] [CrossRef]

43. Schmittgen, T.D.; Livak, K.J. Analyzing real-time PCR data by the comparative CT method. Nat. Protoc. 2008, 3, 1101-1108. [Google Scholar] [CrossRef]

44. Bayo-Canha, A.; Delgado-Benarroch, L.; Weiss, J.; Egea-Cortines, M. Artificial decrease of leaf area affects inflorescence quality but not floral size in Antirrhinum majus. Sci. Hortic. 2007, 113, 383-386. [Google Scholar] [CrossRef]

45. Navarro, P.J.; Fernández, C.; Weiss, J.; Egea-Cortines, M. Development of a configurable growth chamber with a computer vision system to study circadian rhythm in plants. Sensors 2012, 12, 15356-15375. [Google Scholar] [CrossRef]

46. Navarro, P.; Pérez, F.; Weiss, J.; Egea-Cortines, M. Machine Learning and Computer Vision System for Phenotype Data Acquisition and Analysis in Plants. Sensors 2016, 16, 641. [Google Scholar] [CrossRef]

47. Ruiz-Hernández, V.; Hermans, B.; Weiss, J.; Egea-Cortines, M. Genetic Analysis of Natural Variation in Antirrhinum Scent Profiles Identifies BENZOIC ACID CARBOXYMETHYL TRANSFERASE As the Major Locus Controlling Methyl Benzoate Synthesis. Front. Plant Sci. 2017, 8, 1-13. [Google Scholar] [CrossRef]

48. Ruiz-Hernández, V.; Roca, M.J.; Egea-Cortines, M.; Weiss, J. A comparison of semiquantitative methods suitable for establishing volatile profiles. Plant Methods 2018, 14, 67. [Google Scholar] [CrossRef]

49. Wu, G.; Anafi, R.C.; Hughes, M.E.; Kornacker, K.; Hogenesch, J.B. MetaCycle: An integrated $\mathrm{R}$ package to evaluate periodicity in large scale data. Bioinformatics 2016, 32, 3351-3353. [Google Scholar] [CrossRef]

50. Wickham, H. ggplot2: Elegant Graphics for Data Analysis; Springer: Berlin/Heidelberg, Germany, 2016; ISBN 978-3-319-24277-4. [Google Scholar] 
51. Garnier, S.; Ross, N.; Rudis, B.; Sciaini, M.; Scherer, C. viridis: Default Color Maps from "matplotlib". 2018. [Google Scholar]

52. Kutmon, M.; van Iersel, M.P.; Bohler, A.; Kelder, T.; Nunes, N.; Pico, A.R.; Evelo, C.T. PathVisio 3: An Extendable Pathway Analysis Toolbox. PLoS Comput. Biol. 2015, 11, e1004085. [Google Scholar] [CrossRef]

53. Ogata, K.; Kanei-Ishii, C.; Sasaki, M.; Hatanaka, H.; Nagadoi, A.; Enari, M.; Nakamura, H.; Nishimura, Y.; Ishii, S.; Sarai, A. The cavity in the hydrophobic core of Myb DNA-binding domain is reserved for DNA recognition and trans -activation. Nat. Struct. Biol. 1996, 3, 178. [Google Scholar] [CrossRef]

54. Schaffer, R.; Ramsay, N.; Samach, A.; Corden, S.; Putterill, J.; Carre, I.A.; Coupland, G.; Centre, J.I.; Lane, C. The late elongated hypocotyl Mutation of Arabidopsis Disrupts Circadian Rhythms and the Photoperiodic Control of Flowering. Cell 1998, 93, 1219-1229. [Google Scholar] [CrossRef]

55. Andersson, C.R.; Harmer, S.L.; Schultz, T.F.; Kay, S.A. The Reveille (RVE) family of DNA binding proteins and circadian clock. Abstract. In Proceedings of the 10th International Conference on Arabidopsis Research, Melbourne, Australia, 4-8 July 1999. [Google Scholar]

56. Weiss, J.; Terry, M.I.; Martos-Fuentes, M.; Letourneux, L.; Ruiz-hernández, V.; Fernández, J.A.; Egea-cortines, M. Diel pattern of circadian clock and storage protein gene expression in leaves and during seed filling in cowpea (Vigna unguiculata ). BMC Plant Biol. 2018, 18, 33-53. [Google Scholar] [CrossRef]

57. Yon, F.; Seo, P.-J.; Ryu, J.Y.; Park, C.-M.; Baldwin, I.T.; Kim, S.-G. Identification and characterization of circadian clock genes in a native tobacco, Nicotiana attenuata. BMC Plant Biol. 2012, 12, 172. [Google Scholar] [CrossRef]

58. Delgado-Benarroch, L.; Causier, B.; Weiss, J.; Egea-Cortines, M. FORMOSA controls cell division and expansion during floral development in Antirrhinummajus. Planta 2009, 229, 1219-1229. [Google Scholar] [CrossRef]

59. Kahm, M.; Hasenbrink, G.; Ludwig, J. grofit: Fitting Biological Growth Curves with R. J. Stat. Softw. 2010, 33, 1-21. [Google Scholar] [CrossRef]

60. Weiss, J.; Mühlemann, J.K.; Ruiz-Hernández, V.; Dudareva, N.; Egea-Cortines, M. Phenotypic Space and Variation of Floral Scent Profiles during Late Flower Development in Antirrhinum. Front. Plant Sci. 2016, 7, 1-12. [Google Scholar] [CrossRef]

61. Adams, S.; Grundy, J.; Veflingstad, S.R.; Dyer, N.P.; Hannah, M.A.; Ott, S.; Carré, I.A. Circadian control of abscisic acid biosynthesis and signalling pathways revealed by genome-wide analysis of LHY binding targets. New Phytol. 2018, 220, 893-907. [Google Scholar] [CrossRef]

62. Dudareva, N.; Pichersky, E. Biochemical and Molecular Genetic Aspects of Floral Scents. PLANT Physiol. 2000, 122, 627-634. [Google Scholar] [CrossRef]

63. Yakir, E.; Hilman, D.; Harir, Y.; Green, R.M. Regulation of output from the plant circadian clock. FEBS J. 2007, 274, 335-345. [Google Scholar] [CrossRef]

64. Dodd, A.N.; Belbin, F.E.; Frank, A.; Webb, A.A.R. Interactions between circadian clocks and photosynthesis for the temporal and spatial coordination of metabolism. Front. Plant Sci. 2015, 6. [Google Scholar] [CrossRef]

65. Mara, C.D.; Huang, T.; Irish, V.F. The Arabidopsis Floral Homeotic Proteins APETALA3 and PISTILLATA Negatively Regulate the BANQUO Genes Implicated in Light Signaling. Plant Cell 2010, 22, 690-702. [Google Scholar] [CrossRef]

66. Delgado-Benarroch, L.; Weiss, J.; Egea-Cortines, M. The mutants compacta ähnlich, Nitida and Grandiflora define developmental compartments and a compensation mechanism in floral development in Antirrhinum majus. J. Plant Res. 2009, 122, 559569. [Google Scholar] [CrossRef] 
67. Vargas, P.; Ornosa, C.; Ortiz-Sánchez, F.J.; Arroyo, J. Is the occluded corolla of Antirrhinum bee-specialized? J. Nat. Hist. 2010, 44, 1427-1443. [Google Scholar] [CrossRef]

68. Suchet, C.; Dormont, L.; Schatz, B.; Giurfa, M.; Simon, V.; Raynaud, C.; Chave, J. Floral scent variation in two Antirrhinum majus subspecies influences the choice of naïve bumblebees. Behav. Ecol. Sociobiol. 2011, 65, 1015-1027. [Google Scholar] [CrossRef]

(C) 2019 by the authors. Licensee MDPI, Basel, Switzerland. This article is an open access article distributed under the terms and conditions of the Creative Commons Attribution (CC BY) license (http://creativecommons.org/licenses/by/4.0/). 


\section{Supplementary files}

Supplementary Figure S1. Multiple sequence alignment of the predicted AmLHY and other proteins belonging to the LHY/CCA1 family. Vu (Vigna unguiculata), $\operatorname{Vr}$ (Vigna radiata), Pv (Pisum vulgaris), Gm (Glycine max), At (Arabidopsis thaliana), Na (Nicotiana attenuata), Ns (Nicotiana sylvestris), Ph (Petunia hybrida), Am (Antirrhinum majus), Amt (Amborella trichopoda), Zm (Zea mays), Os (Oryza sativa), Hv (Hordeum vulgare), Pp (Physcomitrella patens), Ot (Ostreococcus tauri).

Supplementary Figure S2. AtLHY and AmLHY protein alignment.

Supplementary Figure S3. Floral parameters in non-transgenic (WT) and transgenic lines (RNAi:AmLHY). Asterisk $\left({ }^{*}\right)$ denotes significant differences among wild type and transgenic flowers (see Supplementary Table S4).

Supplementary Figure S4. 24-h scent profile. Major (A) and minor compounds (B) of wildtype, RNAi lines and its average are represented in bars.

Supplementary Figure S5. Total volatile amounts, expressed as area divided by flower fresh weight, of wild type (WT) and transgenic lines (RNAi:AmLHY). 
क̊

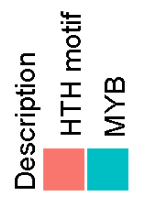

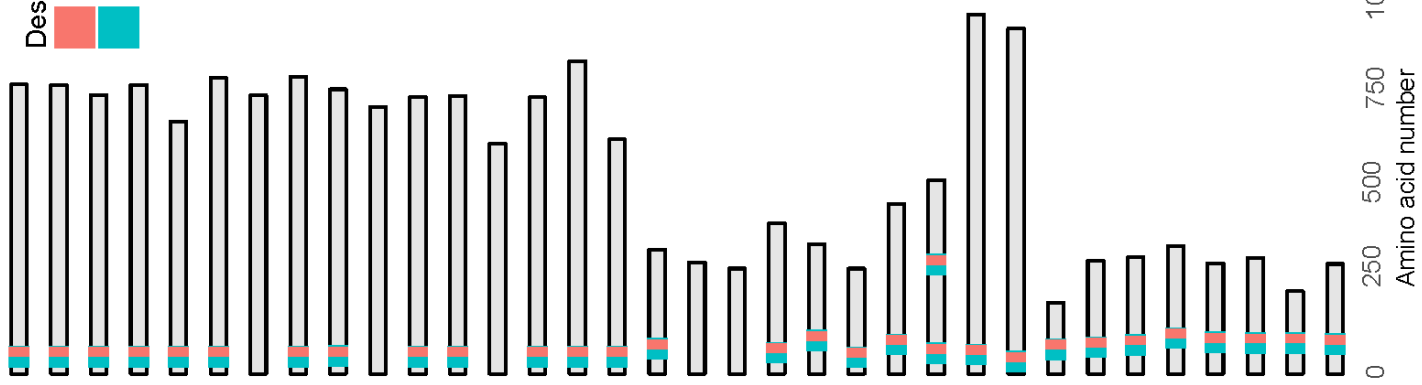

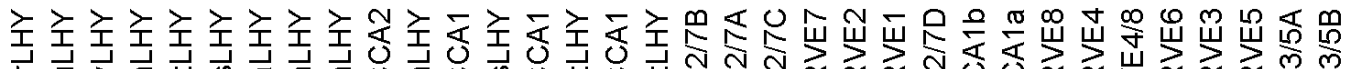

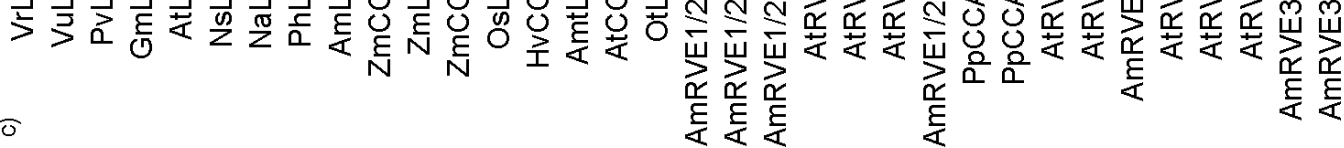
o
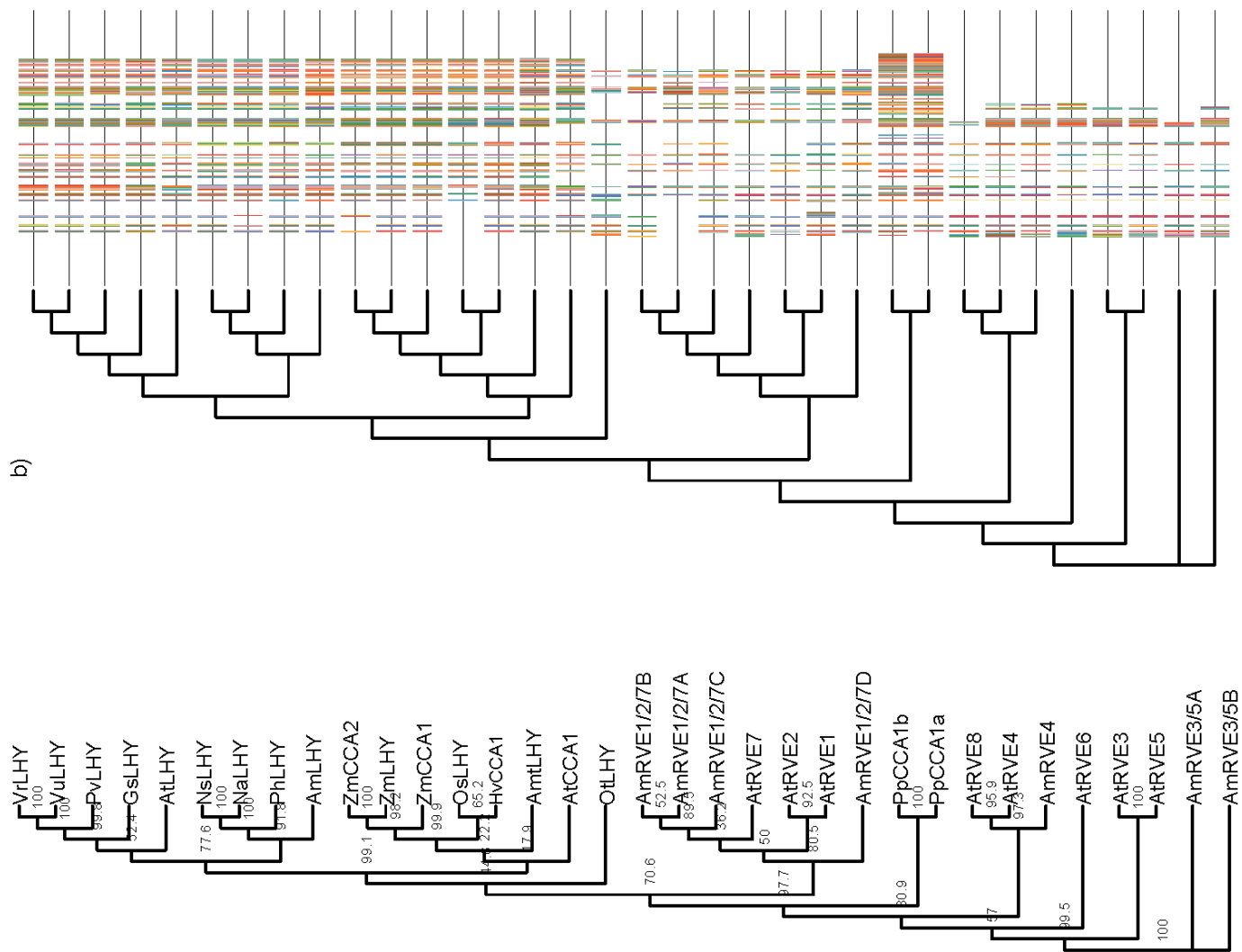

$\widehat{\pi}$ 
กิ

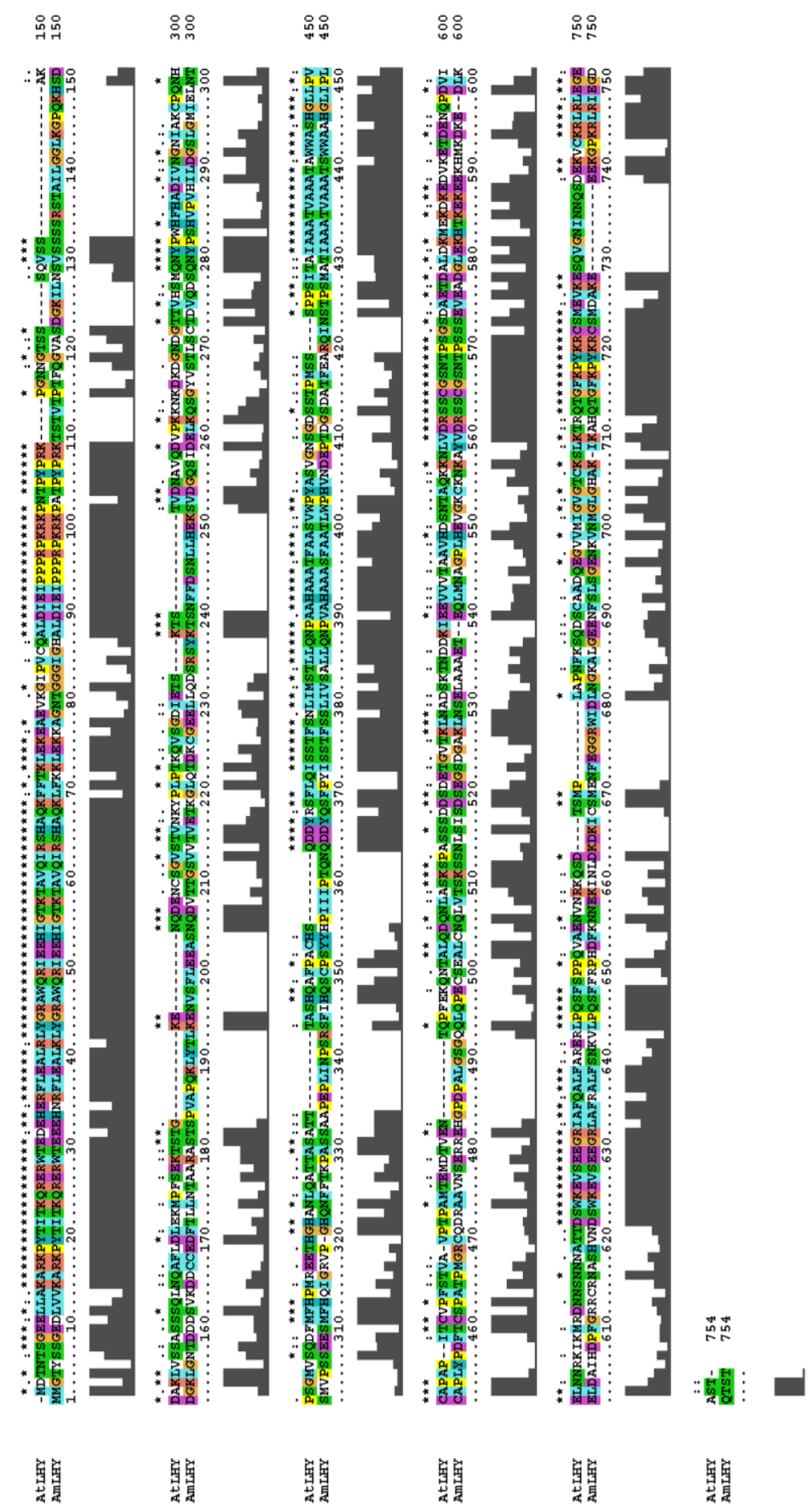

Figure S2: AtLHY and AmLHY protein alignment. 

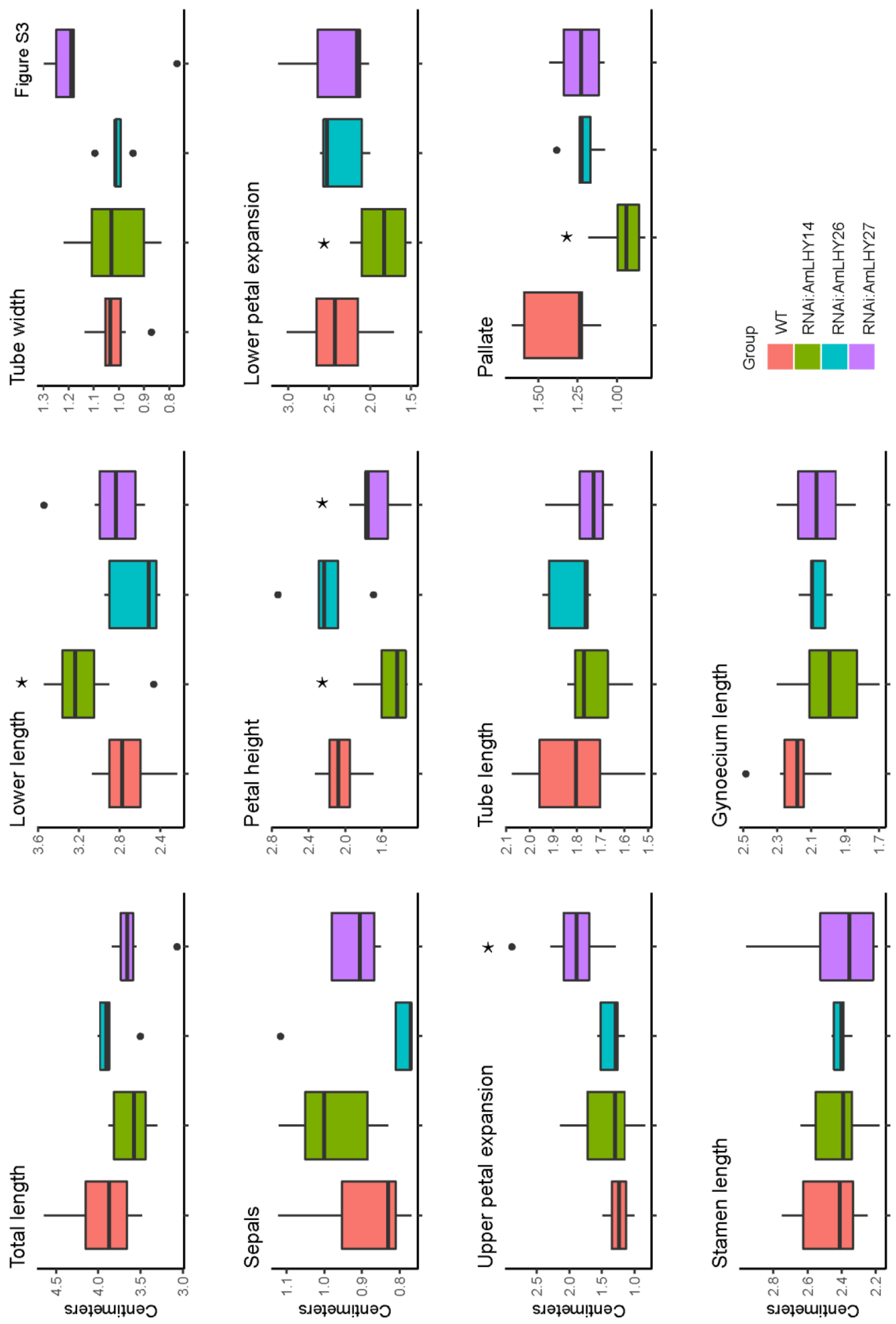

Figure S3: Floral parameters in non-transgenic (WT) and transgenic lines (RNAi:AmLHY). 
a) 24-h emission (major VOCs)

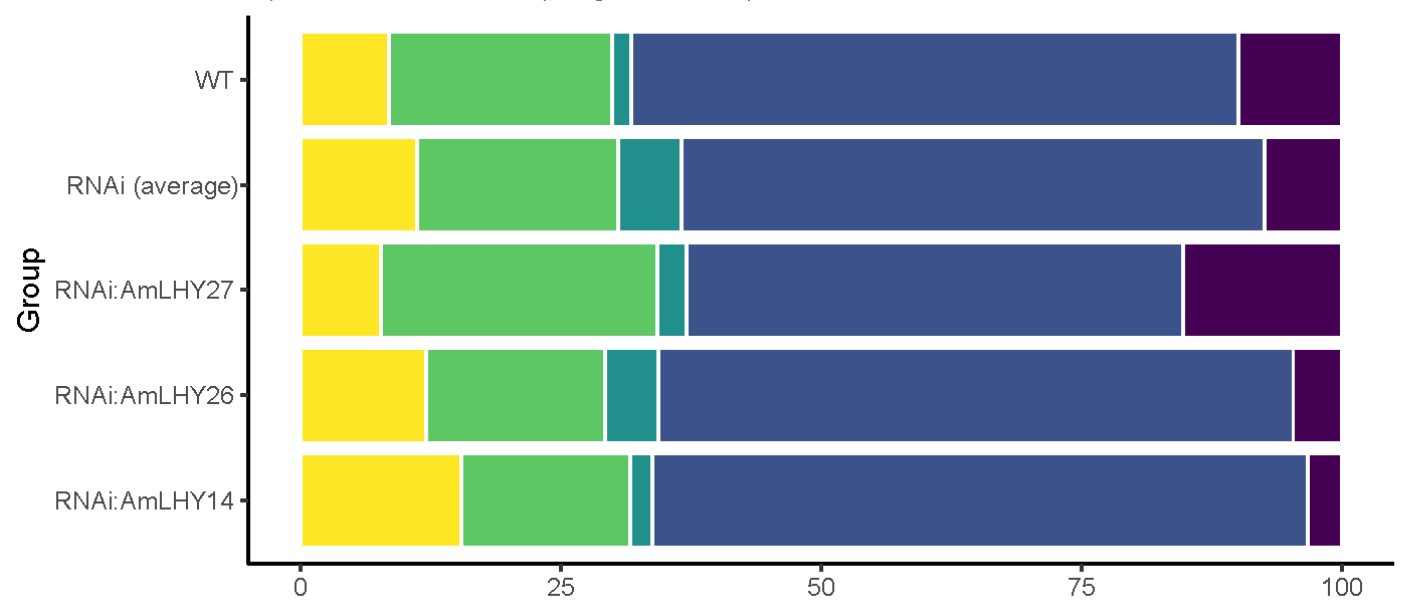

b) $24-\mathrm{h}$ emission (minor VOCs)

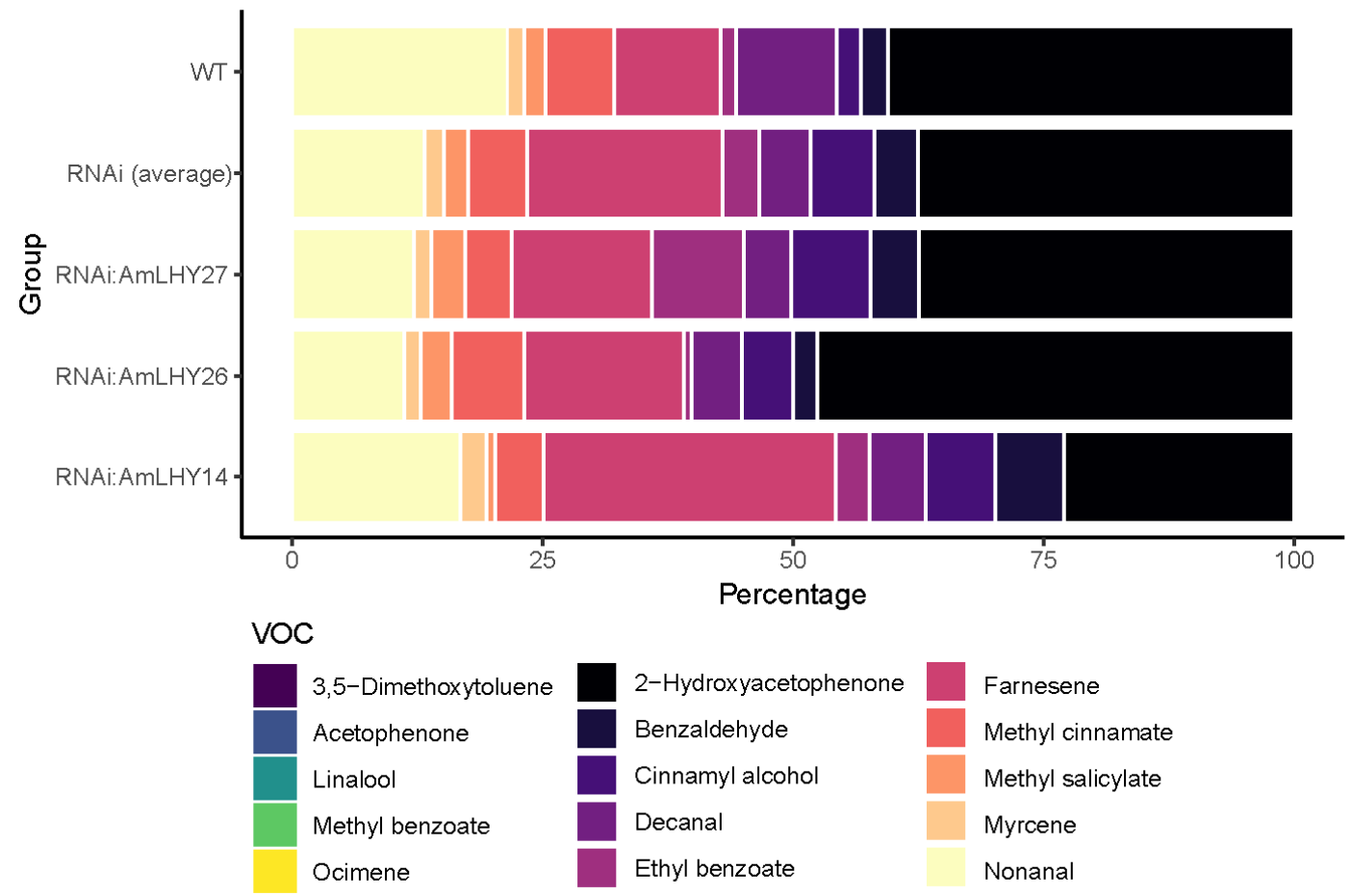

Figure S4: 24-h scent profile. 

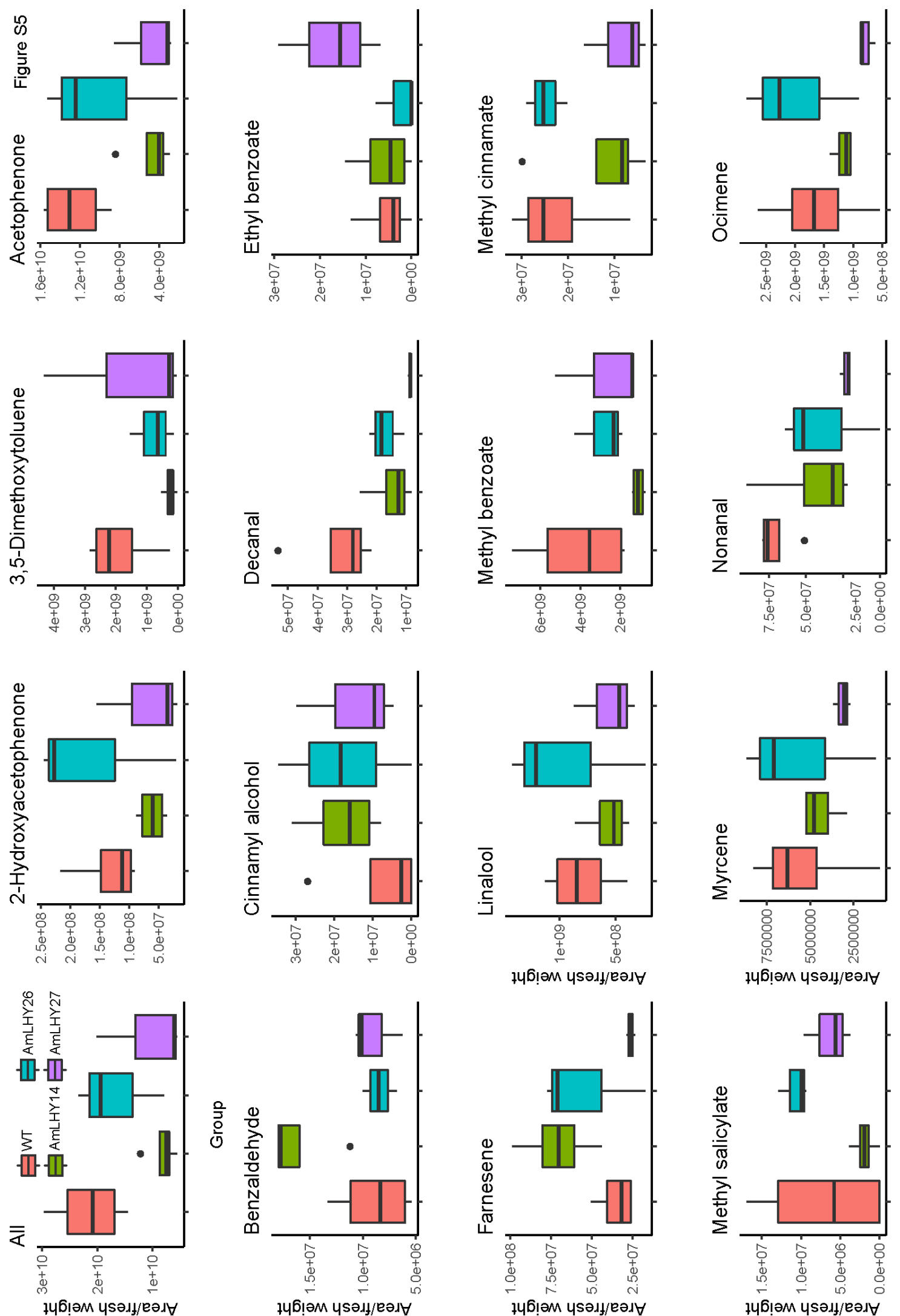

Figure S5: Total volatile amounts.

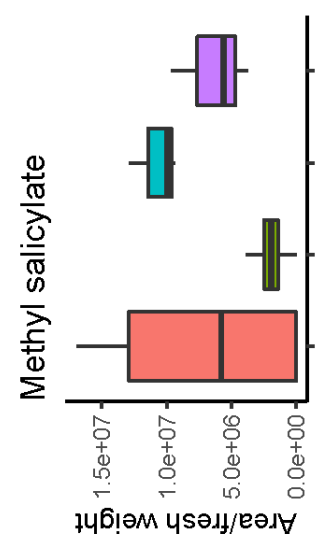


Table S1: Accession numbers of proteins used in phylogenetic reconstruction.

\begin{tabular}{|c|c|c|}
\hline Specie & Accession & Protein \\
\hline \multirow[t]{10}{*}{ Arabidopsis thaliana (At) } & AT1G01060 & LATE ELONGATED HYPOCOTYL \\
\hline & OAP07470.1 & CIRCADIAN CLOCK ASSOCIATED \\
\hline & OAO92169.1 & REVEILLE 1 (RVE1) \\
\hline & OAO90963.1 & REVEILLE 2 (RVE2) \\
\hline & AT1G01520 & REVEILLE 3 (RVE3) \\
\hline & gi $\mid 75324470$ & REVEILLE 4 (RVE4) \\
\hline & gi $\mid 576017836$ & REVEILLE 5 (RVE5) \\
\hline & AT5G52660 & REVEILLE 6 (RVE6) \\
\hline & gi| 576017949 & REVEILLE 7 (RVE7) \\
\hline & OAP05994.1 & REVEILLE 8 (RVE8) \\
\hline Amborella trichopoda (Amt) & XP_00682921 & LATE ELONGATED HYPOCOTYL \\
\hline \multirow[t]{9}{*}{ Antirrhinum majus (Am) } & Am03g44570 & LATE ELONGATED HYPOCOTYL \\
\hline & LT978479.1 & (LHY) \\
\hline & Am04g07010 & REVEILLE 1A-like (RVE1A-like) \\
\hline & Am06g21890 & REVEILLE 1B-like (RVE1B-like) \\
\hline & Am04g18800 & REVEILLE 2A-like (RVE2A-like) \\
\hline & Am06g21900 & REVEILLE 2B-like (RVE2B-like) \\
\hline & Am02g37040 & REVEILLE 3/5A-like (RVE3/5A- \\
\hline & Am03g44150 & REVEILLE 3/5B-like (RVE3/5B-like) \\
\hline & Am08g25850 & REVEILLE 4/8-like (RVE4/8-like) \\
\hline Glycine soja (Gs) & KHN11366.1 & LATE ELONGATED HYPOCOTYL \\
\hline Hordeum vulgare $(\mathrm{Hv})$ & AEW48245.1 & CIRCADIAN CLOCK ASSOCIATED \\
\hline Nicotiana attenuata $(\mathrm{Na})$ & OIS99379.1 & LATE ELONGATED HYPOCOTYL \\
\hline Nicotiana sylvestris (Ns) & XP_00979479 & PREDICTED: protein LHY \\
\hline Oryza sativa (Japonica Group) & XP_01564984 & LHY isoform $X 4$ \\
\hline Ostreococcus tauri (Ot) & AAU14271.1 & LHY-like protein, partial \\
\hline Petunia hybrida $(\mathrm{Ph})$ & AKL88450.1 & LATE ELONGATED HYPOCOTYL \\
\hline Phaseolus vulgaris (Pv) & CAD12767.2 & LATE ELONGATED HYPOCOTYL \\
\hline \multirow[t]{2}{*}{ Physcomitrella patens (Pp) } & BAI39991.1 & CIRCADIAN CLOCK ASSOCIATED \\
\hline & BAI39992.1 & CIRCADIAN CLOCK ASSOCIATED \\
\hline Vigna radiata $(\mathrm{Vr})$ & XP_01452159 & LATE ELONGATED HYPOCOTYL \\
\hline Vigna unguiculata $(\mathrm{Vu})$ & XP_02790607 & LATE ELONGATED HYPOCOTYL- \\
\hline \multirow[t]{3}{*}{ Zea mays $(\mathrm{Zm})$} & NP_00113152 & LATE ELONGATED HYPOCOTYL \\
\hline & ADU60099.1 & CIRCADIAN CLOCK ASSOCIATED \\
\hline & AQK41466.1 & CIRCADIAN CLOCK \\
\hline
\end{tabular}


Table S2: BLAST analysis. Arabidopsis accessions (Query ID) were used to identify REVEILLE (RVE, Protein column) sequences in the snapdragon genome database (http://bioinfo.sibs.ac.cn/Am/index.php). RVE names were assigned based on a tree generated by simple phylogeny (EMBL-EBI, https://www.ebi.ac.uk/).

\begin{tabular}{|l|l|l|l|l|l|}
\hline Query ID & Protein & Snapdragon accession & P identity & e value & Assigned name \\
\hline \multirow{3}{*}{ OA092169.1 } & \multirow{2}{*}{ AtRVE1 } & Am04g07010 & 86.49 & $9 \mathrm{e}^{-23}$ & AmRVE1/2/7A \\
\cline { 3 - 6 } & & Am06g21890 & 47.15 & $5 \mathrm{e}^{-20}$ & AmRVE1/2/7B \\
\hline \multirow{2}{*}{ OA090963.1 } & \multirow{2}{*}{ AtRVE2 } & Am04g18800 & 80.56 & $2 \mathrm{e}^{-23}$ & AmRVE1/2/7C \\
\cline { 3 - 6 } & & Am06g21900 & 51.00 & $2 \mathrm{e}^{-20}$ & AmRVE1/2/7D \\
\hline \multirow{2}{*}{ AT1G01520 } & \multirow{2}{*}{ AtRVE3 } & Am08g25850 & 76.79 & $1 \mathrm{e}^{-18}$ & AmRVE4/8 \\
\cline { 3 - 6 } & & Am02g37040 & 88.37 & $4 \mathrm{e}^{-17}$ & AmRVE3/5B \\
\hline \multirow{2}{*}{ gi|75324470| } & \multirow{2}{*}{ AtRVE4 } & Am04g07010 & 72.97 & $8 \mathrm{e}^{-14}$ & AmRVE1/2/7A \\
\cline { 3 - 6 } & & Am04g18800 & 70.27 & $1 \mathrm{e}^{-13}$ & AmRVE1/2/7C \\
\hline \multirow{2}{*}{ gi|576017836| } & \multirow{2}{*}{ AtRVE5 } & Am03g44150 & 76.60 & $1 \mathrm{e}^{-15}$ & AmRVE3/5A \\
\cline { 3 - 6 } & & Am02g37040 & 79.55 & $4 \mathrm{e}^{-15}$ & AmRVE3/5B \\
\hline \multirow{2}{*}{ AT5G52660 } & \multirow{2}{*}{ AtRVE6 } & Am04g07010 & 72.97 & $3 \mathrm{e}^{-14}$ & AmRVE1/2/7A \\
\cline { 3 - 6 } & & Am04g18800 & 70.27 & $5 \mathrm{e}^{-14}$ & AmRVE1/2/7C \\
\hline \multirow{2}{*}{ gi|576017949| } & AtRVE7 & Am04g18800 & 67.57 & $2 \mathrm{e}^{-21}$ & AmRVE1/2/7C \\
\cline { 3 - 6 } & & Am06g21890 & 44.86 & $6 \mathrm{e}^{-20}$ & AmRVE1/2/7B \\
\hline \multirow{2}{*}{ OAP05994.1 } & \multirow{2}{*}{ AtRVE8 } & Am04g07010 & 78.38 & $2 \mathrm{e}^{-15}$ & AmRVE1/2/7A \\
\cline { 3 - 6 } & & Am04g18800 & 72.97 & $5 \mathrm{e}^{-15}$ & AmRVE1/2/7C \\
\hline
\end{tabular}


Table S3: PCR primers used in the current study

\begin{tabular}{|c|c|c|}
\hline Gene & Forward $\left(5^{\prime}-3^{\prime}\right)$ & Reverse $\left(5^{\prime}-3^{\prime}\right)$ \\
\hline RNAi:AmLH & TCTGGATGAAACAAGTGTCC & TAAAAAGTTTCTGGGCATGA \\
\hline NPTII & CCTGCTTGCCGAATATCATGGTG & CGAAATCTCGTGATGGCAGGTTGG \\
\hline AmUBI & CCGATGGAAGTATATGTTTG & CCAGTCTTACAAGACCTAGAAGCT \\
\hline AmLHY & TTACTTGCTCTCCGGCAACT & TTGAAGTCACAAGCTGATTGC \\
\hline
\end{tabular}


Table S4: Analysis of floral parameters in non-transgenic and transgenic lines. Parameters were analyzed using a Student's t test. $P$ value $<0.05$ indicates a significant difference between non-transgenic and transgenic snapdragon flowers, significance levels are indicated with one asterisks ( ${ }^{*}$ for $\left.p<0.05\right)$, two asterisks ( ${ }^{* *}$ for $\left.p<0.001\right)$ and three asterisks ( ${ }^{* * *}$ for $\left.p<0.0001\right)$.

\begin{tabular}{|c|c|c|c|}
\hline Parameter & RNAi:AmLHY14 & RNAi:AmLHY26 & RNAi:AmLHY27 \\
\hline Total length & $0.037^{*}$ & 0.858 & 0.069 \\
\hline Lower length & $0.014^{*}$ & 0.486 & 0.210 \\
\hline Tube width & 0.927 & 0.927 & $0.001^{*}$ \\
\hline Sepal length & 0.337 & 0.646 & 0.762 \\
\hline Petal height & $0.000^{* * *}$ & 0.060 & $0.004^{*}$ \\
\hline Lower petal expansion & $0.005^{*}$ & 0.885 & 0.885 \\
\hline Upper petal expansion & 0.137 & 0.419 & $0.000^{* * *}$ \\
\hline Tube length & 0.404 & 0.881 & 0.404 \\
\hline Pallate & $0.000^{* * *}$ & 0.258 & 0.160 \\
\hline Stamen length & 0.974 & 0.974 & 0.974 \\
\hline Gynoecium length & $0.048^{*}$ & 0.278 & 0.278 \\
\hline
\end{tabular}


Table S5: Retention time in minutes (RT), CAS number of detected volatiles.

\begin{tabular}{|c|c|c|}
\hline RT & CAS & Volatile \\
\hline 4.61 & $100-52-7$ & Benzaldehyde \\
\hline 5.23 & $123-35-3$ & Myrcene \\
\hline 6.29 & $3779-61-1$ & Ocimene \\
\hline 7.70 & $124-19-6$ & Nonanal \\
\hline 7.84 & $98-86-2$ & Acetophenone \\
\hline 8.41 & $93-58-3$ & Methyl benzoate \\
\hline 8.51 & $78-70-6$ & Linalool \\
\hline 8.77 & $118-93-4$ & 2-Hydroxyacetophenone \\
\hline 9.38 & $119-36-8$ & Methyl salicylate \\
\hline 9.54 & $112-31-2$ & Decanal \\
\hline 9.83 & $93-89-0$ & Ethyl benzoate \\
\hline 10.5 & $4179-19-5$ & 3,5-Dimethoxytoluene \\
\hline 11.1 & $104-54-1$ & Cinnamyl alcohol \\
\hline 12.3 & $19713-73-6,103-26-$ & Methyl cinnamate \\
\hline 14.0 & $502-61-4$ & Farnesene \\
\hline
\end{tabular}


Table S6: Analysis of daily emitted volatiles with the algorithm JTK_CYCLE in wild type (WT) and RNAi lines. Phase indicates the time point (ZT hours) with maximum emission. Shift indicates if the maximum emission of a VOC was advanced (A), delayed (D) or did not changed (NC) compared to the wild type. No data indicates that a parameter could not be determined.

\begin{tabular}{|l|l|l|l|l|l|l|l|l|}
\hline & WT & \multicolumn{2}{|l|}{ RNAi:AmLHY14 } & \multicolumn{2}{l|}{ RNAi:AmLHY26 } & \multicolumn{2}{l|}{ RNAi:AmLHY27 } \\
\hline Volatile & Phase & Phase & Shift & Phase & Shift & Phase & Shift \\
\hline Myrcene & 0 & 6 & D & 6 & D & 6 & D \\
\hline Decanal & 3 & 3 & NC & 3 & NC & 3 & NC \\
\hline Ocimene & 3 & 6 & D & 6 & D & 6 & D \\
\hline 2-Hydroxyacetophenone & 6 & 6 & NC & 6 & NC & 6 & NC \\
\hline 3,5-Dimethoxytoluene & 6 & 6 & NC & 6 & NC & 6 & NC \\
\hline Linalool & 6 & 6 & NC & 6 & NC & 6 & NC \\
\hline Nonanal & 6 & 6 & NC & 6 & NC & 6 & NC \\
\hline Methyl cinnamate & 6 & 3 & A & 6 & NC & 3 & A \\
\hline Cinnamyl alcohol & 9 & 9 & NC & 9 & NC & 9 & NC \\
\hline Farnesene & 9 & 6 & A & 6 & A & 6 & A \\
\hline Methyl benzoate & 15 & 18 & D & 18 & D & 18 & D \\
\hline Acetophenone & 15 & 12 & A & 12 & A & 12 & A \\
\hline Methyl salicylate & 15 & 21 & D & 21 & D & 21 & D \\
\hline Benzaldehyde & 18 & 12 & A & 12 & A & 12 & A \\
\hline Ethyl benzoate & No data & No data & & No data & & No data & \\
\hline
\end{tabular}



Conclusions 



\section{Conclusions}

The analysis of the circadian clock in different species contributes to the understanding about evolution and diversification across the green lineage. We have described the transcriptional structure of circadian clock and related genes in petunia leaves and petals, revealing a tissue-specific clock that may set specialized processes in both tissues. Growth speed in stems and flowers is controlled by the circadian clock. In the present work we also examined the complexity of the scent profile in the diurnally emitting snapdragon and the nocturnally emitting petunia. The flower scent proved to be controlled by the circadian clock, which affected both composition and timing emission.

\section{Chapter I}

- The genes PSEUDO-RESPONSE REGULATOR 5, 7 and GIGANTEA are duplicated in petunia. The differences in aminoacid sequence and gene expression, including phase and amplitude, in leaves and petals suggest a specialization of paralogs.

- Expression of circadian clock genes and clock related genes differed among petunia leaves and petals.

- Constant darkness caused, in general, a delayed expression in clock genes as well as clock related genes in leaves and petals.

○ The variability in gene expression differed among tissues, daytime and light cycles.

\section{Chapter II}

- The expression pattern of CHANEL (PhCHL) is dependent on day length.

- PhCHL plays a role growth speed in stems and flowers.

- Petunia fragrance is composed mainly of phenylpropanoid and benzonoid volatiles. The main volatile, methyl benzoate, is rhythmically emitted.

- The contribution of every single compound to the scent varied along the day. $\mathrm{PhCHL}$ is required to maintain the aroma composition and timing of scent emission.

\section{Chapter III}

- LATE ELONGATED HYPOCOTYL (AmLHY) shows the canonical expression pattern described in other plants. 
- AmLHY regulates positively flower growth speed but not its size or morphology.

- The floral aroma of snapdragon is mainly constituted by phenylpropanoid and benzenoid compounds, but also monoterpenes, sesquiterpenes and aldehydes. The most abundant compound is acetophenone, which is constitutively emitted.

- The proportion of every volatile and timing of scent emission are maintained by $A m L H Y$.

- AmLHY regulates volatile biosynthesis at different branches. 


Conferences 

Poster

$13 /$ SIV

P13

\title{
Organ-specific evolution and subfunctionalization of circadian clock in Petunia
}

\author{
Marta Isabel Terry López1, Claudia Brandoli1, Marta Carrera-Alesina1, Marcos Egea- \\ Cortines $^{1}$, Julia Weiss ${ }^{1}$ \\ ${ }^{1}$ Genética Molecular, Instituto de Biotecnología Vegetal, Universidad Politécnica de \\ Cartagena 30202 Cartagena, Spain
}

The plant circadian clock is comprised by a set of genes that form the so-callad loops. These loops are molecular and genetic interactions of activation and repression, and are classified as morning, central and evening loops basad on the expression of their components in Arabidopsis leaves. We have performed a comprehensiva analysis of the clock components in Petunia ${ }^{1}$ and found that PRR7, PRR5, G/, ELF3 and ELF4 show gene copy numbers ranging from 2 to 4 . In contrast, PRR9, PRR3, TOC1, ZTL and LHY are single copy gene while CCA1 is absent. This suggests possible subfunctionalizations of different paralogs. We investigated the transcription of circadian clock genes in leaves and petals of Petunia and found highly significant difference in gene expression in single copy genes such as PRR9 and ZTL. The differences identified included changes in their circadian expression pattern and level of expression. The paralogs $P R R 7 a$ and $P R R 7 b$ showed differences of expression between leaves and flowers in terms of daily expression profiles and expression levels. A similar effect was seen in $P R R 5 a$ and $P R R 5 b$ as $P R R 5 a$ was 159 fold higher in petals than in leaves. Our results shows that the plant circadian clock is different in petals and leaves, and there is a possible subfunctionalization of paralogs that become specific far the leaf or petal.

This work was developed under projects Fundación Séneca 11895/PI/09, 19398/PI/14 and BFU2013- 45148-R

\section{References:}

1. Bombarely, A. et al. Nat. Plants In press, (2016). 
Conferences - 172

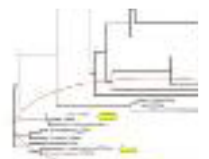

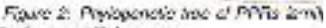

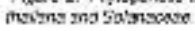




\title{
EFFECT OF SILENCING PHZTL ON GROWTH AND SCENT EMISSION IN PETUNIA
}

\author{
Marta Isabel Terry ${ }^{1}$, Fernando Pérez-Sanz ${ }^{1}$, María Victoria Díaz-Galián ${ }^{1}$, Victoria Ruiz- \\ Hernández ${ }^{3}$, Pedro J. Navarro ${ }^{2}$, Marcos Egea-Cortines ${ }^{1}$, Lulia Weiss ${ }^{1}$ \\ ${ }^{1}$ Genetics, ETSIA, Instituto de Biotecnología Vegetal, UPCT, Cartagena, Spain, ${ }^{2}$ Tecnologías de la \\ Información y las Comunicaciones, ETSIT, UPCT, Cartagena, Spain Corresponding author: Marcos Egea- \\ Cortines (Julia.weiss@upct.es)
}

The circadian clock is an adaptation that allows organisms to anticipate periodic changes. In plants, this biological clock is comprised by a set of genes which form feedback interlocked loops. Zeitlupe (ZTL) codifies an F-box protein that interacts with other two clock components, TIMING OF CAB EXPRESSION 1 (TOC1) and PSEUDO-RESPONSE REGULATOR 5 (PRR5), playing a role in TOC1 and PRR5 degradation (Más et al., 2003; Kiba et al., 2007); additionally ZTL has a PAS domain, present in blue-light receptor molecules (Somers et al., 2000). In Arabidopsis, ztl mutants displayed a longer period, for example, flowering was delayed (Somers et al., 2004). Moreover, the role of circadian clock genes in several processes such as organ development, movement or scent emission is still poorly known (Fenske et al, 20015; Yon et al., 2016). In the present work, we silenced the expression of ZTL by RNAi in Petunia (PhZTL) and we analysed growth and scent emission. Growth was significantly shorter or slower depending on the organ analysed. Most volatile organic compounds showed a rhythmic emission. Time of maximum emission was delayed or advanced in RNAi plants depending on the volatile. The relative contribution of every compound to scent varied between nontransgenic and transgenic Petunia flowers resulting in quantitative changes in scent blends at different times of the day. These results suggest that PhZTL plays a role, directly or indirectly, in biological rhythms in plants, affecting flowering time, stem and flower growth and scent emission.

Fenske, M.P., Hazelton, K.D.H., Hempton, A.K., Shim, J.S., Yamamoto, B.M., Riffell, J.A., \& Imaizumi, T. (2015). Circadian clock gene LATE ELONGATED HYPOCOTYL directly regulates the timing of floral scent emission in Petunia. Proceedings of the National Academy of Sciences, 112(31), 9775- 9780.

Kiba, T., Henriques, R., Sakakibara, H., \& Chua, N.H. (2007). Targeted degradation of PSEUDO- RESPONSE REGULATOR5 by an SCFZTL complex regulates clock function and photomorphogenesis in Arabidopsis thaliana. The Plant Cell, 19(8), 2516-2530.

Más, P., Kim, W.Y., Somers, D.E., \& Kay, S.A. (2003). Targeted degradation of TOC1 by ZTL modulates circadian function in Arabidopsis thaliana. Nature, 426(6966), 567.

Somers, D.E., Kim, W.Y., \& Geng, R. (2004). The F-box protein ZEITLUPE confers dosage-dependent control on the circadian clock, photomorphogenesis, and flowering time. The Plant Cell, 16(3), 769- 782.

Somers, D.E., Schultz, T.F., Milnamow, M., \& Kay, S.A. (2000). ZEITLUPE encodes a novel clock- associated PAS protein from Arabidopsis. Cell, 101(3), 319-329.

Yon, F., Joo, Y., Cortés Llorca, L., Rothe, E., Baldwin, I.T., \& Kim, S.G. (2016). Silencing Nicotiana attenuata LHY and ZTL alters circadian rhythms in flowers. New Phytologist, 209(3), 1058-1066. 
MNAvirncil ine versus wia type recunia

\section{Conclusion}

- Our results show that fnzTL plays a central in

role difters between vegetative and generative

to be the result of decreased growth duratior growth rote. Furthermore, dsily pattem of tha sligrtey advanced in RNAViPhZTL plarts.

- Concerning volatile production, time of mavir plants depending on the volstile. The relotive I between non-tranogeric and tranggenic Pet scert blends st different times of the day.

- Result suegest thot PhET ploys a roke, direct

Acknowiedgments. This work has bee 


\section{Other communications}

Title: Identification of nana as circadian clock mutant in Antirrhinum majus Authors: Marta Terry López; Fabiola Ruíz-Ramón; Julia Weiss; Marcos Egea Gutiérrez-Cortines.

Poster.

Conference: XII Reunión de Biología Molecular de Plantas.

Venue: Cartagena (Spain). Date: 11-13th June, 2014.

Title: Análisis genético del reloj circadiano de Antirrhinum majus

Authors: Marta Terry López; Julia Weiss y Marcos Egea Gutiérrez-Cortines.

Poster.

Conference: $4^{\circ}$ Workshop de Investigación Agroalimentaria - WiA.15

Venue: Cartagena (Spain). Date: 11-12th May, 2015.

http://repositorio.upct.es/handle/10317/5290

Title: Genetic and Environmental Factors Affecting Scent and Volatile Production

Authors: Egea Gutiérrez-Cortines; Julia Weiss; Victoria Ruiz-Hernández; Marta Terry-López.

Conference: BIT's $6^{\text {th }}$ World Gene Convention.

Venue: Qingdao (China). Date: 13-15th November, 2015.

Title: Influencia de la condiciones ambientales en la emisión de volátiles en boca de dragón (Antirrhinum majus).

Authors: Marta Terry López; Julia Weiss; Marcos Egea Gutiérrez-Cortines. Oral communication.

Conference: $5^{\circ}$ Workshop de Investigación Agroalimentaria - WiA.16

Venue: Cartagena (Spain). Date: 9-10th May, 2016.

http://repositorio.upct.es/handle/10317/5558

Title: Estructura del reloj circadiano en hoja y pétalo de petunia Authors: Marta Terry López; Marcos Egea Gutiérrez-Cortines; Julia Weiss. Oral communication.

Conference: 6⿳⺈⿴囗十一 Workshop de Investigación Agroalimentaria - WiA.17

Venue: Cartagena (Spain). Date: 8-9th May, 2017.

http://repositorio.upct.es/handle/10317/6706 
Title: Circadian regulation of lateral organ development.

Authors: Marcos Egea-Cortines; Julia Weiss; Marta I. Terry; Fernando PérezSanz; Victoria Ruiz-Hernández; María Victoria Díaz-Galián; Pedro Javier Navarro

Conference: X Jornadas de Genética e Biotecnologia Venue: Vila Real (Portugal). Date: 6-8th March, 2018.

Title: Análisis genético del reloj circadiano de Antirrhinum majus.

Authors: Marta Terry López; Julia Weiss; Marcos Egea Gutiérrez-Cortines.

Conference: I Jornadas Doctorales de la UPCT.

Poster.

Venue: Cartagena (Spain). Date: 16th April, 2018.

Title: Efecto del silenciamiento de PhZTL en la emisión de aromas en petunia (Petunia $x$ hybrida).

Authors: Marta Terry López; Marcos Egea Gutiérrez-Cortines; Julia Weiss. Oral communication.

Conference: $7^{\mathfrak{0}}$ Workshop de Investigación Agroalimentaria - WiA.18

Venue: Cartagena (Spain). Date: 7-8th May, 2018.

http://repositorio.upct.es/handle/10317/7652

Title: El silenciamiento de LATE ELONGATED HYPOCOTYL en boca de dragón modifica la emisión de aromas.

Authors: Marta Terry López; Marcos Egea Gutiérrez-Cortines; Julia Weiss. Oral communication.

Conference: $8^{\text {o }}$ Workshop de Investigación Agroalimentaria - WiA.19

Venue: Cartagena (Spain). Date: 27-28th May, 2019. 


\section{Contributions unrelated to the $\mathrm{PhD}$ thesis}

THE CRUSTACEAN SOCIETY MID-YEAR MEETING

\section{Alien brachyurans in eastern Iberian Peninsula coast: the case of Callinectes sapidus and Percnon gibbesi}

\section{Marta Isabel Terry ${ }^{1}$ Diego Castejón $^{2}$}

1. Instituto de Biotecnología Vegetal. Universidad Politécnica de Cartagena, Spain

2. IRTA. Centre d'Aqüicultura, Sant Carles de la Ràpita, Spain

The portunid Callinectes sapidus (Rathbun, 1896) and the grapsoid Percnon gibbesi $(\mathrm{H}$. Milne-Edwards, 1853) are considered among the 100 'worst invasive' species in the Mediterranean Sea.

The presence of $C$. sapidus was studied in the Ebro Delta (Tarragona, North-Eastern Iberian Peninsula) from 2012 to 2016 using specimens provided by local fishermen. The captures occurred in the coastal waters of Ebro Delta and associated brackish lagoons and channels, being obtained 12 males and 19 females with a mean size of 147 $\pm 32 \mathrm{~mm}$ considering the tips of the lateral spines. The specimens included a "berried" female with mature eggs in June 2016. In August 2016 was officially established the local fishery of $C$. sapidus in Ebro Delta, the monthly catches varied from $20 \mathrm{Kg}$ in December to $229 \mathrm{Kg}$ in September. The presence of P. gibbesi was studied in Cabo Palos (Murcia, South-Eastern Iberian Peninsula) during the years 2012, 2015 and 2016 by snorkel surveys performed at a depth from 0 to $3 \mathrm{~m}$. P. gibbesi was found in 17 of 37 replicate trials in four sampling localities (53.1\%). In total, 59 individuals were counted.

The higher density was observed in rocky bottoms between 0.5 and $1.5 \mathrm{~m}$ depth with abundance of crevices and rock walls as shelters. 


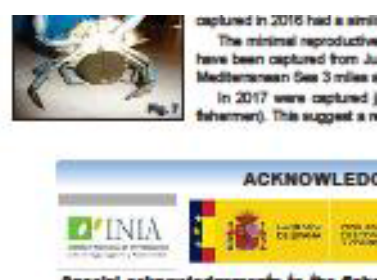

speolal acknowedgoments to the flche for their inectimnatio contribution for th Lopez for her helphul ocmements on the 


Agradecimientos - acknowledgements 

En primer lugar, quiero agradecer a mis directores, Marcos Egea y Julia Weiss, no solo el apoyo recibido, sino también la oportunidad de realizar esta tesis doctoral.

Por supuesto, agradecer también a toda la gente de la UPCT que me ha acompañado estos años, ¡sois muchos! A Paco Artés, por su dedicación y coordinación del Programa de Doctorado TAIDA. A mis predecesores, los doctores Mallona, Martos, Ruiz-Hernández y Pérez-Sanz y a mis actuales compañeros de fatigas y futuros doctores, Raquel, Claudio, Victoria, Semih y Onurcan, por estar ahí en todo momento. A Perla, Mariano y María José, siempre dispuestos a echarme una mano, desde mis peleas con la impresora hasta mis dramas con los Twisters. Agradecer también a los técnicos que han pasado por nuestro laboratorio, especialmente a Samsara, Julia, Pedro y Paqui. Y no me olvido de tí, Mari Carmen, igracias bonica!, ni de Hannah, Sara y Malou, con las que he compartido alguna etapa de mi tesis. También le doy las gracias Dina Cifuentes, Cati Egea y Juan Fernández por la ayuda prestada, y al doctor Petri, por su infinita paciencia. Y por supuesto, a Marisa y Trini, por la parte administrativa y “papeleo variado (y múltiple)” relacionado con la tesis, ¡mil gracias!

I would like to thank Dr. Robert Schuurink for his help during my stay at the University of Amsterdam.

Siguiendo con los agradecimientos, por supuesto a mi familia, por apoyarme y "aguantarme en mis mejores momentos".

A mis amigos, Alejandro, Diego, Mila, Óscar, Kike y Miri por animarme a seguir y preguntar constantemente: “Pero, ¿has acabado ya? ¿Cuándo defiendes?” 